\title{
Uma arquitetura de baixo acoplamento para execução de padrões de controle de fluxo em grades
}

\author{
Alexandre Ricardo Nardi
}

Tese apresentada ao

Instituto de Matemática e Estatística da

Universidade de São Paulo para obtenção do título de Doutor em Ciências

\author{
Programa: Ciência da Computação \\ Orientador: Prof. Dr. João Eduardo Ferreira
}

São Paulo, maio de 2009 


\section{Uma arquitetura de baixo acoplamento para execução de padrões de controle de fluxo em grades}

Este exemplar corresponde à redação final da tese, devidamente corrigida, defendida por Alexandre Ricardo Nardi e aprovada pela comissão julgadora.

São Paulo, 27 de maio de 2009

Comissão Julgadora:

- Prof. Dr. João Eduardo Ferreira (orientador) - IME/USP

- Prof. Dr. Philippe Olivier Alexandre Navaux - UFRGS

- Prof. Dr. Duncan Dubugras Alcoba Ruiz - PUC/RS

- Prof. Dr. Luciano Antonio Digiampietri - EACH/USP

- Prof. Dr. Francisco Carlos da Rocha Reverbel - IME/USP 
Para Ednilza, Pedro e Natália 


\section{Agradecimentos}

Em primeiro lugar, agradeço ao Prof. Dr. João Eduardo Ferreira, meu orientador, pela atenção e meticulosidade com que teceu observações no transcorrer deste trabalho mas, acima de tudo, pela compreensão das dificuldades profissionais que enfrentamos durante o desenvolvimento desta pesquisa.

À minha esposa, Ednilza, pelo carinho, incentivo e paciência, muito obrigado! E agradeço também aos pequenos Pedro e Natália, meus filhos que, apesar da pouca idade, permitiram que o papai se dedicasse a este projeto.

Obrigado ao Prof. Dr. Francisco Carlos da Rocha Reverbel, que me acompanha desde os tempos do mestrado e que, juntamente com o Prof. Dr. Roberto Hirata, a quem também agradeço, fez críticas ao trabalho durante a qualificação, que certamente contribuíram para melhorar a qualidade desta tese.

Minha gratidão também à equipe de Recife que me ajudou com boa parte da implementação da parte prática deste trabalho, imprescindível para validar a arquitetura aqui proposta: Thiago Seixas, Diogo Burgos, Murilo Pontes (que ajudou muito na integração com o Ourgrid) e especialmente ao Fabiano Arruda Ferreira das Graças, com quem tive longas discussões madrugadas adentro. Vocês foram fundamentais para que este trabalho pudesse se realizar.

Aos professores Dr. Philippe Olivier Alexandre Navaux e Dr. Nicolas Bruno Maillard da Universidade Federal do Rio Grande do Sul, que ofereceram suas instalações para realização de testes que validassem este trabalho, e ao Dr. Roberto Souto, do Instituto Nacional de Pesquisas Espaciais, pelas discussões e pelo empenho em realizar testes com dados reais, o meu muito obrigado!

Um agradecimento especial, que aqui não poderia faltar, vai para a Opus Software e para a Microsoft Brasil, que proporcionaram flexibilidade suficiente para que eu pudesse cursar o doutorado. E também ao Prof. Dr. Carlos Humes Junior, pelas orientações iniciais, quando ainda estava avaliando o melhor caminho acadêmico a seguir.

Por compartilharem um pouco de seu conhecimento comigo, agradeço aos professores do IME, e aos colegas por assistirem às minhas palestras e seminários.

Aos meus amigos e familiares, agradeço pelo apoio e interesse em me ouvir falar sobre o curso.

Enfim, a todas as pessoas que de alguma forma contribuíram para a realização deste trabalho, seja por me ouvirem, por lerem o texto em suas versões incompletas ou ainda por se interessarem pelo assunto, meu sincero agradecimento. 


\section{Resumo}

O uso de padrões de workflow para controle de fluxo em aplicações de eScience resulta em maior produtividade por parte do cientista, permitindo que se concentre em sua área de especialização. Todavia, o uso de padrões de workflow para paralelização em grades permanece uma questão em aberto. Este texto apresenta uma arquitetura de baixo acoplamento e extensível, para permitir a execução de padrões com ou sem a presença de grade, de modo transparente ao cientista. Descreve também o Padrão Junção Combinada, que atende a diversos cenários de paralelização comumente encontrados em aplicações de e-Science. Com isso, espera-se auxiliar o trabalho do cientista, oferecendo maior flexibilidade na utilização de grades e na representação de cenários de paralelização.

Palavras-chave: workflow, grade, control-flow, padrões, e-Science, workflows científicos 


\section{Abstract}

The use of workflow control-flow patterns in e-Science applications results in productivity improvement, allowing the scientist to concentrate in his/her own research area. However, the use of workflow control-flow patterns for execution in grids remains an opened question. This work presents a loosely coupled and extensible architecture, allowing use of patterns with or without grids, transparently to the scientist. It also describes the Combined Join Pattern, compliant to parallelization scenarios, commonly found in e-Science applications. As a result, it is expected to help the scientist tasks, giving him or her greater flexibility in the grid usage and in representing parallelization scenarios.

Keywords: workflow, grid, control-flow, pattern, e-Science, scientific workflows 


\section{Sumário}

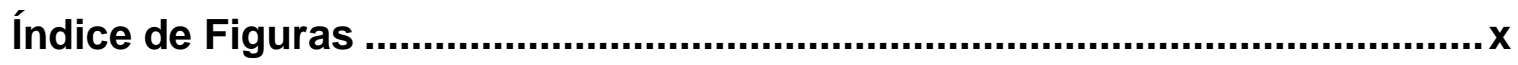

Índice de Tabelas .................................................................................... xiii

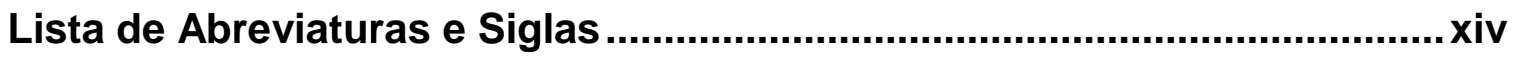

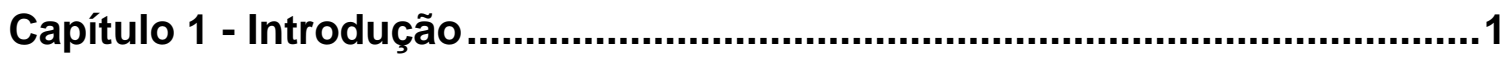

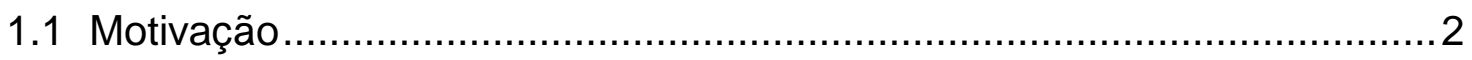

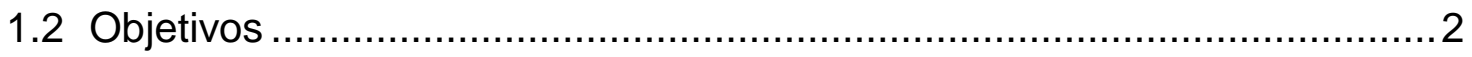

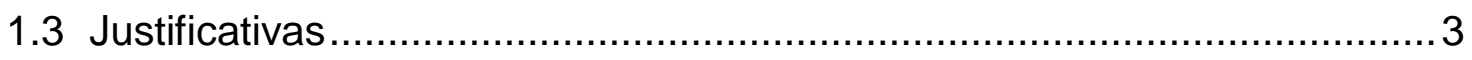

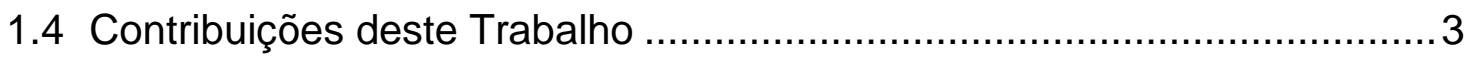

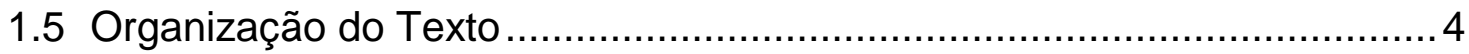

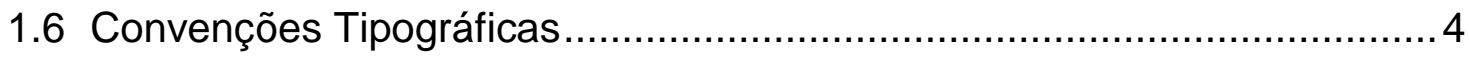

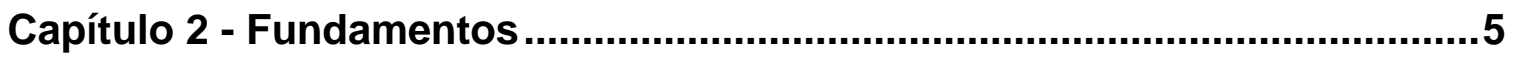

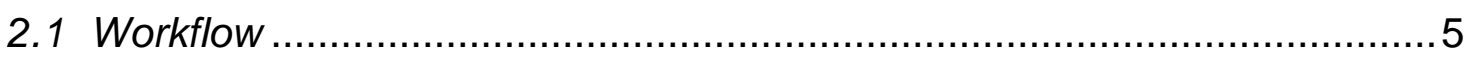

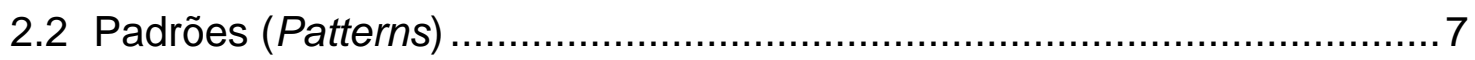

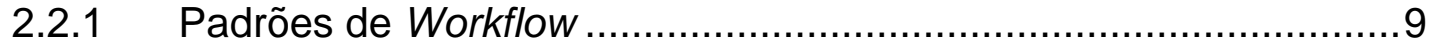

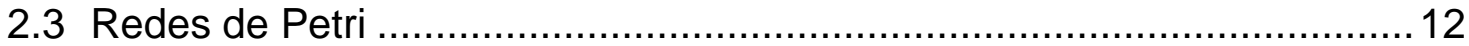

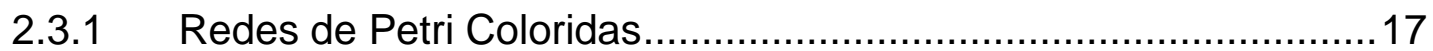

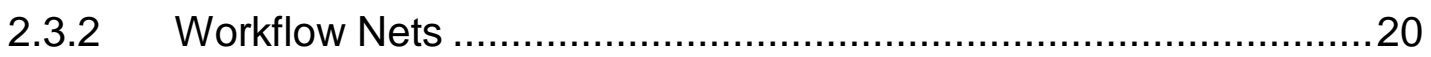

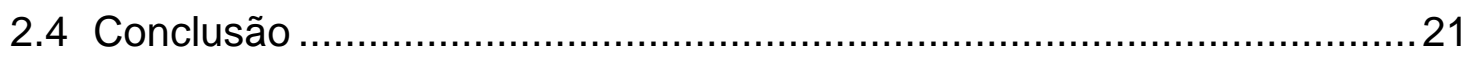

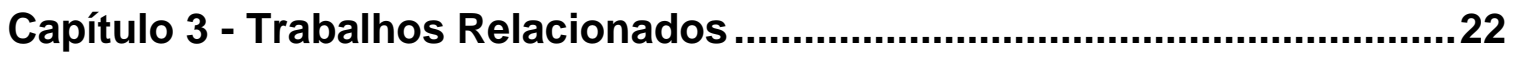

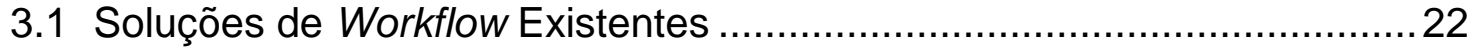

3.2 Soluções de Grade Existentes ...........................................................23

3.2.1 Berkeley Open Infrastructure for Network Computing (BOINC) ....23

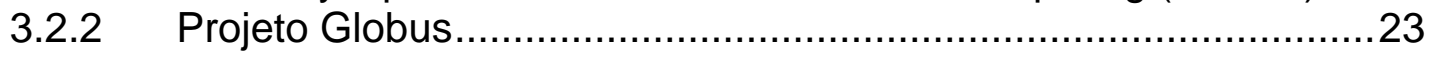

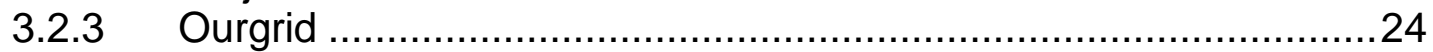

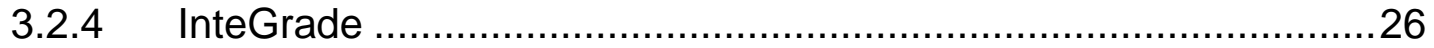

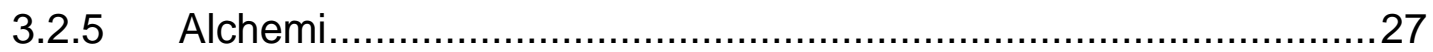

3.2.6 Considerações sobre as Soluções de Grade .............................28

3.3 Execução de Workflows em Grade ......................................................29

3.3.1 Abstract Grid Workflow Language (AGWL) e ASKALON ..............29

3.3.2 Padrões de Workflow para Grades..........................................32

3.3.3 Condor, Condor-G, DAGMan, Pegasus e GriPhyN VDS................33 
3.3.4 Grid Process Execution Language (GPEL) e CROWN FlowEngine 37

3.3.5 Considerações sobre a Execução de Workflows em Grades........38

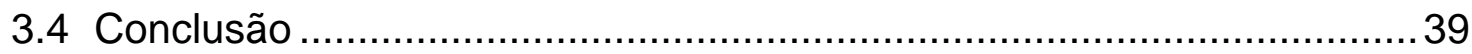

Capítulo 4 - Padrões de Workflow Paralelizáveis...........................................40

4.1 Padrões de Workflow Relacionados ......................................................40

4.1.1 (WCP-2) Divisão Paralela........................................................42

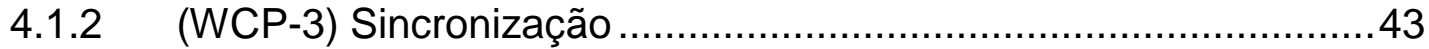

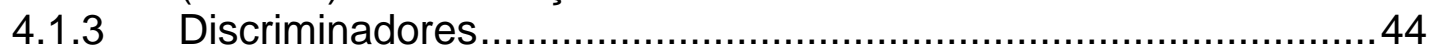

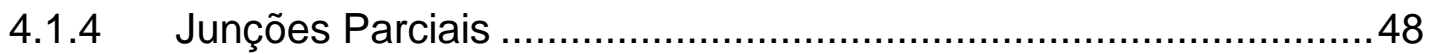

4.1.5 Padrões para Múltiplas Instâncias ............................................50

4.2 O Padrão Junção Combinada (PJC) ................................................. 53

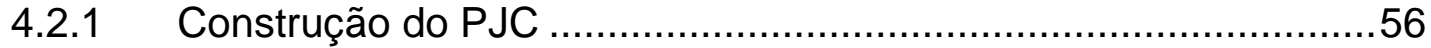

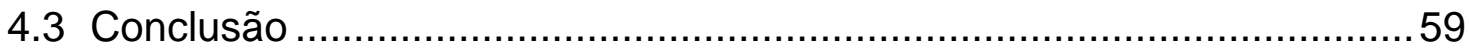

Capítulo 5 - Uma Arquitetura de Baixo Acoplamento...................................60

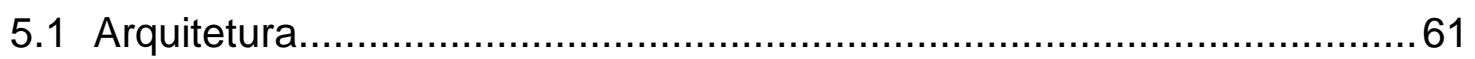

5.1.1 Uso de Múltiplas Camadas.......................................................62

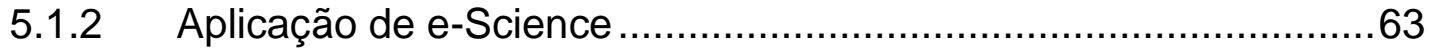

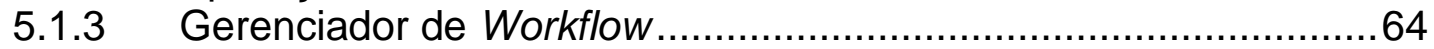

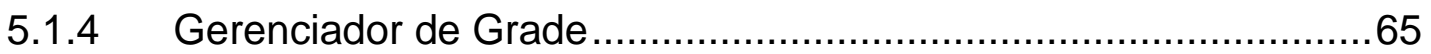

5.1.5 Elementos Constituintes do Middleware........................................65

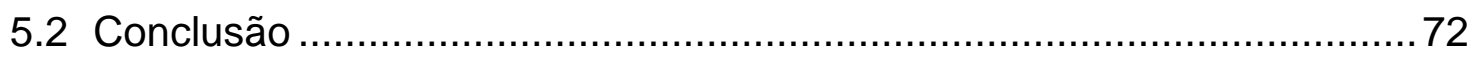

Capítulo 6 - Considerações sobre a Implementação ………...........................73

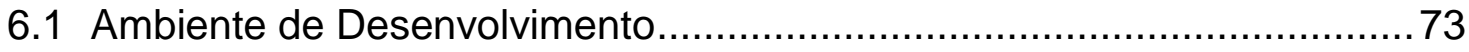

6.2 Uso de Serviços Web - Interoperabilidade ......................................... 74

6.2.1 Comunicação com Serviços - Endpoints....................................74

6.2.2 Hospedagem de Serviços Web .............................................78

6.2.3 Proxies e a Utilização de Endpoints ........................................ 81

6.3 Comunicação entre Camadas.......................................................... 84

6.3.1 Relação entre a Aplicação, o Gerenciador de Workflow e o

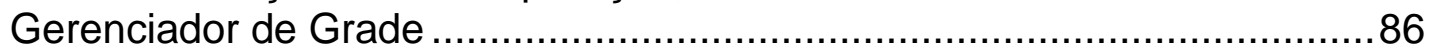

6.3.2 Interface Disponibilizada pelo EGP ….................................. 87

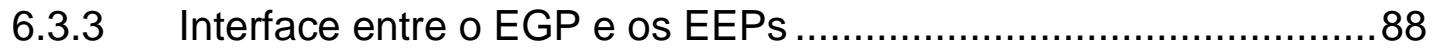

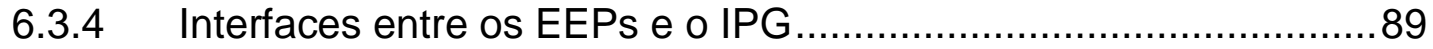

6.3.5 Interfaces entre o IPG e os EGGs .......................................... 90

6.3.6 Comunicação entre o EGG e o Gerenciador de Grade .................90

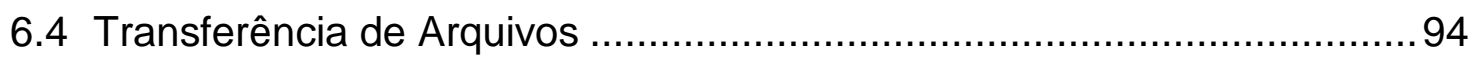

6.5 Baixo Acoplamento - Extensibilidade e Flexibilidade .............................96

6.6 Integração a um Gerenciador de Workflow ..........................................97 


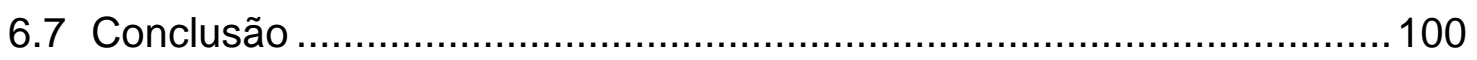

Capítulo 7 - Testes e Resultados Obtidos ....................................................101

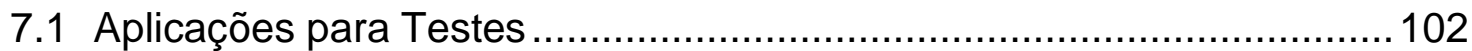

7.1.1 Soma de Dois Números Inteiros................................................ 102

7.1.2 Cálculo Aproximado de $\pi$.....................................................103

7.1.3 Torres de Hanoi..................................................................104

7.1.4 Brazilian Regional Atmospheric Modeling System - BRAMS [71]105

7.1.5 Submissão de Atividades ao EGG para Threads .......................108

7.1.6 Submissão de Atividades ao EGG para Ourgrid .........................111

7.2 Testes de Funcionalidade ...................................................................... 113

7.3 Testes de Desempenho .................................................................114

7.3.1 Desempenho em Função da Duração das Atividades ................115

7.3.2 Desempenho em Função do Número de Atividades ...................117

7.3.3 Desempenho em Função do Número de Arquivos......................118

7.3.4 Desempenho em Função do Tamanho dos Arquivos...................123

7.4 Testes de Independência de Plataforma ................................................. 124

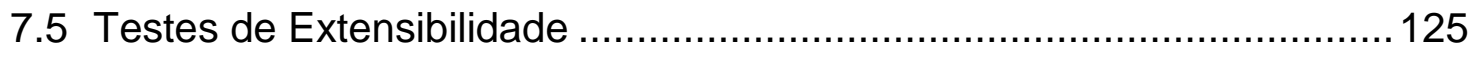

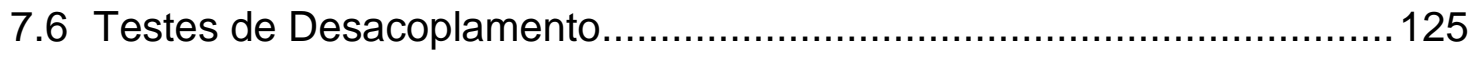

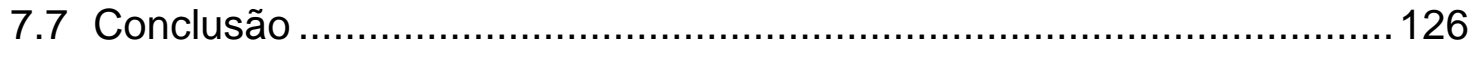

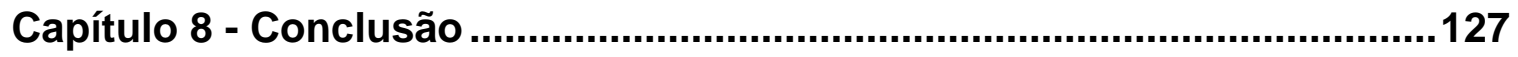

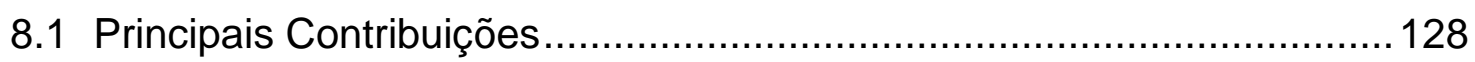

8.2 Sugestões de Trabalhos Futuros ................................................... 128

Apêndice A - Diagramas de Classes da Implementação ..............................129

A.1 Interfaces e Classes Utilizadas e Expostas pelo EGP ......................... 130

A.2 Interfaces e Classes Utilizadas e Expostas pelos EEPs ........................ 132

A.3 Interfaces e Classes Utilizadas e Expostas pelo IPG ........................... 135

A.4 Interfaces e Classes Utilizadas e Expostas pelos EGGs ....................... 138

Apêndice B - Modelo de Dados para Persistência do PJC .........................141

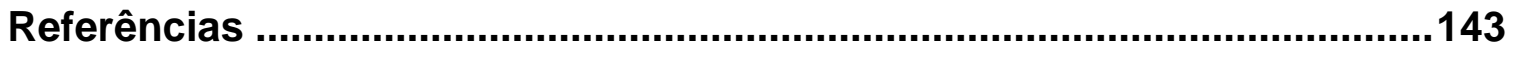




\section{Índice de Figuras}

Figura 1: diagrama de estados ilustrando as etapas de uma linha de produção 12 Figura 2: representação das atividades de alocação e desalocação de recursos

Figura 3: Rede de Petri mostrando o fluxo da fabricação de carros

Figura 4: marcação $M_{1}$, obtida a partir da marcação da Figura 3 ....................15

Figura 5: PT-net com marcação $\mathrm{M}_{0}$, representando a linha de montagem de dois

modelos de veículos ...................................................................15

Figura 6: marcação $\mathrm{M}_{1}{ }_{1}$, diretamente atingível a partir de $\mathrm{M}_{0}{ }_{0} \ldots \ldots \ldots \ldots \ldots \ldots \ldots \ldots \ldots . . . \ldots 16$

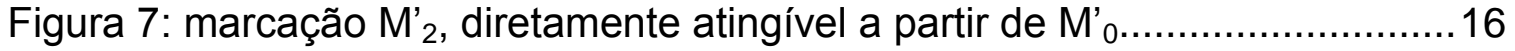

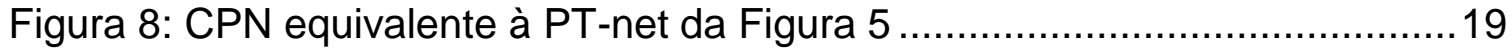

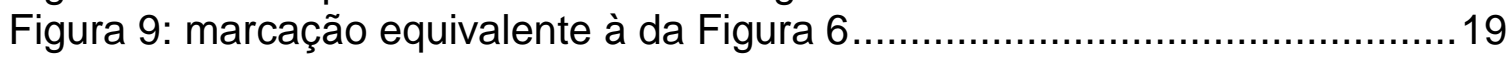

Figura 10: arquitetura do Globus Toolkit 4 [32] ........................................24

Figura 11: elementos constituintes do Ourgrid Toolkit [34] ...........................25

Figura 12: exemplo dos componentes do InteGrade em federação [37] ............26

Figura 13: arquitetura do Alchemi [39] ..................................................28

Figura 14: processamento pelo ASKALON de workflows definidos em AGWL [40]

Figura 15: arquitetura do ASKALON [41]

Figura 16: representação de grafo dirigido acíclico no DAGMan........................33

Figura 17: grafo acíclico dirigido da Figura 16 com informações de fluxo de

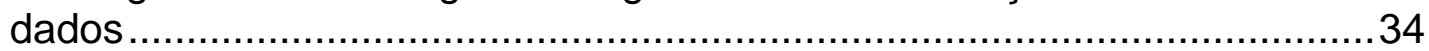

Figura 18: representação, transformação e execução de workflows em grades (Adaptado de [51])

Figura 19: arquitetura do CROWN FlowEngine [57] .....................................38

Figura 20: representação do padrão "Discriminador Estruturado" usando CPN [2]

Figura 21: construção a ser utilizada pelo cientista .......................................42

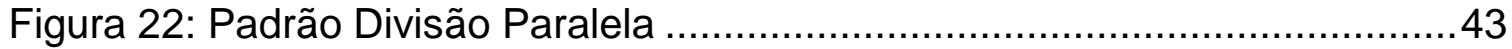

Figura 23: Padrão Sincronização................................................................43

Figura 24: combinação do uso dos padrões "Divisão Paralela" e "Sincronização"

Figura 25: Padã...............................................................................4

Figura 26: Padrão Discriminador com Bloqueio.........................................46

Figura 27: Padrão Discriminador com Cancelamento......................................47

Figura 28: Padrão Junção Parcial Estruturada. ..............................................49

Figura 29: Padrão Junção Parcial com Bloqueio [2] ........................................49

Figura 30: Padrão Junção Parcial com Cancelamento [2] ..............................50

Figura 31: Padrão Junção Parcial Dinâmica para Múltiplas Instâncias. Adaptado

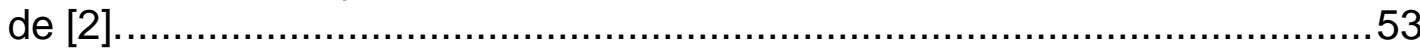

Figura 32: representação simplificada do Padrão Junção Combinada ...............54

Figura 33: Junção Parcial com Bloqueio e Cancelamento...............................57

Figura 34: Padrão Junção Combinada ....................................................58 
Figura 35: arquitetura da solução proposta. A área delimitada pela região tracejada indica os elementos que compõem o middleware desenvolvido neste trabalho.

Figura 36: diagrama de seqüência da requisição de execução do PJC no Ourgrid

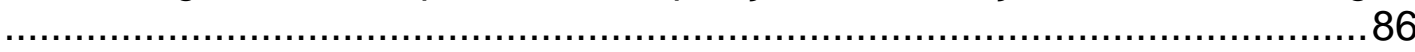

Figura 37: relação entre o IPG, o Stub para EGG e a implementação dos EGGs

Figura 39: representação de uma máquina de estados simples utilizando

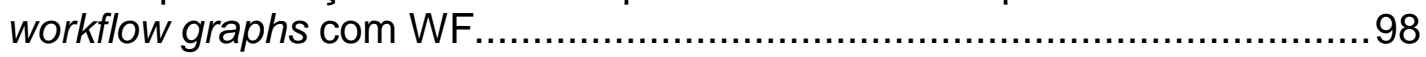

Figura 40: representação do PJC em workflow graphs ..................................99

Figura 41: Portal GridSphere para gerenciamento de jobs BRAMS ................106

Figura 42: exemplo de saída produzida pelo BRAMS ....................................107

Figura 43: aplicação para submissão de atividades ao middleware .................109

Figura 44: execução de simulações com BRAMS sem o middleware ..............112

Figura 45: execução de simulações com BRAMS e com o middleware ............112

Figura 46: desempenho do middleware em função da duração de atividades $\mathrm{O}(n)$ e $\mathrm{O}(2 n)$

Figura 47: desempenho do middleware em função do número de atividades ..117

Figura 48: desempenho do middleware em função do número de arquivos de entrada com uma atividade.

Figura 49: desempenho do middleware em função do número de arquivos de entrada com dez atividades.....

Figura 50: desempenho do middleware em função do número de arquivos de saída com uma atividade

Figura 51: desempenho do middleware em função do número de arquivos de saída com dez atividades

Figura 52: desempenho do middleware em função do tamanho dos arquivos.123

Figura 53: interface IEgp exposta pelo EGP e classe EgpService, que a implementa

Figura 54: classes internas para tratamento do Mapa Padrão-Implementação 131

Figura 55: proxy utilizado pelo EGP para acessar os EEPs .

Figura 56: interfaces expostas pelo EEP e classe EepPj cService, que as implementa

Figura 57: classes internas ao EEP para PJC, que realizam persistência de estado do padrão

Figura 58: proxy utilizado pelos EEPs para acessar o IPG..........................134

Figura 59: classes para o contrato de dados utilizado pelo EEP para o PJC ...134

Figura 60: interfaces expostas pelo IPG e classe IpgService, que as implementa

Figura 61: classes utilizadas pelo IPG para transferência de arquivos usando $\mathrm{SSH}$

Figura 62: classes internas para tratamento do Mapa Grade-Implementação .136

Figura 63: proxy utilizado pelo IPG para acessar os EEPs. 137

Figura 64: proxy utilizado pelo IPG para acessar os EGGs 137

Figura 65: classes para o contrato de dados utilizado pelo IPG 138 
Figura 66: interface IEggIpg exposta pelo EGP e classe EggThreadService, que a implementa

Figura 67: classe interna do EggThreadService, para gerenciamento das threads de execução

Figura 68: proxy utilizado pelos EGGs para acessar o IPG.........................139

Figura 69: classes para o contrato de dados utilizado pelo EGG de threads (sem grade)

Figura 70: modelo de dados para armazenar o estado das execuções do PJC 140 141 


\section{Índice de Tabelas}

Tabela 1: operações da interface GridMachine .............................................25

Tabela 2: padrões de junção para múltiplas instâncias e para atividades distintas

Tabela 3: comparação entre os bindings oferecidos pelos serviços

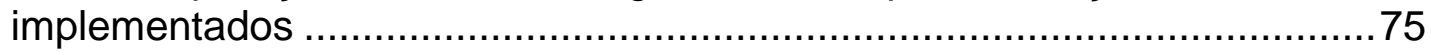

Tabela 4: testes funcionais em laboratório ................................................113

Tabela 5: testes de desempenho em função da duração das atividades .........116

Tabela 6: testes de desempenho em função do número de atividades ............117

Tabela 7: testes de desempenho em função do número de arquivos de entrada com uma atividade.................................................................119

Tabela 8: testes de desempenho em função do número de arquivos de entrada com dez atividades

Tabela 9: testes de desempenho em função do número de arquivos de saída com uma atividade.

Tabela 10: testes de desempenho em função do número de arquivos de saída com dez atividades

Tabela 11: testes de desempenho em função do tamanho dos arquivos .........123

Tabela 12: testes de independência de plataforma 


\title{
Lista de Abreviaturas e Siglas
}

\author{
AGWL - Abstract Grid Workflow Language \\ CPN - Coloured Petri-Net \\ EGP - Executor Genérico de Padrões \\ GPEL - Grid Process Execution Language \\ IPG - Integrador Padrão-Grade \\ NPDL - Navigation Plan Description Language \\ PJC - Padrão Junção Combinada \\ RPC - Remote Procedure Call \\ SGWF - Sistema Gerenciador de Workflow \\ SOA - Service-Oriented Architecture \\ UCP - Unidade Central de Processamento \\ WASA - Workflow-based Architecture to support Scientific Applications \\ WCF - Windows Communication Foundation \\ WCP - Workflow Control-Flow Patterns \\ WDP - Workflow Data Patterns \\ WF - Windows Workflow Foundation \\ WRP - Workflow Resource Patterns \\ XAML - Extensible Application Markup Language \\ $X M L$ - Extensible Markup Language \\ XPDL - XML Process Definition Language
}




\section{Capítulo 1}

\section{Introdução}

O avanço nas indústrias de hardware e software nos últimos 40 anos possibilitou a utilização da computação em diversas áreas da ciência, a que se chama e-Science, como astronomia, química, genética e agricultura, entre outras.

As aplicações desenvolvidas contribuem para a validação de hipóteses estabelecidas pelos cientistas. Dessa forma, agilizam os resultados e, conseqüentemente, as análises e as pesquisas.

Tipicamente, essas aplicações contêm workflows científicos, com fluxos simples ou complexos, constituídos por conjuntos de atividades a serem executadas seguindo padrões, dentre os quais os seqüenciais e os paralelos. Pode haver também dependência, utilização de recursos e tráfego de dados para e entre as atividades.

Cada padrão pode ser implementado diretamente pelo cientista. Todavia, como os padrões apresentam comportamentos que se repetem, podem ser encapsulados e oferecidos ao cientista como parte de soluções de workflow. Assim, a utilização dos padrões torna-se mais simples. Além disso, permite que o cientista de outras áreas, que não seja a de computação, possa empregar seu tempo em suas pesquisas, ao invés de ocupá-lo na construção de infra-estrutura para testar suas teorias ou conceitos.

Wil van der Aaslt et al. [1] realizaram estudos voltados à identificação de padrões de workflow em aplicações de e-Science. Nesse trabalho, avaliaram quatorze produtos, comparando-os quanto à disponibilidade de implementação dos padrões. A partir desse trabalho, novos estudos têm sido realizados envolvendo padrões de workflow, como o de Russell et al. [2], que identificou outros padrões, diversos sendo especializações dos descritos inicialmente por Aalst. 
Embora os padrões simplifiquem o uso de workflows pelos cientistas, existem ainda alguns desafios. O primeiro deles é a representação de workflows, que pode ser realizada de diversas formas, como: redes de Petri coloridas (CPN - Coloured Petri-Nets) [3]; expressões de álgebra de processos - como NPDL [4]; linguagens baseadas em comandos em texto - como XPDL [5]; ou workflow graphs [6]. Várias abordagens são analisadas em [7], que descreve vantagens e desvantagens de cada uma.

Do ponto de vista da computação, para cada solução de workflow e para cada representação, os padrões devem ser novamente implementados, o que oferece baixo índice de reaproveitamento de código.

O tempo gasto no processamento de análises e cálculos é outro ponto relevante, principalmente se considerado para execução de atividades paralelamente. Para atender a essa questão, tem-se lançado mão do uso de software para computação em grades, clusters ou equipamentos multiprocessados. Tal software, entretanto, acrescenta novo fator de complexidade a ser considerado, o que onera 0 tempo de pesquisas e análises e exige conhecimento especializado.

Esta pesquisa, apoiada pela Microsoft Brasil e Microsoft Research, propõe a arquitetura de um middleware para a utilização dos padrões de workflow para aplicações de e-Science. Essas aplicações podem ou não ter atividades sendo executadas paralelamente em grades, o que é aqui apresentado de modo transparente ao cientista.

\subsection{Motivação}

No contexto de aplicações de e-Science, existem duas necessidades fundamentais no dia-a-dia de cientistas, que não são totalmente cobertas pelas soluções analisadas até o momento [2]: 1) a representação de padrões de workflows de modo simples e integrado ao gerenciador de workflow já utilizado; 2) abstração da utilização de software de grade.

Para o cientista, a utilização da grade é um recurso para aumentar o desempenho do processamento, reduzindo o tempo total. Assim, tal tarefa, embora complexa, é meramente técnica: o cientista deveria ser especialista em sua área e fornecer o algoritmo específico de sua pesquisa, ao invés de utilizar parte de seu tempo pensando em execução em grade.

\subsection{Objetivos}

Esta pesquisa pretende oferecer recursos para cobrir as duas necessidades acima, ou seja, a integração às aplicações existentes do uso de padrões de workflow para paralelização e a transparência da presença de grade para 0 
cientista. Desse modo, a representação de workflows deve ser realizada sem que o cientista precise conhecer álgebra de processos, redes de Petri ou linguagens de workflow. A apresentação dos padrões de workflow deve ser feita de tal modo que estes possam ser utilizados pelo cientista para representar 0 problema de sua área de pesquisa de forma mais intuitiva, e pretende-se abstrair a interação com software de grade, fazendo com que sua presença seja informada como uma configuração do sistema.

\subsection{Justificativas}

O uso de padrões de workflow em aplicações de e-Science aumenta o número de possibilidades de análises em diversas áreas do conhecimento, sem o ônus da complexidade de implementar os comportamentos encapsulados nos padrões diretamente nas aplicações. Esse é o caso de padrões de paralelização como os descritos por Russell et al. em [2].

O uso de grades para execução de tarefas paralelizáveis, por sua vez, reduz o tempo gasto no processamento de análises e cálculos, oferecendo ao cientista maior agilidade em suas pesquisas e estudos.

Russell et al [2] não avaliam nem propõem a execução dos padrões em grades. Ao possibilitar o uso dos padrões de modo integrado, porém com baixo acoplamento, às grades, esta pesquisa oferece uma abordagem mais completa para o cientista que desenvolve pesquisas em e-Science.

Embora o principal interesse deste trabalho sejam aplicações de e-Science, workflows comerciais também podem se beneficiar dos conceitos aqui apresentados e discutidos.

\subsection{Contribuições deste Trabalho}

Como resultado desta pesquisa, espera-se oferecer uma arquitetura de baixo acoplamento para execução de padrões de controle de fluxo, potencialmente com a utilização de grades. Tal arquitetura resulta nos seguintes benefícios:

- Facilita o uso de padrões de workflow por cientistas que não tenham informática como sua área de pesquisa;

- Permite a execução de padrões de paralelização em clusters, grades ou equipamentos multi-processados;

- Oferece infra-estrutura extensível para ser complementada com a implementação de outros padrões além dos aqui apresentados; 
- Permite que outros grupos de pesquisa utilizem outras soluções de grades, também por meio da extensibilidade da solução aqui proposta.

\subsection{Organização do Texto}

Os principais conceitos utilizados neste trabalho são brevemente revistos no Capítulo 2.

O Capítulo 3 apresenta diversos trabalhos acadêmicos e produtos comerciais relacionados a esta pesquisa.

No Capítulo 4 são descritos os padrões de controle de fluxo definidos por Russell et al em [2], que podem se beneficiar de execução paralela. É então feita a apresentação do Padrão Junção Combinada, cuja implementação unifica diversos desses padrões.

O Capítulo 5 apresenta a arquitetura em camadas que permite 0 desacoplamento entre a aplicação de e-Science e o gerenciador de grade. Essa arquitetura foi implementada em um middleware, com interfaces e serviços web descritos no Capítulo 6.

Para validar os benefícios propostos pelo middleware e para analisar o impacto no desempenho resultante de sua utilização, o Capítulo 7 apresenta os resultados de um conjunto de testes e os cenários em que foram realizados.

Por fim o Capítulo 8 encerra este texto apresentando as conclusões e principais contribuições de nossa proposta.

Complementam este trabalho o Apêndice $A$, que descreve os modelos de classes dos serviços que integram o middleware, e o Apêndice $B$, que apresenta o modelo de dados utilizado pela implementação do Padrão Junção Combinada.

\subsection{Convenções Tipográficas}

Neste texto foram utilizadas as seguintes convenções tipográficas:

- Termos em inglês ${ }^{1}$ são grafados em itálico;

- Trechos de código utilizam a fonte courier New, tamanho 9;

- No corpo do texto, referências a termos utilizados em código fonte ou palavras reservadas aparecem com a fonte Courier New, tamanho 12.

\footnotetext{
${ }^{1}$ Alguns termos empregados no texto foram propositadamente deixados em inglês.
} 


\section{Capítulo 2}

\section{Fundamentos}

Os trabalhos científicos envolvendo workflows e padrões utilizam termos e conceitos específicos, necessários para manter a consistência entre os grupos de pesquisa sobre esses temas.

Neste capítulo, apresentamos a terminologia que será utilizada nos demais capítulos do texto. A Seção 2.1 explicita o que são workflows, e descreve as diferenças entre workflows científicos e workflows de negócio. Na Seção 2.2 são apresentados a importância e os ganhos com o uso de padrões, entrando em maior detalhe quanto aos padrões de workflow. Na Seção 2.3 é apresentada uma visão informal sobre Redes de Petri, amplamente utilizadas no Capítulo 4 na representação de padrões de workflow usados em paralelização de tarefas, e para descrever como tais padrões foram combinados, constituindo o Padrão Junção Combinada.

\subsection{Workflow}

A necessidade por sistemas capazes de isolar o fluxo de tarefas na automatização de processos de escritório foi identificada nos anos 1970. Até então, tanto o fluxo quanto as demais atividades eram contidas num mesmo sistema ou aplicação. Com isso, havia dificuldades na manutenção dos fluxos, exigindo o desenvolvimento de nova versão dos sistemas a cada mudança de fluxo, o que era comum no cenário em questão.

Ao separar o fluxo do restante do sistema, ganhou-se flexibilidade e agilidade quando modificações eram necessárias. Além disso, aos profissionais especialistas em áreas de negócios, puderam ser atribuídas as 
responsabilidades por essas tarefas, sem que fossem necessários conhecimentos de programação.

O tema ganhou a atenção de diversas empresas, que constituíram a Workflow Management Coallition (WfMC) [8] em 1993. Essa organização tem conduzido estudos e publicado diversos padrões sobre workflows e sistemas para gerenciá-los. Segundo a WfMC, um workflow pode ser definido como "A automação de um processo de negócio, no todo ou em partes, no qual documentos, informações ou tarefas são passados de um participante a outro para ser processado, de acordo com um conjunto de regras procedurais".

Essa abordagem pode ser entendida tanto no âmbito de um sistema quanto no contexto da convivência entre diversos sistemas que devam ser utilizados para perfazer as tarefas de um dado processo de negócio. Um exemplo deste último caso é a integração entre sistemas de gerenciamento de estoque, vendas, compras e financeiro, todos desempenhando sua função dentro do processo de vendas de produtos em uma empresa no segmento varejista. Vale notar que essa utilização estende-se a interações B2B (business-to-business), em que empresas compartilham informações e serviços, como ocorre no Sistema de Pagamentos Brasileiro (SPB) [9]. Nesse caso, as instituições financeiras precisam trocar mensagens para que operações entre elas possam ser realizadas de acordo com as diretrizes impostas pelo Banco Central do Brasil.

Além das aplicações para sistemas de negócios, workflows também fazem parte do cenário científico, que acrescenta algumas complexidades, como:

- Fluxos com grande número de etapas, comum no processamento de tarefas como ocorre em bioinformática, química, astronomia, agronomia, entre outras;

- Volatilidade dos fluxos, que devem poder ser alterados freqüentemente, na avaliação de hipóteses científicas;

- Necessidade de parametrização para grande número de tarefas: por exemplo, em buscas por padrões no genoma;

- Monitoramento e acompanhamento da execução, que deve levar em conta a dinamicidade dos fluxos;

- Execução em ambientes cujos recursos sejam desconhecidos a priori.

Desse modo, existem duas categorias de workflows bem definidas: workflows de negócio e workflows científicos. Cada uma possui suas particularidades, mas vale notar que uma solução que atenda a cenários científicos geralmente também se aplica a cenários de negócio. Uma exceção fica por conta da heterogeneidade de ambiente e tecnologias, comum principalmente no contexto de processos de negócios entre empresas (B2B). Em [10], Barga e Gannon apresentam essas características de workflows de negócio e científicos, no âmbito também de outros aspectos, como a existência de transações de longa duração, mais comuns em cenários científicos. Os autores 
ainda contextualizam os workflows de negócio como tratando do fornecimento de serviços para clientes, um uso distinto da realização de experimentos, como é o caso dos workflows científicos.

No que diz respeito à representação de workflows, utilizaremos neste texto uma variação das Redes de Petri, denominada Workflow Net. Ambas são descritas e definidas mais à frente neste capítulo.

\subsection{Padrões (Patterns)}

A busca por maiores oportunidades de reuso tem sido uma constante em várias áreas do conhecimento. A Revolução Industrial pode ser considerada um marco na padronização de processos de produção, com a automatização de tarefas repetitivas. Até então, os processos eram manuais, resultando em longo tempo para fabricação de produtos, inexistência de padronização das peças produzidas, altos custos de produção e do produto final. A adoção de procedimentos industriais automatizados e sua evolução solucionaram esses problemas, mostrando a importância da padronização.

Nesse sentido, um padrão (pattern) representa uma estratégia para solucionar problemas recorrentes. Cada padrão encapsula conhecimento de modo independente de implementação.

O mesmo se aplica à área da computação. Um exemplo é a concepção de subrotinas parametrizáveis, utilizadas constantemente em diversos paradigmas de programação, como a estruturada ou a orientada a objetos. Existem exemplos também em níveis mais elevados de abstração, como a concepção e o reconhecimento de padrões arquiteturais, usados fundamentalmente para maior controle e previsibilidade de desempenho, segurança, escalabilidade, disponibilidade, entre outros requisitos que são considerados principalmente para sistemas críticos.

O uso de padrões aumenta o índice de reutilização de código ao representar cenários, condições e ações específicas em diversos casos que se repetem. Com isso, espera-se ser possível o desenvolvimento de código mais robusto e de mais alta qualidade.

Embora padrões tenham sido apresentados como um conceito arquitetural em 1977 por Christopher Alexander et al [11], sua popularização veio em 1994, quando Gamma et al [12] compilaram um conjunto de vinte e três padrões para uso no desenvolvimento de sistemas. Esse trabalho é tido como leitura obrigatória sobre reutilização de software, no qual os padrões são propostos e exemplificados em três categorias:

- Padrões para criação, usados quando da instanciação de objetos. Um exemplo desta categoria é o padrão Singleton, que se aplica quando for necessário criar uma instância única de um objeto; 
- Padrões estruturais, que tratam da composição de classes e objetos, como é o caso do padrão Bridge, que desacopla a abstração da implementação de uma classe, portanto permitindo que ambas possam evoluir de modo independente;

- Padrões comportamentais, que tratam da comunicação entre objetos. Por exemplo, o padrão Iterator permite que se navegue pelos elementos de um objeto sem expor sua representação interna.

Em [13], Martin Fowler apresenta um conjunto de cinqüenta e um padrões arquiteturais, frequentemente presentes em aplicações empresariais, divididos em dez categorias:

- Padrões para Lógica de Domínio, que descrevem modelos de aplicações, levando em conta um balanceamento entre o processo de desenvolvimento e a produtividade. Um exemplo é o padrão de desenvolvimento Domain Model, que se aplica a processos mais sofisticados e complexos. O padrão Transaction Script, por sua vez, aplica-se a desenvolvimento de sistemas mais simples, que não demandem grandes formalismos em sua concepção, como sistemas ou aplicações periféricas e auxiliares;

- Padrões de Arquitetura para Fontes de Dados: referem-se a usos comuns de conjuntos de dados, como linhas, no padrão Row Data Gateway, ou tabelas, como no padrão Table Data Gateway;

- Padrões Objeto-Relacionais: são três categorias com padrões para representar objetos em entidades relacionais, como nos padrões Foreign Key Mapping e Repository;

- Padrões para Apresentação Web, que estão entre os mais populares e tratam da representação e uso de elementos de interface com o usuário. Um exemplo é o padrão Model View Controller, que separa os modelos a serem apresentados conforme indicado dinamicamente pelo controlador. Esse padrão é particularmente útil para aplicações multi-plataforma e/ou multi-dispositivo de apresentação;

- Padrões para Distribuição: tratam do envio de dados entre camadas da aplicação, como o padrão Data Transfer Object, que foi utilizado na implementação da arquitetura proposta neste trabalho;

- Padrões de Concorrência para Operações Offline, como é o caso do padrão Optimistic Offline Lock, usado para garantir concorrência otimista aos recursos envolvidos na operação offline;

- Padrões para Sessão, usados no gerenciamento de estado de objetos e componentes, como no padrão Client Session State;

- Padrões Base, como Mapper e Gateway.

Esses dois exemplos de usos de padrões e o sucesso em sua adoção e popularidade ilustram a importância do tema. A seguir serão apresentadas 
algumas considerações sobre a reutilização de elementos comumente vistos em representações de workflows.

\subsubsection{Padrões de Workflow}

Em 1999, Wil van der Aalst e Arthur ter Hofstede se uniram em torno de uma iniciativa para identificar, documentar e avaliar padrões em fluxos: a Workflow Patterns Initiative [14]. O objetivo com esse esforço foi auxiliar o desenvolvimento de tecnologias voltadas para processos, de modo a estabelecer critérios para o desenvolvimento e comparação entre elas.

Do mesmo modo como em outras áreas, as diversas atividades dentro de um workflow podem ser vistas como padrões, refletindo comportamentos comuns em cenários de processos de negócios ou aplicações de e-Science. A fim de atender a tais cenários, Aalst et al [1] propuseram quatro categorias de padrões para workflow, relativas à natureza das operações a serem realizadas, que foram denominadas perspectivas pelos autores:

- Padrões para Controle de Fluxo (Workflow Control-Flow Patterns WCP): um conjunto proposto em [1] contendo vinte padrões que apresentam cenários comuns na seqüência de execução dos passos de um workflow. No mesmo trabalho, Aalst et al fizeram um levantamento comparando diversos produtos gerenciadores de workflow quanto à disponibilidade ou não de cada padrão. Essa publicação serviu como base para avaliação de sistemas gerenciadores de workflow (SGWF), sejam comerciais ou para fins científicos. Posteriormente, Russell, Aalst et al [2] identificaram diversas especializações de padrões, e as separaram em novos padrões, completando um total de quarenta e três, classificados em oito sub-categorias:

- Padrões Básicos: identificam e descrevem as operações triviais de um fluxo, como seqüência, divisão paralela, sincronização e escolha exclusiva;

- Padrões Avançados para Ramificação e Sincronização: detalham diversas possibilidades para execução de ramificações como discriminadores e junções parciais, incluindo tratamento de atividades pendentes. Por exemplo, no Padrão Junção Parcial com Cancelamento é estudado o caso de execução paralela de um conjunto de atividades; a saída deve ser produzida assim que um número determinado de atividades tiver sido concluído, sendo que as demais recebem sinalização para que sejam canceladas. Pela natureza paralela da execução de tais padrões, apropriada para execução em grades, esses padrões foram escolhidos para o desenvolvimento deste trabalho; 
- Padrões para Múltiplas Instâncias: são um caso específico de padrões para ramificação e sincronização. Aqui, todas as atividades são instâncias de uma mesma atividade. Por exemplo, a execução de diversas buscas genômicas que possam ser realizadas paralelamente. $O$ algoritmo de busca é o mesmo, havendo variação apenas nos parâmetros de entrada;

- Padrões Baseados em Estado: quando a relação entre atividades a serem executadas dependerem de estado, 0 controle do fluxo deve prever situações de concorrência e ordem de execução. Isso ocorre, por exemplo, quando diversas atividades puderem ser executadas em seqüência, porém em qualquer ordem. Outros usos são a marca de um ponto na execução do fluxo (milestone) ou a escolha postergada (deferred choice), em que a escolha depende do estado de uma variável do ambiente de execução;

- Padrões para Cancelamento e Conclusão Forçada: alguns padrões avançados para ramificação e sincronização tratam do cancelamento de atividades no cenário em que um conjunto de atividades tenha sido concluído, permitindo o prosseguimento do fluxo, e as atividades restantes devam ser canceladas. Aqui, são tratados padrões de cancelamento isoladamente, particularmente úteis em situações de tratamento de exceções. O Padrão de Conclusão Forçada permite que, a partir de informações externas, as atividades pendentes sejam concluídas. Por exemplo, diversos testes com amostras devem ser feitos paralelamente. Após certo período, o usuário solicita ao sistema que cancele os testes que não foram concluídos, forçando o término da execução paralela;

- Padrões para Iteração: tratam ciclos e laços, incluindo recursão;

- Padrões para Terminação: para os casos em que é necessário saber da conclusão da execução do fluxo, seja implícita ou explícita. No primeiro caso, o sistema infere o término da execução; já no segundo, o usuário explicitamente informa o término;

- Padrões para Gatilhos: para os casos em que um sinal externo identifica o prosseguimento ou não do fluxo. Há dois padrões: transiente, em que a atividade deve estar pronta para execução no momento do disparo do gatilho, sob o risco do sinal ser perdido; ou persistente, que espera até que a atividade esteja pronta para então consumir o sinal do gatilho; 
- Padrões para Recursos (Workflow Resource Patterns - WRP): segundo [15], recursos são entidades capazes de realizar algum trabalho. Podem ser classificados como humanos e não-humanos, em função da dependência de pessoas. Por exemplo, um supervisor que aprova uma tarefa é um Recurso Humano, enquanto threads de execução são Recursos Não-Humanos. Exemplos de Padrões de Recursos são a autorização e a separação de tarefas;

- Padrões para Dados (Workflow Data Patterns - WDP): se propõem a descrever de que modo dados podem ser representados e utilizados em workflows. Russell et al [16] descrevem 39 padrões, divididos em quatro grupos, ilustrados como segue:

- Visibilidade de Dados: dados acessíveis pelo workflow apenas no contexto de uma tarefa específica - locais ou globais, por exemplo;

- Interação de Dados: dados fluindo do ambiente para um caso do workflow. Um caso pode ser entendido como uma instância do workflow;

- Transferência de Dados: entrada, saída, passados por valor ou por referência, por exemplo;

- Roteamento Baseado em Dados: a partir de um determinado valor, uma pré-condição de uma tarefa conduz o fluxo para certa atividade.

- Padrões para Manipulação de Exceções (Exception Handling Patterns). Russell et al [17] apresentam um arcabouço de classificação para exceções considerando três elementos que, combinados, geram 135 possibilidades de comportamentos:

- Como o item que gerou a exceção será manipulado: são quinze possibilidades aventadas como, por exemplo, seguir em frente usando o mesmo recurso alocado, falhar ou oferecer esse item para outro recurso;

- Como outros itens no mesmo caso serão manipulados: Russell et al vislumbraram três possibilidades - continuar o caso corrente, remover o caso corrente e remover todos os casos;

- Qual ação de recuperação deve ser empregada, dentre três possíveis: nada, desfazer ou compensar.

Este trabalho aborda os Padrões para Controle de Fluxo (Workflow ControlFlow Patterns - WCP). Os padrões que foram selecionados como parte do escopo deste estudo são apresentados na seção 4.1. 


\subsection{Redes de Petri}

São modelos gráficos para representação e estudo de processamento concorrente. Neste trabalho, as Redes de Petri são utilizadas como uma ferramenta para apresentação e ilustração de workflows e padrões para controle de fluxo. Por isso, optou-se aqui em se fazer uma introdução informal sobre o assunto, e então apresentar definições formais para as Redes de Petri, que podem ser complementadas em [18], onde são definidas várias propriedades e características dessas redes, mas que não são utilizadas neste texto.

Existem diagramas para representação de fluxos baseados em estados ou então em atividades. As Redes de Petri combinam esses dois tipos de diagramas, obtendo ao mesmo tempo as mudanças de estado e as atividades que fazem as transições de um estado a outro. A seqüência de figuras abaixo ilustra um diagrama de estados e um diagrama de atividades, ambos baseados no mesmo exemplo: a representação de uma linha de produção de automóveis, na qual há quatro atividades a serem realizadas e três tipos de profissionais distintos. Essas atividades podem ser a montagem de pára-brisa, instalação de motores para operação dos vidros e ligação do sistema elétrico ao mecânico. Os profissionais poderiam ser técnicos em vidraçaria, elétrica ou mecânica. Os estados demarcam o ponto de um carro na linha de produção.

A Figura $1^{2}$ apresenta um estágio inicial da linha de montagem de um carro do "Modelo a" e três estados adicionais, mostrando a utilização dos recursos em cada estado. Por exemplo, a "Etapa 1" pode ser a instalação de vidros nas portas, e o recurso $r_{1}$ pode ser um técnico em vidraçaria. $O$ estado inicial é indicado pela seta vazada, que também informa o número de unidades - neste exemplo carros - a serem processadas.

Modelo a

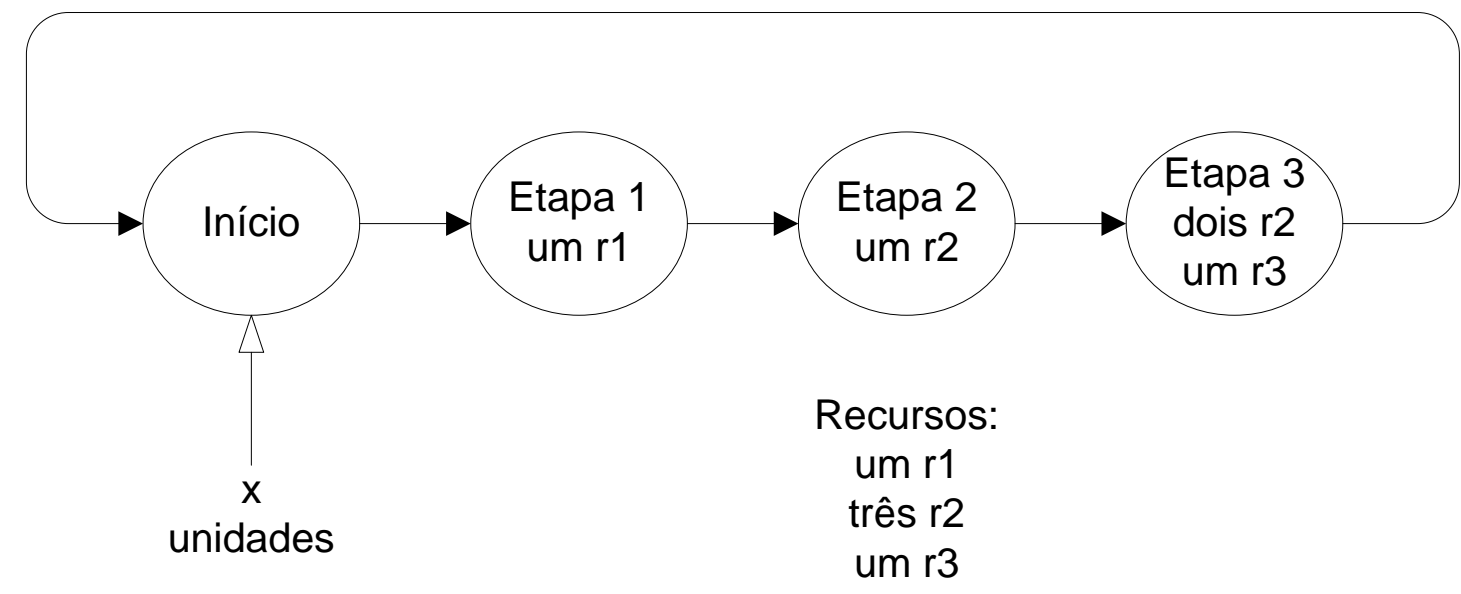

Figura 1: diagrama de estados ilustrando as etapas de uma linha de produção

\footnotetext{
${ }^{2}$ As figuras desta seção foram baseadas nas figuras de Kurt Jensen em [18]
} 
A Figura 2, por sua vez, representa o mesmo processo de fabricação de carros, porém sob a ótica da alocação e desalocação de recursos.

Modelo a

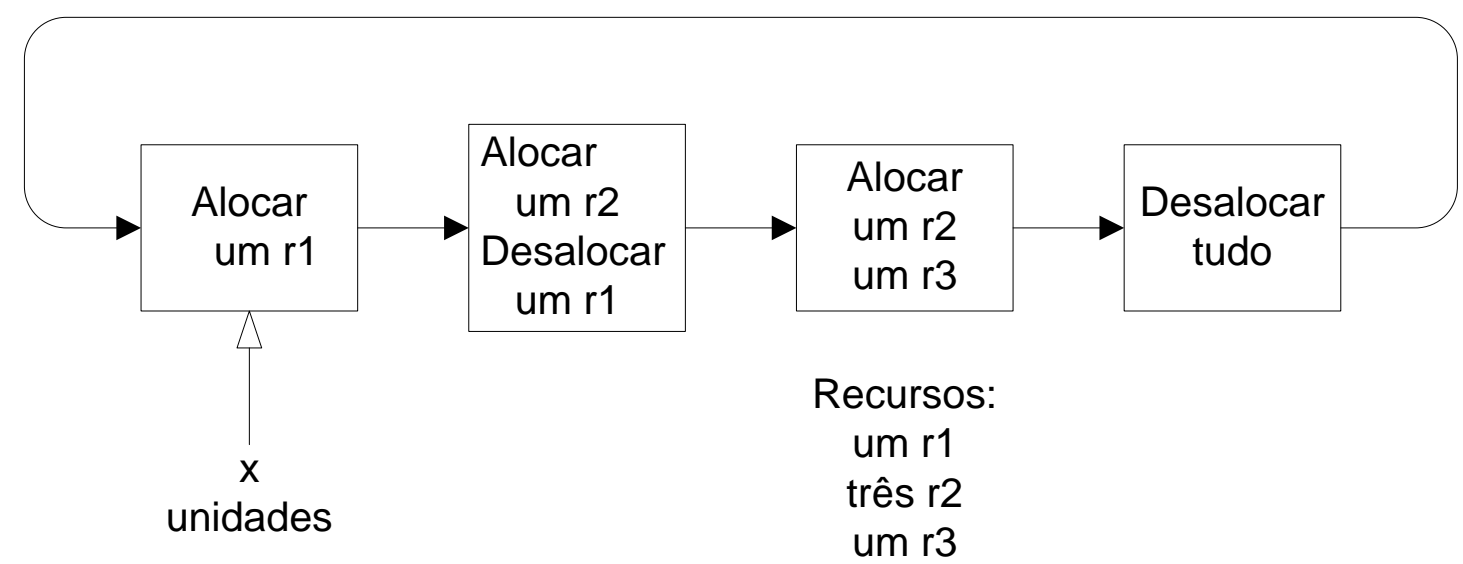

Figura 2: representação das atividades de alocação e desalocação de recursos

Para a representação do processo de fabricação de carros, ambos os diagramas desempenham seus papéis, e são complementares. Uma Rede de Petri, que combina as informações desses diagramas, é um grafo dirigido $\mathrm{G}=$ $(\mathrm{V}, \mathrm{A})$, no qual $\mathrm{V}$ é um conjunto de vértices e $\mathrm{A}$ é um conjunto de arestas. $\mathrm{O}$ conjunto $\mathrm{V}$ possui dois tipos de vértices (também denominados nós): $\mathrm{L}$, um conjunto contendo os lugares - ou estados - da rede; e T, o conjunto de transições - ou ainda atividades, ações ou tarefas ${ }^{3}$.

DEFINIÇÃO 2.1 (Rede de Petri): uma Rede de Petri é uma tripla (L, T, A), em que:

- L é um conjunto finito de lugares;

- T é um conjunto finito de transições, $L \cap T=\varnothing$;

- $A \subseteq(L \times T) \cup(T \times L)$ é um conjunto de arestas.

A Figura 3 é uma Rede de Petri que mostra os lugares como círculos (por vezes são mostrados como ovais) e as transições como retângulos. Existem sete lugares, sendo quatro representando os estágios de utilização de recursos e três representando a quantidade de recursos disponíveis. Uma Rede de Petri com esses elementos é chamada PT-net (sendo que P representa lugares places - e $\mathrm{T}$ representa transições - transitions). Na próxima seção será apresentada uma Rede de Petri com características adicionais, a Rede de Petri Colorida, ou CPN - Coloured Petri Net.

\footnotetext{
${ }^{3}$ Os termos atividades, ações e tarefas serão utilizados como sinônimos no restante deste texto
} 
Modelo a

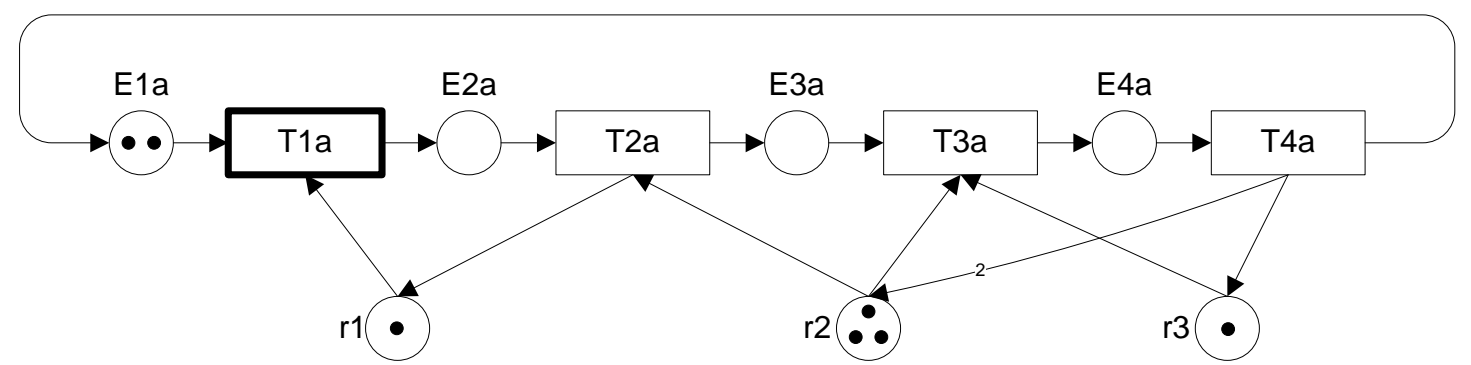

Figura 3: Rede de Petri mostrando o fluxo da fabricação de carros

As "bolinhas" no interior dos lugares são chamadas marcas. Uma distribuição das marcas pelos lugares é denominada marcação. Na Figura 3, as duas marcas em $E_{1 a}$ indicam que há dois carros a serem fabricados, e as marcas nos recursos $r_{1}, r_{2}$ e $r_{3}$ indicam o número de cada tipo de recurso.

As setas dirigidas nas PT-nets são chamadas arestas ou arcos. Elas indicam o fluxo de um nó a outro. Cada elemento da rede pode ainda ser classificado como de entrada ou saída de acordo com as setas. Por exemplo, a transição $T_{1 a}$ possui dois arcos de entrada conectando-a com os lugares de entrada $E_{1 a}$ e $r_{1}$. Do mesmo modo, $T_{1 a}$ possui um arco de saída que a conecta com o lugar de saída $E_{2 a}$. Usa-se a notação $\bullet l$ para representar o conjunto de transições de entrada do lugar $l$. De modo análogo, $l \bullet$ denota o conjunto de transições de saída do lugar $l, \bullet t$ e $t \bullet$ sendo os conjuntos de lugares de entrada e saída, respectivamente, da transição $t$.

Em uma PT-net, uma transição é dita habilitada quando todos os seus arcos de entrada vierem de lugares com o número de marcas maior ou igual ao número apontado no arco. Por convenção, esse número pode ser omitido quando for igual a um. As transições habilitadas em uma determinada marcação são indicadas por seu contorno em negrito. $\mathrm{Na}$ Figura 3, apenas $\mathrm{T}_{1 \mathrm{a}}$ está habilitada.

Os elementos até aqui descritos compõem a representação sintática das PT-nets. A semântica, ou seja, o comportamento das PT-nets, é descrita a seguir. Uma PT-net pode ser interpretada como um jogo de tabuleiro em que uma marcação inicial indica o início do jogo, e as peças são as marcas. A regra para movimentação das peças é: a cada jogada, marcas são removidas dos lugares de entrada de uma ou mais transições habilitadas; então tais transições têm suas atividades realizadas e marcas são inseridas nos lugares de saída de acordo com o que a transição indicar. Diz-se que uma transição ocorre quando estiver habilitada e tanto a retirada de marcas dos lugares de entrada, a realização de atividades da transição e a produção de marcas nos lugares de saída acontecerem.

Desse modo, sendo a marcação da Figura 3 chamada $M_{0}$, a ocorrência da transição $T_{1 a}$ produz a marcação $M_{1}$, apresentada na Figura 4: foram removidas 
marcas de $E_{1 a}$ e $r_{1}, T_{1 a}$ teve sua atividade executada - que poderia ser a colocação dos vidros nas portas do veículo, neste exemplo - e então foi produzida uma marca em $\mathrm{E}_{\mathrm{a} 2}$. Neste ponto, a transição $\mathrm{T}_{2 \mathrm{a}}$ passa a estar habilitada.

Modelo a

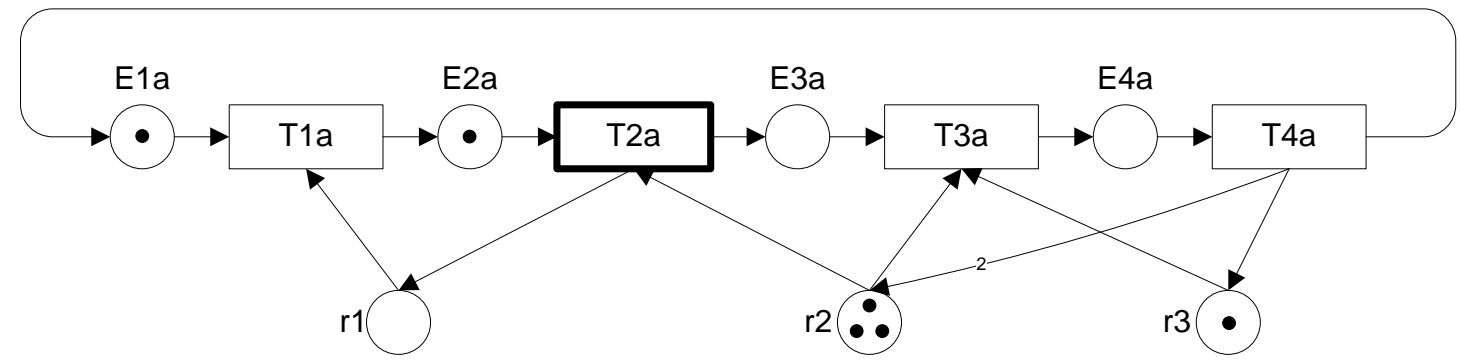

Figura 4: marcação $M_{1}$, obtida a partir da marcação da Figura 3

O exemplo até aqui apresentado mostra uma única transição habilitada para cada marcação. No entanto, podem existir múltiplas transições habilitadas em uma PT-net, que podem ou não ocorrer. A Figura 5 apresenta uma PT-net para a linha de montagem de dois modelos de veículos, que compartilham o mesmo conjunto de recursos. Esta marcação, chamada aqui de $\mathrm{M}_{0}$, possui duas transições habilitadas: $\mathrm{T}_{1 \mathrm{a}}$ e $\mathrm{T}_{1 \mathrm{~b}}$.

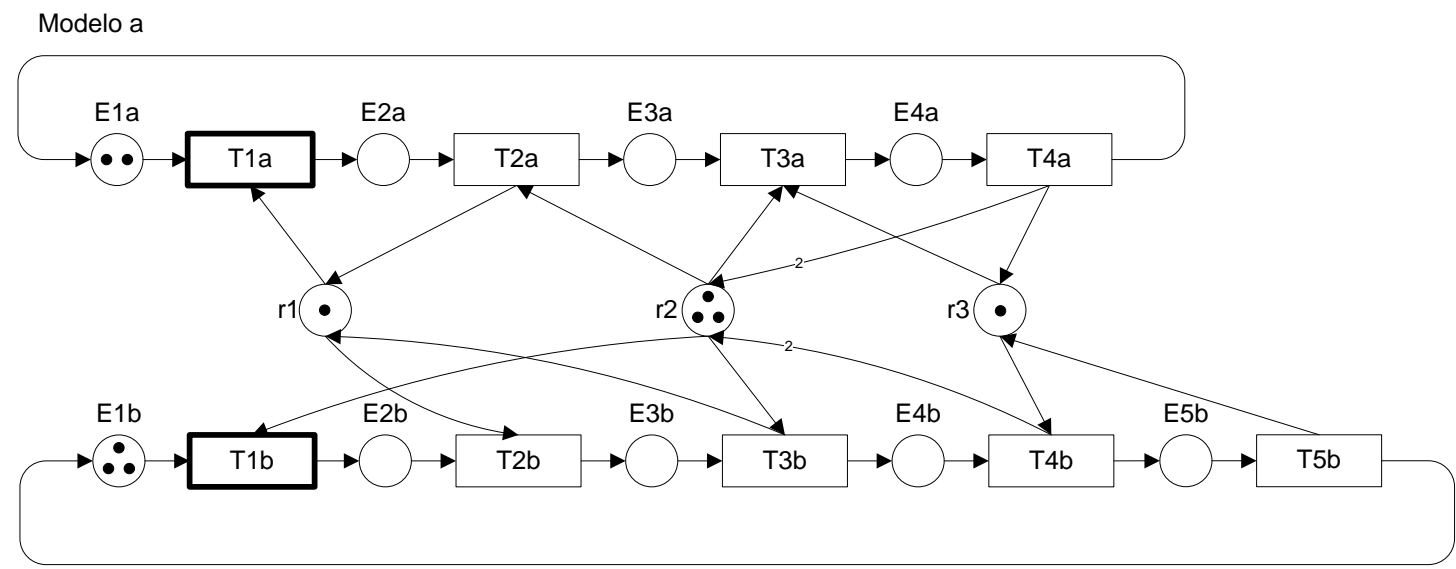

Modelo b

Figura 5: PT-net com marcação $\mathrm{M}_{0}$, representando a linha de montagem de dois modelos de veículos

Diz-se que uma marcação $\mathrm{M}_{1}$ é diretamente atingível a partir de $\mathrm{M}_{0}$ quando puder ser obtida com a ocorrência de uma ou mais transições habilitadas de $\mathrm{M}^{\prime}$. Desse modo, as marcações $\mathrm{M}_{1}{ }_{1}$ e $\mathrm{M}_{2}{ }_{2}$ mostradas na Figura 6 e na Figura 7, respectivamente, são diretamente atingíveis a partir de $\mathrm{M}^{\prime}{ }_{0}$. 


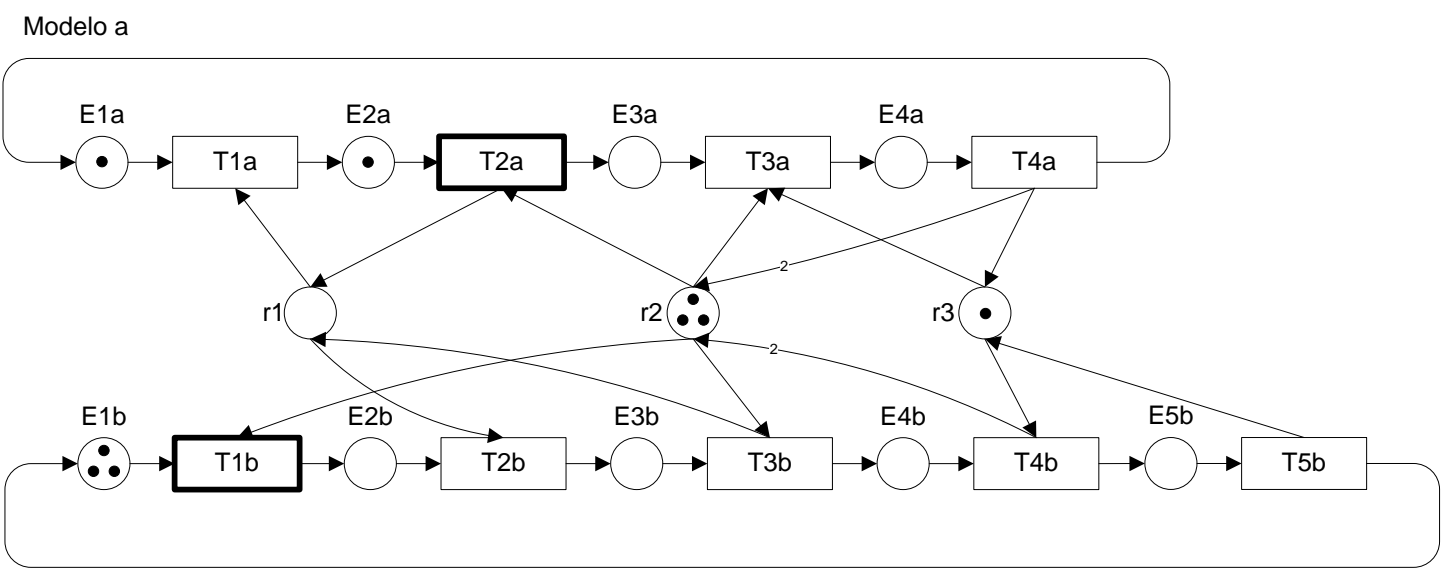

Modelo b

Figura 6: marcação $\mathrm{M}_{1}$, diretamente atingível a partir de $\mathrm{M}_{0}$

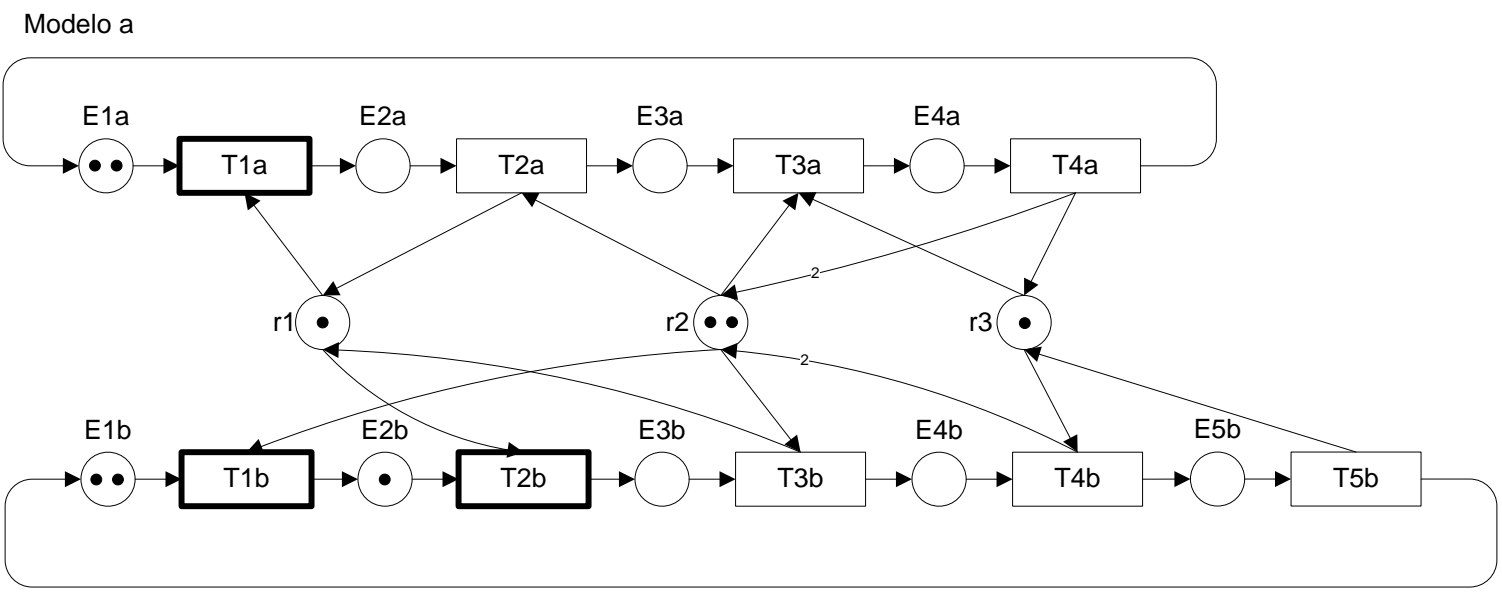

Modelo b

Figura 7: marcação $\mathrm{M}_{2}$, diretamente atingível a partir de $\mathrm{M}_{0}$

As transições $T_{1 a}$ e $T_{2 b}$, em $M_{2}^{\prime}$, embora estejam habilitadas, não podem ocorrer simultaneamente, uma vez que não há marcas suficientes em $r_{1}$. Todavia, as transições $T_{1 a}$ e $T_{1 b}$ podem ocorrer "em paralelo", dizendo-se que estão concorrentemente habilitadas. Ainda, vale notar que em $\mathrm{M}_{2}$ há marcas suficientes para que $\mathrm{T}_{1 \mathrm{~b}}$ ocorra duas vezes. Nesse caso, diz-se que essa transição pode ocorrer concorrentemente com ela mesma.

Este texto utiliza ainda o conceito de passo: um multi-conjunto de transições concorrentemente habilitadas a partir de uma marcação. Multiconjuntos são conjuntos nos quais um elemento pode aparecer mais de uma vez. Por exemplo, o passo (step) $S_{1}=\left\{T_{1}\right\}$ está habilitado em $M_{2}^{\prime}$. Do mesmo modo, os seguintes passos estão habilitados em $\mathrm{M}_{2}$ :

- $S_{2}=\left\{T_{1 b}\right\}$

- $\mathrm{S}_{3}=\left\{\mathrm{T}_{2 \mathrm{~b}}\right\}$

- $S_{4}=\left\{T_{1 a}, T_{1 b}\right\}$ 
- $S_{5}=\left\{T_{1 b}, T_{1 b}\right\}$, indicando duas ocorrências de $T_{1 b}$

- $S_{6}=\left\{T_{1 b}, T_{2 b}\right\}$

- $S_{7}=\left\{T_{1 b}, T_{1 b}, T_{2 b}\right\}$

Vale notar ainda que as atividades das transições concorrentemente habilitadas são independentes, de modo que a ordem em que ocorrerem em um determinado passo é irrelevante.

Outra representação para passos é o uso de coeficientes indicando o número de vezes em que uma transição está habilitada:

- $\mathrm{S}_{1}=\mathrm{T}_{1 \mathrm{a}}$

- $\mathrm{S}_{2}=\mathrm{T}_{1 \mathrm{~b}}$

- $\mathrm{S}_{3}=\mathrm{T}_{2 \mathrm{~b}}$

- $\mathrm{S}_{4}=\mathrm{T}_{1 \mathrm{a}}+\mathrm{T}_{1 \mathrm{~b}}$

- $S_{5}=2 T_{1 b}$

- $\mathrm{S}_{6}=\mathrm{T}_{1 \mathrm{~b}}+\mathrm{T}_{2 \mathrm{~b}}$

- $\mathrm{S}_{7}=2 \mathrm{~T}_{1 \mathrm{~b}}+\mathrm{T}_{2 \mathrm{~b}}$

\subsubsection{Redes de Petri Coloridas}

As PT-nets são intuitivas e de fácil compreensão para sistemas pequenos, como o ilustrado na Figura 5. Nesse exemplo, a PT-net descreve o processo de fabricação de dois modelos de veículos, usando três tipos de recursos. Extrapolando este exemplo para a produção de trinta modelos usando quinze tipos de recursos, chega-se a uma rede muito menos legível, dado o número de repetições de atividades e estados - nesse caso, enquanto há duas atividades $T_{1}\left(T_{1 a}\right.$ e $\left.T_{1 b}\right)$ na rede da Figura 5 , para o novo cenário haveria até trinta atividades $T_{1}$, sendo uma para cada modelo. Desse modo, pode-se concluir que as PT-nets tornam-se ilegíveis para sistemas grandes ou complexos. Dessa necessidade de simplificação da representação da rede, surgiram as Redes de Petri Coloridas, ou CPNs.

Uma CPN possui alguns elementos adicionais que oferecem maior flexibilidade quando da representação de processos e workflows. O elemento inicialmente acrescido foi a distinção das marcas através de cores. Uma cor permite que um dado seja carregado com uma marca. Esse dado pode ser simples como um número inteiro, ou complexo como tuplas com elementos de tipos distintos. O tipo de dado que uma marca pode assumir é denominado conjunto de cores. O uso de cores nas CPNs é análogo ao dos tipos de dados em linguagens de programação. Do mesmo modo, os conjuntos de cores identificam o domínio de valores que as marcas podem assumir. 
A CPN apresentada na Figura 8 é análoga à PT-net da Figura 5. Houve redução no número de estados e transições, e um acréscimo de informações nos arcos. Os pontos que ilustram características específicas das CPNs são:

- O retângulo no canto superior esquerdo indica as diferentes marcas (identificadas por cores) e seus tipos:

- Modelo: é uma enumeração composta pelos elementos "a" e "b", e indicam que modelo de automóvel está sendo produzido;

- Qtdd: indica a quantidade de veículos a ser produzido;

- P: é um par que representa o modelo sendo produzido e o número de veículos daquele modelo que já foi produzido;

- R: é a quantidade de recursos disponíveis;

- " $x$ " e "i": variáveis usadas durante a operação da CPN para passar o modelo e que unidade estão sendo produzidos.

- A marcação corrente é indicada pelas expressões junto aos lugares, contendo o número de marcas de cada tipo, como " 2 ' $(a, 0)+3$ ' $(b, 0)$ " para o lugar $E_{1}$ e "3' $r$ " para $r_{2}$, por exemplo;

- Quando houver uma única marca de um determinado tipo em um lugar ou arco, o algarismo "1" pode ser omitido, como o ilustrado no arco que vai de $r_{2}$ a $T_{3}$;

- Expressões condicionais nos arcos, indicando o contexto a ser satisfeito;

- Restrições nas transições, como " $[x=b]$ " em $T_{5}$, que devem ser satisfeitas para que as atividades de uma transição sejam executadas. Aqui, $T_{5}$ será executada se e somente se for acionada pela linha de produção do modelo "b". Por exemplo, é o que acontece no seguinte cenário: o modelo "a" possui vidros manuais, o modelo "b" possui vidros elétricos, e $T_{5}$ é a montagem do equipamento de vidros elétricos. Logo, $T_{5}$ só deve ser executada para o modelo "b". 


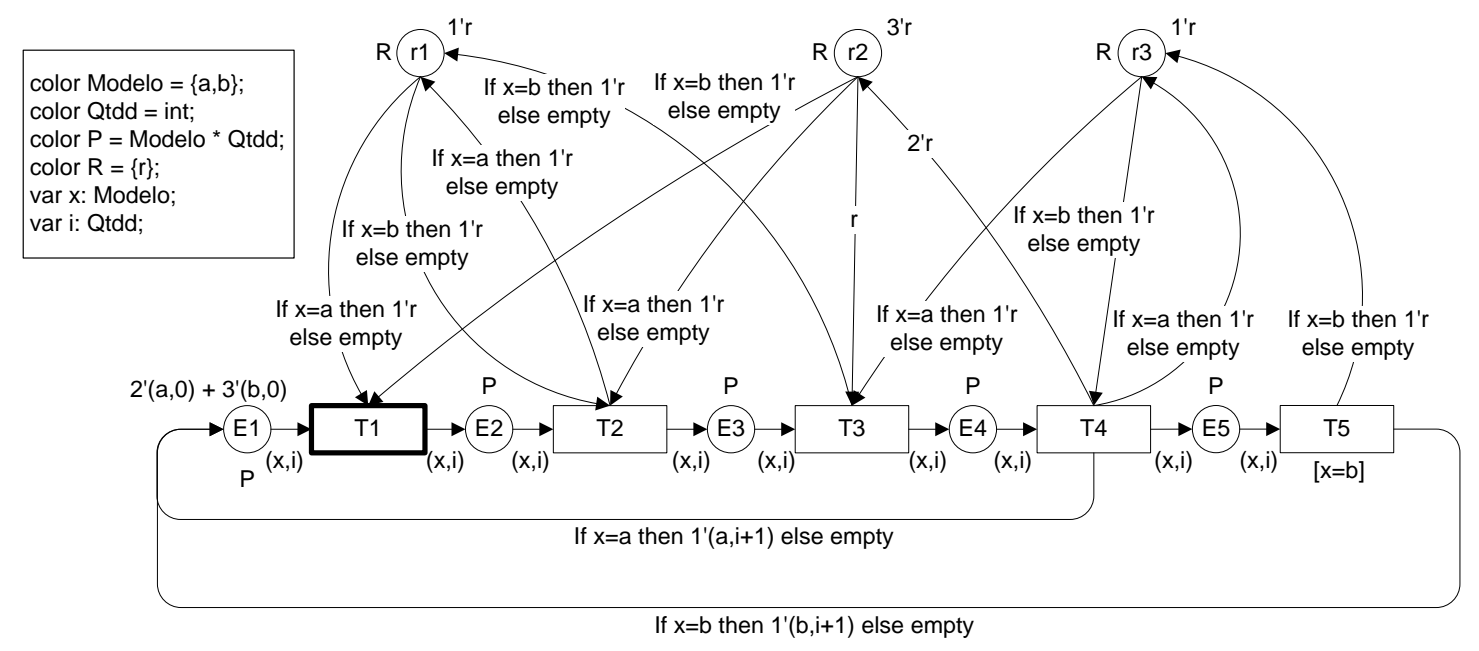

Figura 8: CPN equivalente à PT-net da Figura 5

Do mesmo modo que para as PT-nets, a cada passo, uma ou mais transições são executadas e marcas são movimentadas. A Figura 9 apresenta marcação equivalente à da Figura 6, M' 1 .

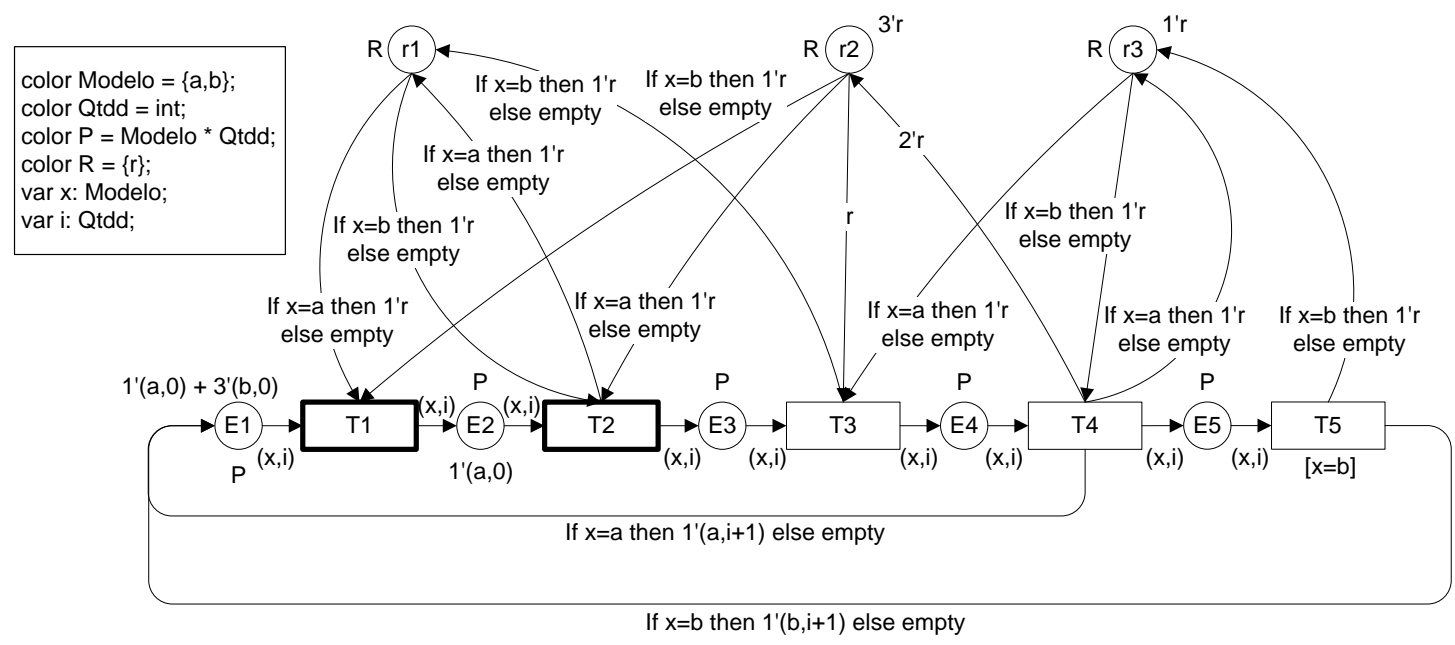

Figura 9: marcação equivalente à da Figura 6

Nesse caso, assim como para $\mathrm{M}_{1}{ }_{1}$, a transição $\mathrm{T}_{1}$ está habilitada para 0 modelo "b" e $T_{2}$ para o modelo "a".

As definições e comandos aqui ilustrados seguem a sintaxe da linguagem CPN ML, descrita em [18]. Os elementos da linguagem CPN ML utilizados neste texto e que não foram explicitados nesta seção, são os seguintes:

- Marca sem tipo, denotada pelo símbolo "()" sobre um arco. É usada quando for necessário indicar apenas a presença de uma marca, independentemente do tipo. Assim, o domínio da cor desta marca é "color X = unit", indicando um único valor, representado por "()". Por exemplo, informa a gerência da fábrica após dez carros terem sido 
fabricados, para controle da produção e então segue produzindo outros carros. Para isso, não é necessário um tipo específico de marca, pois independe do modelo do carro;

- Tipo de dado procedente da entrada. É a declaração em um lugar, para uma cor do mesmo tipo das que vêm como entrada, e é denotada por "color $X=$ input". É usado principalmente com listas de valores. Por exemplo, a cada carro produzido, insere o número do chassi em uma lista. O tipo da marca é o mesmo da entrada;

- Definições e operações sobre listas:

o "[]": lista vazia;

- " $x:: y$ ": insere o elemento $x$ na lista $y$;

o "elt $(\mathrm{x}, \mathrm{y})^{\text {": }}$ devolve verdadeiro se $\mathrm{x}$ está contido na lista $\mathrm{y}$, ou falso, caso contrário;

○ "del( $(x, y)$ ": encontra e remove o elemento $x$ da lista $y$.

\subsubsection{Workflow Nets}

Uma PT-net pode ser utilizada para representar processos de workflow. Neste caso, essa rede é chamada Workflow net, ou WF-net. Diferentemente das PT-nets, uma WF-net deve representar uma execução isolada de um processo.

DEFINIÇÃO 2.2 (WF-net): uma Rede de Petri PN = (L, T, A) é uma WF-net (workflow net) se e somente se:

- Existe um único lugar de entrada $i \in L$, tal que $\bullet i=\varnothing$;

- Existe um único lugar de saída $o \in L$, tal que $o \bullet=\varnothing$;

- Cada nó da rede $x \in L \cup T$ deve estar em um caminho do lugar de entrada $i$ ao lugar de saída $o$.

Neste texto são utilizadas CPNs ou WF-nets na representação de padrões. Para a implementação, contudo, esta proposta possibilita a integração do middleware ao gerenciador de workflow de preferência do usuário. O grau de integração pode variar em função dos recursos para extensão oferecidos pelo gerenciador. Por exemplo, pode ser possível desde apenas utilizar serviços web a partir de um workflow desenvolvido em uma determinada ferramenta, até acrescentar novas atividades por meio de interface gráfica. Nesse último caso, a representação de padrões fica restrita àquela disponibilizada pela ferramenta. Para demonstrar essa integração, como parte do desenvolvimento foi construído um módulo para integração ao Windows Workflow Foundation [19], que baseia sua interface gráfica em workflow graphs [20]. 


\subsection{Conclusão}

Alguns dos termos apresentados neste capítulo, como workflows e padrões, possuem definições informais, o que pode resultar em interpretações diferentes de conceitos baseados em tais termos. Por esse motivo, este capítulo apresentou a semântica que é adotada no restante deste texto.

Além disso, os fundamentos de Redes de Petri e uma visão geral sobre os Padrões de Workflow também foram apresentados, no intuito de facilitar a leitura dos próximos capítulos. 


\section{Capítulo 3}

\section{Trabalhos Relacionados}

A arquitetura descrita neste texto possibilita a execução de padrões de workflow em grades, de modo a simplificar o uso desses recursos, no tocante à representação de padrões e ao uso de grades.

Existem trabalhos acadêmicos e comerciais sobre cada um desses assuntos: padrões, workflows e grades. Este capítulo descreve o estado da arte sobre esses temas e identifica, para cada trabalho, os pontos complementados por este estudo.

Neste capítulo, além dos trabalhos relacionados aos temas workflows e grades, são também apresentados aqueles sobre a execução de workflows em grades.

\subsection{Soluções de Workflow Existentes}

Aalst et al [1] publicaram padrões de workflow citados em diversos trabalhos acadêmicos. Posteriormente, Russell et al [2] estenderam o conjunto de padrões, criando diversas especializações para os padrões descritos em [1]. Em ambas publicações, os autores estudaram diversos produtos comerciais e linguagens de workflow, dentre os quais Staffware, IBM WebSphere MQ Workflow, FLOWer, COSA, BPMN, BPEL, XPDL, SAP Workflow e FileNet. Cada produto foi avaliado quanto à implementação ou não dos padrões de controle de fluxo. A mesma análise é realizada em [21] por Aalst, Hofstede e Russell para gerenciadores de workflow de código aberto, como jBPM, OpenWFE e Enhydra Shark. Todavia, o objetivo desses trabalhos não inclui a execução em grade. 
Sistemas gerenciadores de workflows científicos, como Kepler [22], Taverna [23] e Triana [24], por sua vez, usam abordagem orientada a fluxo de dados ao invés de fluxo de controle, não possuindo implementações de padrões de paralelização.

$\mathrm{Na}$ plataforma Windows existem o BizTalk Server [25], ferramenta para integração de sistemas, que inclui um gerenciador de workflow, e o Windows Workflow Foundation (WF) [19], gerenciador de workflow incluso no .NET Framework [26]. As duas soluções implementam padrões básicos de paralelização, também sem prever execução em grade.

\subsection{Soluções de Grade Existentes}

Existem diversas soluções para execução de aplicações distribuídas em grades, o que colabora para a melhoria de desempenho da solução como um todo. Tal diversidade de opções pode ser observada em diferentes soluções de grade.

\subsubsection{Berkeley Open Infrastructure for Network Computing (BOINC)}

Em 1999 foi lançado o projeto SETI@Home [27], que procura por vida extraterrestre utilizando tempo ocioso de computadores na Internet. Essa solução tornou-se popular, e se caracteriza por ser de propósito específico, não sendo aplicável para outros cenários. A partir de 2005, o SETI@Home passou a utilizar - BOINC [28], que possui propósito geral, mas não possui construções específicas para execução paralela. A utilização do BOINC é feita a partir de API escrita em $\mathrm{C}++$.

\subsubsection{Projeto Globus}

O Projeto Globus [29] oferece infra-estrutura para grades geograficamente distribuídas e apresenta Arquitetura Orientada a Serviços, SOA [30]. Como parte das ferramentas e componentes que o integram está o Globus Toolkit [31]. Este permite que o Globus seja utilizado por meio de serviços web, tornando viável a integração de uma série de aplicações, potencialmente em plataformas heterogêneas.

Seguindo o modelo cliente-servidor, o Globus apresenta um conjunto de componentes, ilustrado na Figura 10. É uma solução robusta, no tocante à sua completude, e é utilizada em diversas instalações, sendo amplamente referenciada em trabalhos acadêmicos.

Os contêineres Java, Python e C permitem que sejam acrescidos novos serviços ao servidor. Com isso, torna-se possível utilizar o Globus para o 
desenvolvimento em soluções verticais, como saúde, finanças e outros segmentos específicos.

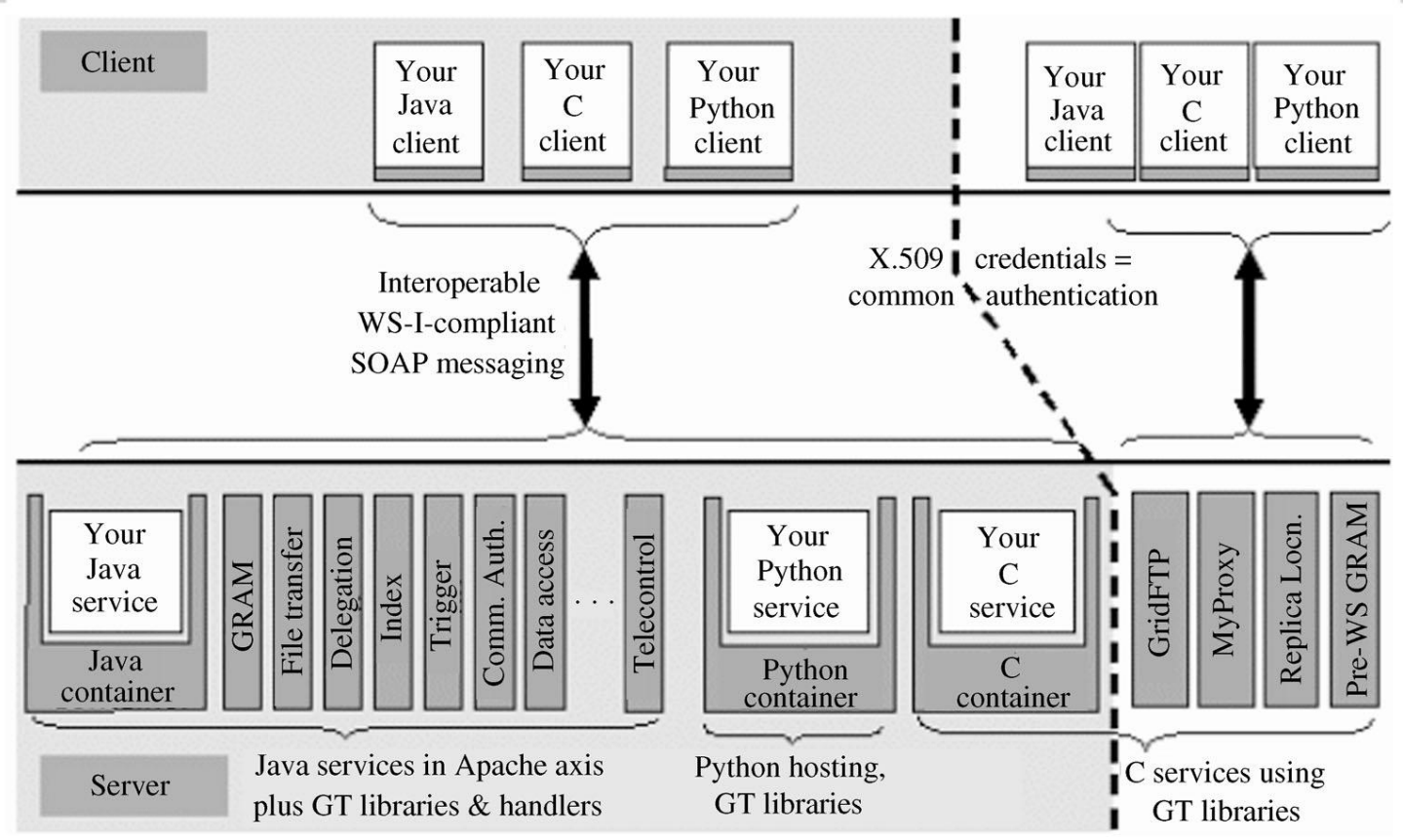

Figura 10: arquitetura do Globus Toolkit 4 [32]

\subsubsection{Ourgrid}

Desenvolvido pela equipe do Laboratório de Sistemas Distribuídos da Universidade Federal de Campina Grande, o Ourgrid [33] é um gerenciador de grade que se baseia em modelo peer-to-peer, e se aplica a tarefas que sejam consumidoras de recursos de modo independente umas das outras. Aplicações desse tipo são denominadas bag-of-tasks applications. Exemplos de aplicações indicadas para uso do Ourgrid são: mineração de dados, previsão de clima, estudos genéticos, simulações de Monte Carlo e processamento de imagens, entre outros.

Os principais apelos do Ourgrid são sua simplicidade de implantação e a pouca burocracia para que uma instituição possa aderir à rede, uma vez que não são necessários certificados ou protocolos de federação de identidade.

O Ourgrid é distribuído gratuitamente sob o licenciamento GPL, em um conjunto denominado Ourgrid Toolkit. Este é composto por três elementos principais, conforme a Figura 11:

- Ourgrid Community: agrega um conjunto de instituições que implantaram o Ourgrid. Cada instituição possui um servidor com o Ourgrid Peer instalado. Este, por sua vez, é o responsável pela alocação de tarefas nos nós da grade da instituição; 
- MyGrid: é a interface do Ourgrid com o usuário, através do qual as Tarefas, agrupadas em Jobs, são submetidas à grade. Cada MyGrid deve estar associado a um Ourgrid Peer;

- Swan: é um modelo de sandbox, que isola a execução das tarefas no nó da grade, dos demais aplicativos e recursos do nó, inclusive acesso à rede.

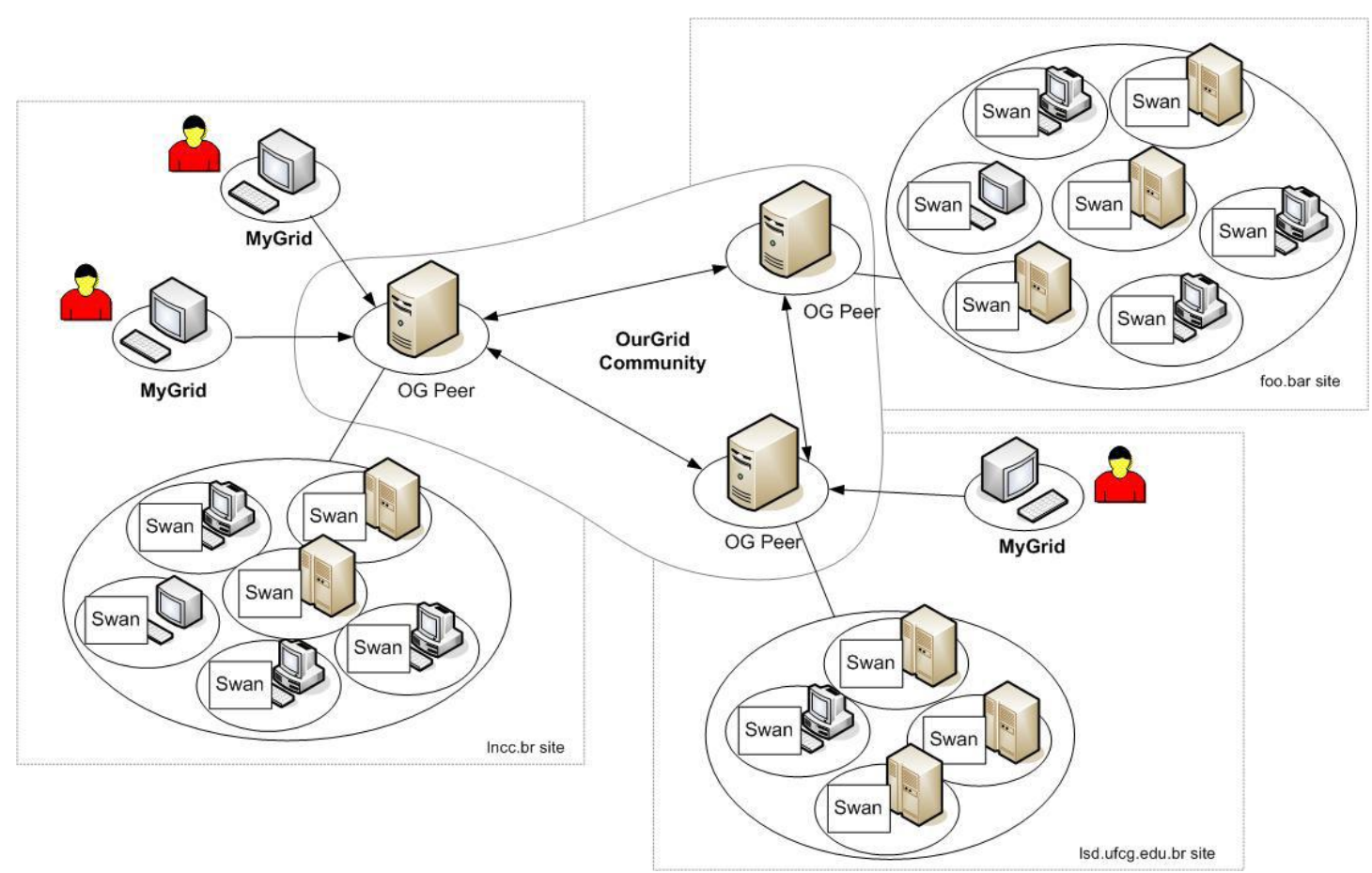

Figura 11: elementos constituintes do Ourgrid Toolkit [34]

Cada Ourgrid Peer acessa os recursos de seus nós através de uma interface chamada GridMachine. O conjunto de funções dessa biblioteca, apresentado na Tabela 1, é bastante reduzido, simplificando a utilização.

\begin{tabular}{|l|l|}
\hline Operação & Descrição \\
\hline Ping & Avabela 1: operações da interface GridMachine \\
\hline run & Submete um job para um nó da grade \\
\hline putFile & Armazena dados em um nó da grade \\
\hline getFile & Recupera dados de um nó da grade \\
\hline kill & Cancela um job \\
\hline
\end{tabular}


Os testes realizados neste trabalho utilizaram o Ourgrid, conforme descrito nas seções "6.3.6 Comunicação entre o EGG e o Gerenciador de Grade" e "7.1.6 Submissão de Atividades ao EGG para Ourgrid".

\subsubsection{InteGrade}

Baseado em CORBA [35], o InteGrade [36] oferece uma solução orientada a objetos para distribuição e execução de aplicações em grades, utilizando o tempo ocioso dos nós. Caracteriza-se por atender a cenários em que haja intensa comunicação entre os nós, e os componentes da aplicação sejam fortemente acoplados.

Os principais elementos que o compõem são os apresentados na Figura 12.

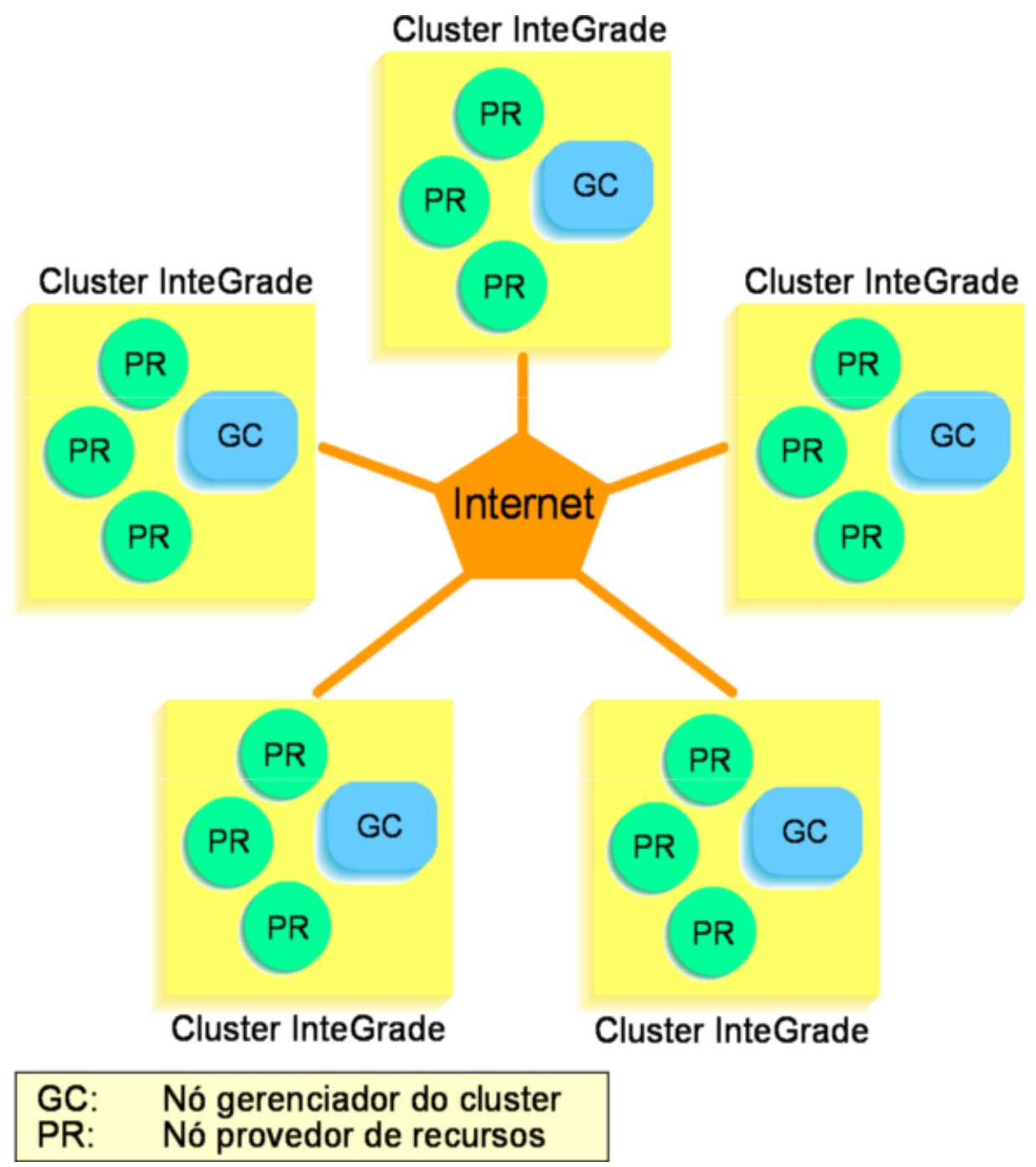

Figura 12: exemplo dos componentes do InteGrade em federação [37] 
O InteGrade pode ser utilizado dentro de um cluster ou em modelo de federação, para integração com outras instalações. O projeto foi desenvolvido e testado por um conjunto de universidades brasileiras: IME-USP, PUC/RJ, UFMS, UFG e UFMA. Cada cluster possui:

- Cluster Resource Manager (GC na Figura 12), responsável pelo gerenciamento do cluster e pela comunicação com outros clusters;

- Resource Providers (PR na Figura 12): são os nós da grade, que oferecem seus recursos para compartilhamento. são:

Os principais tipos de aplicações que podem ser executadas no InteGrade

- As que seguem o Modelo BSP (Bulk Synchronous Parallel), proposto pela Universidade de Oxford, por intermédio da BSPLib, uma biblioteca disponível em $\mathrm{C}$ e Fortran;

- As que se comunicam usando MPI. O InteGrade usa uma implementação que modifica a MPICH2;

- Aplicações Bag-of-Tasks (conforme apresentado na seção 3.2.3).

\subsubsection{Alchemi}

Baseado na Plataforma .NET [26], o Alchemi [38] é uma infra-estrutura para distribuição de execução de componentes .NET sobre plataforma Windows.

A arquitetura do Alchemi, ilustrada na Figura 13, segue o modelo de um distribuidor de tarefas para os nós da grade, denominado Alchemi Manager. Em cada nó deve haver um serviço para execução das tarefas, chamado Alchemi Executor.

A submissão de tarefas (Grid Threads) para execução na grade pode ser feita de dois modos:

- Diretamente pela aplicação cliente em .NET, usando uma biblioteca de classes, a Alchemi .NET API;

- Pelo envio de aplicações executáveis, usando um arquivo de configuração em XML, no qual são explicitados os executáveis e seus parâmetros. Esse envio pode ser feito usando uma interface para console, a Alchemi Console Interface, ou ainda por intermédio do Alchemi Cross-Platform Manager, uma interface baseada em serviços web.

Por se tratar de uma arquitetura baseada na plataforma .NET, pode ser utilizada para redes onde os nós possuam Windows e 0 .NET Framework instalados. 
É possível a integração com outras plataformas e soluções por meio de serviços web fornecidos pelo Alchemi Cross-Platform Manager. Assim, uma tarefa escrita em plataforma diferente da .NET, como Java, por exemplo, pode ser enviada e executada nos nós da grade gerenciada pelo Alchemi.

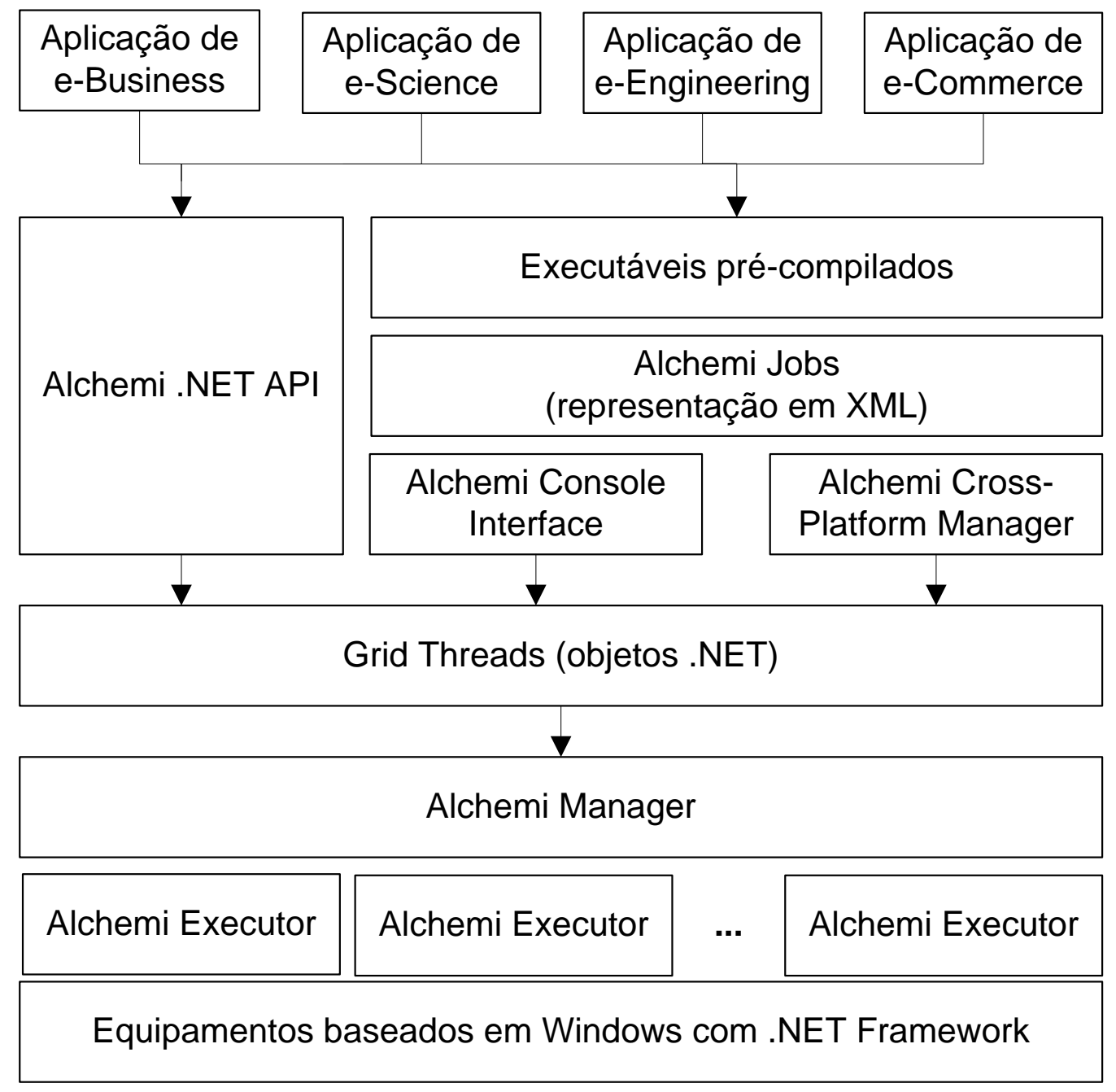

Figura 13: arquitetura do Alchemi [39]

\subsubsection{Considerações sobre as Soluções de Grade}

Os itens acima ilustram diversas soluções com mecanismos de acesso e recursos distintos. Apesar disso, todos apresentam interfaces que podem ser encapsuladas em um serviço web e disponibilizadas de um modo padrão. Por isso, a arquitetura desenvolvida neste trabalho pode operar com qualquer implementação de grade dentre as acima. Como prova de conceito, o desenvolvimento aqui proposto e realizado utilizou o Ourgrid, que está em uso pelo Grupo de Processamento Paralelo e Distribuído da Universidade Federal do Rio Grande do Sul, onde parte dos testes foram realizados. 
Foi desenvolvido também um componente para execução de aplicações paralelas sem o uso de grade, demonstrando a flexibilidade da arquitetura proposta.

\subsection{Execução de Workflows em Grade}

Alguns trabalhos descrevem a execução de workflows em grades.

\subsubsection{Abstract Grid Workflow Language (AGWL) e ASKALON}

Apresentado por Fahringer et al em [40], a AGWL contém construções de paralelização, sem mencionar padrões mais sofisticados como os descritos por Russell et al [2].

A AGWL permite a representação de workflows em XML, de modo independente de plataforma ou implementação. A Figura 14 mostra como a AGWL é utilizada pelo ASKALON [41], um ambiente para desenvolvimento e execução de workflows em grades. 


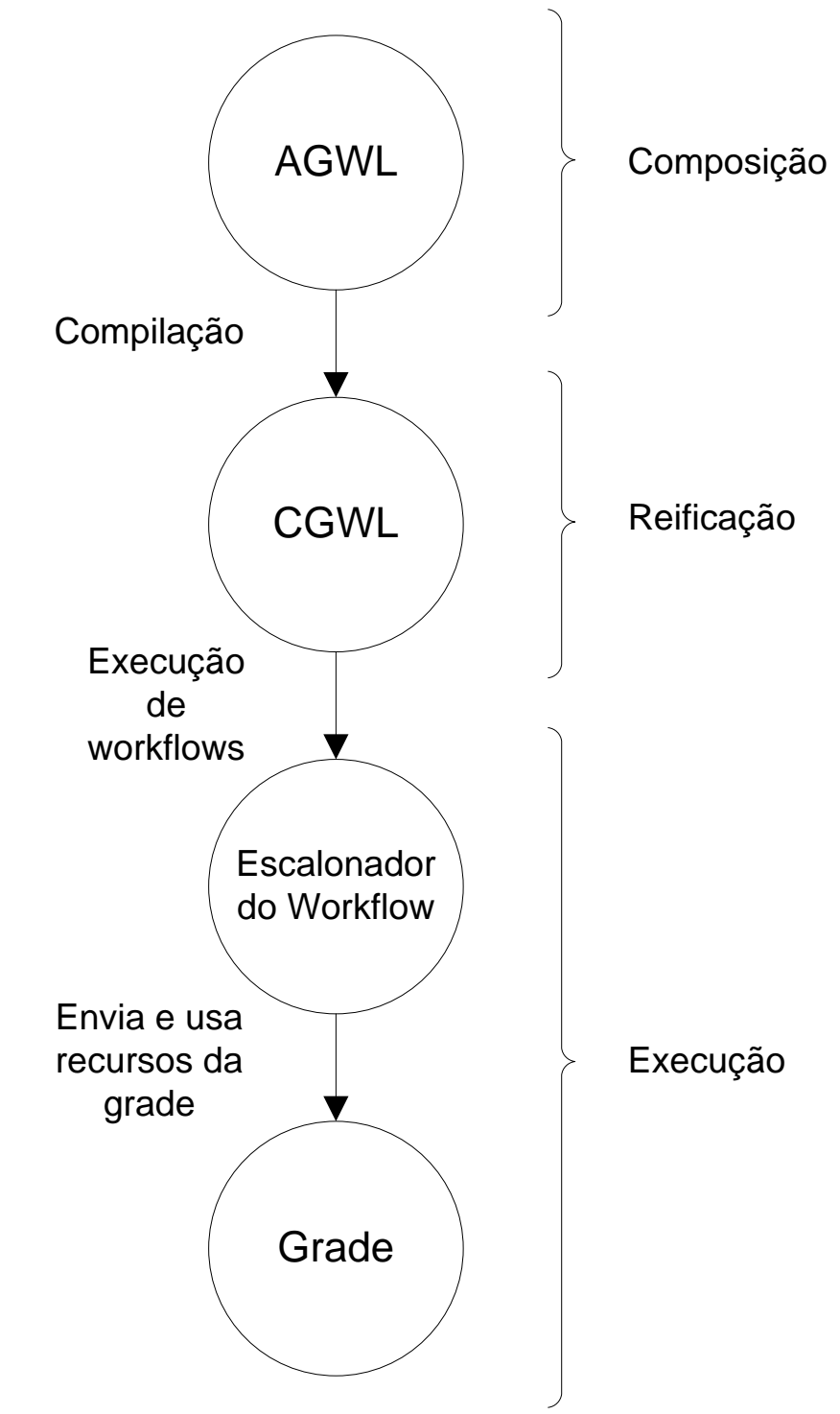

Figura 14: processamento pelo ASKALON de workflows definidos em AGWL [40]

Trata-se de um processo com três etapas: composição, reificação e execução. O workflow é definido em AGWL na etapa de composição. $\mathrm{Na}$ reificação, a representação abstrata é então concretizada. Isso é feito através da compilação do workflow em AGWL pelo ASKALON para CGWL (Concrete Grid Workflow Language), uma linguagem dependente de implementação, que acrescenta elementos como tipos de dados. Nesta etapa são ainda realizadas otimizações, ao procurar converter atividades seqüenciais em paralelas, por exemplo. Então, na fase de execução, o executor de workflow do ASKALON escalona as tarefas e as envia para a infra-estrutura de grade para execução.

Existem três construções para paralelismo - parallel, parallelfor e parallelForEach - conforme apresentado a seguir. Nenhuma delas encapsula o funcionamento de padrões mais elaborados descritos por Russell et al [2]. O esquema completo da AGWL está disponível em [42]. 


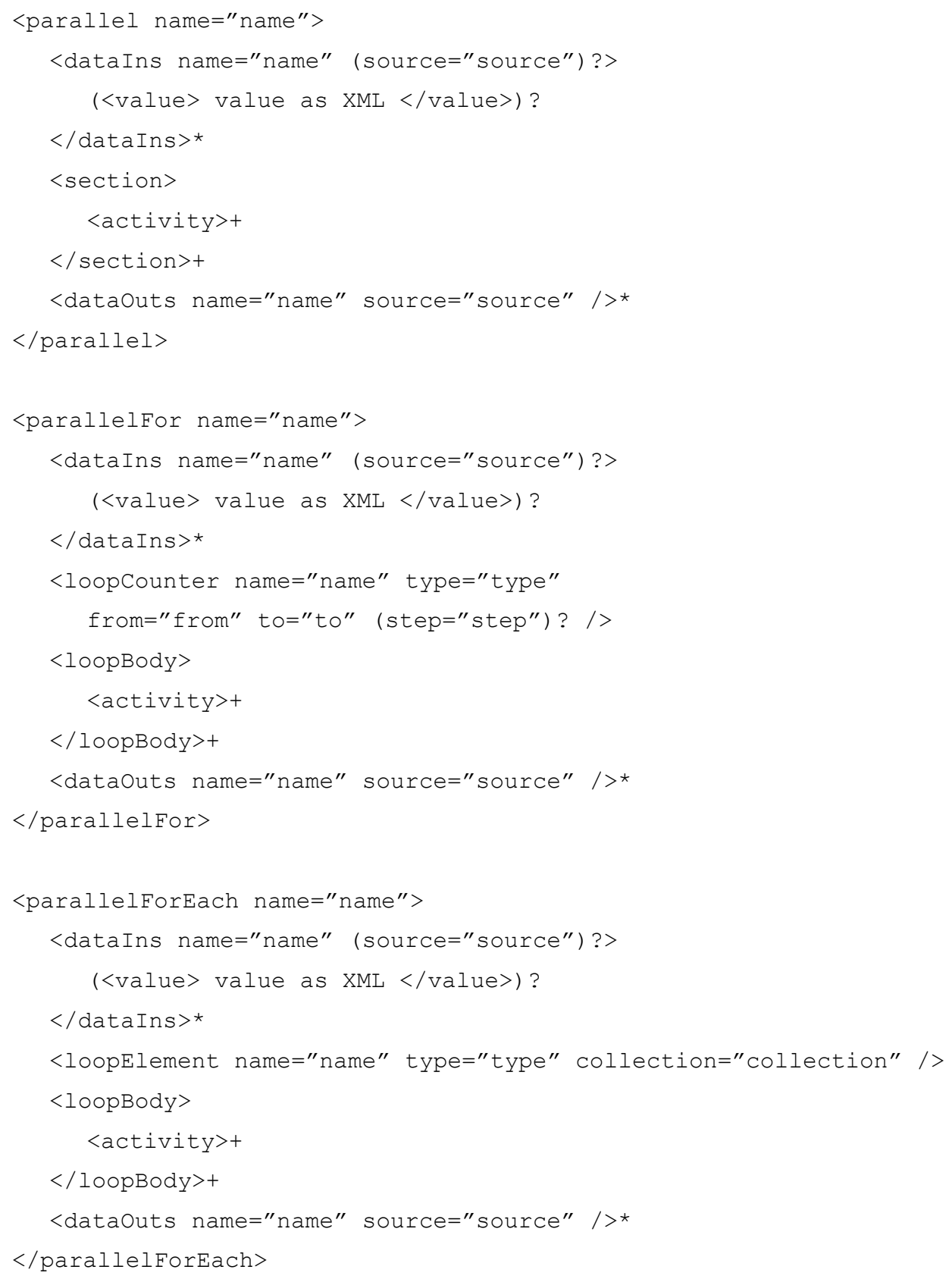

A Figura 15 identifica os elementos constituintes da arquitetura do ASKALON, desde a definição do workflow em AGWL até sua interface com a infra-estrutura da grade. É uma Arquitetura Orientada a Serviços [30], que procura abstrair a presença da grade do usuário. Utiliza o Globus [31] como gerenciador de grade. 


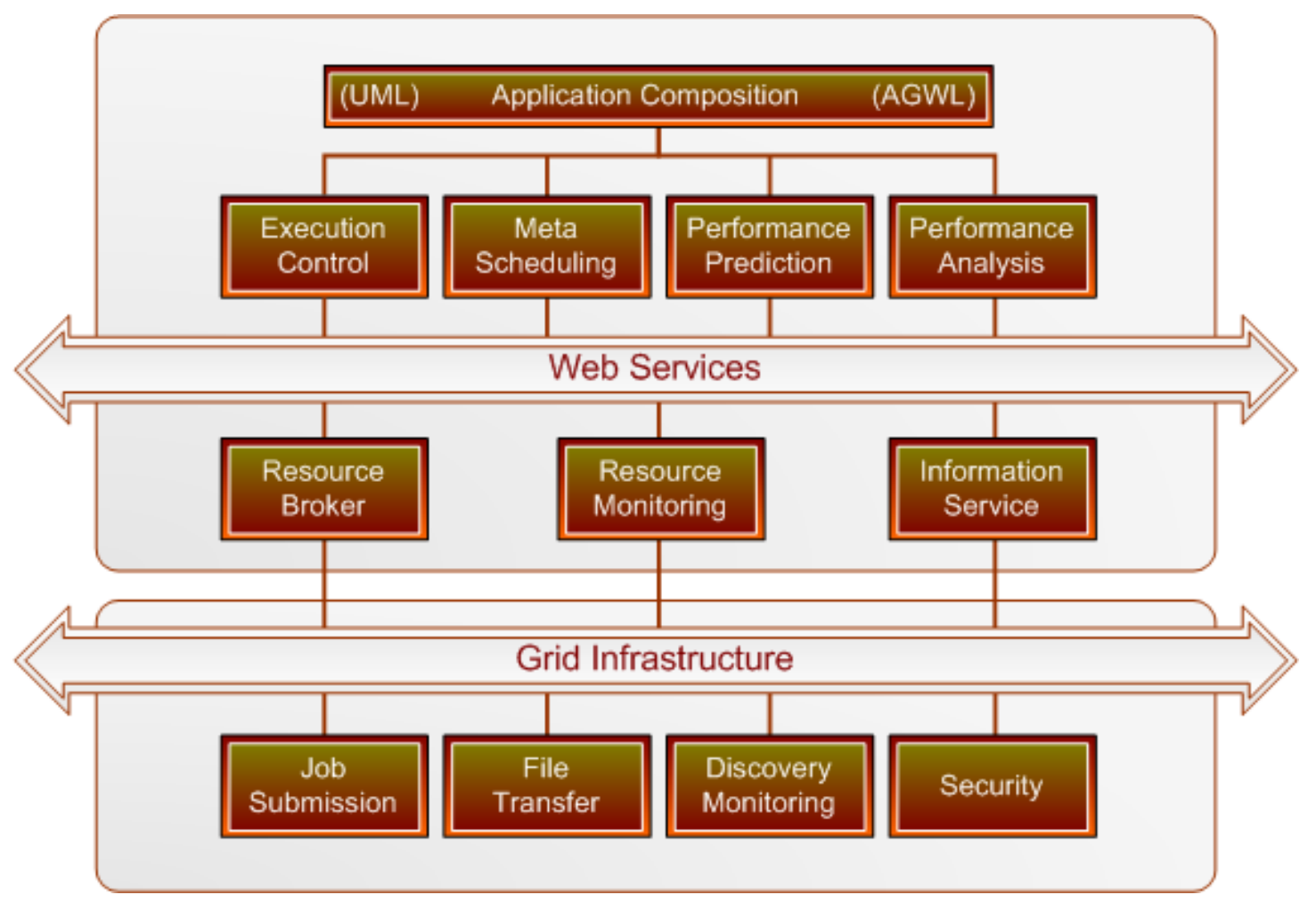

Figura 15: arquitetura do ASKALON [41]

Em [43], Prodan e Fahringer apresentam um algoritmo para escalonamento dinâmico de workflows por meio de um arquivo com código em Java sobre o Globus Toolkit [31]. Os autores utilizaram a ferramenta ZENTURIO [44] para representação e execução dos workflows, e a linguagem ZEN, baseada em diretivas, semelhante à OpenMP.

\subsubsection{Padrões de Workflow para Grades}

Pautasso e Alonso descrevem em [45] o uso de padrões em grades. Eles propõem um conjunto de padrões para paralelização e fluxo de dados sem detalhar combinações de possibilidades como bloqueio e cancelamento. Não é, ainda, abordada como permitir a extensão da arquitetura para incluir outros padrões de paralelização.

Na solução descrita por Pautasso e Alonso, a execução paralela de tarefas é dividida em dois padrões: simples e de dados.

O padrão simples se aplica a casos em que não há compartilhamento de informações entre as tarefas sendo executadas em paralelo.

O paralelismo de dados, por sua vez, consiste em dividir o conjunto de dados a ser processado por uma tarefa em diversas porções para processamento por instâncias daquela tarefa. Esse modelo aplica-se a 
necessidades triviais de computação. ${ }^{4}$ Este padrão se relaciona com os padrões de múltiplas instâncias descritos por Aalst em [2].

\subsubsection{Condor, Condor-G, DAGMan, Pegasus e GriPhyN VDS}

Condor ( [46], [47]) é um sistema gerenciador de carga, constituído de um escalonador para distribuição de tarefas. Condor atende a requisitos de indisponibilidade, fazendo a migração de tarefas quando um determinado recurso for requisitado para outra tarefa. Um cenário em que o Condor é utilizado é no uso de recursos ociosos. Ao contrário do paradigma de Computação de Alto Desempenho, os autores posicionam o Condor como sendo para Computação de Alto Rendimento (throughput). A diferença está no fato do primeiro se destinar a tarefas que consumam recursos por curtos períodos de tempo, como previsão do tempo, enquanto o segundo se aplica para uso dos recursos por meses, como simulações de Monte Carlo para análise de risco [48].

O conjunto de máquinas gerenciadas pelo Condor é chamado Condor Pool. A fim de estender o alcance do Condor para que possa utilizar recursos de outras grades, foi criado o Condor-G ( [49], [50]), que oferece uma interface de gerenciamento para os nós de uma grade que utilize o Globus.

Para que o Condor possa tratar da execução de tarefas que apresentam dependências, foi desenvolvido o DAGMan ( [47], [46]). Isso é feito pela análise de informações de dependência para Grafos Dirigidos Acíclicos (DAG), por meio de uma linguagem declarativa própria, exemplificada na Figura 16. As relações de dependência são definidas através de declarações PARENT/CHILD.

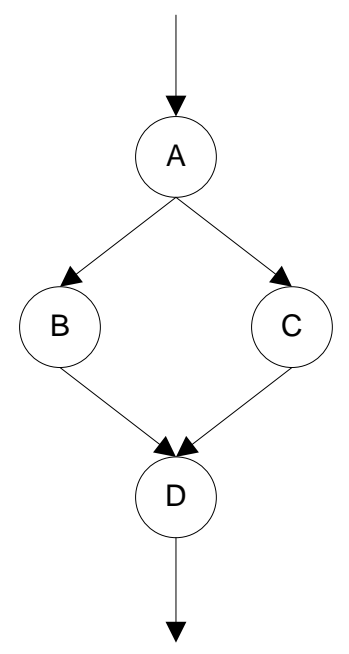

JOB A a.condor

JOB B b.condor

JOB C c.condor

JOB D d.condor

PARENT A CHILD B C

PARENT B C CHILD D

Figura 16: representação de grafo dirigido acíclico no DAGMan

\footnotetext{
${ }^{4}$ Em inglês, usa-se o termo "embarrassingly parallel computations" para se referir a cálculos que possam ser obtidos simplesmente dividindo os dados de entrada em porções que sofram o mesmo processamento. Um exemplo disso é o cálculo aproximado de $\pi$, conforme apresentado na Seção 7.1.2.
} 
O DAGMan não possui elementos para representação de fluxo de dados. Assim, deve ser complementado quanto ao mapeamento de workflows em grades, momento em que é necessário identificar tal fluxo e disponibilidade ou alocação de dados.

A Figura 17 apresenta o mesmo DAG da Figura 16, acrescido de informações de dados nos arcos do grafo. Foi também incluída informação de que tarefa deve ser executada em cada nó, para ilustrar o fato de uma mesma tarefa, "t2", poder ser executada em diversos pontos do fluxo com parâmetros distintos - neste exemplo em B e C.

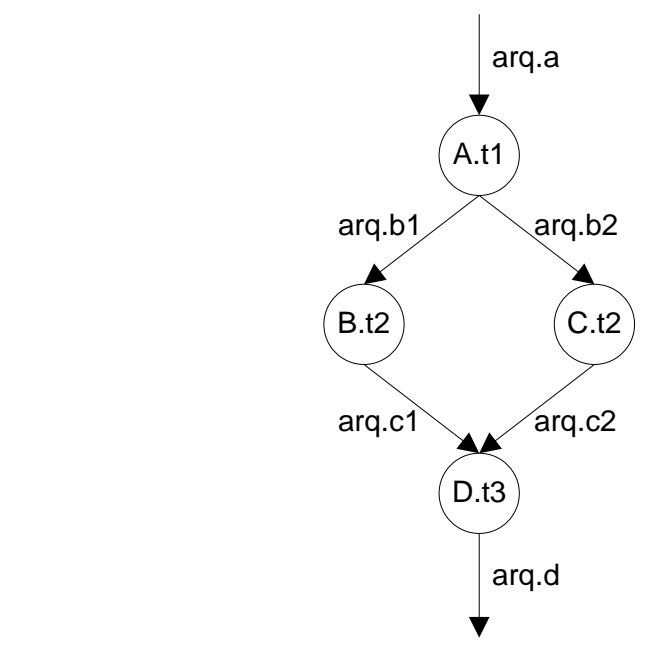

Figura 17: grafo acíclico dirigido da Figura 16 com informações de fluxo de dados

Para o mapeamento de workflows em grades, principalmente sob a ótica dos dados necessários para o processamento das tarefas nos nós da grade, 0 Pegasus ( [51], [52]) - Planning for Execution in Grids - se integra ao DAGMan e ao Globus. Pegasus utiliza como entrada um DAX - DAG in XML, que é uma representação de grafos dirigidos acíclicos em XML. A partir daí, produz um workflow concreto, com o mapeamento das tarefas e recursos aos nós da grade. O DAX pode ser escrito diretamente pelo usuário, ou ainda ser obtido da transformação de outra linguagem, como o GriPhyN Virtual Data System (VDS) ( [51], [53]), anteriormente denominado Chimera. A Figura 18 mostra a relação entre o GriPhyN VDS, Pegasus, Condor DAGMan e Globus. A partir da representação do workflow em Virtual Data Language (VDL) [54], o GriPhyN VDS gera um workflow abstrato que pode então ser oferecido ao Pegasus. Este consulta serviços de disponibilidade de recursos e localização de dados do Globus: o Monitoring and Discovery Service (MDS) e o Replica Locator Service (RLS). Com isso, gera um workflow concreto que é submetido ao DAGMan. Por sua vez, este determina a seqüência de Jobs a serem enviados para execução pelo Globus. 


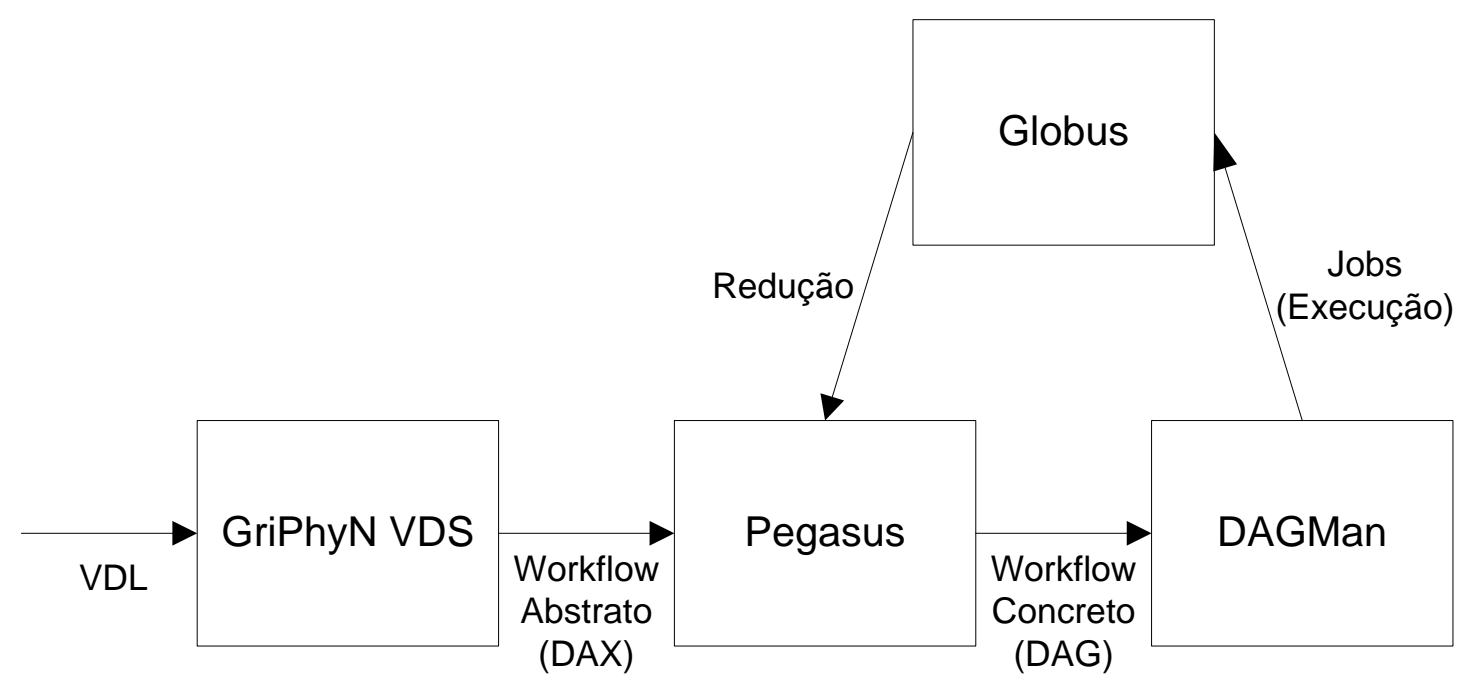

Figura 18: representação, transformação e execução de workflows em grades (Adaptado de [51])

O trecho de código abaixo ilustra o workflow da Figura 17 representado em VDL. TR indica a definição de transformações que serão realizadas nos dados. Em t1 e t2, os dados de entrada serão processados pelas aplicações appl e app2, respectivamente, produzindo suas saídas. O mesmo acontece em t3, porém com a aplicação que realizará a transformação sendo conhecida em tempo de execução (com valor padrão app3), o que confere maior flexibilidade e dinamismo aos workflows. DV representa derivações, em que o mapeamento das transformações é descrito em cada nó do grafo, isto é, em cada tarefa do workflow.

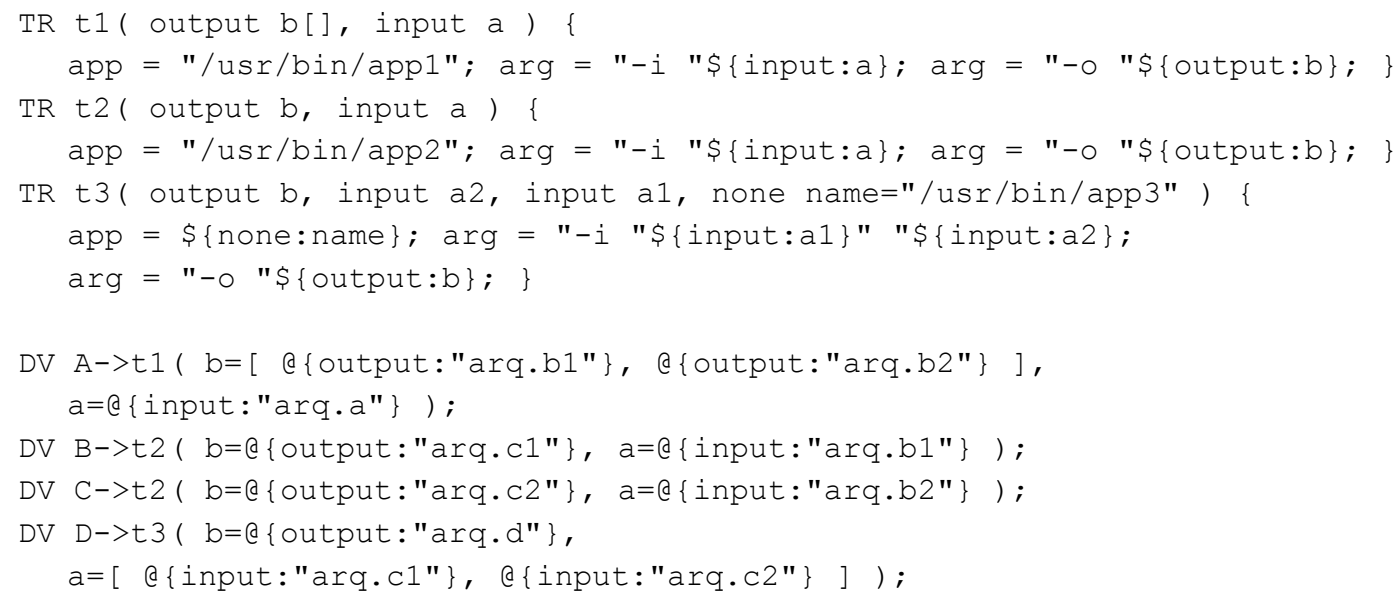

Após o processamento pelo GriPhyN VDS, é gerada a seguinte representação em DAX, que finalmente resulta nas instruções constantes da Figura 16. As marcas <child> indicam a dependência entre as tarefas do workflow. 


\section{Trabalhos Relacionados}

<job id="ID000001" name="t1" dv-name="A">

<argument>

-a "/usr/bin/appl"

-i <filename file="arq.a"/>

-o <filename file="arq.b1"/> <filename file="arq.b2"/>

$</$ argument $>$

<uses file="arq.a" link="input" ......>

<uses file="arq.b1" link="output" ......>

<uses file="arq.b2" link="output".....>

$</$ job $>$

<job id="ID000002" name="t2" dv-name="B">

<argument>

$-\mathrm{a}$ "/usr/bin/app2"

-i <filename file="arq.b1"/>

- $<<$ filename file="arq.c1"/>

$</$ argument $>$

<uses file="arq.bl" link="input" ......>

<uses file="arq.c1" link="output" ......>

$</ j o b>$

$<j o b$ id="ID000003" name="t2" dv-name="C">

<argument>

$-\mathrm{a}$ "/usr/bin/app2"

-i <filename file="arq.b2"/>

- $<$ <ilename file="arq.c2"/>

$</$ argument $>$

<uses file="arq.b2" link="input" ......>

<uses file="arq.c2" link="output" ......>

$</$ job $>$

<job id="ID000004" name="t3" dv-name="D">

<argument>

$-\mathrm{a}$ "/usr/bin/app3"

-i <filename file="arq.c1"/> <filename file="arq.c2"/>

-o <filename file="arq.d"/>

$</$ argument $>$

<uses file="arq.cl" link="input" ......>

<uses file="arq.c2" link="input" .....>>

<uses file="arq.d" link="output".....>

$</$ job $>$

<child ref="ID000002">

<parent ref="ID000001"/>

$</$ child $>$

<child ref="ID000003">

<parent ref="ID000001"/>

$</ \operatorname{child}>$

<child ref="ID000004">

<parent ref="ID000002"/>

<parent ref="ID000003"/> 
Embora esta solução funcione tanto com Condor Pools quanto com o Globus, ainda assim é de alto acoplamento. Não há indicações de como incluir outros gerenciadores de grade.

Além disso, não há tratamento de padrões mais elaborados de workflow para paralelização, como os previstos por Russell et al [2], ficando a implementação de tais padrões por conta do usuário.

\subsubsection{Grid Process Execution Language (GPEL) e CROWN FlowEngine}

Wang [55] propôs a Grid Process Execution Language (GPEL) com construções de paralelização dependentes de grade e sem o uso de padrões. A GPEL é uma extensão da BPEL4WS [56], que inclui nesta elementos para execução em grades, especificamente a atividade parallel, cuja definição é:

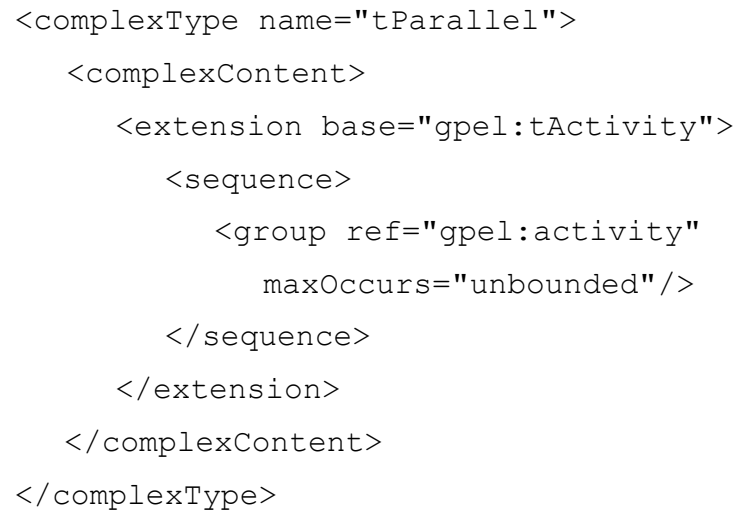

A atividade parallel não permite configurações para representação dos padrões de workflow descritos por Russell et al [2].

Em [57], Zeng et al apresentam o CROWN FlowEngine, uma implementação de GPEL, cuja arquitetura é ilustrada na Figura 19. Vale notar a presença de serviços para persistência, transações e gerenciamento de recursos, tidos pelo Grid Workflow Forum [58] como alguns dos elementos que diferem um workflow para grades de um workflow para uso sem grades. 


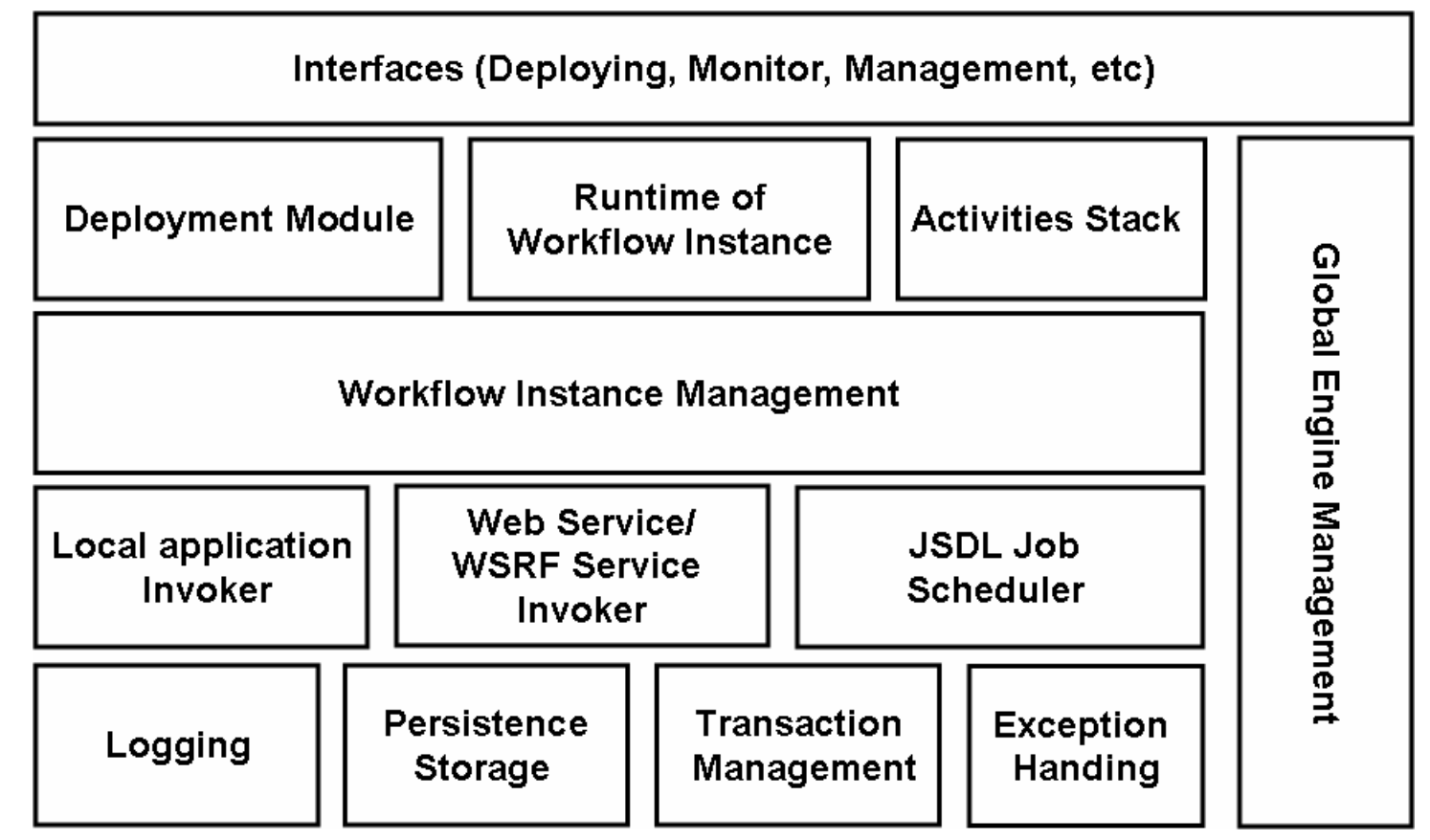

Figura 19: arquitetura do CROWN FlowEngine [57]

\subsubsection{Considerações sobre a Execução de Workflows em Grades}

A execução de workflows em grades apresenta um conjunto de peculiaridades, identificadas e analisadas por Wang et al [55], considerando cada atividade em um workflow como um serviço a ser enviado à grade:

- Definição da ordem de execução de serviços, incluindo seqüência, paralelismo, escolha e repetição;

- Definição de troca de dados entre os serviços e uso de cache;

- Suporte a WSRF [59], que tem se tornado padrão para utilização de recursos em ambiente com uso de serviços web;

- Capacidade de execução de serviços em ambiente de alto desempenho, como clusters;

- Mecanismo de suporte a interações com grandes quantidades de dados;

- Suporte a alternativas de associação (binding) de serviços a nós da grade. Isso se deve à natureza diversa de aplicações a serem executadas, e também da dinamicidade das grades quanto à disponibilidade de recursos.

Há diversas especificações de linguagens para descrição de workflows ( [56], [60], [5]), algumas considerando uso em grades ( [55], [40]). Além disso, há várias implementações que permitem a execução de workflows em grades ( [43], [47]), sendo que as analisadas neste trabalho não tratam de padrões elaborados como os apresentados por Russell et al em [2]. Outro ponto ausente é o 
tratamento simultâneo do baixo acoplamento e da extensibilidade das soluções propostas. Por exemplo, nenhum dos trabalhos avaliados apresenta desacoplamento entre os gerenciadores de workflow e de grade.

\subsection{Conclusão}

As seções anteriores apresentam diversos trabalhos sobre padrões, workflows e grades. No entanto, conforme descrito nas considerações de cada seção, nenhum desses trabalhos apresenta claramente uma arquitetura desacoplada e extensível, no que diz respeito à utilização pela aplicação de eScience, integração a diversos gerenciadores de workflow, escolha de utilizar ou não um gerenciador de grade e, em caso afirmativo, permitir optar pelo que for mais conveniente.

O tratamento de padrões de workflow por diversos gerenciadores, apresentados na seção 3.1 , não leva em consideração a presença de grade. Além disso, não é apresentado algum modo de implementar um novo padrão e integrá-lo a um gerenciador de workflow existente.

A documentação dos gerenciadores de grade apresentados na seção 3.2 não trata padrões ou integração a gerenciadores de workflow. Embora existam trabalhos relacionando workflow e grades, descritos na seção 3.3, estes apresentam arquiteturas de alto acoplamento, sendo específicas para um determinado gerenciador. Além disso, não tratam padrões de paralelização como os descritos em [2].

Este trabalho complementa os apresentados neste capítulo, ao fornecer uma única solução que possui as seguintes características:

- Representação dos padrões de paralelização independentemente da presença de um gerenciador de workflow;

- Facilidade de integração da implementação dos padrões a um gerenciador de workflow;

- Padrões podem ou não ser executados em grade;

- Liberdade de escolha do gerenciador de grade;

- Abstração da presença de grade para o usuário;

- Extensibilidade da solução, com a possibilidade de incluir ou substituir módulos para tratamento de outros padrões e para integração a gerenciadores de workflow e grade. 


\section{Capítulo 4}

\section{Padrões de Workflow Paralelizáveis}

O capítulo anterior apresentou a importância do uso de padrões, e mencionou o trabalho de Aalst, Russell et al ( [14], [3], [21], [1], [2]) no sentido de identificá-los e exemplificá-los.

Vários desses padrões se referem à execução paralela de tarefas, o que os torna candidatos naturais à análise para execução em grades, clusters ou em equipamentos multi-processados.

Neste capítulo, são descritos um padrão de divisão paralela e dez padrões de sincronização apresentados por Russell et al em [2]. A partir desses padrões, foi concebido o Padrão Junção Combinada, apresentado ao final do capítulo, e que oferece um conjunto extenso de opções às aplicações de workflow.

\subsection{Padrões de Workflow Relacionados}

A arquitetura proposta neste trabalho, descrita na Seção 5.1, possibilita a execução em grade. Este trabalho implementa dois grupos de situações:

- Quando não houver a presença de grade: atende ao uso de padrões para paralelização a serem executados em modelo com múltiplas threads, potencialmente alocadas em processadores distintos;

- Quando houver gerenciador de grade: neste trabalho, a flexibilidade da arquitetura permitiu a seleção e utilização do Ourgrid [33], gerenciador de grade em uso pelo Grupo de Processamento Paralelo e Distribuído da Universidade Federal do Rio Grande do Sul.

Não está incluso no escopo, contudo, o gerenciamento da execução quanto a tolerância a falhas ou outros aspectos não funcionais. 
No tocante aos padrões de workflow, o baixo acoplamento e a estruturação da arquitetura em camadas - vide Seção 5.1.1 - permitem a adição de implementação de padrões a qualquer tempo. Assim, foi possível selecionar um conjunto de padrões para implementar, de modo a permitir a validação e os testes da arquitetura.

Dos quarenta e três padrões descritos por Russell et al [2], vinte e sete se relacionam a ramificação, sincronização ou múltiplas instâncias, podendo se aproveitar da execução em grades. Por suas similaridades, expostas nesta seção, este trabalho se propõe a tratar o padrão "(WCP-2) Divisão Paralela", e os seguintes padrões de sincronização:

- (WCP-3) Sincronização;

- (WCP-9) Discriminador Estruturado;

- (WCP-28) Discriminador com Bloqueio;

- (WCP-29) Discriminador com Cancelamento;

- (WCP-30) Junção Parcial Estruturada;

- (WCP-31) Junção Parcial com Bloqueio;

- (WCP-32) Junção Parcial com Cancelamento;

- (WCP-34) Junção Parcial Estática para Múltiplas Instâncias;

- (WCP-35) Cancelamento de Junção Parcial de Múltiplas Instâncias;

- (WCP-36) Junção Parcial Dinâmica para Múltiplas Instâncias.

No restante deste capítulo, serão utilizadas Redes de Petri Coloridas (CPN) para representar e exemplificar o funcionamento de cada padrão. Uma vez implementados, os padrões devem exibir interface simplificada ao cientista, encapsulando os detalhes de sua operação. Portanto, o processo de modelagem por parte do cientista deve abstrair quaisquer aspectos intrínsecos da representação formal dos padrões. Por exemplo, a Figura 20 mostra uma representação do padrão "(WCP-9) Discriminador Estruturado", apropriada para compreensão do padrão e seu funcionamento - descrito mais adiante neste capítulo. 


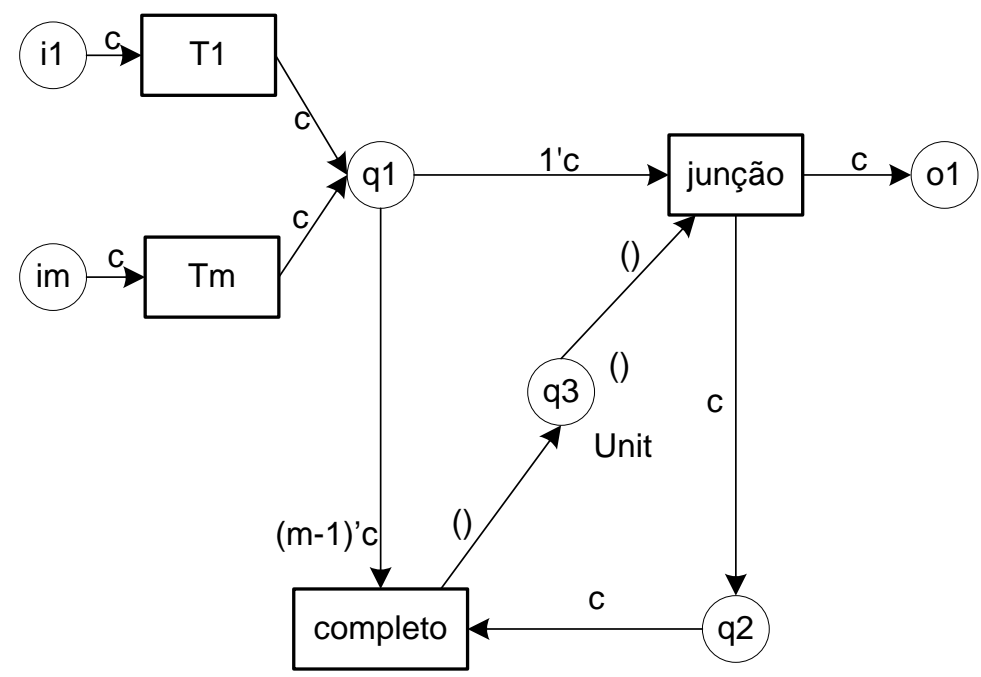

Figura 20: representação do padrão "Discriminador Estruturado" usando CPN [2]

Essa representação é completa para fornecer o fluxo de execução. Todavia, é inadequada para o cientista, que necessita apenas modelar seu fluxo informando as entradas e saídas do padrão. Desse modo, uma representação como a da Figura 21 é mais apropriada. O gerenciador de workflows utilizado nos testes permite a construção de elementos visuais que são funcionalmente equivalentes.

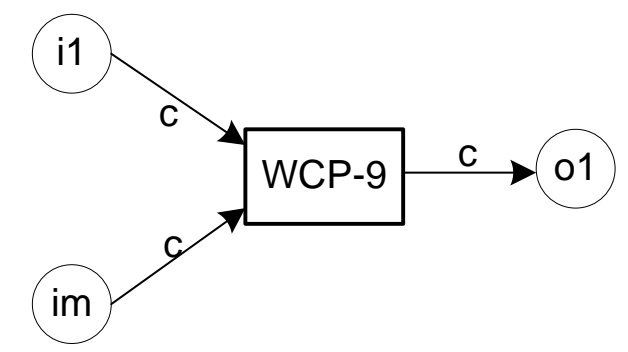

Figura 21: construção a ser utilizada pelo cientista

As próximas seções revisam os padrões de workflow descritos por Russell et al [2]. As figuras foram adaptadas de modo a tornar explícita a semelhança entre os padrões. Tal semelhança justifica a escolha desses padrões para a implementação neste trabalho, conforme descrito em 4.2.

\subsection{1 (WCP-2) Divisão Paralela}

É o padrão que explicita a possibilidade de execução em grade. As saídas deste padrão são as entradas para os padrões de sincronização, descritos nas próximas seções. Na Figura 22, i 1 representa o início da execução do padrão, que realiza o disparo das atividades a serem executadas em paralelo, a partir 
das transições $\left\{T_{1}, \ldots, T_{m}\right\}$. O término da execução do padrão ocorre quando cada lugar de saída $\left\{0_{1}, \ldots, \mathrm{O}_{\mathrm{m}}\right\}$ receber uma marca.

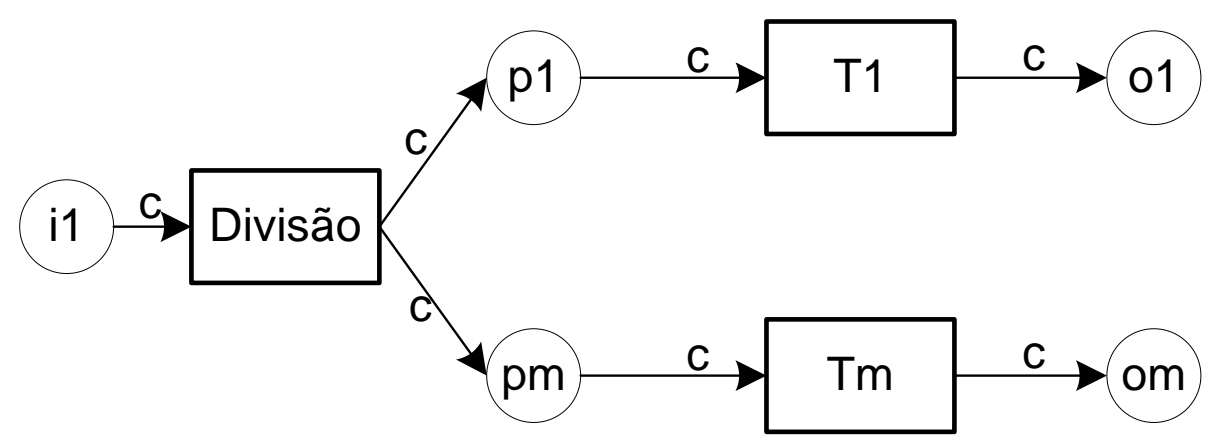

Figura 22: Padrão Divisão Paralela

Este padrão faz parte do conjunto de padrões básicos identificados por Aalst et al [1], sendo implementado por todas as soluções de workflow citadas no Capítulo 3.

Este texto assume a execução assíncrona das atividades associadas às transições $\left\{T_{1}, \ldots, T_{m}\right\}$, ficando os padrões de sincronização responsáveis por verificar quando essas tarefas tenham sido concluídas. Desse modo, logo que uma atividade é colocada em execução por $T_{i}$, com $(1 \leq i \leq m)$, uma marca é depositada em $o_{i}$. Essa suposição é importante para garantir o funcionamento dos padrões de sincronização.

\subsection{2 (WCP-3) Sincronização}

É o padrão mais simples para junção (sincronização) dos fluxos de execução paralela de atividades. As entradas deste padrão são as saídas do padrão "Divisão Paralela". Na Figura 23, $\left\{\mathrm{i}_{1}, \ldots, \mathrm{i}_{\mathrm{m}}\right\}$ representam o início da execução do padrão, que realiza a junção das tarefas executadas em paralelo, sendo que $\left\{T^{\prime}{ }_{1}, \ldots, T^{\prime}{ }_{m}\right\}$ representam o término das atividades dos ramos de entrada do padrão. O lugar $0_{1}$ representa o término da execução do padrão.

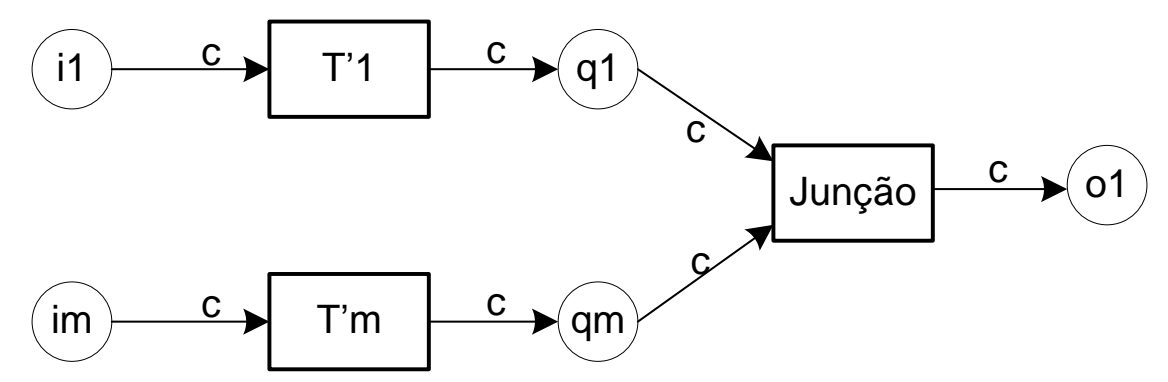

Figura 23: Padrão Sincronização 
Este padrão também faz parte do conjunto de padrões básicos identificados por Aalst et al [1], sendo implementado por todas as soluções de workflow citadas no Capítulo 3.

A Figura 24 ilustra a utilização combinada dos padrões "Divisão Paralela" e "Sincronização".

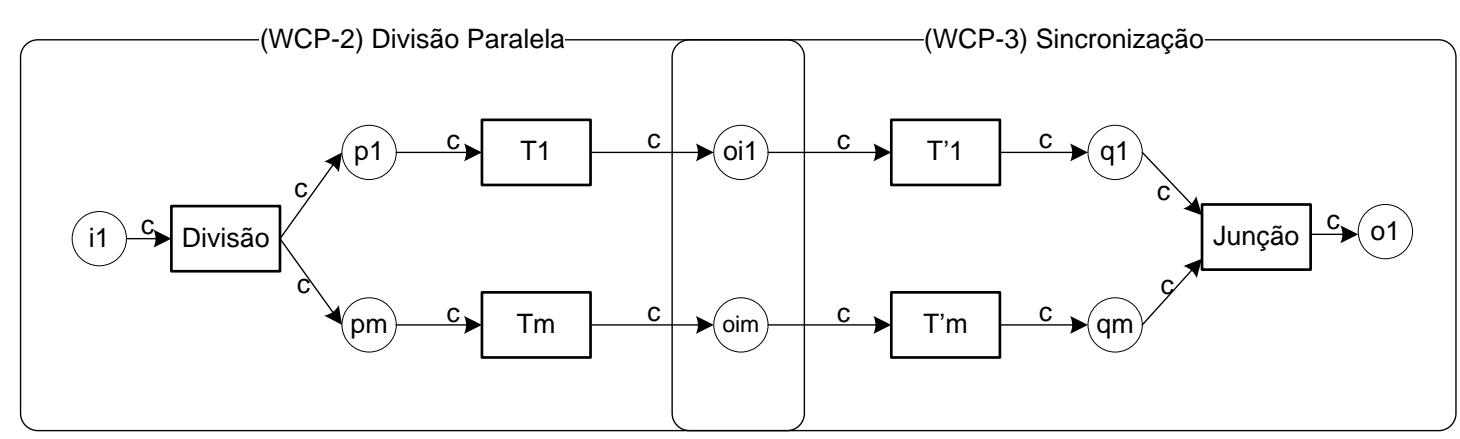

Figura 24: combinação do uso dos padrões "Divisão Paralela" e "Sincronização"

As transições $\left\{T_{1}, \ldots, T_{m}\right\}$ indicam o início da execução das atividades a elas associadas. Assim, por exemplo, a atividade da transição $T_{i}$ é colocada em execução e, ao mesmo tempo, uma marca é inserida em oi ${ }_{i}^{5}$. Nesse caso, a transição $T_{i}^{\prime}$ apenas ocorrerá quando tal atividade tiver sido concluída.

\subsubsection{Discriminadores}

Caracterizam-se pela produção de saída quando uma das atividades em paralelo tiver sido concluída.

\subsubsection{1 (WCP-9) Discriminador Estruturado}

Assim como os demais padrões de sincronização, o Discriminador Estruturado trabalha juntamente com o padrão Divisão Paralela (WCP-2), conforme ilustrado na Figura 25.

O funcionamento do padrão é: inicialmente existe uma marca em $\mathrm{i}_{1}$, e uma marca sem tipo, identificada por "()", em q $q_{3}$. Esta última controla o momento em que a transição "junção" pode ocorrer, conforme descrito a seguir. Um conjunto de atividades $\left\{A_{1}, \ldots, A_{m}\right\}$ a serem executadas paralelamente é submetido ao padrão WCP-2. Essas atividades são colocadas em execução nas transições $\left\{\mathrm{T}_{1}, \ldots, \mathrm{T}_{\mathrm{m}}\right\}$ e marcas são inseridas nos locais de saída $\left\{\mathrm{oi}_{1}, \ldots, \mathrm{oi}_{\mathrm{m}}\right\}$.

\footnotetext{
${ }^{5} \mathrm{oi}_{\mathrm{i}}$ representa ambos a saída de $\mathrm{T}_{\mathrm{j}}$ na "Divisão Paralela" e a entrada para $\mathrm{T}_{\mathrm{j}}{ }_{\mathrm{j}}$ na "Sincronização"
} 


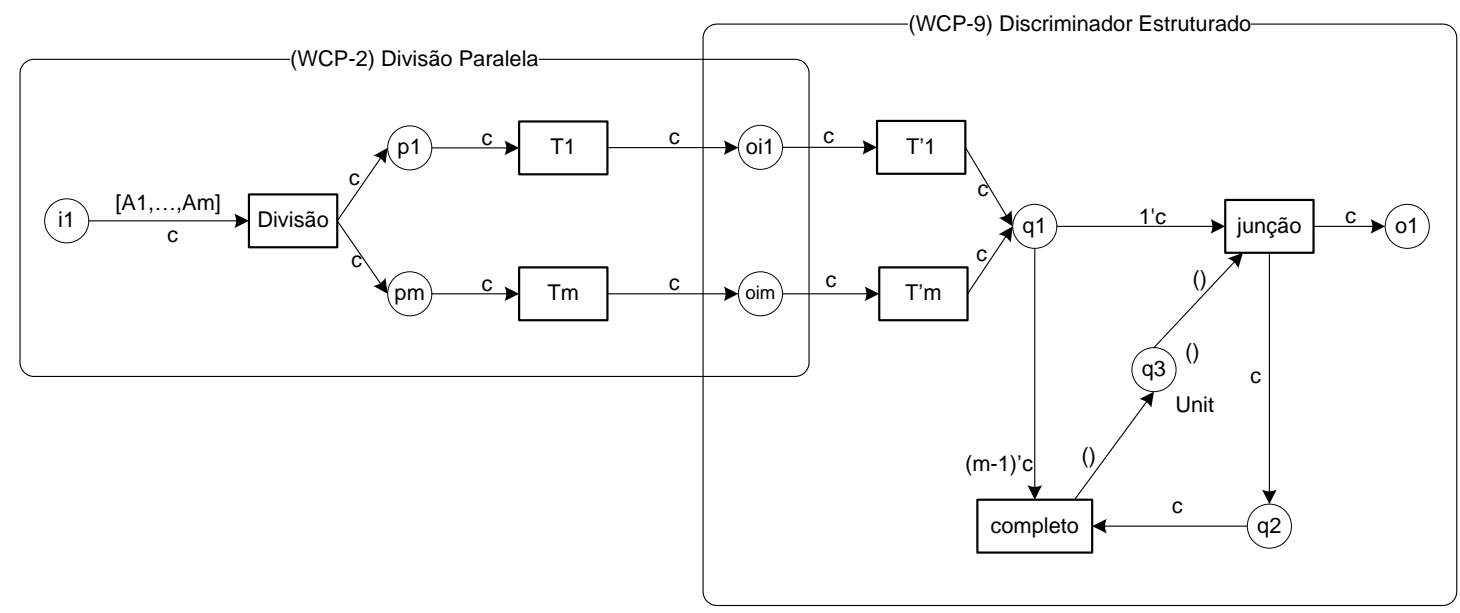

Figura 25: Padrão Discriminador Estruturado e Padrão Divisão Paralela

Quando uma dessas atividades for concluída, por exemplo $A_{i}$, a transição $T_{i}$ ocorrerá e o lugar q $q_{1}$ receberá uma marca, habilitando a transição "junção" e produzindo a saída $o_{1}$. Nesse momento, $q_{2}$ receberá uma marca, e a transição "completo" aguardará o recebimento das " $(\mathrm{m}-1)$ " demais marcas, vindas de $\mathrm{q}_{1}$, à medida que as demais atividades forem concluídas. Quando isso ocorrer, uma marca sem tipo será inserida no lugar $q_{3}$, habilitando o padrão a ser novamente utilizado.

\subsubsection{2 (WCP-28) Discriminador com Bloqueio}

A aplicação que utiliza o padrão "Discriminador Estruturado" é responsável por garantir que nova execução no mesmo processo não seja possível até que todas as tarefas tenham sido concluídas. Caso esse cuidado não seja tomado, uma nova execução da(s) tarefa(s) que tenha(m) sido concluída(s) será possível, com conseqüências que o padrão não prevê.

Por exemplo, seja um conjunto $\left\{A_{1}, \ldots, A_{m}\right\}$ de testes genéticos a serem realizados para avaliar uma hipótese diagnóstica para uma determinada doença. Caso um dos testes seja positivo, digamos $A_{i}$, a transição T'i ocorre, indicando a confirmação da hipótese diagnóstica e o conjunto de testes pode ser realizado para outro paciente - isso é obtido ao inserir uma marca em $q_{1}$, habilitando a transição "junção" (que também irá consumir a marca sem tipo de $q_{3}$ ). Antes que os demais testes sejam concluídos, os dados de outro paciente são submetidos ao processamento. Nesse momento, 0 teste $A_{i}$ passa a ser realizado para 0 novo paciente. Caso tal teste se confirme ainda antes dos testes do primeiro paciente serem concluídos, uma marca será inserida em $q_{1}$. Porém, como neste caso a atividade "junção" não estará habilitada (pois a marca sem tipo em q $q_{3}$ foi consumida ao término do teste $A_{i}$ do primeiro paciente), essa nova marca será consumida quando a transição "completo" for realizada, de modo que a saída $0_{1}$ não será produzida. 
Para que essa situação não ocorra, existem duas possibilidades: a aplicação garantir que o padrão somente será utilizado após completar a execução de todas as atividades; ou o padrão ser acrescido de construções que garantam esse comportamento, dito bloqueante. Neste último caso, o padrão resultante é previsto por Russell et al [2] como (WCP-28) - Discriminador com Bloqueio.

Ilustrado na Figura $26^{6}$, este padrão contém elementos para não permitir que uma execução seja possível antes do término da execução anterior, de modo independente da aplicação. Esses elementos, representados pelas transições $\left\{t_{1}, \ldots, t_{m}\right\}$ e pela lista $c s$, garantem ao padrão o comportamento bloqueante. A lista contém um identificador para cada lugar de entrada oi $\mathrm{i}_{\text {. }}$ Quando o padrão for acionado pela primeira, vez, a lista estará vazia, tendo sido inicializada no lugar "entradas em uso". Assim que a atividade $A_{k}$ for colocada em execução pela transição $T_{k}$, uma marca será inserida em oi $i_{k}$ Como o elemento " $k$ " não está na lista (até o momento vazia), ocorrerão as seguintes ações: $t_{k}$ será habilitado; uma marca será inserida em $i_{k}$; e " $k$ " será inserido na lista cs. Caso seja feita nova tentativa de uso do padrão, essa execução fica bloqueada pelas atividades estarem na lista. Apenas quando as tarefas da primeira execução forem concluídas, a lista será esvaziada (arco de "completo" para "entradas em uso"), permitindo a nova execução. Desse modo, não há interferência entre as execuções do padrão.

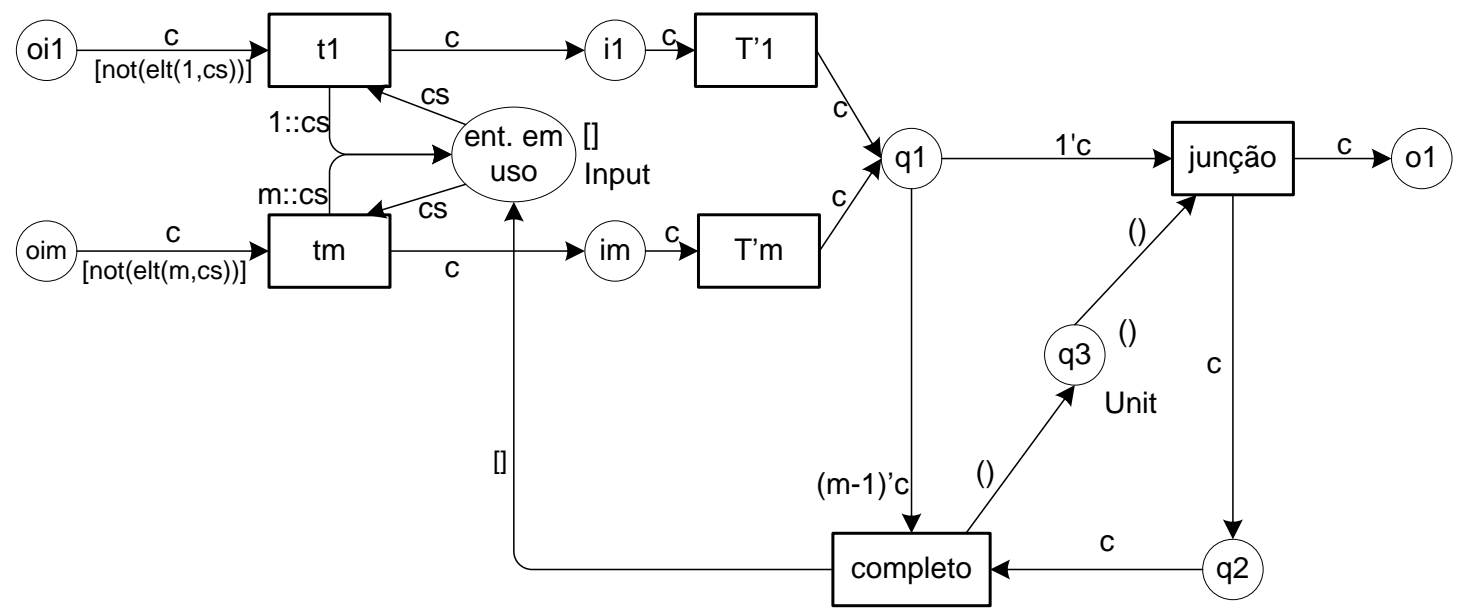

Figura 26: Padrão Discriminador com Bloqueio. Adaptado de [2].

Trata-se de uma especialização do Padrão Discriminador Estruturado. Aqui, o padrão independe da aplicação no controle de execuções sucessivas.

\footnotetext{
${ }^{6}$ Para simplicidade desta e das demais figuras relativas aos padrões, foi omitida a representação do padrão "Divisão Paralela". Os elementos desse padrão $\left(\left\{\mathrm{A}_{1}, \ldots, \mathrm{A}_{\mathrm{m}}\right\}\right.$ e $\left.\left\{\mathrm{T}_{1}, \ldots, \mathrm{T}_{\mathrm{m}}\right\}\right)$ continuarão a ser referenciados no texto para exemplificar a execução dos demais padrões
} 


\subsubsection{3 (WCP-29) Discriminador com Cancelamento}

Ao produzir a saída $0_{1}$, o Padrão Discriminador Estruturado aguarda que todas as demais atividades sejam concluídas para então poder ser novamente utilizado. Todavia, quando essa espera for desnecessária, o padrão pode ser colocado em prontidão novamente ao sinalizar às demais atividades que seu resultado será descartado. Esse comportamento é particularmente útil em cenários de alta concorrência pelo uso do padrão, aumentando sua disponibilidade.

Por exemplo, a análise de risco operacional de uma fábrica pode demandar manutenção corretiva quando um dentre dez possíveis indicadores ultrapassar determinado limite. Quando isso ocorrer, a manutenção será realizada, independentemente dos demais indicadores.

Este padrão oferece esse comportamento, e é ilustrado na Figura 27.

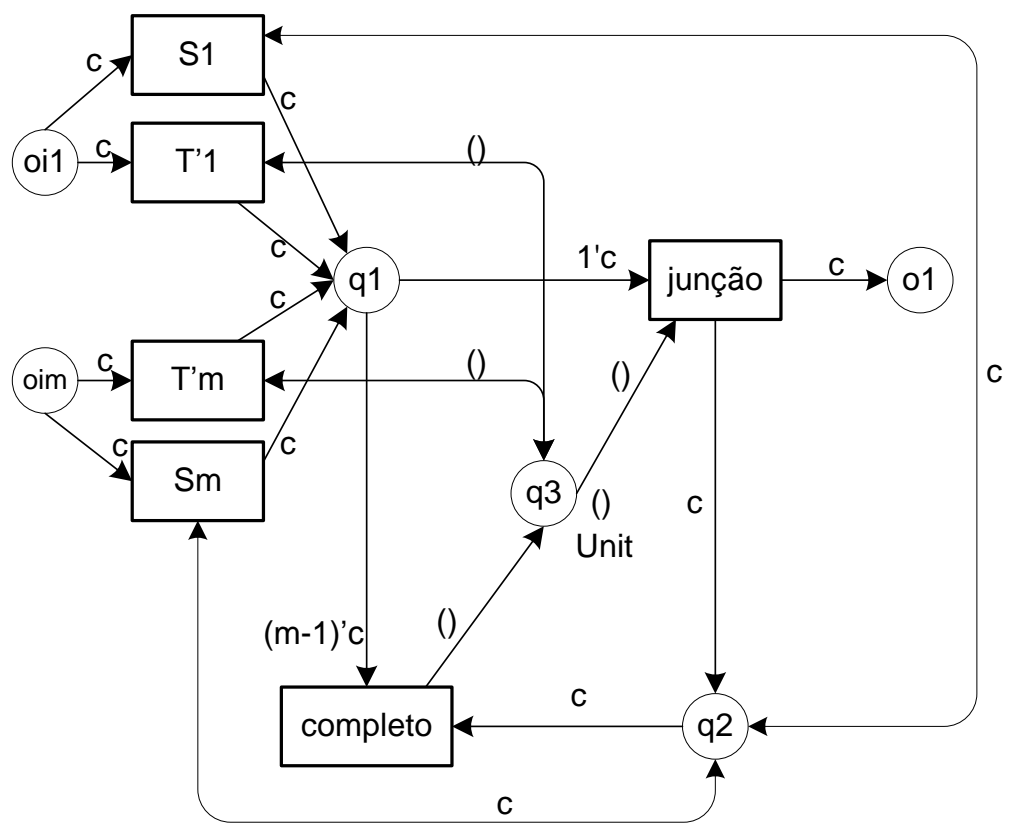

Figura 27: Padrão Discriminador com Cancelamento. Adaptado de [2].

Em relação ao Padrão Discriminador Estruturado, existem duas diferenças: a inclusão de atividades $\left\{S_{1}, \ldots, S_{m}\right\}$ e novos arcos, ligando $q_{3}$ às transições $\left\{\mathrm{T}^{\prime}{ }_{1}, \ldots, \mathrm{T}_{\mathrm{m}}{ }_{\mathrm{m}}\right\}$.

Uma atividade $S_{i}$ é executada durante o cancelamento, quando a atividade $A_{i}$ correspondente não for mais necessária. Tal $S_{i}$ pode representar uma atividade de desfazimento ou compensação, ou ainda simplesmente não fazer ação específica, servindo nesse caso apenas para colocar o padrão novamente em estado de prontidão. 
Os novos arcos, por sua vez, impedem a execução das transições $\left\{\mathrm{T}^{\prime}{ }_{1}, \ldots, \mathrm{T}_{\mathrm{m}}\right\}$ após uma delas ter sido completada.

$O$ funcionamento do padrão é: à medida em que as atividades $\left\{A_{1}, \ldots, A_{m}\right\}$ são colocadas em execução, marcas são inseridas nos lugares $\left\{0 \mathrm{i}_{1}, \ldots, 0 \mathrm{i}_{\mathrm{m}}\right\}$. Quando uma atividade $A_{i}$ for concluída, a transição $T_{i}^{\prime}$ irá ocorrer. Para isso, irá consumir as marcas em oi $\mathrm{i}_{\mathrm{i}} \mathrm{e}$ em $\mathrm{q}_{3}$. Então uma marca será inserida em $\mathrm{q}_{1} \mathrm{e}$ outra em $\mathrm{q}_{3}$, habilitando a transição "junção". No próximo passo de execução, esta transição pode ocorrer, ou ainda outra transição $T^{\prime}$, caso a atividade $A_{k}$ tenha sido concluída. Embora o padrão não determine qual dessas transições irá ocorrer primeiro, ele garante que a transição "junção" ocorra em algum momento, uma vez que o número de atividades é finito. Assim que a transição "junção" ocorrer, $0_{1}$ receberá uma marca, permitindo o prosseguimento do fluxo.

A partir daí, o padrão procede ao cancelamento das demais atividades. Como o lugar $q_{3}$ estará sem marca, o padrão não poderá reconhecer o término de outras atividades, ou seja, $q_{1}$ só poderá receber marcas vindas das transições de cancelamento. Ao mesmo tempo, $q_{2}$ receberá uma marca, habilitando as transições de cancelamento associadas às atividades que ainda não foram concluídas (as que possuírem marca nos lugares "oi" de entrada). Uma por vez, as transições de cancelamento consomem a marca de $\mathrm{q}_{2}$, possivelmente enviam algum sinal de cancelamento de atividade, e inserem uma marca em $\mathrm{q}_{1}$ e outra em $\mathrm{q}_{2}$, habilitando outra transição de cancelamento. Esse processo se repete até que todas as marcas de entrada tenham sido consumidas. Então a transição "completo" será habilitada e poderá colocar uma marca sem tipo em q $\mathrm{q}_{3}$, habilitando o padrão para ser novamente utilizado.

\subsubsection{Junções Parciais}

São padrões semelhantes aos discriminadores, sendo uma forma mais genérica daqueles. Aqui, a saída $o_{1}$ é produzida quando $n(n \leq m)$ atividades tiverem sido concluídas. Os discriminadores são junções parciais em que $n=1$.

\subsubsection{1 (WCP-30) Junção Parcial Estruturada}

Semelhantes aos Discriminadores Estruturados, a única diferença é a transição "junção" ser habilitada quando $n$ atividades dentre $\left\{A_{1}, \ldots, A_{m}\right\}$ tiverem sido concluídas. A transição "completo" permanece sendo habilitada quando as demais atividades forem concluídas. Enquanto nos discriminadores eram (m-1) atividades, nas junções parciais esse número é (m-n). O padrão é representado na Figura 28, onde essas modificações podem ser observadas nos arcos que saem de $q_{1}$. 


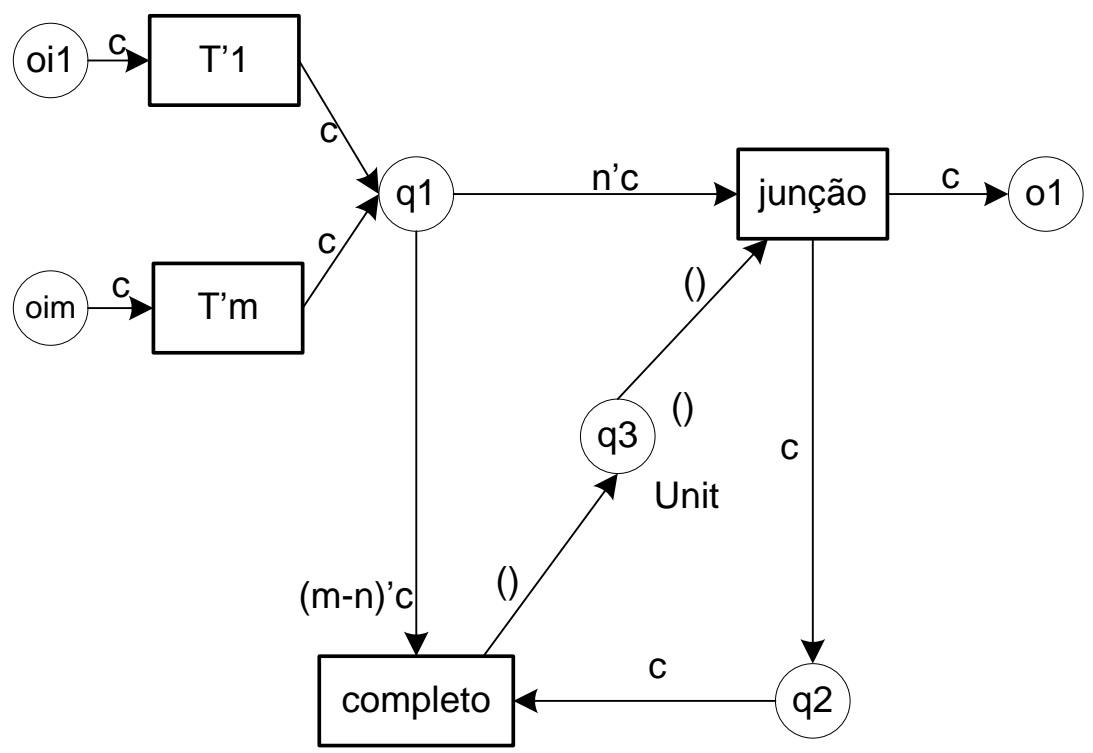

Figura 28: Padrão Junção Parcial Estruturada. Adaptado de [2].

A menos dos pontos acima, o funcionamento deste padrão é idêntico ao descrito na seção 4.1.3.1.

Vale notar que os Discriminadores Estruturados representam uma especialização deste padrão.

\subsubsection{2 (WCP-31) Junção Parcial com Bloqueio}

Do mesmo modo que os Discriminadores com Bloqueio, tornam o padrão independente da aplicação, no tocante ao tratamento de bloqueios de execução de atividades antes do término da execução anterior, conforme ilustrado na Figura 29.

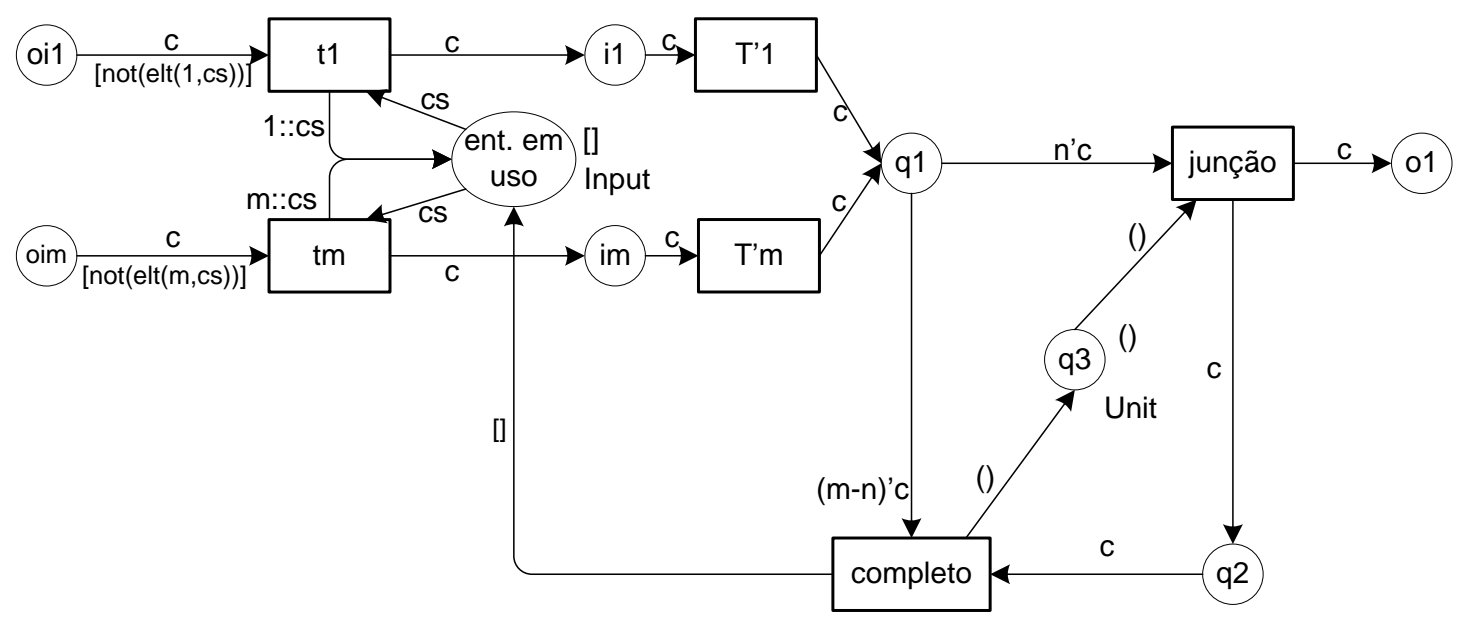

Figura 29: Padrão Junção Parcial com Bloqueio [2]. 
Exceto pelo fato das transições "junção" e "completo" serem habilitadas quando houver $n$ e $(m-n)$ marcas em $q_{1}$, respectivamente, o funcionamento deste padrão é idêntico ao descrito na seção 4.1.3.2.

\subsubsection{3 (WCP-32) Junção Parcial com Cancelamento}

Semelhante aos Discriminadores com Cancelamento, permite a reutilização do padrão após $\mathrm{n}$ tarefas terem sido concluídas, cancelando as demais, conforme a Figura 30.

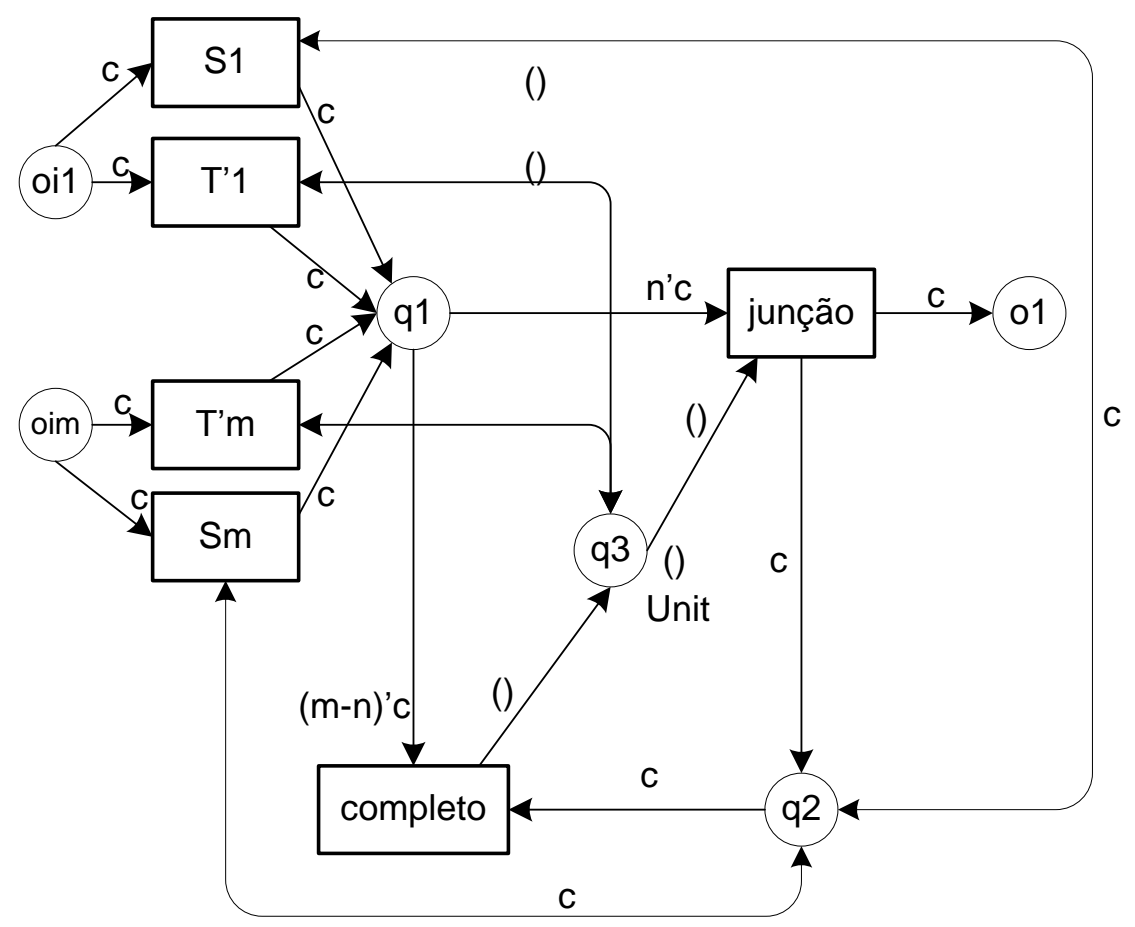

Figura 30: Padrão Junção Parcial com Cancelamento [2].

Exceto pelo fato das transições "junção" e "completo" serem habilitadas quando houver $n$ e $(m-n)$ marcas em $q_{1}$, respectivamente, o funcionamento deste padrão é idêntico ao descrito na seção 4.1.3.3.

\subsubsection{Padrões para Múltiplas Instâncias}

São aqueles em que as atividades a serem executadas em paralelo são instâncias de uma mesma atividade. Muitas vezes são utilizados em contexto de computações triviais, conforme constatado por Pautasso [45], mais especificamente quando as instâncias puderem ser executadas independentemente umas das outras. 


\subsubsection{1 (WCP-34) Junção Parcial Estática para Múltiplas Instâncias}

Embora Russell et al [2] apresentem este como um novo padrão, trata-se de uma especialização do Padrão Junção Parcial Estruturada, em que as atividades a serem executadas possuem mesmo código, ou seja, são instâncias de uma mesma atividade, possivelmente com parâmetros distintos. A Figura 28 se aplica para ilustrar este padrão, sem modificações.

\subsubsection{2 (WCP-35) Junção Parcial de Múltiplas Instâncias com Cancelamento}

Embora Russell et al [2] apresentem este como um novo padrão, trata-se de uma especialização do Padrão Junção Parcial com Cancelamento, em que as atividades a serem executadas possuem mesmo código, ou seja, são instâncias de uma mesma atividade, possivelmente com parâmetros distintos. A Figura 30 se aplica para ilustrar este padrão, sem modificações.

\subsubsection{3 (WCP-36) Junção Parcial Dinâmica de Múltiplas Instâncias}

É uma extensão da Junção Parcial Estática de Múltiplas Instâncias. Aqui, é possível executar novas instâncias da atividade em questão, antes que o padrão tenha produzido a saída $0_{1}$. Um exemplo de uso deste padrão é no contexto de controle sismográfico por meio de sensores. Cada ponto de checagem pode conter um sensor de reserva, a ser acionado dinamicamente caso o sensor principal apresente alguma falha.

Mostrado na Figura 31, este padrão apresenta as seguintes diferenças em relação à Junção Parcial Estática de Múltiplas Instâncias:

- O lugar "Permite novas instâncias" é o responsável por receber comandos externos ao padrão para criação de novas instâncias;

- A transição "Inicia instância" é responsável por executar uma nova instância da atividade em questão, semelhante ao funcionamento das atividades $\left\{T_{1}, \ldots, T_{m}\right\}$ do padrão "Divisão Paralela". Assim, uma nova instância da atividade é criada e colocada em execução, ao mesmo tempo que uma marca é inserida no lugar o $i_{i}$. A transição $T_{i}$ estará habilitada quando a atividade for completada;

- Este padrão permite que novas instâncias sejam criadas apenas enquanto a transição "junção" não for executada. Para que esse comportamento seja garantido, o lugar "Não permite novas instâncias" recebe uma marca apenas quando a transição "desabilita criação de instâncias" for executada. 
O funcionamento do padrão é o mesmo do Padrão Junção Parcial Estática de Múltiplas Instâncias, exceto pelos seguintes pontos:

- Inicialmente o lugar "Permite novas instâncias" possui uma marca e o número inicial de instâncias sendo executadas em paralelo, como resultado da execução do Padrão Divisão Paralela. Desse modo, as transições "Inicia instância" e "desabilita criação de instâncias" estão habilitadas;

- Quando houver um comando externo para criação de instâncias, a transição "Inicia instância" dispara nova instância e, ao mesmo tempo, insere uma marca em oi ${ }_{i}$, habilitando a transição $T^{\prime}$, que aguardará o término da execução da atividade. Uma marca então é colocada em "Permite novas instâncias", atualizando o número de instâncias com o valor $(\mathrm{c}, \mathrm{m}+1)$ no arco de entrada desse lugar;

- Do mesmo modo que para o Padrão Junção Parcial Estática de Múltiplas Instâncias, à medida que as atividades terminam sua execução, marcas são depositadas em q $q_{1}$;

- Para que a transição "junção" seja habilitada, a transição "desabilita criação de instâncias" necessita ocorrer, momento em que o número total de instâncias é informado ao lugar "Não permite novas instâncias";

- Quando a transição "junção" ocorrer, uma marca é inserida em $0_{1}$, permitindo o prosseguimento do fluxo. Ao mesmo tempo, o número de instâncias é informado a $q_{2}$ e à transição "completo", que então aguarda o término da execução das atividades restantes. 


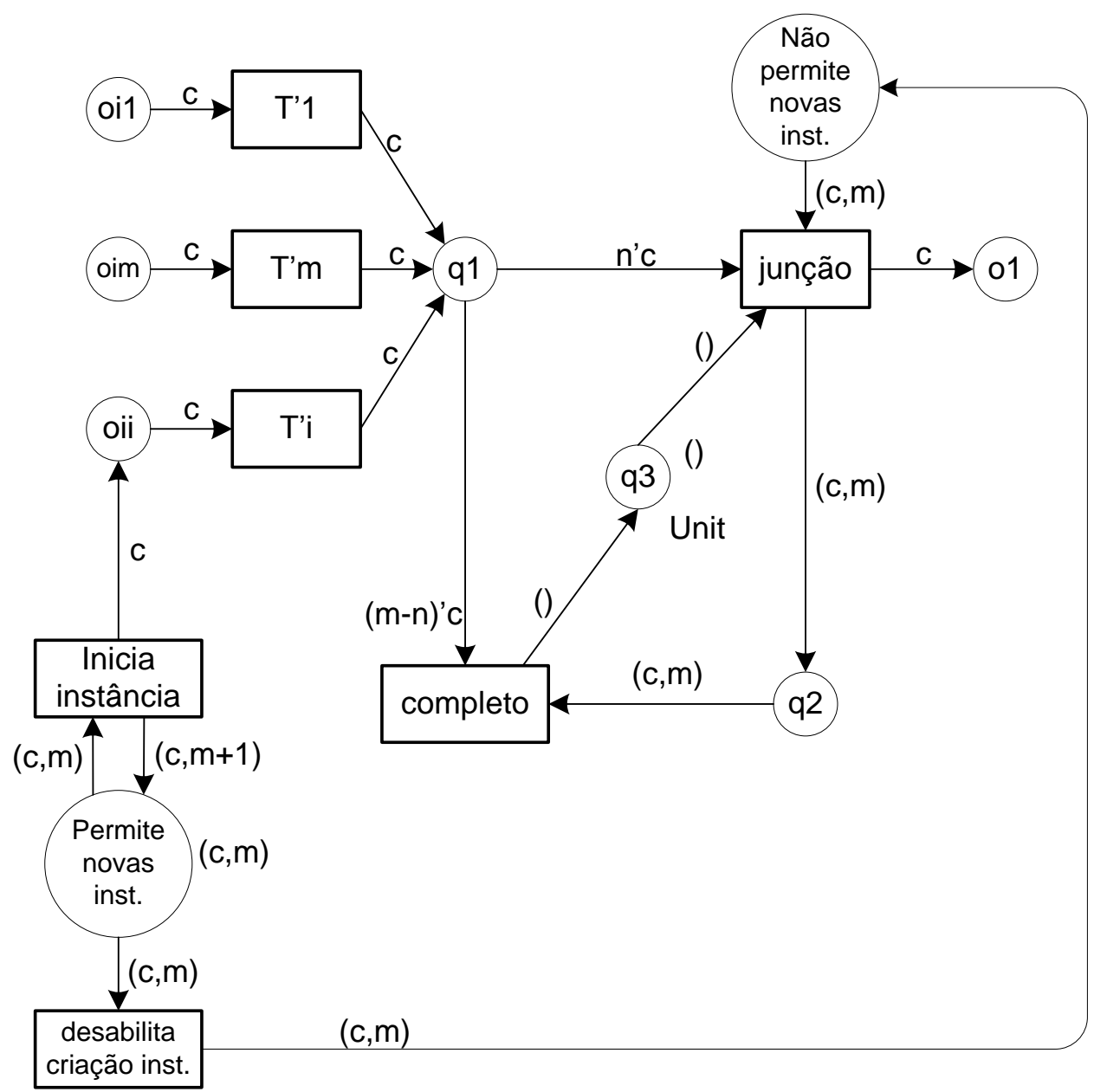

Figura 31: Padrão Junção Parcial Dinâmica para Múltiplas Instâncias. Adaptado de [2]. T'i aguarda a conclusão da execução de uma instância dinamicamente criada.

Este padrão pode ter seu uso estendido para a execução de atividades distintas, uma vez que nada impede que isso ocorra. Desse modo, atende à seguinte situação: um conjunto de testes para tentar confirmar uma hipótese diagnóstica é iniciado, sendo que alguns desses testes podem ser de longa duração. Para confirmar a hipótese supõe-se que cinco destes devem ser positivos. Após o início dos testes, um novo método pode surgir e deve ser então testado, sem que o processo precise ser recomeçado.

\subsection{O Padrão Junção Combinada (PJC)}

No tocante à implementação, a presença de número elevado de padrões pode ser confusa e deixar de atender ao requisito de simplicidade de utilização por parte do usuário. Segundo Aalst et al [3], diversos padrões são especializações de outros, o que pode ser constatado na seção anterior. Dessa forma, no modelo físico, esses padrões podem ser combinados e oferecerem 
seu comportamento associado a pré-condições que dependam de parâmetros de entrada.

A fim de facilitar a implementação, os padrões referentes a paralelização, destacados na Seção 4.1 podem ser combinados no modelo apresentado de modo simplificado na Figura 32. Desse modo, pode-se propor um único algoritmo que implemente os casos previstos por Aalst et al, além de outros não previstos, em decorrência da combinação. Denominamos esse modelo de "Padrão Junção Combinada", ou PJC.

C

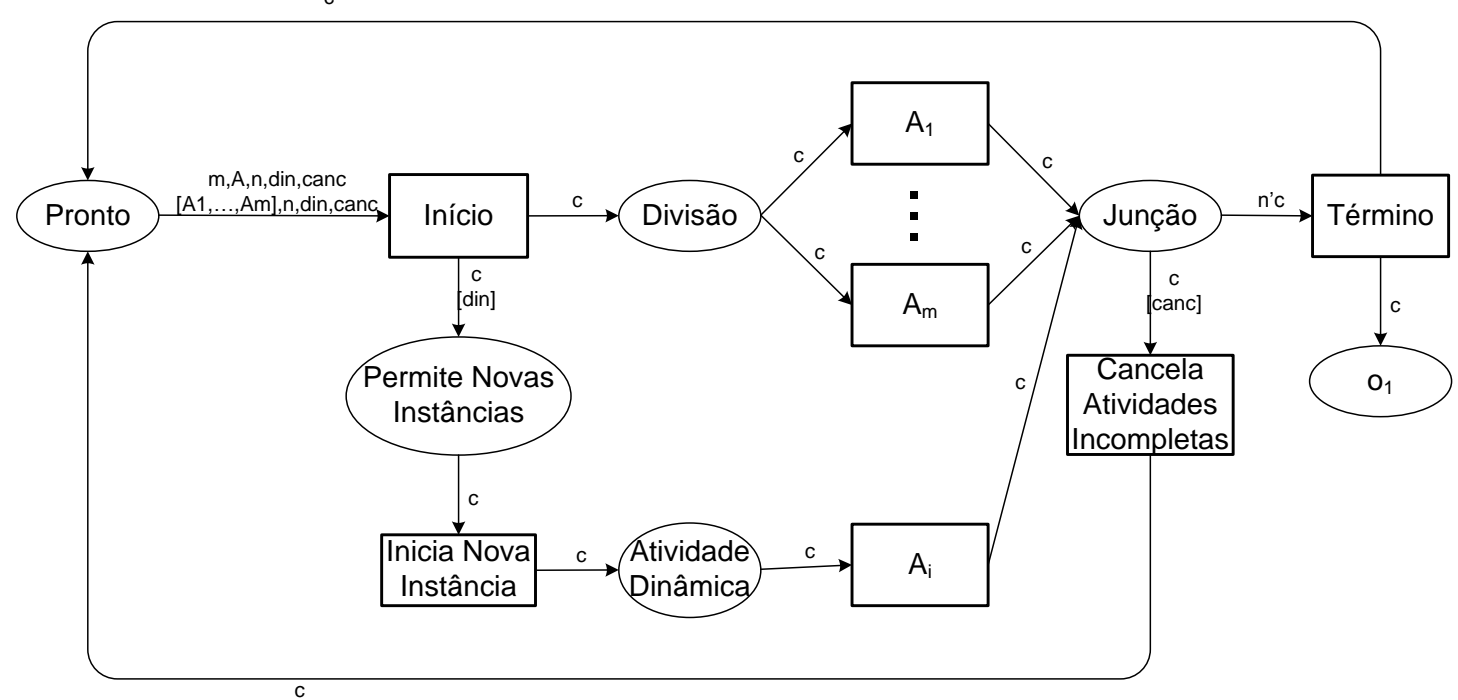

Figura 32: representação simplificada do Padrão Junção Combinada

Para auxiliar na comparação com os padrões descritos por Aalst, foi decidido representar aqui também utilizando CPN. Contudo, workflow graphs permitem que cientistas de outras áreas representem seus fluxos de modo mais flexível [7], sendo mais apropriados para a utilização dos padrões a partir de alguma ferramenta com interface gráfica.

No que diz respeito a comportamento bloqueante, definido na Seção 4.1.3.2, Russell et al [2] apresentam os padrões de modo didático, evitando combinar este recurso com outros, como cancelamento. Além disso, afirmam que 0 uso de padrões sem bloqueios pode resultar em comportamento imprevisível, e não apresentam cenários de uso para este caso. Tal uso ainda exige que a aplicação que utiliza os padrões evite o acionamento destes antes do término da execução anterior.

Este trabalho considera que padrões devem refletir conjuntos de comportamentos herméticos. Assim, quanto menor a dependência entre seu funcionamento e variáveis externas, maior a previsibilidade sobre sua execução. Por esse motivo, o PJC sempre apresenta comportamento bloqueante, tirando da aplicação a responsabilidade por permitir ou não o uso do padrão antes que uma execução anterior tenha sido concluída. 
O comportamento da junção combinada é determinado pelos parâmetros de entrada:

- Quando a entrada for a tupla (m,A,n,din,canc), serão executadas m instâncias da atividade $A ; n$ indica o número de atividades que deve ser completado para a produção da saída em $0_{1}$; din determina se é possível acrescentar novas instâncias dinamicamente durante a execução; e canc indica se as demais atividades, após $\mathrm{n}$ terem sido completadas, devem ou não ser canceladas;

- Quando a entrada for a tupla ([A $\left.A_{1}, \ldots, A_{m}\right], n$, din,canc), a execução das atividades $A_{1}, \ldots, A_{m}$ será realizada em paralelo, com $n$, din e canc como acima.

A tabela a seguir ilustra possíveis valores de entrada e o padrão ao qual a combinação corresponde.

Tabela 2: padrões de junção para múltiplas instâncias e para atividades distintas

\begin{tabular}{|c|c|c|c|c|}
\hline Padrão & Entrada $(m>1)$ & $\mathrm{n}$ & din & canc \\
\hline $\mathrm{P} 1$ & $(\mathrm{~m}, \mathrm{~A}, \mathrm{n}, \mathrm{din}, \mathrm{canc})$ & 1 & não & não \\
\hline $\mathrm{P} 2$ & $(\mathrm{~m}, \mathrm{~A}, \mathrm{n}, \mathrm{din}, \mathrm{canc})$ & 1 & não & $\operatorname{sim}$ \\
\hline $\mathrm{P} 3$ & $(\mathrm{~m}, \mathrm{~A}, \mathrm{n}, \mathrm{din}, \mathrm{canc})$ & 1 & $\operatorname{sim}$ & não \\
\hline $\mathrm{P} 4$ & (m,A,n,din,canc) & 1 & $\operatorname{sim}$ & $\operatorname{sim}$ \\
\hline $\mathrm{P5}$ & $(\mathrm{m}, \mathrm{A}, \mathrm{n}, \mathrm{din}, \mathrm{canc})$ & $1<\mathrm{n}<=\mathrm{m}$ & não & não \\
\hline P6 & $(\mathrm{m}, \mathrm{A}, \mathrm{n}, \mathrm{din}, \mathrm{canc})$ & $1<\mathrm{n}<=\mathrm{m}$ & não & $\operatorname{sim}$ \\
\hline $\mathrm{P} 7$ & (m,A,n,din,canc) & $1<\mathrm{n}<=\mathrm{m}$ & $\operatorname{sim}$ & não \\
\hline P8 & $(\mathrm{m}, \mathrm{A}, \mathrm{n}, \mathrm{din}, \mathrm{canc})$ & $1<\mathrm{n}<=\mathrm{m}$ & $\operatorname{sim}$ & $\operatorname{sim}$ \\
\hline WCP-28 & $([\mathrm{A} 1, \ldots \mathrm{Am}], \mathrm{n}, \mathrm{din}, \mathrm{canc})$ & 1 & não & não \\
\hline P9 & ([A1,...Am],n,din,canc) & 1 & não & $\operatorname{sim}$ \\
\hline P10 & $([\mathrm{A} 1, \ldots \mathrm{Am}], \mathrm{n}, \mathrm{din}, \mathrm{canc})$ & 1 & $\operatorname{sim}$ & não \\
\hline P11 & $([\mathrm{A} 1, \ldots \mathrm{Am}], \mathrm{n}, \mathrm{din}, \mathrm{canc})$ & 1 & $\operatorname{sim}$ & $\operatorname{sim}$ \\
\hline WCP-31 & ([A1,...Am],n,din,canc) & $1<\mathrm{n}<=\mathrm{m}$ & não & não \\
\hline P12 & $([\mathrm{A} 1, \ldots \mathrm{Am}], \mathrm{n}, \mathrm{din}, \mathrm{canc})$ & $1<\mathrm{n}<=\mathrm{m}$ & não & $\operatorname{sim}$ \\
\hline P13 & ([A1,...Am],n,din,canc) & $1<\mathrm{n}<=\mathrm{m}$ & $\operatorname{sim}$ & não \\
\hline P14 & $([\mathrm{A} 1, \ldots \mathrm{Am}], \mathrm{n}, \mathrm{din}, \mathrm{canc})$ & $1<\mathrm{n}<=\mathrm{m}$ & $\operatorname{sim}$ & $\operatorname{sim}$ \\
\hline
\end{tabular}

Vale notar que a combinação dos parâmetros de entrada permite ao Padrão Junção Combinada representar três tipos de padrões:

- Padrões previstos por Russell et al [2]:

- Discriminador com bloqueio (WCP-28);

- Junção parcial com bloqueio (WCP-31).

- Combinações de padrões mapeados por Russell et al [2], acrescidos de comportamento bloqueante:

- P5: junção parcial estática de múltiplas instâncias (WCP-34) com bloqueio; 
- P6: junção parcial estática de múltiplas instâncias com cancelamento (WCP-35) e bloqueio;

- P7: junção parcial dinâmica de múltiplas instâncias (WCP-36) com bloqueio;

- P8: junção parcial dinâmica de múltiplas instâncias (WCP-36) com bloqueio e cancelamento;

- P9: discriminador com bloqueio (WCP-28) e cancelamento;

- P12: junção parcial com bloqueio (WCP-31) e cancelamento.

- Padrões não previstos por Russell et al [2]:

- P1: discriminador para múltiplas instâncias com bloqueio;

- P2: discriminador para múltiplas instâncias com cancelamento e bloqueio;

- P3: discriminador dinâmico para múltiplas instâncias com bloqueio;

- P4: discriminador dinâmico para múltiplas instâncias com cancelamento e bloqueio;

- P10: discriminador dinâmico com bloqueio;

- P11: discriminador dinâmico com bloqueio e cancelamento;

- P13: junção parcial dinâmica com bloqueio;

- P14: junção parcial dinâmica com bloqueio e cancelamento.

\subsubsection{Construção do PJC}

O Padrão Junção Combinada foi idealizado a partir da aplicação incremental dos conceitos específicos de cada padrão de Aalst. Esta seção apresenta como o PJC pode ser obtido a partir do Padrão Junção Parcial com Bloqueio (WCP-31), acrescido de cancelamento e da possibilidade de adição dinâmica de atividades.

\subsubsection{Junção Parcial com Bloqueio}

Descrito e ilustrado na Seção 4.1.4.2, foi o ponto de partida, dadas as seguintes características:

- Inclui os discriminadores, sendo um caso mais genérico;

- Faz o tratamento de bloqueio. O PJC deve atender ao maior conjunto de cenários possível. Desse modo, optou-se por eliminar a dependência da aplicação quanto à utilização bloqueante;

- Inclui o Padrão Junção Parcial Estática de Múltiplas Instâncias (WCP-34). 


\subsubsection{Cancelamento}

Russell et al [2] descreveram a Junção Parcial com Cancelamento (WCP32) de modo independente da Junção Parcial com Bloqueio (WCP-31), dado seu objetivo de isolamento dos diversos padrões. Aqui, a finalidade é a implementação dos padrões. Por esse motivo, a escolha recaiu na combinação de padrões. Neste ponto, Bloqueio e Cancelamento estão combinados, conforme a Figura 33.

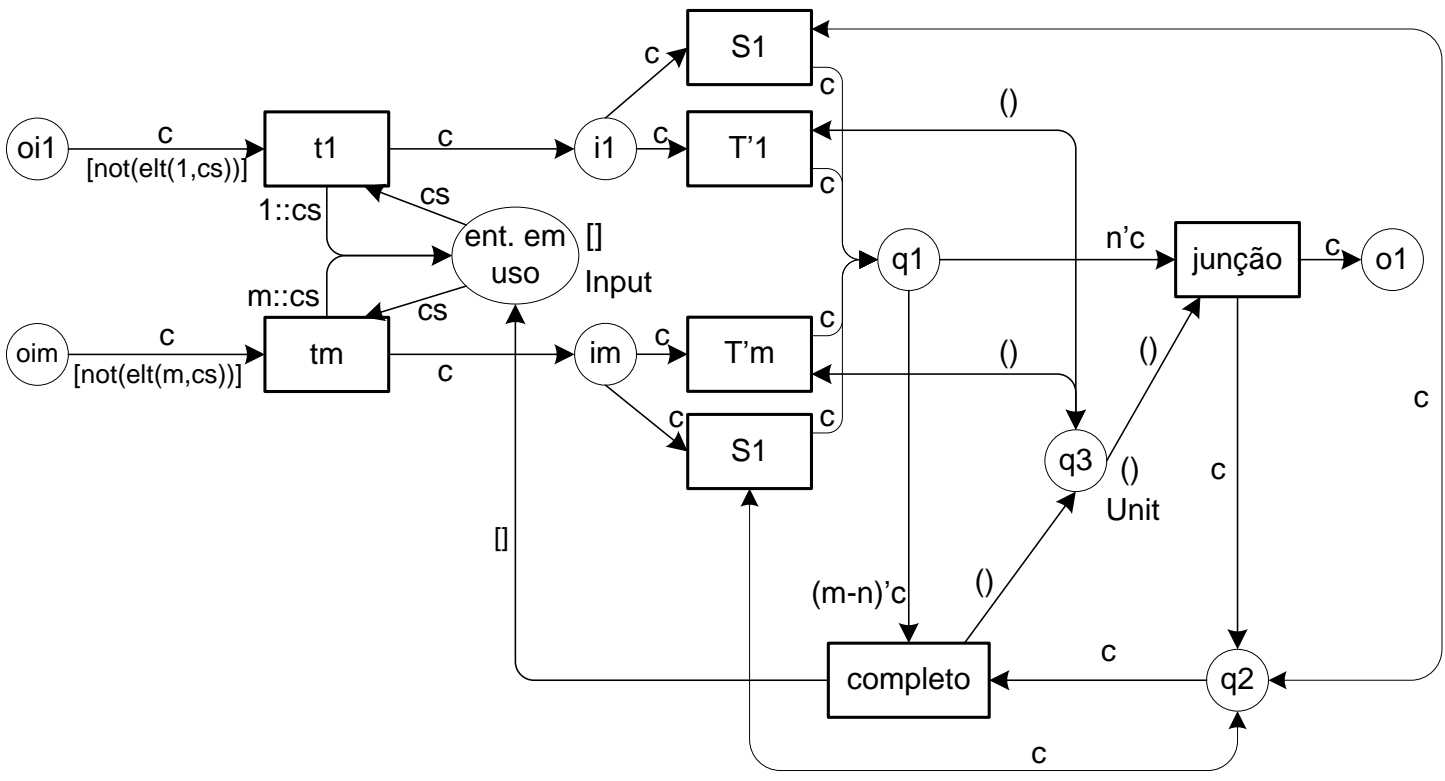

Figura 33: Junção Parcial com Bloqueio e Cancelamento.

Para melhor compreensão desta figura, recomenda-se a análise prévia de cada um dos padrões acima combinados, conforme as seções 4.1.4.2 e 4.1.4.3.

\subsubsection{Adição Dinâmica de Atividades}

Permite o acréscimo de novas atividades antes que as demais tenham sido concluídas, conforme descrito em 4.1.5.3. Ao contrário do que Russell et al [2] previram, aqui é possível criar novas atividades também para o caso de instâncias distintas.

Como exemplo da utilização deste recurso, considere a realização de um conjunto de testes genéticos. Antes que esses testes sejam concluídos, o que pode levar potencialmente semanas, o cientista decide realizar também um novo teste. Isso é possível sem que seja necessário interromper ou esperar a conclusão dos testes em andamento. Existe portanto um aumento na 
flexibilidade desta solução, como alternativa a fluxos previamente conhecidos, o que pode ser útil principalmente em casos de experimentação científica, como no exemplo supracitado.

Com a inclusão da possibilidade de adicionar dinamicamente novas atividades, chega-se à representação completa do padrão, mostrada na Figura 34.

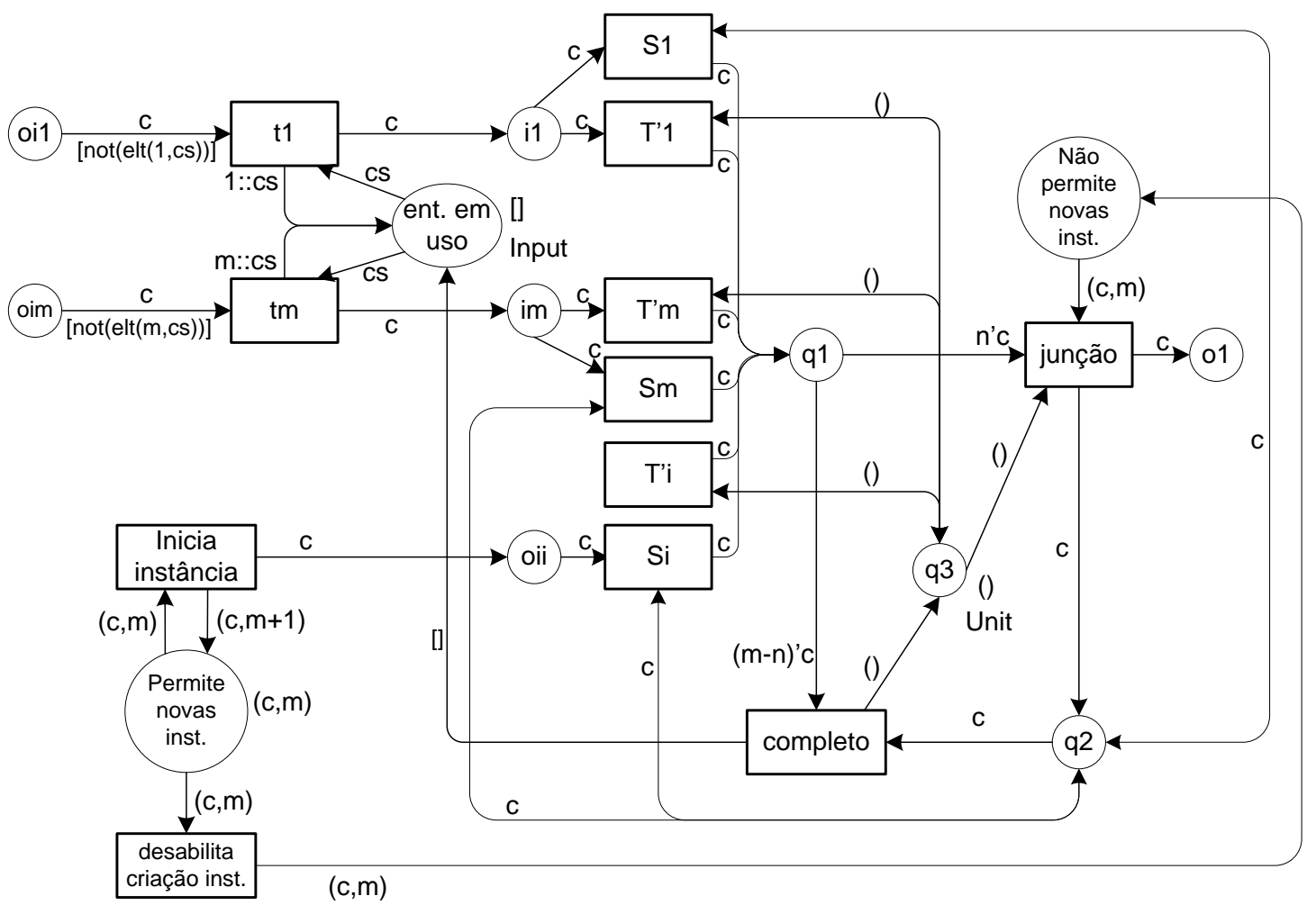

Figura 34: Padrão Junção Combinada

Para melhor compreensão desta figura, recomenda-se a análise prévia da Figura 33 e do Padrão Junção Parcial Dinâmica de Múltiplas Instâncias (WCP36), conforme a seção 4.1.5.3.

Vale ainda notar que a importância desta representação completa refere-se à implementação do PJC. Caso o objetivo seja apenas de compreender 0 padrão, a Figura 32 é suficiente. Para o cientista, que é o usuário do padrão, a simplicidade de representação, como a da Figura 21, é apropriada. 


\subsection{Conclusão}

Cada padrão apresentado nas seções anteriores ilustra um comportamento específico, como bloqueio, cancelamento, número de atividades concluídas para produção de saída, e assim por diante.

O número de padrões considerados, ao serem disponibilizados através da implementação da arquitetura descrita no Capítulo 5 oferecem aos gerenciadores de workflows mais recursos do que possuem isoladamente, principalmente se for considerada execução em grades.

A representação dos padrões em CPN e a apresentação isolada de cada padrão, permitem boa compreensão, sendo didática e clara. Tais características são apropriadas para a modelagem conceitual e lógica dos padrões. Entretanto, do ponto de vista físico, a implementação de cada padrão de modo isolado acrescenta complexidade de manutenção. Isso se deve à redundância de código, dado que os padrões apresentados possuem grande similaridade, como fica claro a partir de uma comparação entre as figuras da seção 4.1.

Para solucionar a questão, foi criado o Padrão Junção Combinada (PJC), uma proposta para a representação e implementação conjunta desses padrões.

No contexto da arquitetura apresentada no Capítulo 5, o PJC exemplifica como a implementação de um padrão se associa aos demais elementos, oferecendo flexibilidade e extensibilidade à solução. 


\section{Capítulo 5}

\section{Uma Arquitetura de Baixo Acoplamento}

Para que uma solução para execução de padrões de workflows em grades seja utilizada no maior número de cenários possível, sua arquitetura deve ser de baixo acoplamento, pois isso confere independência de gerenciadores de workflow e grades à aplicação. A solução, por sua vez, ganha em flexibilidade e extensibilidade.

Esse baixo acoplamento é obtido por meio de interfaces, expostas à aplicação de e-Science, ao gerenciador de workflow e ao gerenciador de grade escolhidos. Isso é feito por meio de serviços web, que "fazem uma ponte" entre a aplicação e sua execução. Esses serviços são dispostos em um middleware com camadas de abstração que permitem o uso dos padrões nos seguintes cenários:

- Em aplicações existentes, com ou sem uso de gerenciadores de workflow, acrescenta a possibilidade de uso de padrões de controle de fluxo para paralelização. Este uso não é inteiramente contido nas principais soluções de workflow analisadas por Russell et al [2];

- Em novas aplicações, oferece a flexibilidade de escolha e substituição dos gerenciadores de workflow e de grade a qualquer tempo, demandando pouco esforço de adaptação através de configurações do middleware;

- A camada que abstrai a presença de gerenciador de grade permite que uma aplicação de e-Science utilize os padrões de workflow em equipamentos multi-processados e posteriormente seja inserida no contexto de grades.

Este capítulo descreve esta arquitetura, concebida portanto com o intuito de garantir a independência entre os principais elementos da solução: a aplicação de e-Science e os gerenciadores de workflow e de grade. 
Cada camada do middleware proposto é detalhada, de modo que seja possível ter uma visão abrangente da solução.

\subsection{Arquitetura}

Aplicações de e-Science que utilizam as soluções apresentadas no Capítulo 3 caracterizam-se por arquiteturas de alto acoplamento. Tais aplicações incorporam tarefas como o gerenciamento do fluxo de execução e a integração do software de grade. Considerando cada aplicação isoladamente, esse acoplamento apresenta o inconveniente de não permitir a modificação de fluxo independentemente do restante do sistema. No entanto, do ponto de vista de desempenho, esse acoplamento não é prejudicial. Ao se observar conjuntos de aplicações e as plataformas para seu desenvolvimento e execução, esse acoplamento dificulta a utilização de padrões que, nesse caso, precisam ser implementados para cada solução. Por exemplo, Russell et al [2] avaliam quatorze produtos comerciais de workflow, identificando quais oferecem implementações para os padrões de controle de fluxo.

Outra limitação decorrente do acoplamento é a impossibilidade de abstração da presença de grade. Ou uma aplicação é desenvolvida para uso em grade, e para software específico de gerenciamento de grade, ou é desenvolvida para ser executada sem grade. Essa característica faz com que a implementação dos padrões de workflow relacionados a execução paralela seja específica para execução em grade ou sem ela.

A solução de baixo acoplamento idealizada nesta pesquisa e ilustrada na Figura 35, atende a um conjunto mais amplo de cenários. Para tal, a presença de camada de abstração em relação ao gerenciador de workflow utilizado pela aplicação viabiliza a implementação de padrões uma única vez, podendo ser utilizada por vários produtos de workflow. Do mesmo modo, uma camada genérica com provedores específicos de acesso a gerenciadores de grade, torna possível a integração a soluções para grade - e mesmo a execução sem o uso de grade, sendo possível o uso de equipamentos multi-processados, útil para casos envolvendo alto tráfego de dados. 


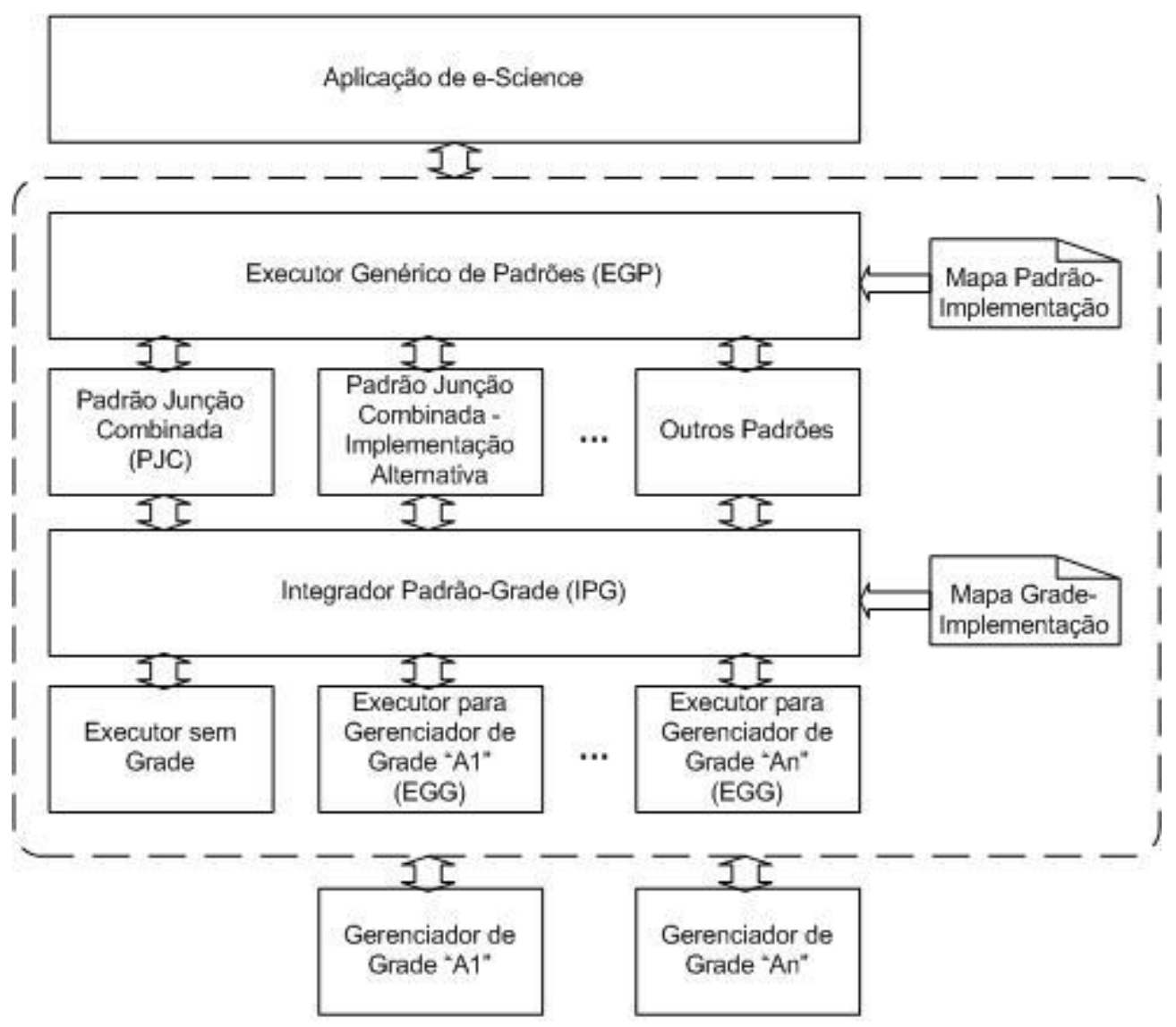

Figura 35: arquitetura da solução proposta. A área delimitada pela região tracejada indica os elementos que compõem o middleware desenvolvido neste trabalho.

Com o objetivo de tornar a solução desacoplada e independente de plataforma, a arquitetura proposta nesta seção, orientada a serviços (SOA) [30], apresenta o uso de camadas, e sua implementação, descrita no Capítulo 6, utiliza serviços web como mecanismo de comunicação entre elas.

\subsubsection{Uso de Múltiplas Camadas}

Os componentes da solução proposta são independentes, de modo a poderem ser substituídos em função da escolha de plataforma e dos gerenciadores de workflow e de grade. Tal independência é obtida a partir de arquitetura em camadas, conforme ilustrado na Figura 35.

As camadas que acrescentam abstrações para garantir a independência supracitada são o Executor Genérico de Padrões (EGP) e o Integrador PadrãoGrade (IPG). Ambos funcionam de modo análogo ao ODBC (Open Database Connectivity) [61], camada de abstração de banco de dados, amplamente utilizada em ambientes de programação. O ODBC é composto por duas camadas: uma genérica, oferecida às aplicações clientes, e outra com drivers específicos para diversos gerenciadores de bancos de dados, como Oracle, SQL 
Server, DB/2, Progress,... O EGP e o IPG são camadas genéricas, que se comunicam com camadas contendo módulos específicos:

- Executor Genérico de Padrões (EGP): abstrai a implementação de um padrão de workflow e também da presença de grade da aplicação de e-Science. Esta deve utilizar uma interface do EGP para submeter um conjunto de tarefas e informar qual padrão deve ser utilizado. O EGP é o responsável por identificar onde se localiza a implementação do padrão, e então encaminhar a requisição àquela. Para tornar o uso do EGP independente de plataforma ou implementação, sua interface é disponibilizada à aplicação de eScience como um serviço web, e as informações a ele enviadas o são no formato XML;

- Integrador Padrão-Grade (IPG): abstrai a presença de gerenciador de grade das implementações dos padrões de workflow. O IPG é uma camada genérica que oferece uma interface independente do gerenciador de grade. A implementação de um determinado padrão, como o PJC, por exemplo, utiliza um serviço web disponibilizado pelo IPG. Este possui as seguintes funcionalidades:

- Encaminhar arquivos a serem utilizados como entrada, a partir da localização indicada pela aplicação cliente até o equipamento onde se encontra o Executor para o Gerenciador de Grade (EGG) a ser utilizado;

- Identificar se um gerenciador de grade deve ser utilizado e, em caso positivo, encaminhar a requisição a ele. Em caso negativo, a requisição é encaminhada a um módulo que executa as atividades em threads, podendo se aproveitar dos recursos de equipamentos multi-processados, se disponíveis;

- Monitorar a execução das atividades na grade ou nas threads. À medida em que estas são concluídas, informar o término à implementação do padrão, para que este proceda conforme sua heurística.

As interfaces entre as camadas são pré-definidas e a comunicação entre elas realizada por meio de serviços web. Desse modo obtém-se independência de plataforma. Vale notar, todavia, que essa independência ainda está sujeita à afinidade de plataforma dos gerenciadores de grade e de workflow.

\subsubsection{Aplicação de e-Science}

Este trabalho se propõe a atender tanto a aplicações existentes quanto a novas aplicações que envolvam workflows científicos contendo tarefas a serem executadas paralelamente, com padrões mais sofisticados, como o PJC. 
Potencialmente, tal execução pode ainda ser realizada em grade, dependendo da presença desta e das seguintes características da aplicação:

- As tarefas devem ser independentes umas das outras: desse modo haverá ausência de comunicação entre os nós. Embora este pressuposto restrinja o universo de problemas que possam ser atendidos, é necessário, uma vez que a comunicação entre os nós depende do software selecionado como gerenciador de grade. Como esta solução foi concebida para uso com diversos gerenciadores de grade, pode ser utilizado algum que não possua tal recurso, como Alchemi [38], por exemplo;

- Aplicação centrada em processamento ao invés de trânsito de dados: a transferência intensa de dados de e/ou para os nós pode onerar o sistema, invalidando os benefícios da utilização de grade. Neste caso, pode ser mais apropriado o uso de computação em cluster, que possui barramento de comunicação de alta velocidade;

- A criticidade da execução nos nós da grade, como garantia de execução e tolerância a falhas, pode exigir controles adicionais do software gerenciador de grade, possivelmente ausentes, como é o caso do Alchemi [38].

Caso haja necessidade de comunicação entre as atividades sendo executadas paralelamente, ou intenso trânsito de dados entre estas, pode-se utilizar implementação específica do "Executor sem Grade", apresentado na Figura 35. Nesse caso, o executor pode fazer a distribuição das atividades entre nós de um cluster de alto desempenho ou com máquinas multi-processadas.

A fim de reduzir o impacto em termos de modificações nas aplicações existentes, as atividades a serem executadas paralelamente com uso do PJC devem ser passadas adiante por meio da utilização de serviços web. Consequentemente, aumenta-se também o número de aplicações que podem ser atendidas por esta proposta, que se torna independente de plataforma de desenvolvimento e execução, do ponto de vista da aplicação.

\subsubsection{Gerenciador de Workflow}

A utilização de construções paralelizáveis avançadas, como o PJC, e a execução em grade, aplicam-se a porções específicas dentro do fluxo de uma aplicação de e-Science. Assim, ambas podem ser consideradas como otimizações e sofisticações para tais aplicações.

Posto isso, faz-se mister que aplicações existentes continuem funcionando com o mesmo gerenciador de workflow. Esse é o motivo pelo qual a solução proposta deve ser independente do gerenciador escolhido.

Para eliminar qualquer possível dependência de gerenciador ou plataforma, as construções implementadas, como é o caso do PJC, devem sê-lo utilizando padrões abertos. 
Cada construção paralela deve ser acionada a partir da aplicação de eScience como um serviço web, de modo isolado do restante da aplicação. Após o retorno da execução paralela, o fluxo segue para a próxima atividade do workflow.

\subsubsection{Gerenciador de Grade}

A arquitetura proposta, orientada a serviços, garante autonomia às partes da solução. Desse modo, é possível utilizá-la com ou sem a presença de grade, atendendo a cenários diversos:

- Execução paralela de atividades sem a presença de gerenciador de workflow: a aplicação pode submeter um conjunto de atividades para execução paralela. Esse caso é tratado como um workflow com uma única construção paralela;

- Aumento das opções de paralelização em workflows: a extensão dos recursos de workflow, com o uso dos padrões com construções paralelizáveis avançadas, pode não demandar o uso de software gerenciador de grade. Nesse caso, o modelo de paralelização baseado em threads de execução é apropriado;

- Aumento de desempenho de porções paralelizáveis da solução: pode ser necessária a presença de gerenciador de grade, para padrões convencionais de paralelização;

- Aumento das opções de workflow e de desempenho: é a combinação da extensão dos recursos de paralelização em workflows com a presença da grade.

\subsubsection{Elementos Constituintes do Middleware}

A arquitetura da solução proposta define um middleware composto por dois grupos de camadas: EGP/Executores Específicos de Padrões e IPG/Executores para Gerenciadores de Grades.

A presença de dois grupos é importante aqui, pois cada um deles garante a abstração de um elemento diferente na execução, aumentando o grau de desacoplamento, conforme descrito na Seção 5.1.1.

\subsubsection{Executor Genérico de Padrões (EGP)}

Oferece uma interface como serviço web para ser chamada pela aplicação de e-Science, para submissão de atividades e consulta quanto ao seu resultado.

A partir de configuração constante do Mapa Padrão-Implementação, o executor decide qual implementação de padrão deve ser acionada. Então, faz a chamada através de um serviço web. 
Esse modelo de serviços permite a implementação de novos padrões, o que confere extensibilidade à arquitetura. Além disso, novas implementações, potencialmente otimizadas em termos de desempenho ou gerenciabilidade, podem ser acrescidas, o que pode contribuir para o uso desta solução em ambientes de maior criticidade.

O código a seguir ilustra um exemplo de entrada que o EGP recebe da aplicação de e-Science, ao submeter atividades para execução:

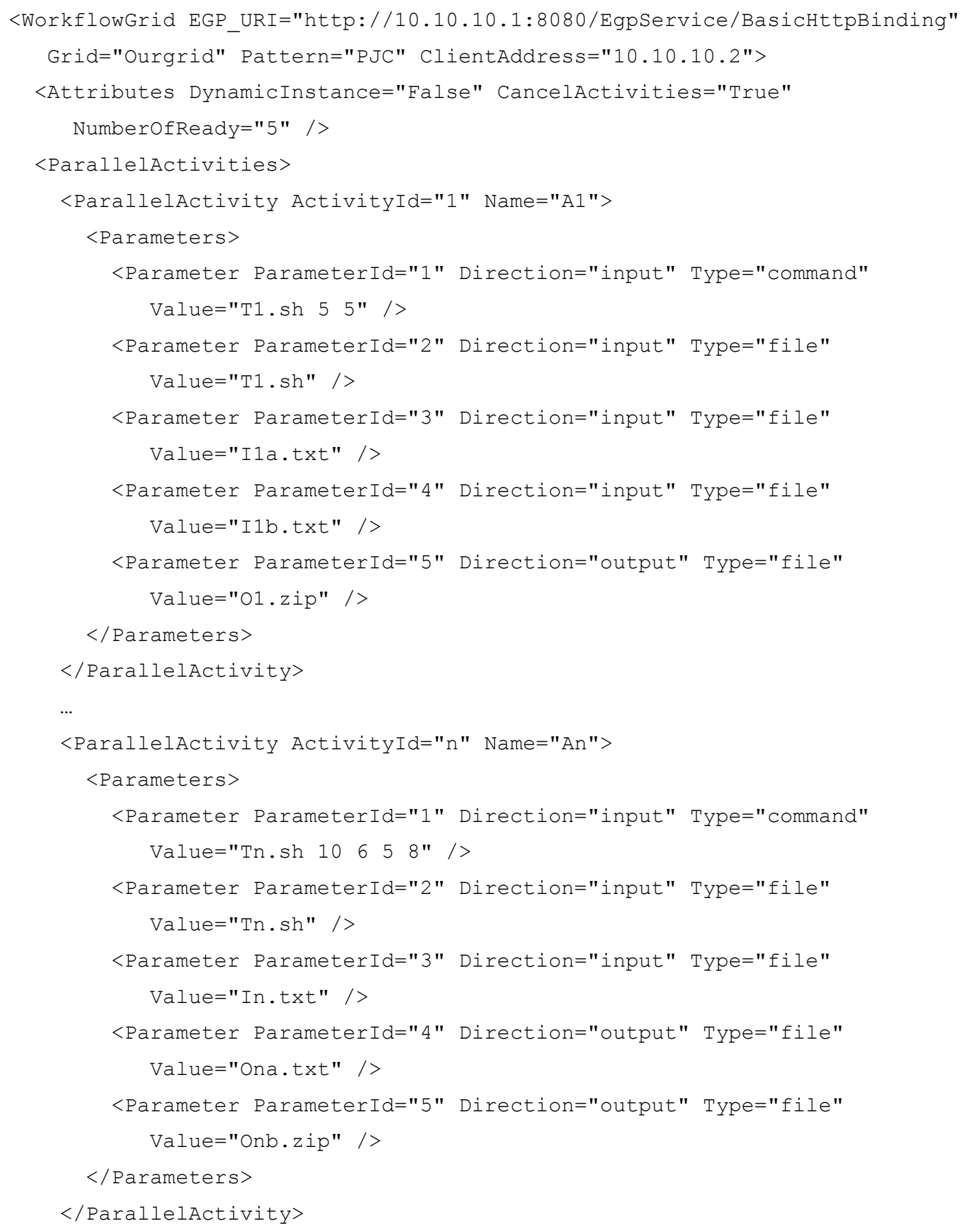


</ParallelActivities $>$

$</$ WorkflowGrid $>$

No exemplo, o elemento WorkflowGrid identifica o uso do EGP com os seguintes atributos:

- EGP_URI: em que se encontra o EGP, que potencialmente pode estar em um equipamento remoto;

- Grid: indica qual gerenciador de grade deve ser utilizado. Para uso em equipamentos multi-processados, sem grade, deve ser utilizado o valor "Gridless";

- Pattern: indica que padrão de controle de fluxo deve ser utilizado;

- ClientAddress: endereço do servidor de arquivos que a aplicação cliente utiliza para armazenar arquivos de entrada e de saída.

Os atributos do padrão indicado em Pattern são identificados no elemento Attributes. Os itens deste elemento, bem como todos os demais elementos desta representação em XML variam conforme o padrão em questão. Os descritos a seguir referem-se ao PJC:

- DynamicInstance (din na Seção 4.2): indica se o padrão aceita a inclusão de novas instâncias;

- NumberOfReady (n na Seção 4.2): indica o número de atividades que precisam ser concluídas para a produção da saída $0_{1}$ (na Seção 4.2), encerrando o uso do PJC;

- CancelActivities (canc na Seção 4.2): indica que procedimento adotar quanto às demais atividades em execução, quando NumberOfReady atividades tenham sido concluídas. Se for "true", cancela tais atividades. Caso contrário, não toma nenhuma medida adicional.

O elemento ParallelActivities é uma coleção de elementos ParallelActivity, cada um representando uma atividade a ser executada paralelamente às demais, com os seguintes atributos:

- ActivityId: identificador para uma atividade. É necessário para que o padrão seja posteriormente informado do término da execução da atividade;

- Name: nome da atividade. É um atributo opcional, que pode ser utilizado pelo usuário para armazenar alguma informação que the seja relevante. 
Cada ParallelActivity contém uma coleção Parameters de parâmetros para a atividade. Cada parâmetro é denotado pelo elemento Parameter, que possui os seguintes atributos:

- ParameterId: identificador do parâmetro;

- Direction: indica se parâmetro é de entrada ou de saída;

- Type: define um parâmetro como sendo um arquivo ou como o comando a ser executado pelo Executor para o Gerenciador de Grade (EGG);

- Value: é o nome do arquivo ou o comando a ser executado.

A combinação dos atributos Direction e Type permite identificar os três tipos de parâmetros existentes: 1) arquivos de entrada; 2) arquivos de saída; 3) comando a ser executado pela atividade.

Com relação ao terceiro tipo, vale a seguinte semântica:

- Uma vez que o comando a ser executado é também um arquivo, este precisa ser enviado para que o EGG possa utilizá-lo. Assim, deve existir um parâmetro com Type="file" e Direction="input", que corresponda a este arquivo. Neste exemplo, isto pode ser observado no segundo parâmetro de cada atividade;

- Para Type="command", o campo Value contém o comando e seus parâmetros no formato de cadeia de caracteres;

- Quando for utilizado o EGG para execução sem grade, descrito na Seção 6.3.6.2, o campo value contém apenas os parâmetros. Nesse caso, a biblioteca contendo a implementação da classe a ser chamada pelo EGG deve ser o primeiro parâmetro com Type="file" e Direction="input".

Para representar múltiplas instâncias de uma mesma atividade, deve haver tantas seções ParallelActivity quanto for o número de instâncias, sendo que estas podem ter arquivos de entrada, saída e parâmetros distintos. Com isso, o PJC permite que sejam executadas diversas atividades, sendo parte delas instâncias de uma mesma atividade.

Com relação à dinâmica deste exemplo, serão executadas paralelamente $\mathrm{n}$ atividades $A_{1}, \ldots, A_{n}$, sendo que o padrão deverá produzir sua saída quando quaisquer cinco tiverem sido completadas. As demais atividades deverão ser notificadas para que possam ser canceladas. O padrão a ser executado é o PJC, no gerenciador de grade Ourgrid.

A aplicação que submeteu o XML para execução recebe um identificador único que deve ser utilizado para posteriormente consultar o resultado. 
A partir do XML acima, o EGP consultará o Mapa Padrão-Implementação, que possui o seguinte formato:

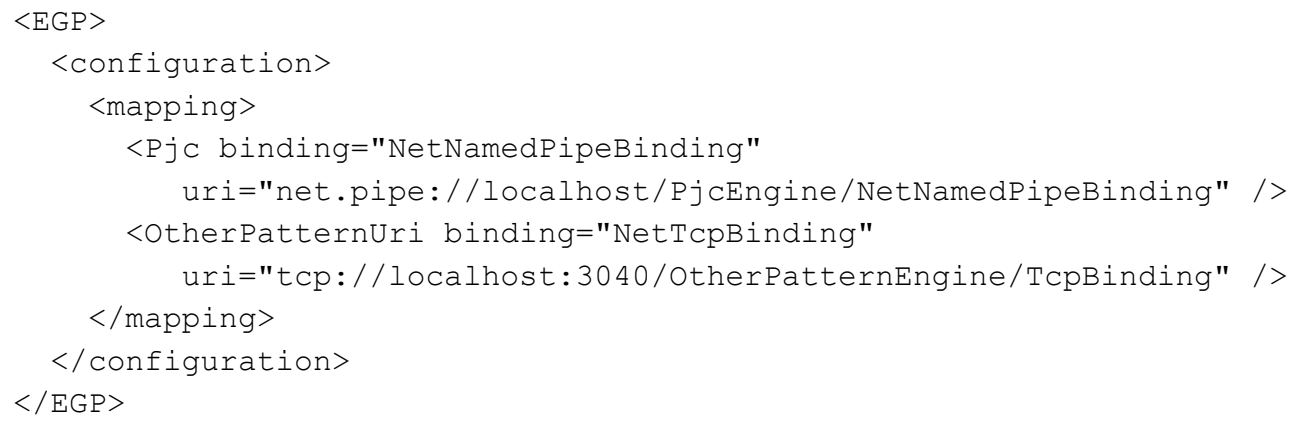

No mapa, o elemento Pjc indica onde se encontra a implementação do PJC. O elemento OtherPatternUri ilustra o local da implementação de algum outro padrão.

O código a seguir ilustra o retorno devolvido pelo EGP à aplicação de eScience, quando esta solicita o resultado, a partir do identificador único devolvido no processo de submissão:

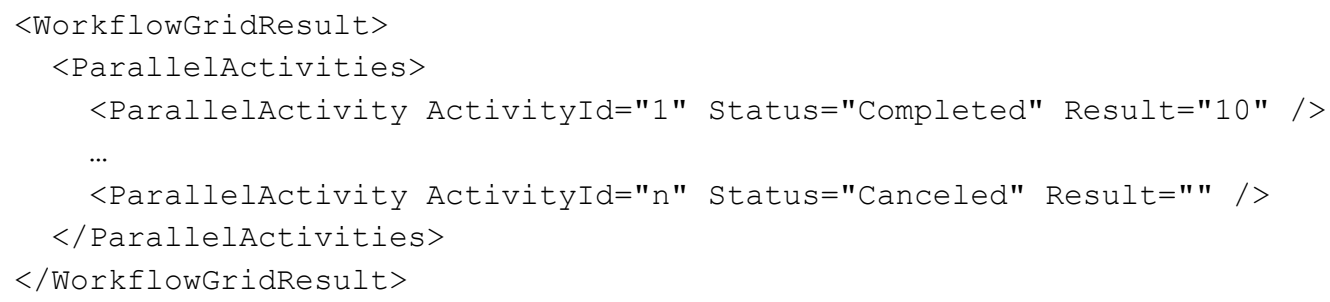

De modo análogo ao da submissão de atividades, o elemento WorkflowGridResult contém uma coleção ParallelActivities. Esta possui um conjunto de elementos ParallelActivity, cada um contendo 0 resultado da execução de uma atividade, denotado pelos seguintes atributos:

- ActivityId: identificador da atividade, de mesmo valor do enviado no XML de submissão;

- Status: indica a situação da atividade, podendo assumir os valores:

- Running: a atividade está sendo executada;

- Completed: execução concluída;

- Canceled: execução cancelada.

- Result: é uma cadeia de caracteres que contém o resultado da execução, que pode ser utilizado para complementar os resultados constantes dos arquivos de saída. 


\subsubsection{Executores Específicos de Padrões (EEP)}

Esta camada contém implementações para os padrões de controle de fluxo. Neste trabalho, contém uma implementação para o PJC, embora tenha sido concebida para que seja estendida de modo a conter outras implementações, seja do PJC ou de outros padrões.

O PJC é implementado aqui sem o uso de um gerenciador de workflow para cuidar do fluxo interno do padrão. Essa decisão foi resultado do balanço dos seguintes fatores:

- O PJC inclui a combinação de diversos padrões cujo fluxo é determinado, e não deve sofrer modificações;

- No início do projeto foi cogitado o uso do Windows Workflow Foundation [19], um gerenciador de workflows disponível como parte da plataforma .NET [26]. Para que pudesse ser empregado, seu escalonador de tarefas, baseado em threads, teria de ser modificado ou substituído;

- O gerenciamento da execução das tarefas é específico e deve ser realizado fora do escopo de um gerenciador de workflow, cujas tarefas de gerenciamento são genéricas. Por exemplo, a análise de cancelamento e a execução das tarefas para esse fim, não se beneficiam da presença de um gerenciador de workflow.

A arquitetura proposta, no entanto, permite que seja realizada implementação do PJC utilizando-se dos recursos que se julgue apropriados, e também permite a inclusão de novos padrões.

O EEP interpreta o XML recebido, e então envia as atividades a serem executadas ao IPG.

Além disso, o EEP deve oferecer uma interface ao IGP, para que este informe o resultado das atividades, à medida que forem sendo concluídas. Desse modo, é possível para o EEP tomar decisões como solicitar ao IPG o cancelamento de atividades, quando NumberOfReady tiverem sido concluídas.

\subsubsection{Integrador Padrão-Grade (IPG)}

Do mesmo modo que o Executor Genérico de Padrões, EGP, este integrador é uma camada genérica. Neste caso, entretanto, abstrai o gerenciador de grade dos Executores Específicos de Padrões, EEPs.

Um EEP envia um conjunto de atividades que devem ser executadas paralelamente, e então pede ao IPG que as execute. 
A partir da informação de que gerenciador de grade utilizar, o IPG consulta - Mapa Grade-Implementação, que contém o endereço do Executor de Gerenciador de Grade. Tal informação está presente no elemento Grid do XML enviado pela aplicação de e-Science, que é repassado até o IPG. O formato do mapa é:

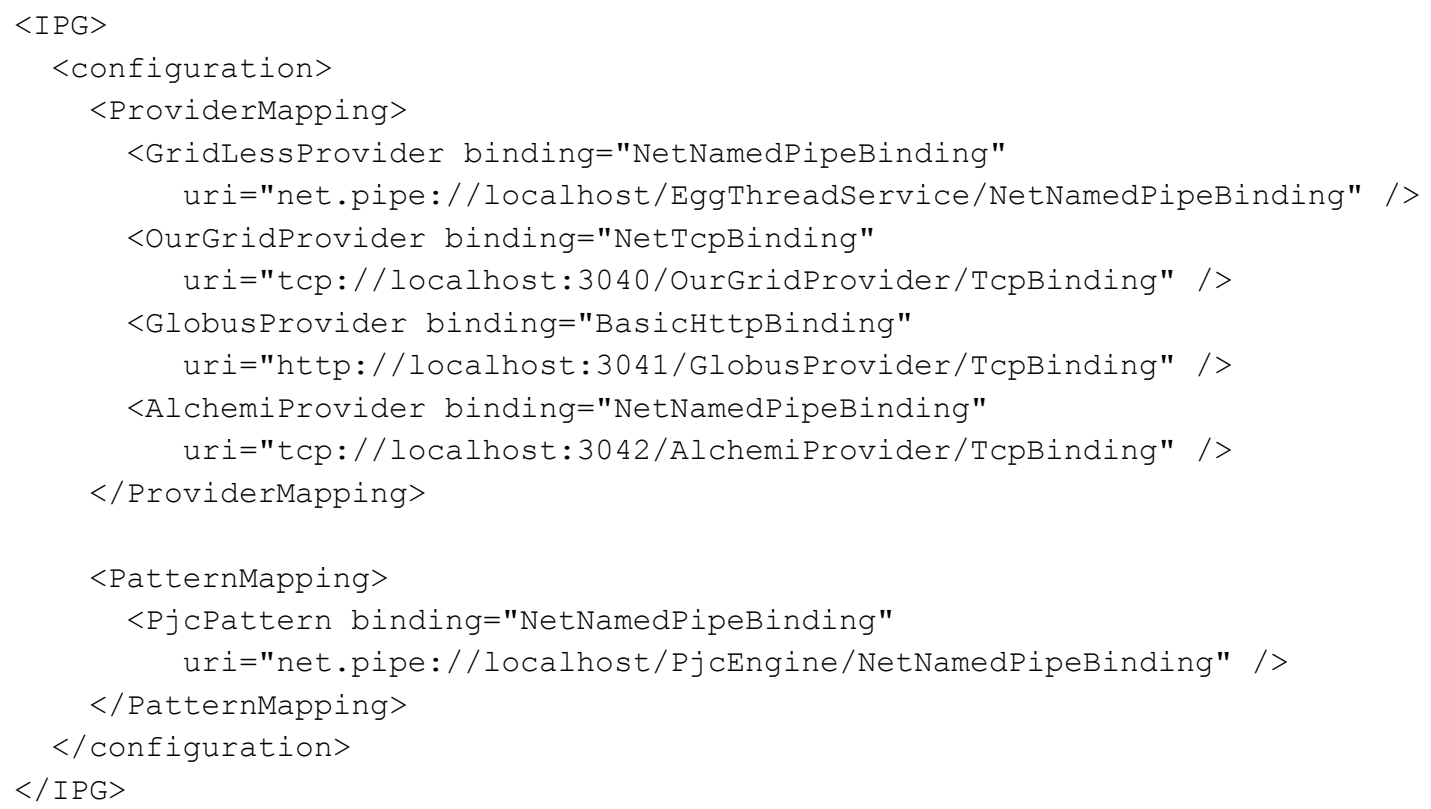

No mapa, o elemento ProviderMapping identifica o endereço de cada gerenciador de grade. O elemento GridLessProvider indica uma implementação que executa as atividades paralelamente sem o uso de grade.

O elemento PatternMapping indica o endereço do EEP, para que o IPG seja capaz de informar o término da execução das atividades. A presença desse elemento permite que a solução seja utilizada em modo assíncrono, particularmente interessante para fluxos com tarefas de longa duração, como dias ou semanas.

\subsubsection{Executores para Gerenciadores de Grades (EGG)}

Para que um gerenciador de grade possa ser integrado ao middleware, basta que ofereça alguma interface para que seja utilizado por meio de programação, como APIs (Application Programming Interfaces) ou serviços web, por exemplo. Esse é o caso de todos os gerenciadores de grade de propósito geral descritos na Seção 3.2.

No caso do Ourgrid, utilizado nos testes, é oferecida nativamente uma API em Java para comunicação com o gerenciador. Desse modo, o EGG para o 
Ourgrid é um serviço web, desenvolvido em Java, portanto podendo ser utilizado pelo IPG e também capaz de utilizar a API mencionada.

Com isso, aumenta-se o alcance da solução, em termos de gerenciadores de grade que podem ser utilizados.

\subsection{Conclusão}

Além dos cenários de execução descritos na introdução deste capítulo, as atividades sendo paralelamente executadas podem ser de curta ou longa duração. Esse fator é determinante para a escolha do modo de comunicação síncrono ou assíncrono - entre as camadas do middleware e de lá para a aplicação de e-Science e o gerenciador de grade.

No primeiro caso, ou seja, síncrono, cada camada deve esperar o retorno da camada seguinte para então prosseguir, ficando portanto bloqueada durante a execução. Embora de implementação mais simples, esse modo de execução restringe-se a atividades de curta duração. Isso porque um serviço utilizado sincronamente ficaria indisponível até o final de sua execução, sendo impróprio para uso concorrente.

Em cenários com grades, nos quais é comum a execução de atividades que podem durar de minutos a semanas, é indicado o uso de comunicação assíncrona. Nesse caso, o controle de execução pode ser realizado por um ou ambos os modelos a seguir:

- Modelo push: o serviço chamado assincronamente utiliza uma função de retorno (callback) fornecida pela aplicação que o chamou para informar ativamente o término de sua execução;

- Modelo pull: o serviço chamado assincronamente é passivo, oferecendo função para que a aplicação chamadora possa consultar o término da execução.

A comunicação da aplicação de e-Science com o middleware é assíncrona, seguindo o modelo pull. Esta opção foi realizada para reduzir impactos na aplicação cliente. Para o modelo push, a aplicação teria de oferecer uma interface para que o middleware pudesse chamar a função de callback, o que aumentaria a complexidade das modificações a realizar para integrá-los.

Neste capítulo foram descritas as camadas que compõem esta arquitetura de baixo acoplamento, e os principais elementos expostos pelo middleware que implementa esta arquitetura, como arquivos de configuração, entradas e saídas.

No próximo capítulo esta arquitetura é detalhada do ponto de vista da implementação, oferecendo subsídio para a realização de testes para avaliar as hipóteses de desempenho, extensibilidade, independência de plataforma e de baixo acoplamento até aqui apresentadas. 


\section{Capítulo 6}

\section{Considerações sobre a Implementação}

A arquitetura proposta descreve os principais elementos e a comunicação entre eles. Este capítulo apresenta várias decisões realizadas para que o resultado da implementação possa ser:

- Utilizado em ambientes heterogêneos, cenário este comumente encontrado em instalações acadêmicas e comerciais;

- Flexível o suficiente para receber melhorias em módulos específicos, como a substituição do algoritmo usado para a implementação do PJC, sem a necessidade de modificação da solução toda;

- Substituição de elementos como os gerenciadores de workflow e de grade com baixo impacto em termos de mudanças na solução e na aplicação de e-Science;

- Extensível para atender a outros cenários de paralelismo, como por exemplo novos padrões que sejam necessários;

- Extensível para permitir o uso da solução com outros gerenciadores de workflow ou de grade.

\subsection{Ambiente de Desenvolvimento}

Com o objetivo de ilustrar a independência de plataforma de desenvolvimento, os módulos desta solução foram desenvolvidos usando dois conjuntos de ferramentas e linguagens:

- Plataforma .NET: permite a criação de serviços a serem executados sobre o Windows. As ferramentas utilizadas foram: 
- Microsoft Visual Studio 2008 Professional Edition: ambiente de desenvolvimento;

- Código desenvolvido na linguagem Visual C\#, utilizando os seguintes recursos do .NET Framework 3.5 [26]: Windows Communication Foundation (WCF) [62] e Windows Workflow Foundation (WF) [19]. Este último foi utilizado para demonstrar como integrar um gerenciador de workflow à solução;

- O serviço que contém a implementação do PJC utiliza o Microsoft SQL Server 2008 para armazenar o estado da execução, garantindo escalabilidade ao uso do padrão;

- Para acesso a dados e para geração de log de eventos foram utilizados blocos de aplicação da Enterprise Library 4.1 [63].

- Plataforma Java: permite a criação de serviços a serem executados em múltiplas plataformas. Foram desenvolvidos serviços para Windows e Linux. As ferramentas utilizadas foram:

- NetBeans 3.5 [64]: ambiente de desenvolvimento;

- Glassfish v3 [65]: servidor de aplicações, usado para hospedar os serviços desenvolvidos em Java.

- Código desenvolvido na liguagem Java, sobre a JRE 1.6.

\subsection{Uso de Serviços Web - Interoperabilidade}

Com o objetivo de permitir que a solução seja utilizada nos ambientes heterogêneos descritos na seção anterior, optou-se pela disponibilização de interfaces em serviços web.

\subsubsection{Comunicação com Serviços - Endpoints}

A comunicação entre um serviço e seu consumidor é realizada por meio de estruturas denominadas endpoints. Estes oferecem acesso às funcionalidades do serviço, e são constituídos por três elementos: endereço, modo de associação e contrato.

Um endpoint pode ser especificado imperativamente, no código tanto do serviço quanto da aplicação consumidora, ou declarativamente, usando-se arquivos de configuração. Com o objetivo de tornar o uso dos serviços web mais flexível e reduzir o acoplamento, optou-se por este segundo caso. Desse modo, - código do middleware não precisa ser modificado na eventualidade de mudança do endpoint de seus serviços. Por exemplo, pode ser necessário transferir um serviço para ser disponibilizado em outro endereço. Para isso, basta alterar o arquivo de configuração da aplicação que utiliza o serviço. 


\subsubsection{Endereço do Serviço}

É uma URI (Uniform Resource Identifier) que permite localizar o servidor e a porta em que um serviço se encontra. Por exemplo, o Executor Genérico de Padrões (EGP) poderia estar localizado em:

$$
\text { http://www.testesvr.com.br: } 8090 \text { /Egpservice }
$$

\subsubsection{Associação ao Serviço - Bindings}

É um conjunto de configurações que determina como o serviço e a aplicação que o utiliza se comunicam. Dentre as configurações estão: o tipo de protocolo de transporte, como HTTP, TCP ou Named Pipe; o formato de codificação das mensagens, texto ou binário; o mecanismo de segurança das mensagens, como uso de Secure Sockets Layer (SSL) ou segurança SOAP. Os bindings indicam que especificações WS-* [66] devem ser utilizadas, podendo ainda se limitar ao Web Services Basic Profile [67]. A Tabela 3 compara os três tipos de bindings utilizados neste trabalho.

Tabela 3: comparação entre os bindings oferecidos pelos serviços implementados

\begin{tabular}{|l|l|l|l|}
\hline Binding & BasicHttpBinding & WSHttpBinding & NetNamedPipeBinding \\
\hline Interoperabilidade & WS-Basic Profile & WS-* & .NET \\
\hline $\begin{array}{l}\text { Escopo de } \\
\text { Comunicação }\end{array}$ & Entre máquinas & $\begin{array}{l}\text { Entre } \\
\text { máquinas }\end{array}$ & Intra máquina \\
\hline $\begin{array}{l}\text { Formato de } \\
\text { Mensagem }\end{array}$ & Texto & Texto & Binário \\
\hline Segurança & Não & Mensagem & Transporte \\
\hline Desempenho & ++ & $\begin{array}{l}+ \text { (menos } \\
\text { eficiente) }\end{array}$ & +++ (mais eficiente) \\
\hline
\end{tabular}

Os recursos apresentados para cada binding correspondem às suas configurações padrão. Algumas considerações com relação aos bindings:

- NetNamedPipeBinding: é o mais eficiente, otimizado em termos de tamanho e formato de mensagens. Entretanto, restringe-se à comunicação com serviços desenvolvidos com o WCF, portanto específicos para a plataforma Windows. Além disso, permite comunicação apenas dentro de uma mesma máquina. Seu uso neste trabalho permite otimizar a comunicação entre os elementos do middleware que tenham sido desenvolvidos em Visual C\#; 
- BasichttpBinding: menos eficiente do que o anterior, permite a comunicação entre máquinas e entre plataformas. $\mathrm{Na}$ implementação, foi utilizado em dois casos: para comunicação entre a aplicação de e-Science e o middleware; e entre o IPG (desenvolvido em Visual C\#) e o Executor para Ourgrid (desenvolvido em Java). Entretanto, todos os demais serviços desenvolvidos usando Visual C\# também disponibilizam este binding, o que permite a substituição de qualquer serviço por outra implementação, possivelmente realizada em outra plataforma;

- WSHttpBinding: é o menos eficiente dos três, uma vez que o tamanho das mensagens é maior, por incluir elementos de segurança. Todos os serviços desenvolvidos disponibilizam este tipo de binding, para permitir que os serviços sejam usados em cenários com requisitos de segurança.

A seleção por qual binding utilizar é realizada em arquivos de configuração.

\subsubsection{Contrato}

É a interface que o serviço implementa, e que pode ser disponibilizada por este na linguagem WSDL (Web Services Description Language). Trata-se de uma linguagem em formato $\mathrm{XML}$, sendo independente da plataforma de desenvolvimento da aplicação consumidora.

Para acesso ao WSDL de um serviço, adiciona-se o texto "?wsdl" ao final do endereço do serviço. Por exemplo, seja a interface IEgp, disponibilizada pelo EGP conforme definição abaixo, em Visual C\#:

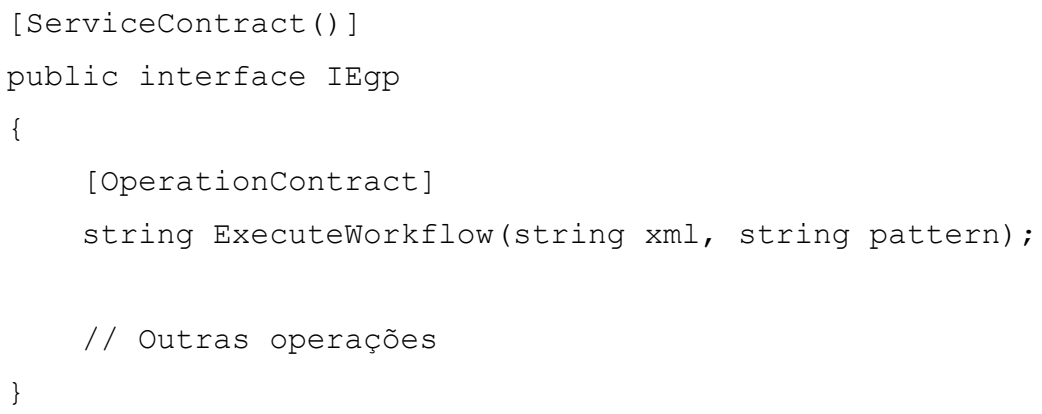

Uma vez disponível como serviço no endereço exemplificado na Seção 6.2.1.1, é possível requisitar o WSDL do EGP utilizando-se o endereço: http://www.testesvr.com.br:8090/EgpService?wsdl. Esta requisição devolve o seguinte resultado, aqui apresentado apenas parcialmente, a fim de simplificar a leitura: 


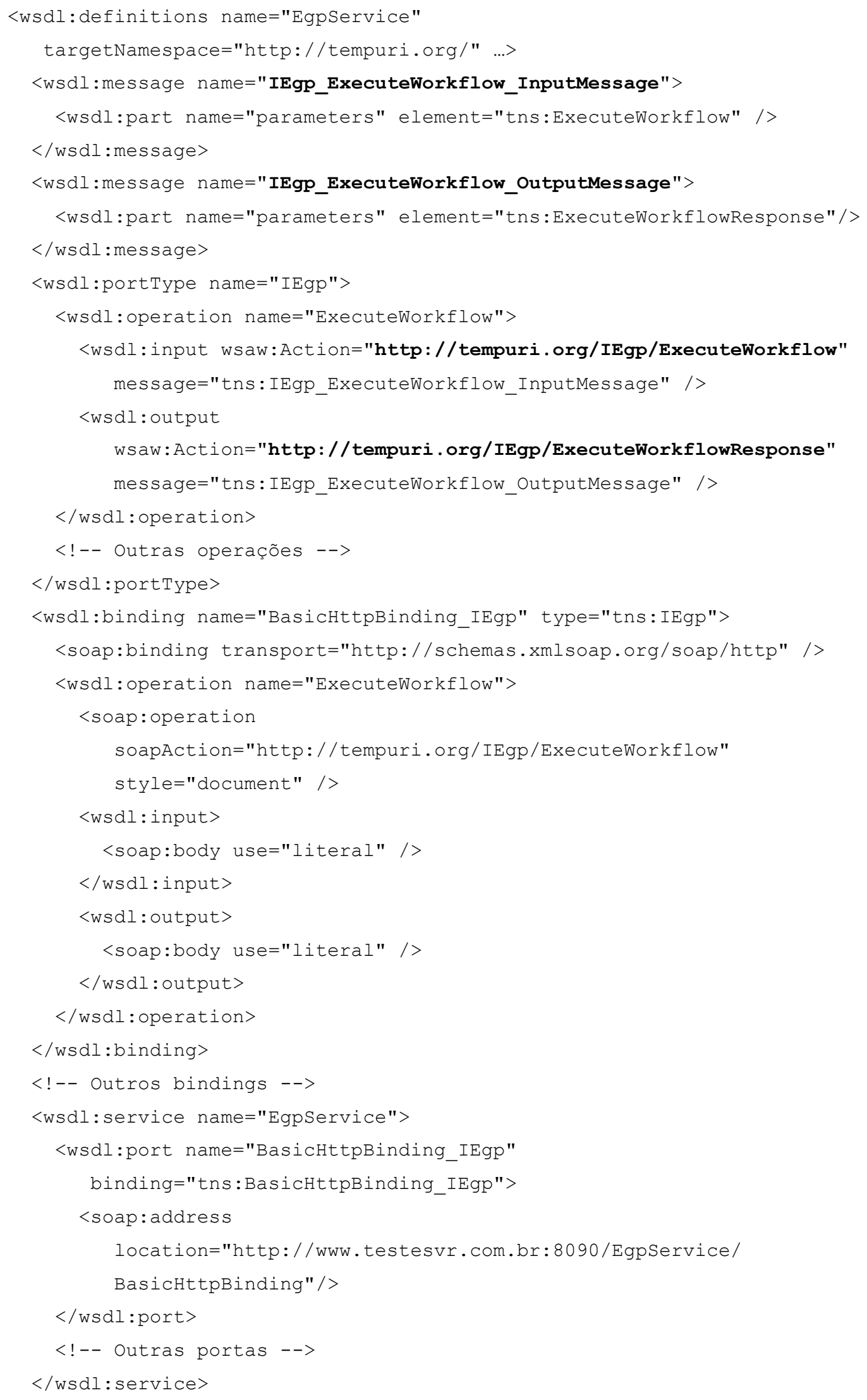


$</$ wsdl:definitions $>$

Os elementos destacados em negrito apresentam as mensagens e
endereços para chamadas das operações. BasicHttpBinding IEGP corresponde à disponibilização da interface IEgp de acordo com o Web Services Basic Profile. Na implementação foram criados outros bindings, omitidos na listagem acima.

\subsubsection{Hospedagem de Serviços Web}

Para que um serviço web tenha seus endpoints ativos, ou seja, prontos para receber requisições das aplicações clientes, é necessário que seja incorporado a alguma aplicação executável. Tal aplicação é denominada hospedeira, e as possibilidades de hospedagem variam dependendo da plataforma. A mais comum é a hospedagem em servidores web, como Apache, Internet Information Server, Tomcat ou Glassfish, por exemplo. A limitação desta forma, entretanto, é o fato de tais servidores web serem capazes de tratar apenas endpoints baseados em HTTP, como o basicHttpBinding ou o wsHttpBinding. Para que seja possível oferecer outros bindings, como o netNamedPipeBinding, existem outras alternativas, como aplicações console ou serviços de ativação, ambos dependentes de plataforma.

Nos testes desta solução foram utilizados:

- Glassfish, para hospedagem do serviço correspondente ao Executor para o Ourgrid, desenvolvido em Java e hospedado em equipamento com Linux;

- Serviço no Windows, para hospedagem os demais serviços, desenvolvidos em Visual $\mathrm{C \#}$ e que, adicionalmente aos bindings baseados em HTTP, oferecem binding baseado em Named Pipes.

A disponibilização em servidores web é realizada ao implantar um serviço web no servidor, e não demanda escrita de código adicional. É o que ocorre no caso do uso do Glassfish. No entanto, para que um serviço Windows ou outro contêiner seja utilizado, seu código deve explicitamente carregar e descarregar tal serviço. O código a seguir foi extraído do serviço Windows descrito acima:

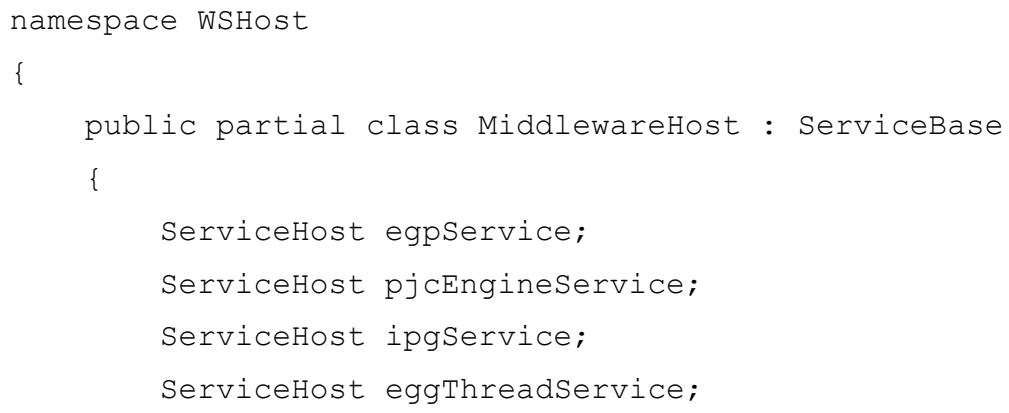




\section{Considerações sobre a Implementação}

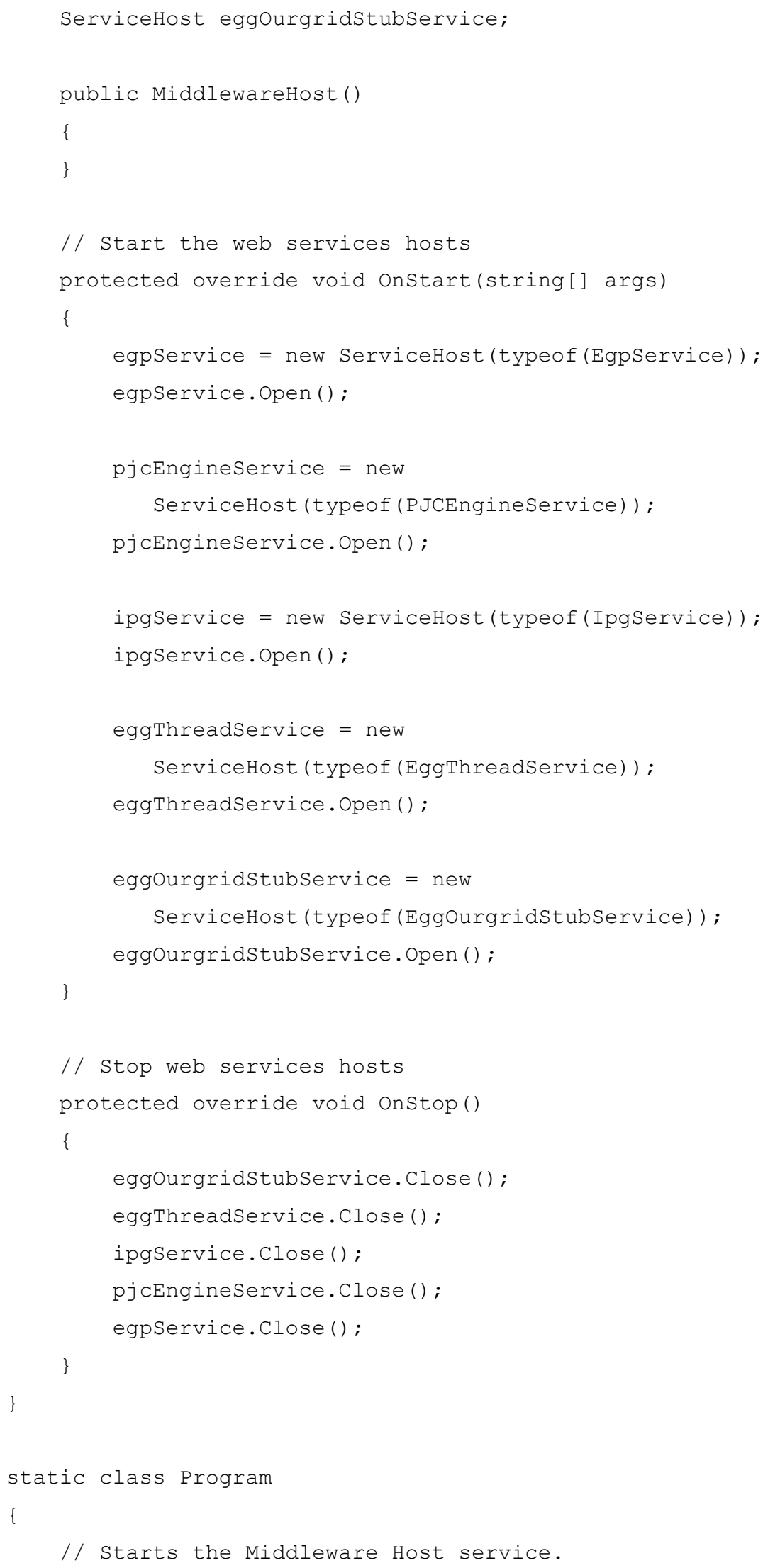




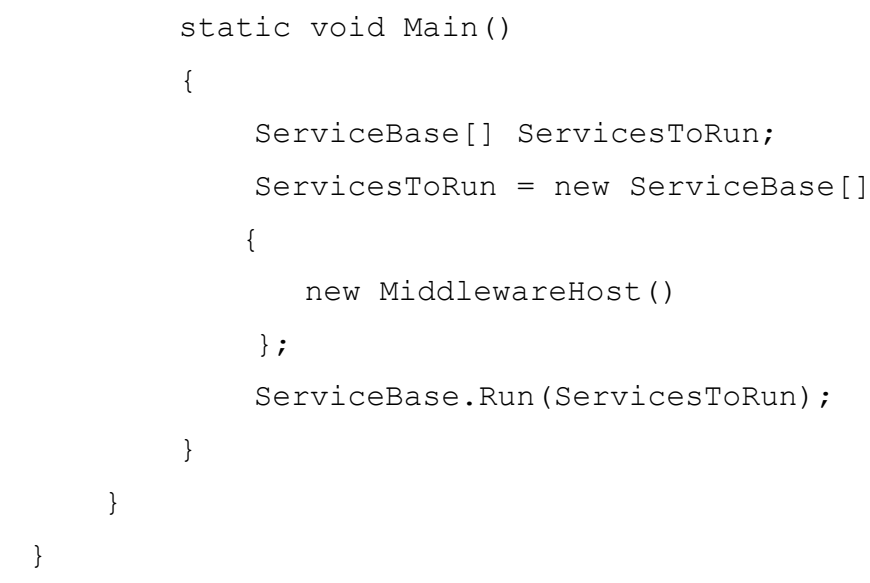

A classe ServiceHost é utilizada para carregar serviços web e disponibilizar seus endpoints. Conforme descrito em 6.2.1, isso pode ser feito imperativamente ou declarativamente. Neste último caso tem-se um menor acoplamento, uma vez que modificações nos endpoints podem ser realizadas sem a necessidade de recompilação da aplicação hospedeira. Para tanto, esta baseia-se na definição em XML dos endpoints dos serviços web.

O código abaixo é parte do arquivo de configuração que a aplicação hospedeira utiliza para carregar os serviços do middleware. Vale notar a disponibilização de dois endpoints, com endereços e bindings distintos. Todavia, o contrato é o mesmo, ou seja, as assinaturas dos métodos e os tipos empregados pelo cliente são os mesmos, independentemente do endpoint utilizado.

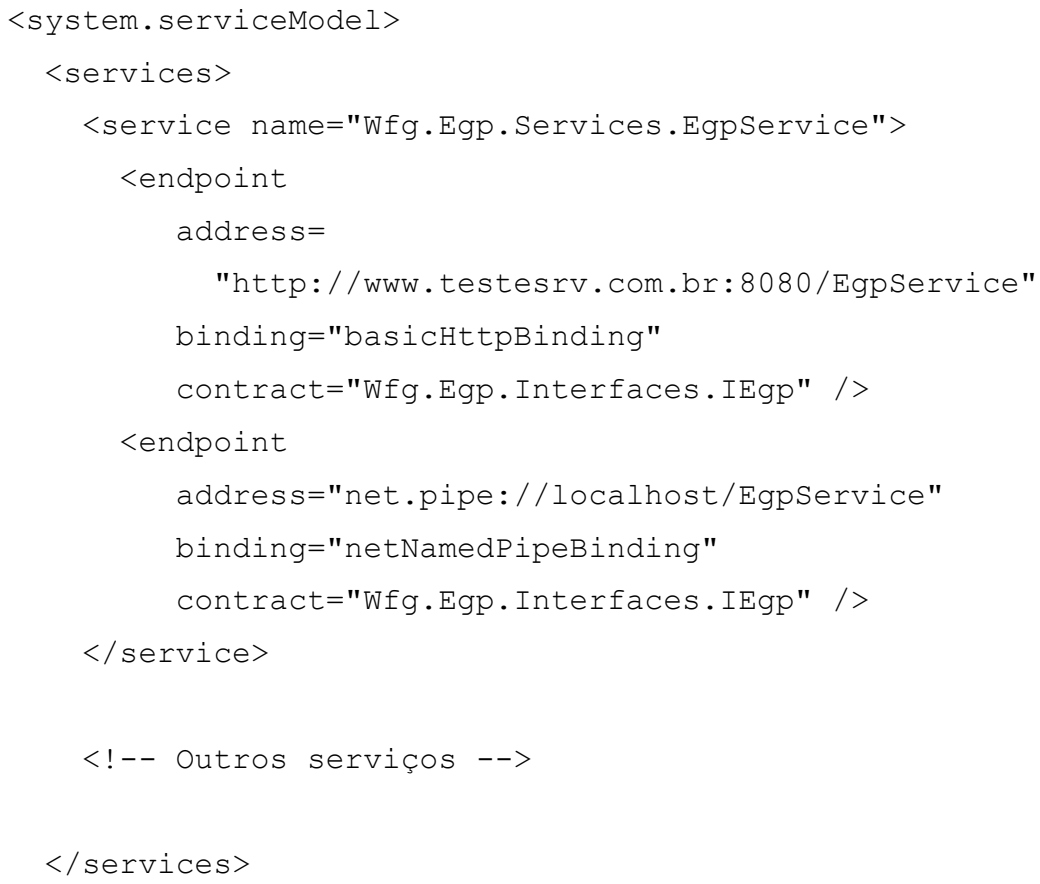




\section{$</$ system.serviceModel>}

O EGP, ilustrado acima, pode ser acessado por uma aplicação cliente que utilize o basicHttpBinding, de modo independente de plataforma de desenvolvimento ou execução. Assim, é possível ter a aplicação cliente desenvolvida em Java, Visual $\mathrm{C \# ,} \mathrm{C}_{++}$ou outra linguagem que dê suporte à utilização de serviços web. Além disso, pode ser executada em Linux, Windows ou outro sistema operacional. Adicionalmente, pode-se reduzir a carga de comunicação entre a aplicação e 0 EGP utilizando-se 0 netNamedPipeBinding. Para isso, é necessário que a aplicação seja desenvolvida em .NET e executada na mesma máquina em que se encontra 0 serviço.

\subsubsection{Proxies e a Utilização de Endpoints}

As operações oferecidas pelos serviços podem ser identificadas em tempo de execução, a partir da definição em WSDL. Entretanto, tal uso é complexo, e não oferece recursos para análise de código em tempo de compilação. Para contornar essas questões, as implementações de serviços web oferecem geradores de código cliente que, a partir do WSDL de um serviço, constroem proxies - classes que encapsulam complexidades das especificações de serviços web.

O código abaixo é parte do proxy gerado pelo Visual Studio, a partir do WSDL do EGP apresentado na Seção 6.2.1.3:

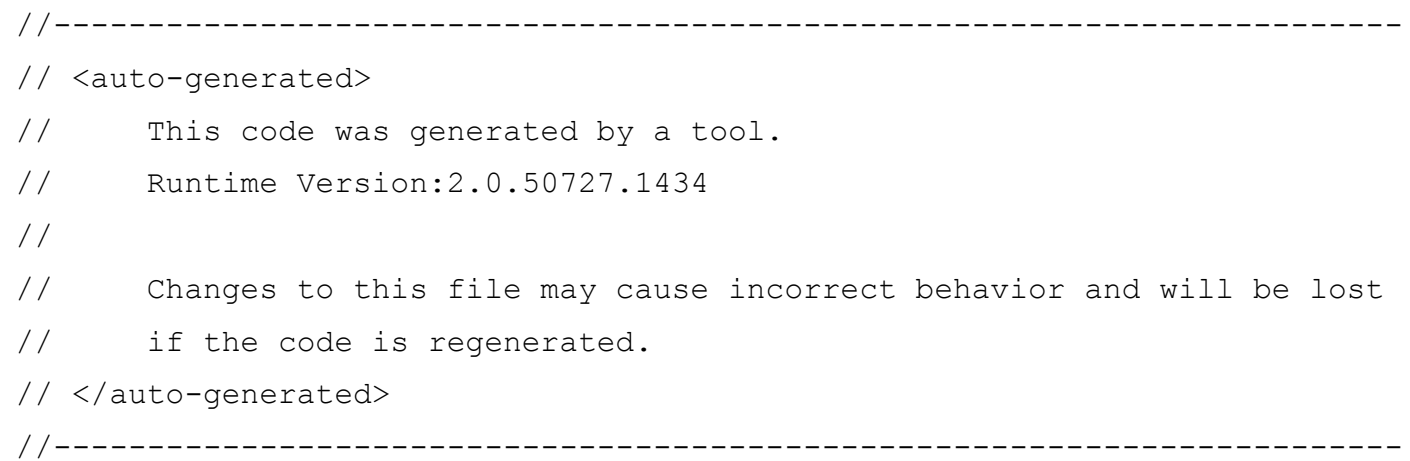

[System.CodeDom. Compiler.GeneratedCodeAttribute ("System.ServiceModel", "3.0.0.0")]

[System.ServiceModel. ServiceContractAttribute (ConfigurationName="IEgp") ]

public interface IEgp

\{ 


\section{Considerações sobre a Implementação}

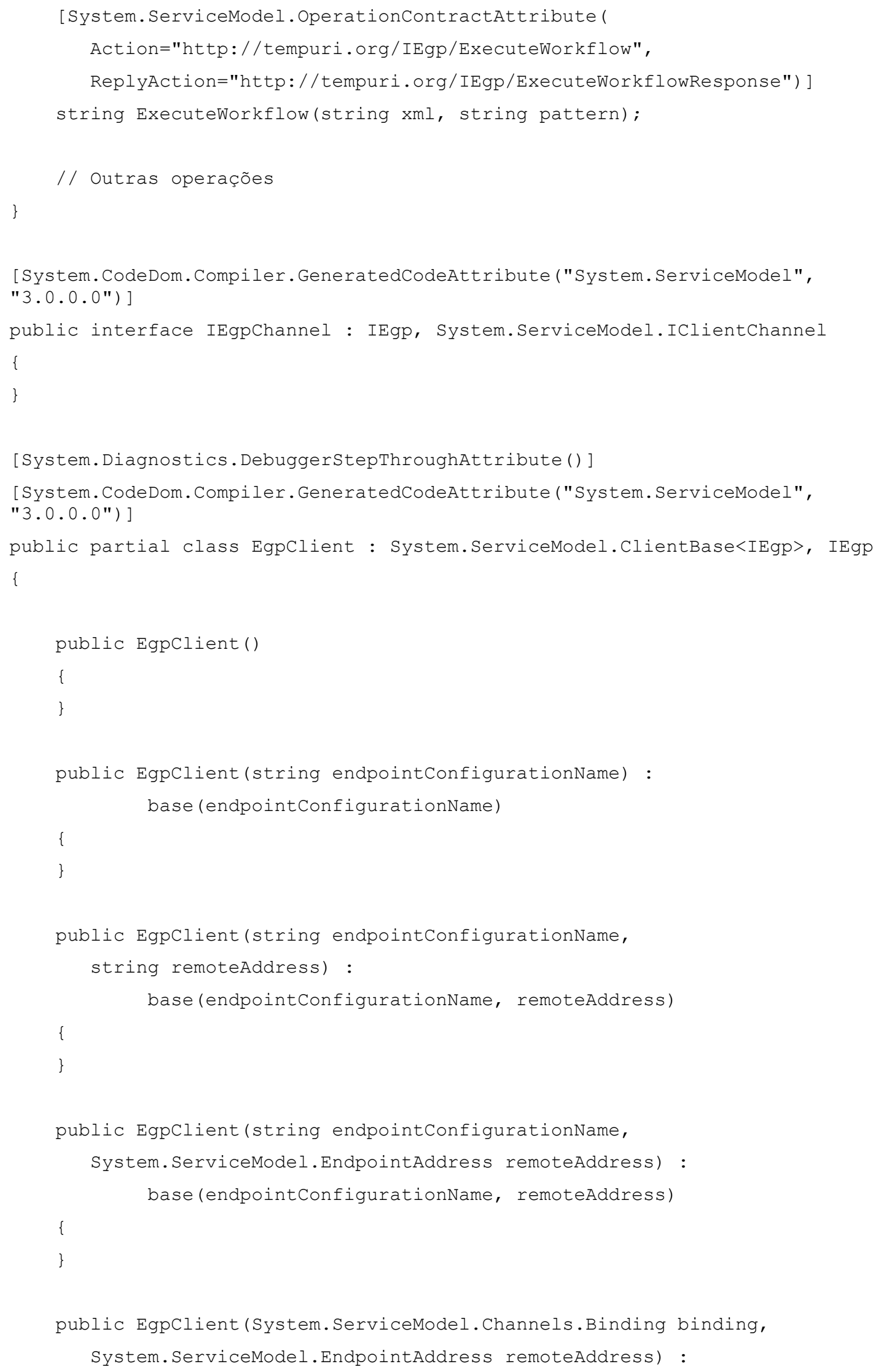


Considerações sobre a Implementação

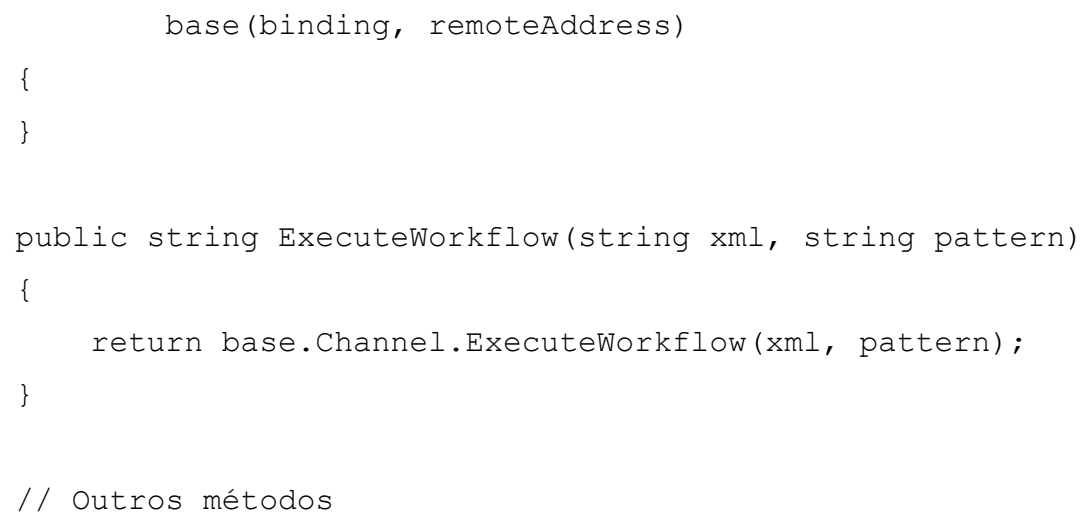

A partir do proxy acima, a aplicação cliente pode utilizar a interface IEGP e a classe EGPClient, sem a necessidade de conhecer os detalhes de comunicação com a infra-estrutura de serviços web, como a presença de canais (channel), por exemplo.

O trecho de código a seguir ilustra como esse proxy pode ser utilizado para instanciar o serviço web e utilizar o método ExecuteWorkflow:

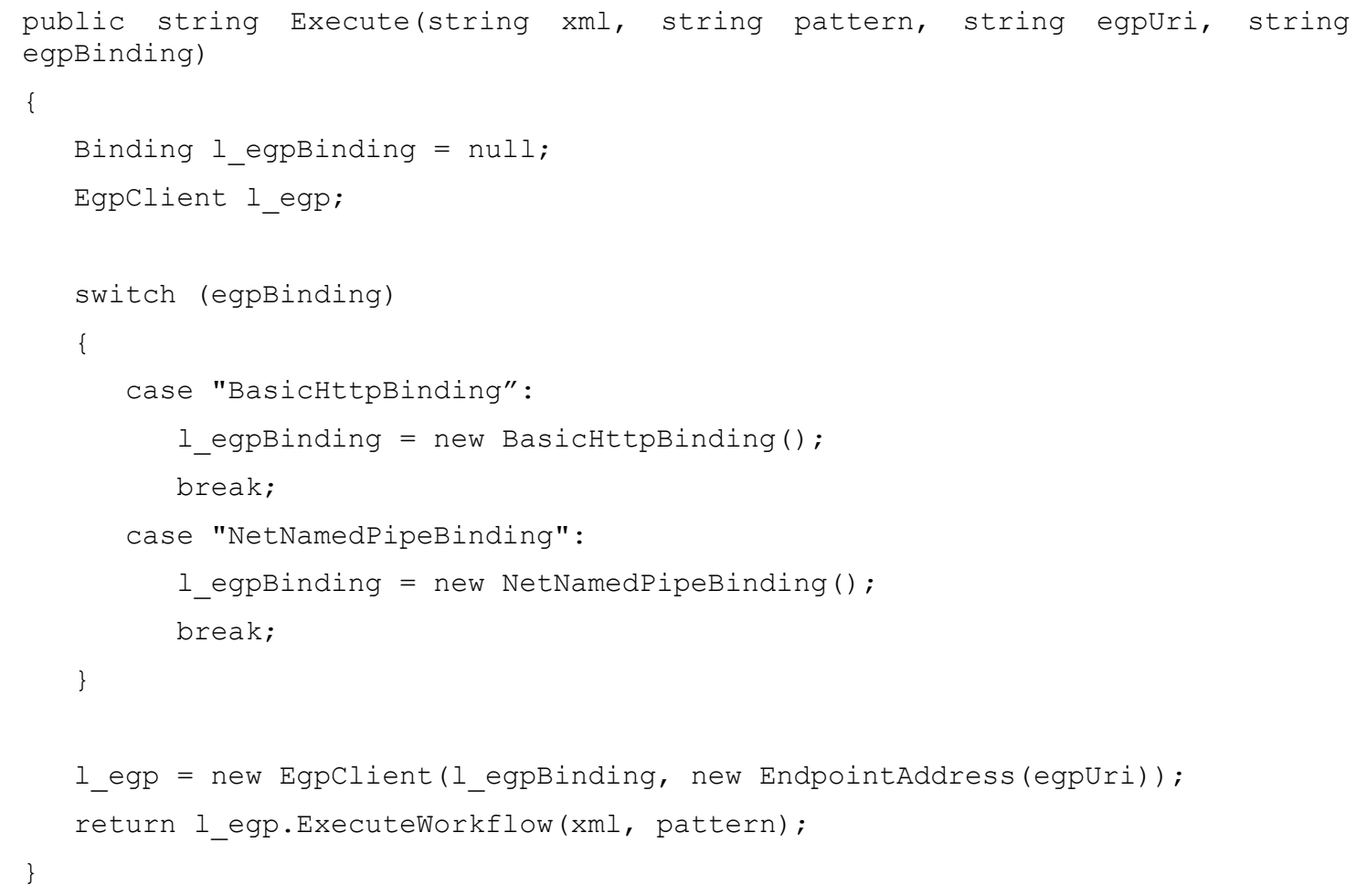




\subsection{Comunicação entre Camadas}

Toda comunicação entre os elementos da solução, desde a aplicação cliente (e-Science) até o Executor para Gerenciador de Grade (EGG) utilizado, é realizada por meio do uso de serviços web, sendo algumas chamadas síncronas e outras assíncronas. O diagrama da Figura 36 ilustra a seqüência de mensagens e chamadas quando do envio de requisição a partir da aplicação, para uso do PJC no Ourgrid. No diagrama foi utilizada a seguinte convenção:

- Flechas com linha cheia $(\longrightarrow)$ : chamada;

- Flechas com linhas tracejadas $(-\rightarrow)$ : retorno;

- Flechas com terminação vazada superior $(\longrightarrow)$ : comunicação assíncrona;

- Reticências (...): indicam uma série de chamadas do mesmo tipo. Por exemplo, diversas chamadas ao método RunJob entre o EGG e - Gerenciador da Grade, para submissão das atividades à grade para execução.

A dinâmica ilustrada na figura é a seguinte:

1. A aplicação utiliza o método ExecuteWorkflow do EGP, que identifica o Executor Específico de Padrão (EEP) a ser utilizado e encaminha a ele a requisição e a representação em XML das atividades a executar, de acordo com o formato descrito na Seção 5.1.5.1;

2. O EEP, neste caso para o PJC, assincronamente utiliza o método Execute do Integrador Padrão-Grade (IPG) para envio das atividades, agora representadas no objeto Job. Além disso, o padrão gera um identificador único para a requisição, que é repassado pelo EGP à aplicação cliente, que pode prosseguir seu fluxo. Desse modo, a implementação realizada para o PJC funciona assincronamente em relação à aplicação cliente, evitando que esta fique bloqueada até o final da execução;

3. No IPG é identificado o Executor para Gerenciador de Grade (EGG) a ser utilizado, e também são realizadas transferências de arquivos de entrada que serão necessários para o processamento da tarefa;

4. O EGG então utiliza método nativo do Gerenciador de Grade empregado, para envio da tarefa a ser executada. Neste exemplo, é o método AddJob, disponibilizado pelo Ourgrid;

5. Assincronamente, O EGG solicita ao Gerenciador de Grade que processe paralelamente as tarefas enviadas. Para o Ourgrid, é o método RunJob; 
6. Quando uma tarefa for concluída, o EGG aciona o IPG, e de lá o EEP, para informar o término da execução da tarefa;

7. O padrão (EEP) prossegue em sua heurística. Para o PJC, é verificado se o número de atividades a ser concluído foi atingido. Em caso positivo, se as demais atividades tiverem que ser canceladas, envia ao IPG essa solicitação, com o método CancelAll, que é repassado até o EEG para o Ourgrid, que então utiliza o método CancelJob.

A qualquer tempo, após receber o identificador da requisição, a aplicação cliente pode utilizar o método IsExecuting (que não consta da figura) do EGP, para questionar se a execução do padrão está concluída. Além disso, o cliente pode solicitar o estado das atividades de um job, utilizando o método GetWorkflowState do EGP, que devolve uma representação em XML, conforme descrito na Seção 5.1.5.1. 


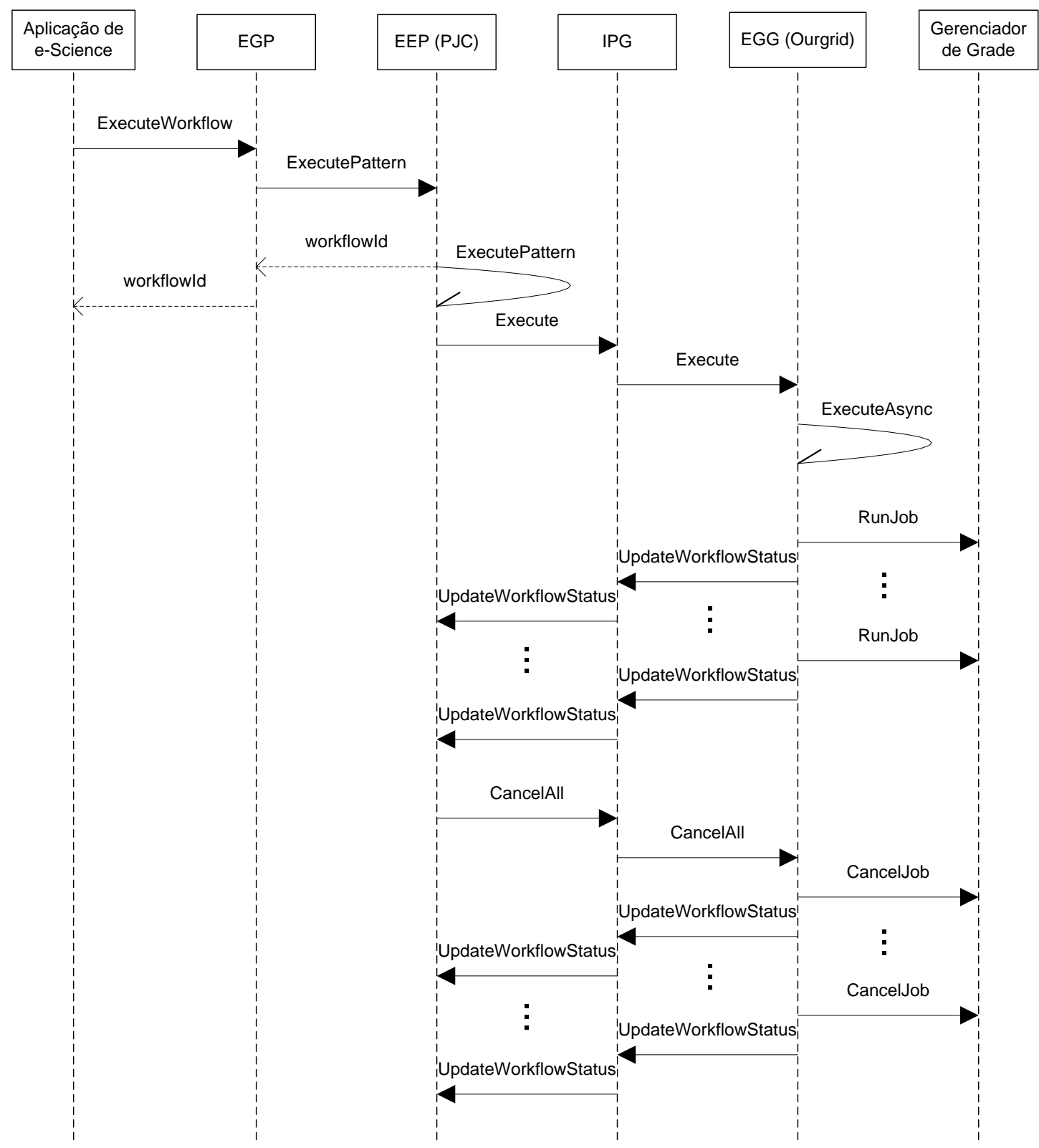

Figura 36: diagrama de seqüência (UML) da requisição de execução do PJC no Ourgrid

As seções a seguir detalham as interfaces de comunicação disponibilizadas em cada serviço.

\subsubsection{Relação entre a Aplicação, o Gerenciador de Workflow e o Gerenciador de Grade}

A relação entre a Aplicação de e-Science, o Gerenciador de Workflow e o Gerenciador de Grade comumente se enquadra em um dentre os seguintes cenários: 
- A aplicação não utiliza Gerenciador de Workflow e utiliza Gerenciador de Grade: neste caso, a aplicação utiliza recursos do Gerenciador de Grade, que podem ser APIs ou serviços web, por exemplo. Desse modo, a aplicação torna-se específica para uso desse gerenciador, dado 0 alto acoplamento entre eles. A substituição ou utilização concomitante com outros gerenciadores é geralmente trabalhosa e complexa, demandando conhecimentos específicos por parte do desenvolvedor da aplicação;

- A aplicação utiliza Gerenciador de Workflow e não utiliza Gerenciador de Grade. Este cenário geralmente se aplica para tornar mais flexível a modificação em fluxos de execução, em que não há necessidade de computação distribuída. Aplica-se também para o caso de paralelismo em equipamentos com múltiplos processadores, se houver necessidade de alto desempenho;

- A aplicação utiliza Gerenciadores de Workflow e de Grade. Este cenário pode ser dividido em dois, dependendo da integração entre os gerenciadores:

- Quando não há integração, ou seja, os gerenciadores são utilizados diretamente pela aplicação. Aqui o acoplamento entre a aplicação e os gerenciadores é o mais alto dentre todos os cenários apresentados;

- Quando há integração. Neste caso, a aplicação utiliza construções de paralelização do gerenciador de workflow e este se comunica com o gerenciador de grade, fazendo a abstração e, portanto, o desacoplamento entre a aplicação e o gerenciador de grade. No entanto, as soluções analisadas neste estudo e descritas no Capítulo 3 apresentam alto acoplamento entre os gerenciadores de workflow e de grades.

Os servicos do middleware, cujas interfaces são descritas nas próximas seções, promovem o desacoplamento desses elementos, permitindo que sejam utilizados em quaisquer dos cenários acima.

\subsubsection{Interface Disponibilizada pelo EGP}

O EGP oferece a interface IEgp, exposta no serviço web EpgService, para receber solicitações de execução de padrões. Essa interface possui três operações, com a seguinte semântica:

- ExecuteWorkflow: recebe a representação em XML do padrão a ser utilizado, conforme esquema definido na Seção 5.1.5.1. Esta operação consulta o arquivo de configuração do EGP e, encaminha a requisição ao EEP correspondente ao padrão informado no atributo Pattern do elemento WorkflowGrid do XML, conforme 
exemplificado na Seção 5.1.5.1. Devolve um identificador para ser utilizado pela aplicação cliente nas demais operações;

- IsExecutingWorkflow: recebe o identificador de uma solicitação de execução de padrão, e devolve um valor booleano que indica o término ou não da execução daquele;

- GetWorkflowState: recebe o identificador de uma solicitação de execução de um padrão, e devolve uma representação em XML da situação das atividades do padrão submetido para execução, conforme esquema definido na Seção 5.1.5.1.

A geração de identificador único pela operação ExecuteWorkflow garante 0 isolamento entre execuções de padrões. Desse modo, resolve-se a questão de interferência entre execuções descrita em 4.1.3.2, com o mesmo resultado, enquanto isolamento, que a solução baseada em bloqueios proposta por Russell et al em [2]. Entretando, uma implementação sem bloqueios permite que 0 padrão seja executado de modo assíncrono, resultando em maior disponibilidade.

\subsubsection{Interface entre o EGP e os EEPs}

O EGP atua como uma ponte genérica entre a aplicação e o EEP do padrão sendo chamado, como o PJC. Para garantir essa generalidade, o EEP deve conter as operações da interface IEepEgp:

- ExecutePattern: recebe do EGP a representação em XML do padrão e o identificador único para posteriores consultas da situação da execução do padrão. Esta operação é assíncrona, e realiza as seguintes tarefas:

- Constrói uma instância da classe Job: uma representação do padrão recebido, descrevendo o conjunto de atividades a serem executadas paralelamente - essa classe é apresentada no Apêndice A;

- Persiste o objeto Job em banco de dados, para ganho de escalabilidade e tolerância a falhas. O modelo de dados e a definição dos procedimentos para acesso a ele são apresentados no Apêndice B;

- Encaminha o objeto Job, sem os elementos específicos do padrão, para o IPG.

- IsExecutingPattern: recebe o identificador de uma solicitação de execução de padrão, consulta o banco de dados e devolve um valor booleano que indica o término ou não da execução do padrão; 
- GetPatternState: recebe o identificador de uma solicitação de execução de um padrão, e devolve uma representação em XML da situação das atividades do padrão submetido para execução, conforme esquema definido na Seção 5.1.5.1.

No caso do PJC, essa interface é oferecida ao EGP no serviço web EepPjcService.

A execução assíncrona segue o modelo pull, reduzindo exigências sobre a aplicação cliente, conforme descrito na Seção 5.2. A importância do comportamento assíncrono ser implementado no EEP, permite que haja EEPs síncronos ou assíncronos, e essa decisão deve ser do EEP. Caso o assincronismo fosse implementado no EGP, todos os padrões possuiriam comportamento assíncrono, restringindo a solução a este cenário.

Quanto à persistência em banco de dados descrita acima, ela é específica do PJC, podendo não existir na implementação de outros EEPs que sejam integrados ao middleware.

\subsubsection{Interfaces entre os EEPs e o IPG}

Os EEPs e o IPG se comunicam em duas vias:

- Ida: quando o EEP utiliza serviços do IPG. Nesse caso, o EEP tem à sua disposição as operações da interface IIpgEep, implementadas pelo IPG e oferecidas no serviço IpgService:

- Execute: para solicitação de execução de um padrão. Recebe uma instância da classe Job. Então providencia o envio dos arquivos de entrada necessários para execução das atividades do job, identifica o Executor para Gerenciador de Grade (EGG) a utilizar, e encaminha a requisição a este;

- CancelAll: identifica o EGG a utilizar e encaminha solicitação para cancelamento de todas as atividades de um job, que não tenham sido concluídas.

- Volta: quando o IPG utiliza serviços do EEP. Nesse caso, o IPG utiliza a seguinte operação da interface IEepIpg, na implementação do EEP, oferecida no serviço web EepPj cService, no caso do PJC:

- UpdatePatternState: recebe o resultado da execução de uma atividade e atualiza o banco de dados. Então, de acordo com a heurística do padrão, decide o próximo passo a realizar. Para o PJC, esse passo pode ser o cancelamento das atividades que não foram concluídas. Nesse caso, o EEP então utiliza a operação CancelAll descrita acima. 


\subsubsection{Interfaces entre o IPG e os EGGs}

Deve haver uma implementação de Executor para cada Gerenciador de Grade (EGG) que se desejar integrar à solução. A seleção deste executor é realizada pelo IPG usando um arquivo de configuração, o Mapa GradeImplementação, conforme descrito e exemplificado na Seção 5.1.5.3. Para que o IPG e o EGG se comuniquem existem duas interfaces, usadas em função da via de comunicação:

- Ida: quando o IPG utiliza serviços do EGG. Nesse caso, o IPG utiliza uma das seguintes operações da interface IEggIpg, oferecidas nesta implementação pelos serviços EggOurgridService (no caso do Ourgrid) e EggThreadService (no caso de não haver gerenciador de grade, em que o atributo Grid do elemento WorkflowGrid possui o valor Gridless, conforme descrito na Seção 5.1.5.1):

- Execute: para solicitação de execução paralela de um conjunto de atividades. Recebe uma instância da classe Job. Então utiliza elementos específicos do gerenciador de grade para proceder à submissão das atividades para a grade - ou então threads, no caso do EggThreadService. Essa submissão é realizada assincronamente. Dependendo do gerenciador de grade escolhido é utilizado o modelo push ou pull para monitorar o término da execução de cada atividade. Para o Ourgrid, é usado o modelo pull. Já o EggThreadService utiliza o modelo push;

- CancelAll: a partir do identificador do job, solicita ao gerenciador da grade o cancelamento de todas as atividades que não tiverem sido concluídas.

- Volta: quando o EGG utiliza serviços do IPG. Nesse caso, o EGG utiliza a seguinte operação da interface I IpgEgg, na implementação do IPG, oferecida no serviço web IpgService:

- UpdateWorkflowstate: chamado pelo EGG para comunicar o resultado da execução de uma atividade, tenha sido ela completada ou cancelada.

\subsubsection{Comunicação entre o EGG e o Gerenciador de Grade}

Cada EGG é responsável por submeter as atividades ao gerenciador de grade e controlar sua execução. No entanto, a submissão das atividades aos nós da grade, bem como o envio e recepção de arquivos de entrada e saída aos 
nós, necessários à execução as atividades, são responsabilidade do gerenciador da grade. Assim, esta solução considera as seguintes responsabilidades:

- O middleware (IPG) é responsável por transferir os arquivos de entrada, de um job do servidor de arquivos onde se encontra a aplicação cliente, ao servidor de arquivos onde se localizam o serviço ou API oferecidos pelo gerenciador de grade e o EGG para este gerenciador;

- O Gerenciador de Grade é responsável por enviar esses arquivos aos nós da grade, onde as atividades serão executadas;

- O Gerenciador de Grade deve transferir os arquivos produzidos pela execução das atividades nos nós da grade para local especificado pelo EGG;

- O IPG então é responsável por repassar os arquivos de saída ao servidor de arquivos onde estiver a aplicação cliente.

Alguns Gerenciadores de Grade possuem construções para execução de fluxos. Entretanto, as implementações pesquisadas, como Prodan em [43], permitem apenas fluxos simples, sem a sofisticação das possibilidades do PJC. Por esse motivo, a solução proposta não utiliza os recursos de workflow que porventura sejam implementados pelos Gerenciadores de Grade.

Como parte desta implementação, foram construídos dois EGGs, descritos a seguir.

\subsubsection{EGG para o Ourgrid}

Este EGG comunica-se com o MyGrid (descrito na Seção 3.2.3) que, por sua vez, é o responsável pela comunicação com os nós da grade. Ao contrário dos demais serviços web, desenvolvidos utilizando Visual C\#, este EGG foi desenvolvido em Java, a fim de permitir a comunicação com o Ourgrid, por meio da utilização de API em Java. A escolha do Ourgrid e a implementação deste EGG possibilitam também demonstrar a interoperabilidade dos serviços desenvolvidos em diferentes plataformas.

Assim como todo EGG, este deve implementar a interface IEggIpg descrita na Seção 6.3.5, a ser disponibilizada ao IPG por intermédio do proxy EggIpgClient, apresentado no Apêndice A, gerado pela ferramenta de desenvolvimento . Todavia, diferentes ferramentas geram implementações diferentes, ou seja, o proxy gerado pelo Visual Studio é diferente do proxy gerado pelo NetBeans. Isso não incorre em maiores preocupações em um cenário de alto acoplamento em que, durante o desenvolvimento da aplicação que utiliza o serviço web, é criada uma referência a este e o proxy é então gerado. Nesse caso, quando outra implementação do serviço for desenvolvida, a aplicação cliente deve ser atualizada para que utilize o novo proxy. 
Entretanto, no cenário de baixo acoplamento aqui proposto, esse processo de desenvolvimento não é apropriado. A inclusão de novos EGGs não pode demandar recompilação do IPG. Assim, o mesmo proxy deve poder ser utilizado pelo IPG para acesso a qualquer EGG. Para solucionar essa questão, foi criada uma implementação de um serviço web na mesma plataforma de desenvolvimento do IPG, e que expõe a interface IEggIpg. Essa implementação, chamada Stub, deve ser fornecida em conjunto com o EGG, e seu único papel é viabilizar a comunicação entre plataformas. A Figura 37 apresenta a relação entre o IPG, o Stub e o EGG.

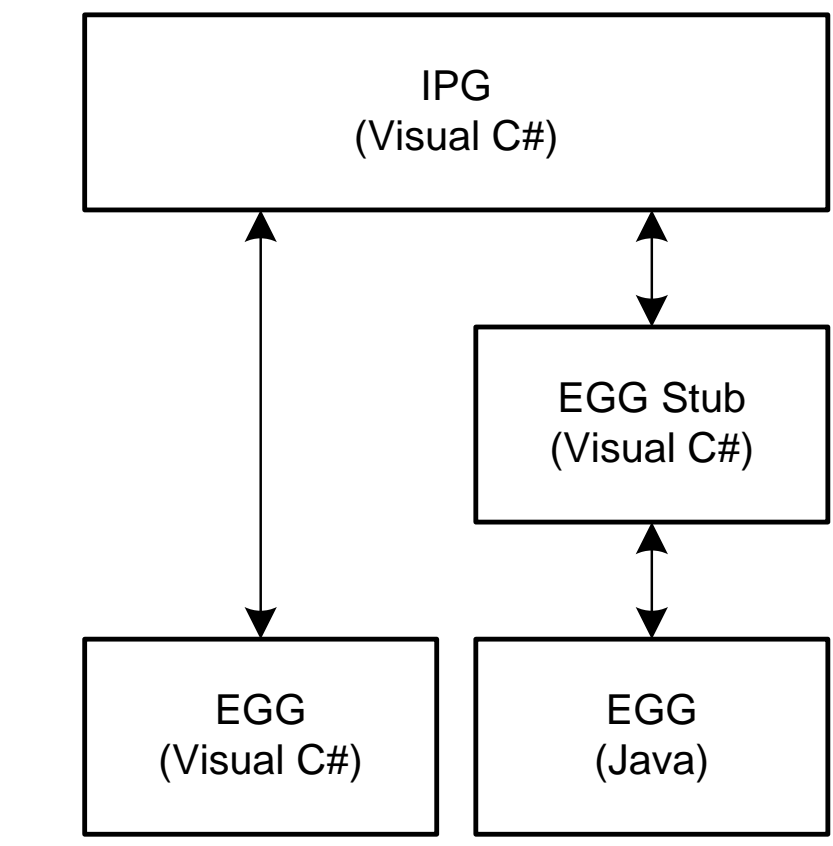

Figura 37: relação entre o IPG, o Stub para EGG e a implementação dos EGGs

Vale notar que, caso o IPG seja substituído por implementação em uma plataforma $X$ (Java, por exemplo), os EGGs desenvolvidos em plataformas diferentes daquela (Visual C\#, COBOL,...) devem ser acessados pelo IPG através de Stubs desenvolvidos na plataforma X.

\subsubsection{EGG para Execução sem Grade}

Este EGG, implementado usando Visual C\#, utiliza threads para executar as atividades de um job. O código para execução de cada atividade deve estar em uma biblioteca de ligação dinâmica (DLL) escrita em Visual C\#, que implemente a interface ITask abaixo: 
Considerações sobre a Implementação

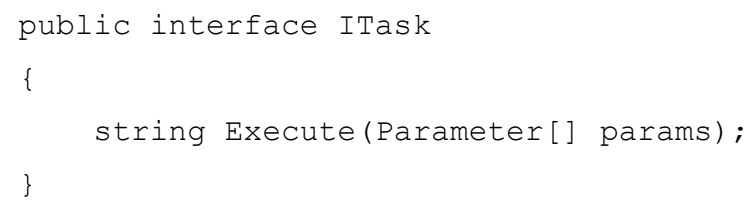

Além disso, para que seja possível a comunicação com o EGG no que diz respeito ao acompanhamento da execução da atividade e para o envio de comando de cancelamento, essa biblioteca deve conter o seguinte código mínimo:

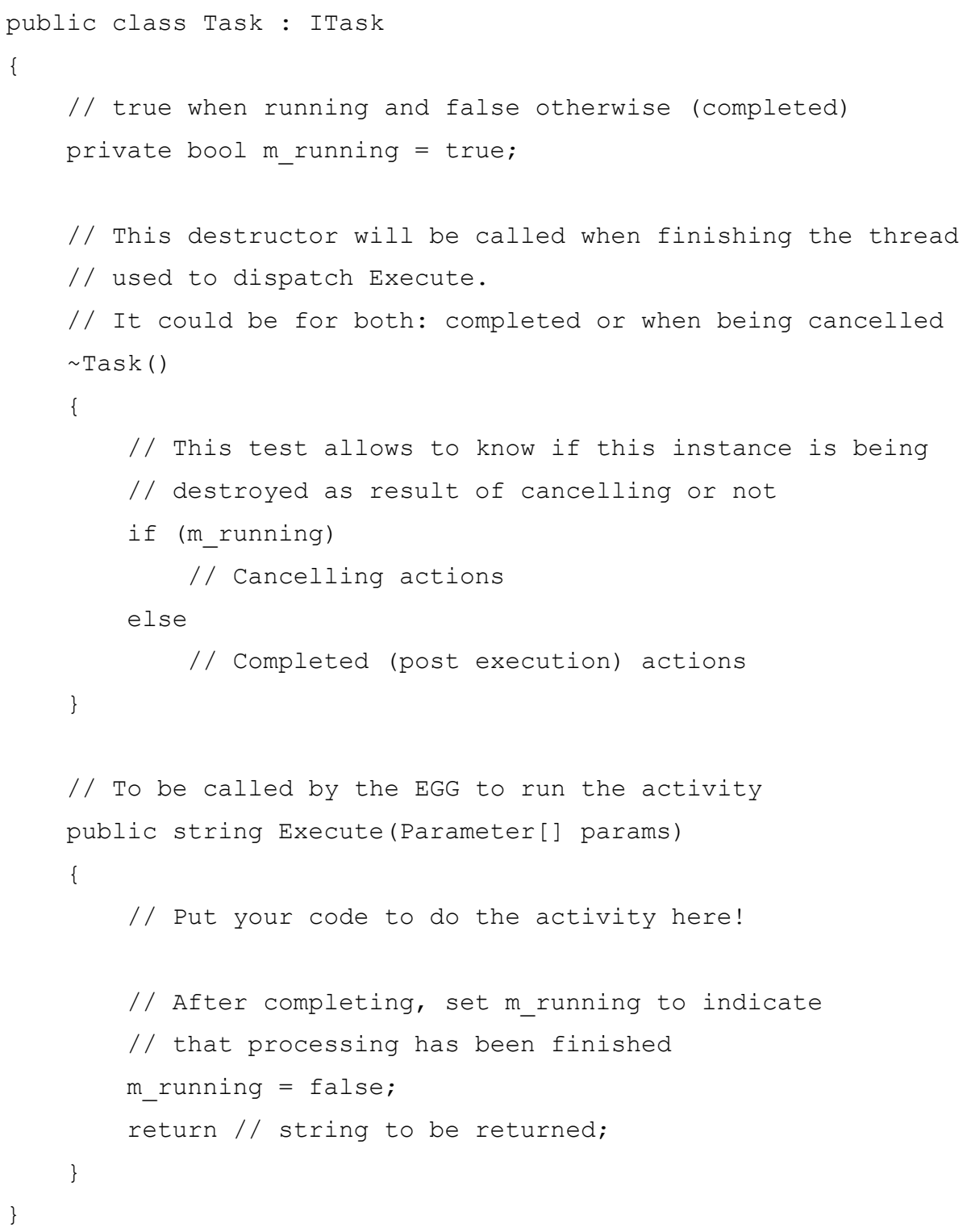


O destrutor da classe Task permite que esta tenha conhecimento de seu eventual cancelamento, útil para execução de ações de desfazimento previstas no PJC, ou outro padrão que envie comando de cancelamento.

O método Execute, por sua vez, é onde deve ser inserido o código a executar. Recebe os parâmetros da atividade em questão, podendo então ler e gravar arquivos de entrada e saída, respectivamente. Opcionalmente, o método pode devolver uma representação em texto do resultado da execução. Este recurso é particularmente útil para a execução paralela de cálculos que devolvam valores simples.

\subsubsection{Desenvolvimento de Outros EGGs}

Com base no código dos dois EGGs anteriores, o desenvolvimento de outros EGGs torna-se uma tarefa que depende do conhecimento dos recursos de cada gerenciador de grade ou tipo de atividade a executar. Por exemplo, é possível o desenvolvimento de outros EGGs que não demandem uso de grade, para serem mais genéricos do que o apresentado na Seção 6.3.6.2, ou ainda para atenderem a necessidades específicas. Alguns cenários em que tais EGGs seriam necessários são:

- EGG para atividades desenvolvidas em Java: deve receber 0 caminho de um arquivo com extensão class ou jar e então o EGG o coloca em execução;

- EGG para atividades que utilizem CORBA: nesse caso, o EGG pode utilizar as configurações de POA mais adequadas antes de acionar 0 objeto ou componente CORBA;

- EGG para execução de atividades em linha de comando: genérico por permitir uma grande variedade de comandos. Entretanto, limitase a execução de comandos que variam em função do sistema operacional em que o EGG é executado.

Cada novo EGG deve fornecer documentação que descreva os cenários em que pode ser utilizado, bem como suas restrições. Por exemplo, um EGG para linha de comando poderia não permitir recepção de comando de cancelamento, o que potencialmente o tornaria incompatível ou, ao menos, limitado, para uso com o PJC.

Os EGGs descritos nas seções anteriores são compatíveis com todas as funcionalidades do PJC.

\subsection{Transferência de Arquivos}

É o mecanismo mais comum e simples para envio e recepção de dados aos nós das grades, utilizados por diversos gerenciadores, conforme pode ser 
observado nos apresentados na Seção 3.2. Por esse motivo, foi escolhido aqui também. Para que o envio de arquivos seja feito de modo seguro e independentemente da aplicação de e-Science ter acesso direto ao servidor onde estiver o Gerenciador da Grade, o middleware assumiu essa tarefa.

O IPG é a camada responsável por esse tratamento de arquivos pois, desse modo, garante-se que nem os EEPs nem os EGGs tenham que conhecer esse processo. Dessa forma, um novo EEP ou um novo EGG não necessitam tratar arquivos. No middleware, acredita-se que essas camadas sejam as que virão a sofrer mais modificações, principalmente com a inclusão de EEPs e EGGs. Já o IPG deve ser modificado apenas para correções de possíveis erros de implementação, para inclusão de tratamento de requisitos não funcionais, como a tolerância a falhas, ou ainda para ser substituído por implementação em outra plataforma, como Java, por exemplo, caso se deseje utilizar o IPG sobre o Linux.

$O$ tratamento de arquivos deve utilizar protocolos abertos, que possuam implementação para os sistemas operacionais sobre os quais os elementos da solução serão executados. Especificamente, aplicação de e-Science, IPG e EGG/Gerenciador de Grade. Por isso, optou-se pelo uso de Secure Shell (SSH) [68] e Secure Copy (SCP). Por construção, o equipamento onde a aplicação de e-Science é executada deve ser o servidor de arquivos de entrada e saída. Do mesmo modo, o EGG deve ser executado no mesmo equipamento do elemento do Gerenciador de Grade utilizado para submissão de atividades (por exemplo, o MyGrid, no caso do Ourgrid).

A Figura 38 ilustra a comunicação entre esses equipamentos.

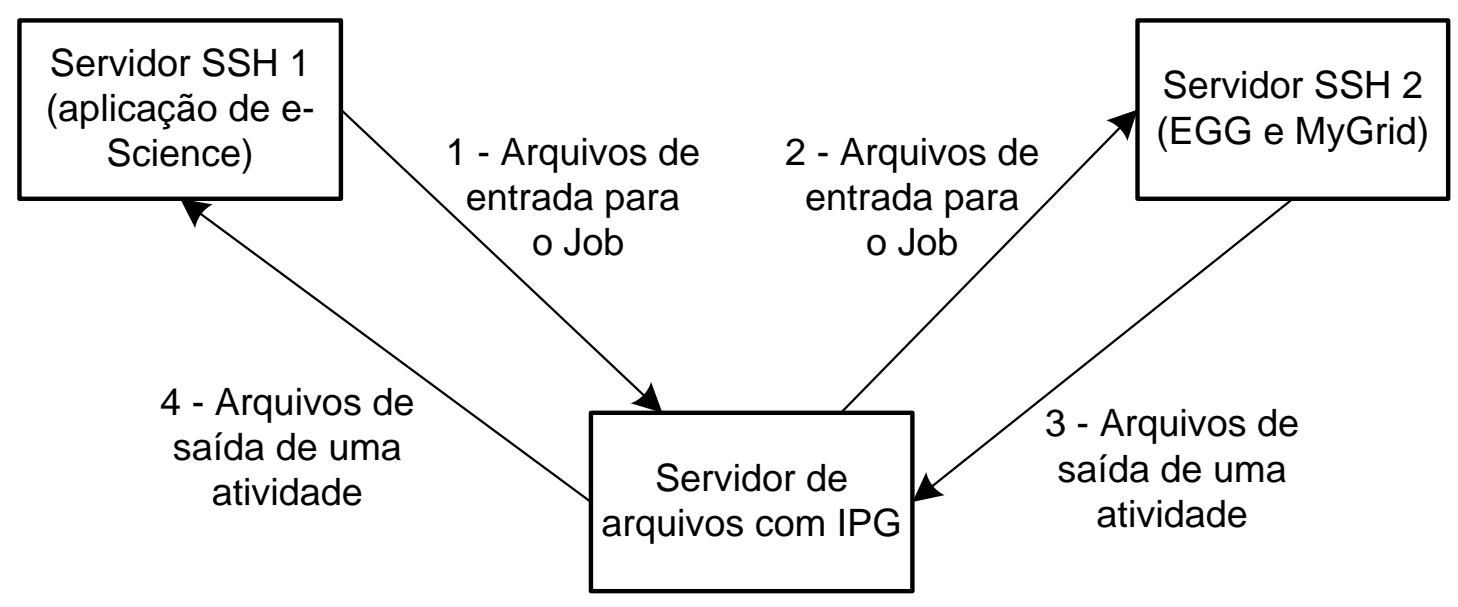

Figura 38: transferência de arquivos entre os servidores

O IPG inicia a conexão SSH para troca de arquivos. Cada servidor de arquivos deve possuir o serviço servidor do $\mathrm{SSH}$. As flechas na figura indicam o fluxo de arquivos, e são realizadas as seguintes operações:

1. Em uma única conexão SSH é enviado um comando de transferência para cada arquivo de entrada; 
2. Em uma única conexão SSH é enviado um único comando para transferir todos os arquivos de entrada;

3. Quando cada atividade for concluída, é aberta uma conexão SSH e é enviado um comando para transferir todos os arquivos de saída de uma única vez;

4. Para cada atividade concluída, é aberta uma conexão SSH e é enviado um comando de transferência para cada arquivo de saída.

Desse modo, é minimizado o número de conexões e comandos para transferência de arquivos, reduzindo o impacto sobre o desempenho da solução, principalmente para quando for utilizado em cenários em que o tempo de execução de atividades for da ordem de segundos, mesma ordem do tempo para estabelecimento de conexão SSH.

Para a implementação e testes, foi usado o OpenSSH [69], tanto no Linux quanto no Windows.

\subsection{Baixo Acoplamento - Extensibilidade e Flexibilidade}

A arquitetura proposta foi implementada utilizando modelo de baixo acoplamento (loose coupling) baseado em serviços web, a fim de garantir maior flexibilidade e extensibilidade à solução.

Uma vez definidas as interfaces de comunicação com os diversos elementos externos, e entre as camadas, conforme apresentado na Seção 6.3, estes podem ser substituídos ou acrescidos resultando baixo impacto no sistema e sua execução. Como exemplos do baixo acoplamento entre as camadas, estão:

- Utilização do EGP para desacoplamento entre a aplicação de eScience e a implementação de padrões (EEPs). Desse modo, a utilização de novos EEPs pela aplicação requer somente a atualização do atributo Pattern no XML enviado ao EGP;

- Do mesmo modo, a utilização de EGGs demanda apenas a atualização do atributo Grid no mesmo XML;

- A inclusão de um novo EEP no middleware, por sua vez, exige atualização no Mapa Padrão-Implementação (Seção 5.1.5.1);

- Analogamente, a inclusão de novo EGG exige atualização no Mapa Grade-Implementação (Seção 5.1.5.3);

- A substituição da implementação de uma camada pode ser realizada sem modificar as demais camadas do middleware, caso o endereço em seus endpoints não seja alterado; ou as modificações nas camadas adjacentes se restringem à atualização desses endereços. 
Por exemplo, pode ser incluído no IPG tratamento específico para transferência de arquivos quando todos os equipamentos envolvidos estiverem na mesma rede local, aumentando significativamente 0 desempenho em relação ao uso de SCP. Isso pode ser feito sem alterações nas camadas adjacentes.

Para atender a um maior número de cenários, resultando em uma solução mais flexível, a arquitetura proposta permite a inclusão ou modificação de elementos do middleware, conforme descrito nos itens acima.

\subsection{Integração a um Gerenciador de Workflow}

Conforme descrito na introdução do Capítulo 5, a aplicação pode ou não utilizar um Gerenciador de Workflow para representar e executar as atividades envolvidas em seus processos. A implementação realizada pode ser aplicada a esses dois cenários.

O primeiro caso, isto é, sem uso de gerenciador de workflow, exige que a representação em XML das atividades a serem executadas paralelamente seja gerada pela aplicação de e-Science e enviada ao EGP. Embora pouco automatizada - o desenvolvedor da aplicação deve, aqui, codificar a criação do $\mathrm{XML}$ - essa tarefa é de baixa complexidade. Esta solução é particularmente indicada quando já houver uma aplicação com interface gráfica para que 0 cientista configure as atividades que deverão ser executadas paralelamente. É o que ocorre com o uso da Load Generation Tool, descrita na Seção 7.1.5 e com o uso do GridSphere, apresentado na Seção 7.1.4.

Já o segundo caso permite a extensão dos padrões oferecidos pelo Gerenciador de Workflow a ser ou sendo utilizado. Para a implementação de aplicações para testes, foi selecionado o Windows Workflow Foundation (WF) [19], um gerenciador de workflows gratuito e extensível. Contudo, vale notar que a solução proposta pode ser integrada a qualquer gerenciador de workflow que esteja em uso, desde que permita a execução de atividades que chamem serviços web.

O WF permite a inclusão de novas atividades, ditas personalizadas. Estas podem ser utilizadas para graficamente representar os elementos a serem executados como parte dos passos em um workflow. Foi, então, desenvolvida uma atividade personalizada, para representar o PJC. Essa atividade é a responsável por criar o XML e por enviá-lo ao EGP.

No tocante à representação gráfica dos padrões, ao invés de utilizar Redes de Petri Coloridas, como Aalst et al [14] e Russell et al [2], o WF utiliza uma variação de workflow graphs, baseado na arquitetura WASA (Workflow-based architecture to support Scientific Applications), descrita por Medeiros [70] como uma solução para aplicações científicas baseadas em workflows e utilizada em 
produtos comerciais como IBM MQSeries Workflow e InConcert. A Figura 39 apresenta a representação de uma máquina de estados simples, composta por três atividades para inicialização, execução e conclusão. Esta aplicação é chamada WorkflowPJC, e foi utilizada para realização de testes funcionais e para testes de integração do middleware a gerenciadores de workflow, descritos no Capítulo 7.

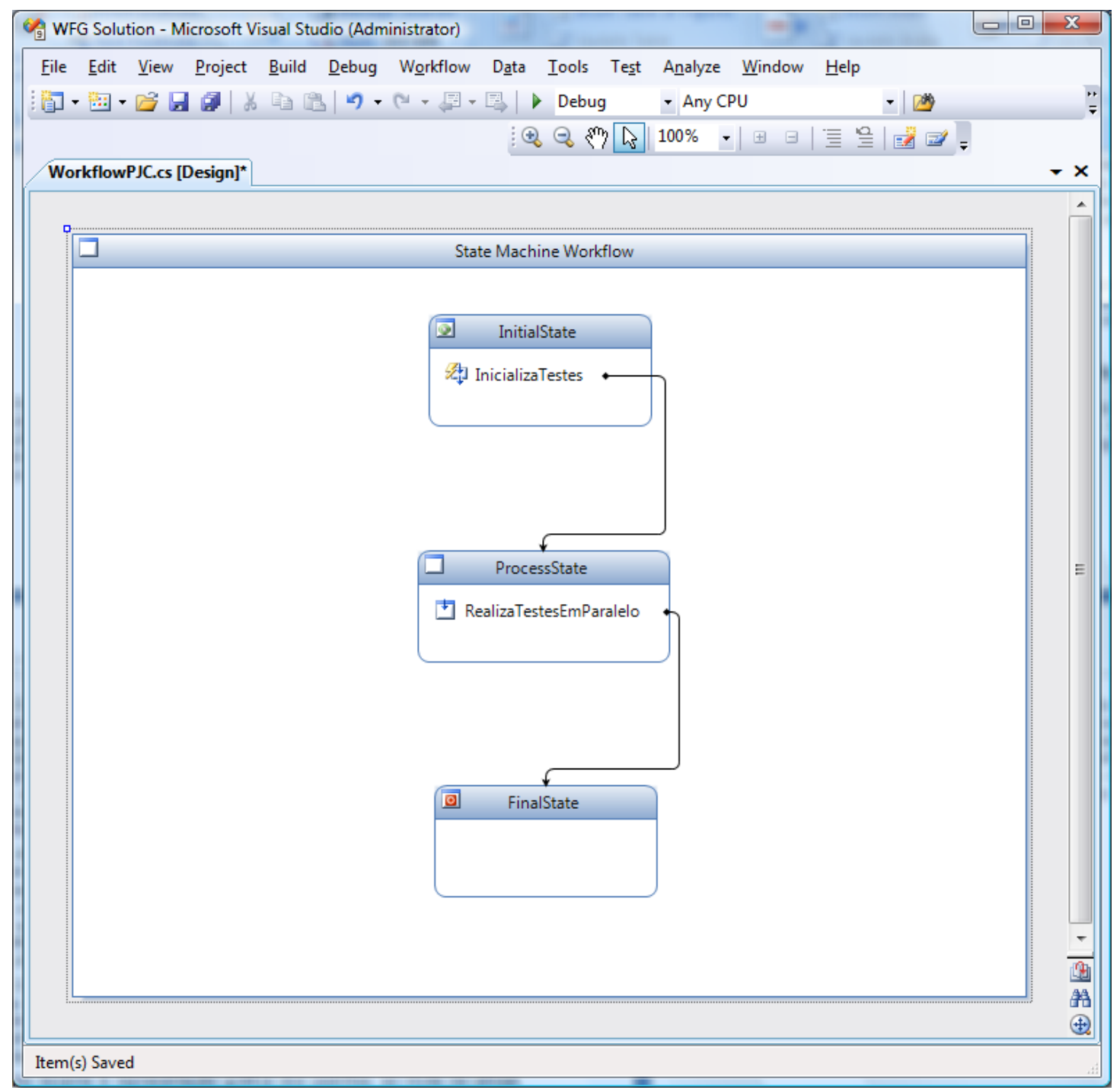

Figura 39: representação de uma máquina de estados simples utilizando workflow graphs com WF

A atividade RealizaTestesEmParalelo utiliza a atividade personalizada PJC, para representação gráfica das atividades a serem executadas paralelamente, ilustrada na Figura 40. O PJC está destacado, e podem ser observadas as propriedades de execução, ao lado direito:

- CancelActivities;

- DynamicInstance; 
- EGP_URI;

- Grid;

- NumberOfReady;

- Pattern.

Essas propriedades correspondem aos atributos da representação em XML, descritos na Seção 5.1.5.1

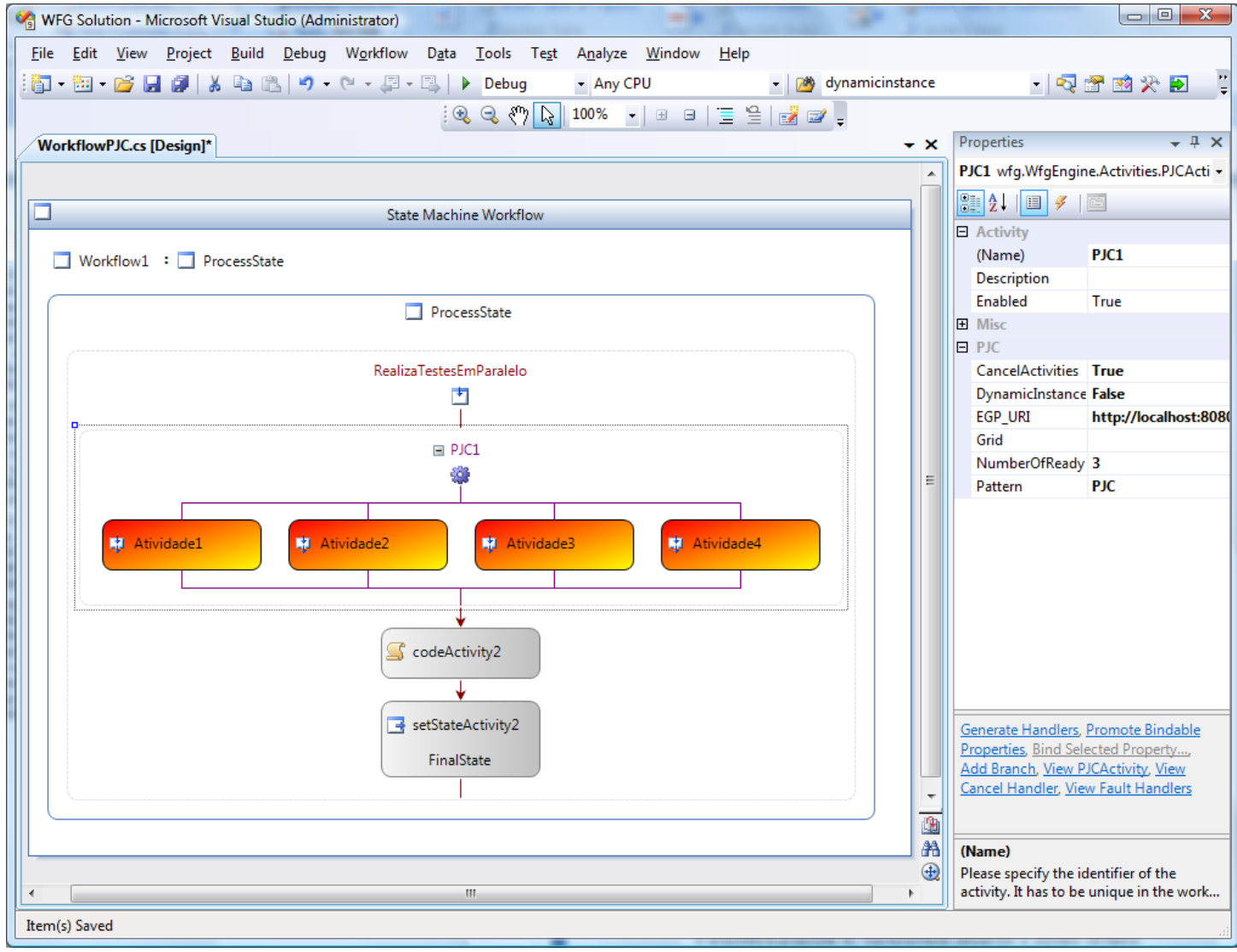

Figura 40: representação do PJC em workflow graphs 


\subsection{Conclusão}

Este capítulo apresentou os elementos implementados, cuja comunicação baseia-se em serviços web. Também descreveu como é realizada a transferência de arquivos, comum em cenários de utilização de gerenciadores de grades.

Durante o desenvolvimento da implementação, esses dois fatores apresentaram-se como os mais relevantes em termos de impacto no desempenho do middleware. Isso deveu-se ao fato da independência de plataforma, obtida pelo trânsito de mensagens que não estejam em formato binário, característica do uso de serviços web, apresentar um custo em termos de desempenho.

Por esse motivo, o próximo capítulo descreve um conjunto de testes que medem o impacto que o uso de serviços web e a transferência de arquivos produzem sobre o desempenho. Além disso, são testadas as funcionalidades da implementação, e outros elementos não funcionais, como extensibilidade, independência de plataforma e baixo acoplamento. 


\section{Capítulo 7}

\section{Testes e Resultados Obtidos}

No intuito de validar a implementação e as hipóteses descritas neste texto, foi realizado um conjunto de testes, que podem ser divididos nos seguintes grupos:

- Testes funcionais, para avaliar o comportamento do middleware quanto à corretude de resultados;

- Testes de desempenho, que visaram avaliar o tempo empregado pelo middleware para comunicação entre as camadas e para a transferência de arquivos. Entretanto, esses testes não pretendem demonstrar ganhos de desempenho com utilização de Gerenciadores de Grade, e sim da carga imposta pelo uso do middleware;

- Testes de independência de plataforma: para comprovar o funcionamento da solução em plataformas homogêneas e heterogêneas, tanto de desenvolvimento quanto de execução;

- Testes de extensibilidade, nos quais foram inseridos um EEP e um $E G G$ àqueles inicialmente existentes;

- Testes de desacoplamento, nos quais uma aplicação cliente pode ser testada com EGGs distintos, mostrando desacoplamento entre a aplicação e o Gerenciador de Grades. Foi realizado ainda um teste de execução de atividades com e sem o uso de Gerenciador de Workflow pela aplicação cliente.

Quando pertinente, serão apresentadas as configurações de hardware e de software utilizadas.

Os testes foram realizados para dois cenários: laboratório e real. O primeiro era composto por execuções paralelas de três aplicações simples: soma de dois números inteiros, cálculo de $\pi$ e Torres de Hanoi - essas aplicações foram utilizadas de diversas formas para avaliar o funcionamento do middleware e a 
carga de comunicação entre suas camadas. O cenário real é uma aplicação que utiliza o Ourgrid para previsão meteorológica, atualmente em uso pelo Instituto Nacional de Pesquisas Espaciais (INPE). Ele permite a realização dos demais testes e avaliar o funcionamento do middleware em produção, bem como a carga imposta por ele para transferência de arquivos, mais intensa neste caso.

\subsection{Aplicações para Testes}

As três aplicações implementadas possuem tempos de execução em ordens de grandeza distintos, sendo que sua combinação permite a realização dos seguintes testes funcionais:

- Uso dos EEPs com uma única atividade;

- Uso dos EEPs com diversas instâncias de uma mesma atividade;

- Uso dos EEPs com atividades distintas.

Cada um dos testes acima, detalhados nesta seção, permite validar a corretude de resultados, carga de comunicação entre camadas do middleware e a evolução desta carga em função do número de atividades sendo executadas.

Esses testes foram realizados com o EGG para execução sem grade, uma vez que este EGG permite fazer testes com o middleware, sem interferência nos resultados em função de gerenciadores de grades.

Cada aplicação é implementada em uma biblioteca semelhante à descrita na Seção 6.3.6.2.

\subsubsection{Soma de Dois Números Inteiros}

É um algoritmo trivial, com tempo de execução O(1). A classe que implementa esta aplicação é a mesma apresentada na listagem da Seção 6.3.6.2, porém com o seguinte código no método Execute:

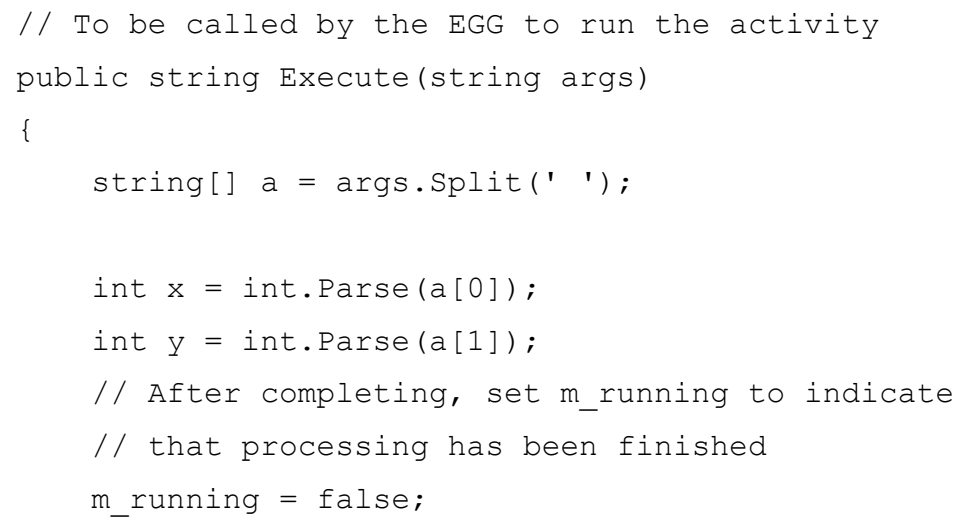


return $(x+y)$. ToString () ;

\}

Esse algoritmo permite avaliar o tempo de comunicação entre as camadas do middleware em função do número de atividades.

O middleware foi implementado com diversos pontos de comunicação assíncrona e uso de threads. A depuração de um programa com tais características não é trivial, uma vez que diversos fatores externos podem afetar o fluxo de execução de suas threads. Alguns exemplos desses fatores são: a execução dentro e fora do ambiente de desenvolvimento; com ou sem símbolos para depuração; o uso de recursos para produção de log de execução; ou ainda a execução concomitante de outras aplicações ou serviços/daemons.

O retorno praticamente imediato deste algoritmo permite maximizar o tempo utilizado para gerenciamento dessas threads, colocando-as praticamente ao mesmo tempo em execução. Além disso, as instâncias desta aplicação retornarão ao middleware assim que forem colocadas em execução, fazendo com que as camadas do middleware sejam chamadas diversas vezes em curto intervalo de tempo, o que auxilia no teste do isolamento de seções críticas utilizadas em diversos pontos do código do middleware.

\subsubsection{Cálculo Aproximado de $\pi$}

É um algoritmo com tempo de execução $\mathrm{O}(n)$. A classe que implementa esta aplicação é a mesma apresentada na listagem da Seção 6.3.6.2, porém com o seguinte código no método Execute:

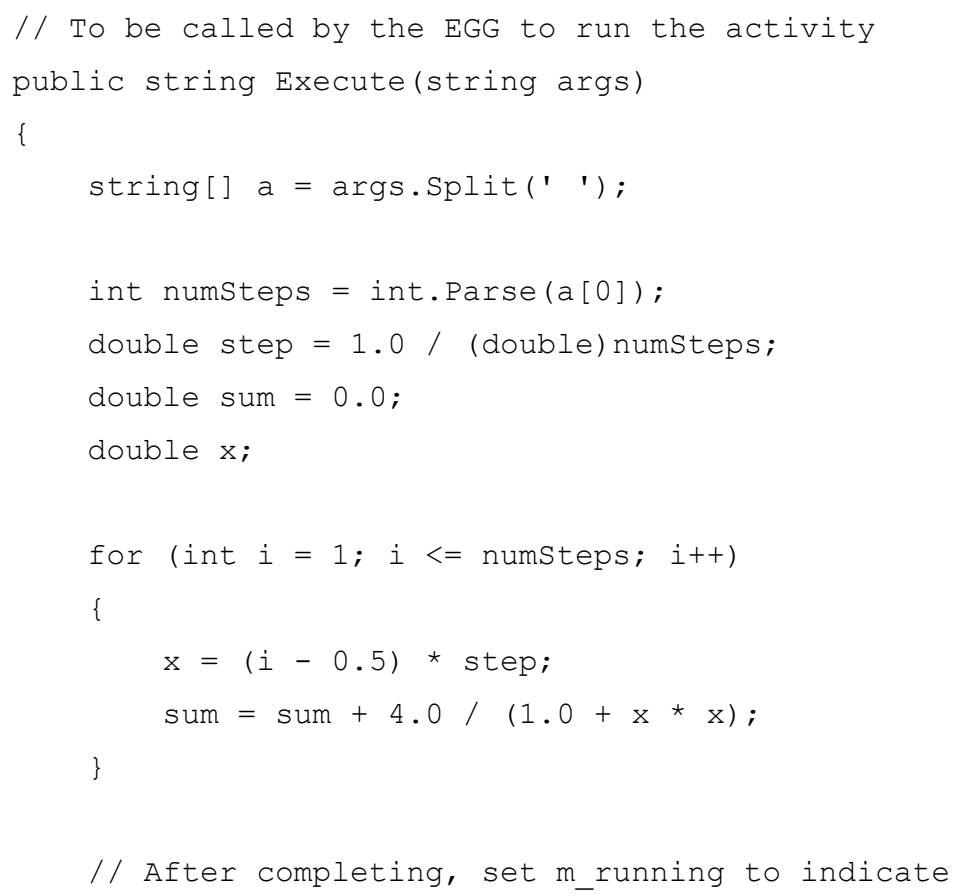




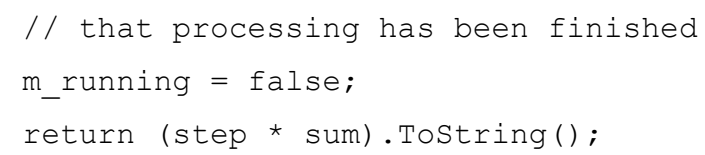

O tempo de execução linear permite que seja testado um cenário comumente encontrado em aplicações de e-Science: a execução paralela de um conjunto de atividades com tempos de execução semelhantes, e que terminam em momentos próximos. Com isso, é possível testar o comportamento do middleware com atividades sendo concluídas minutos após terem sido iniciadas.

\subsubsection{Torres de Hanoi}

É um algoritmo com tempo de execução $O\left(2^{n}\right)$. A classe que implementa esta aplicação é a mesma apresentada na listagem da Seção 6.3.6.2, porém com o seguinte código no método Execute:

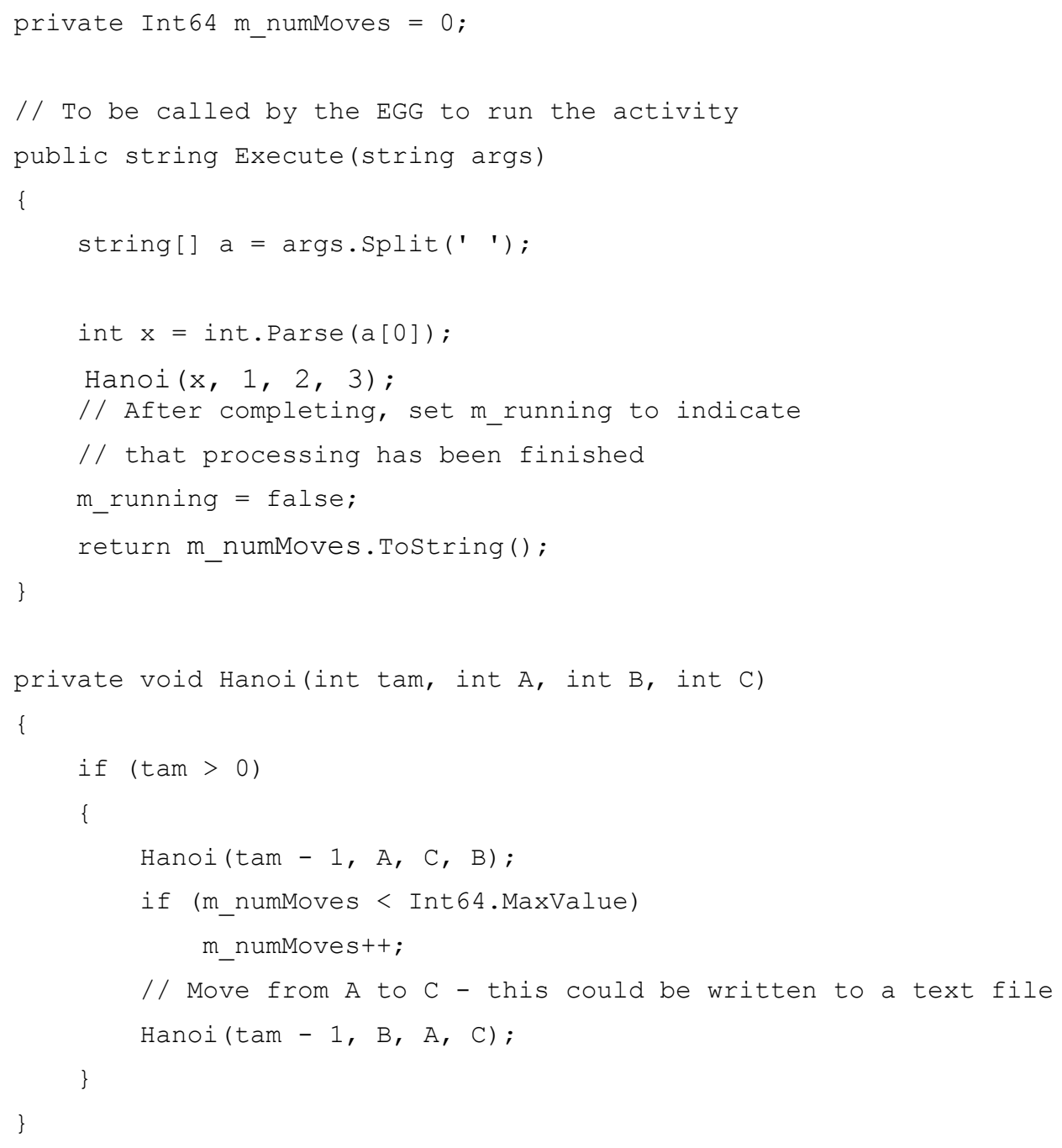


O tempo de execução exponencial permite validar a aplicação do middleware para a execução de atividades que são concluídas em momentos próximos ou não - algumas podem ser concluídas em segundos, enquanto outras podem demorar dias.

\subsubsection{Brazilian Regional Atmospheric Modeling System - BRAMS [71]}

É um sistema destinado aos centros de previsão meteorológica brasileiros, desenvolvido em conjunto por ATMET (Atmospheric, Meteorological and Environment Technologies [72]), IME/USP (Instituto de Matemática e Estatística/Universidade de São Paulo [73]), IAG/USP (Instituto Astronômico e Geofísico/Universidade de São Paulo [74]) e CPTEC/INPE (Centro de Previsão de Tempo e Estudos Climáticos/Instituto Nacional de Pesquisas Espaciais [75]). Destinado à execução sobre Linux, baseia-se no RAMS (Regional Atmospheric Modeling System [76]), desenvolvido por ATMET e grupos de pesquisa que incluem cientistas da Colorado State University. A principal diferença entre 0 RAMS e o BRAMS é a inclusão de características tropicais a este último, como o tratamento de nuvens to tipo cúmulos, tornando o sistema mais adequado para uso pelos centros metereológicos brasileiros. Além disso, melhorias no desempenho para execução serial e paralela também foram realizadas, conforme [77].

O objetivo do sistema é fornecer um modelo preditivo para simulação de condições atmosféricas em regiões geográficas de dimensões variadas, desde regiões circunvizinhas a determinada cidade, a macro regiões como Sul ou Centro-Oeste, por exemplo.

Esse sistema é atualmente utilizado pelo CPTEC/INPE e foi também utilizado pelo grupo de Processamento Paralelo e Distribuído do Instituto de Informática da Universidade Federal do Rio Grande do Sul [77].

A escolha do BRAMS como aplicação de e-Science para validação da arquitetura aqui exposta recaiu nos seguintes fatos:

- É uma aplicação característica de e-Science, com o cientista voltado à sua área de pesquisa, ao invés de questões relacionadas a informática;

- O BRAMS pode ser utilizado com ou sem a presença de software gerenciador de grade. A equipe da UFRGS utilizou o BRAMS com Globus e com Ourgrid, fazendo os ajustes necessários para execução com um ou outro gerenciador. Essa experiência permitiu avaliar as hipóteses de simplicidade de integração e transparência do middleware em relação ao gerenciador de grade; 
- Ajustes na resolução dos modelos a serem gerados permitiram a realização de testes com atividades com duração variável, de minutos a horas.

O BRAMS cria modelos climáticos a partir da execução de scripts que utilizam arquivos de entrada e produzem arquivos de saída. Para facilitar a configuração do modelo a ser criado, a equipe do CPTEC/INPE desenvolveu e utiliza uma aplicação web denominada GridSphere, ilustrada na Figura 41.

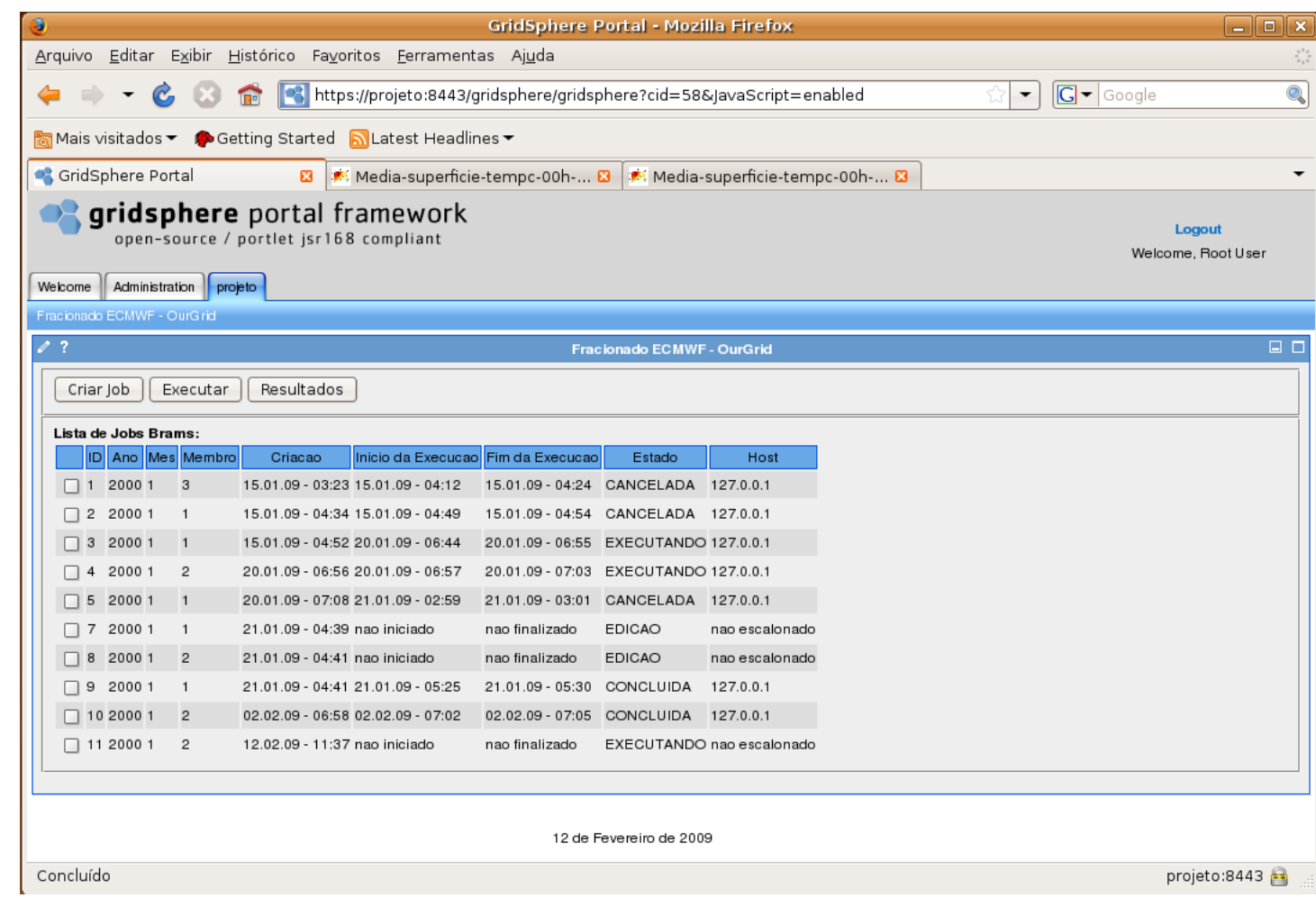

Figura 41: Portal GridSphere para gerenciamento de jobs BRAMS

As informações sobre as simulações, aqui denominadas jobs, ficam armazenadas em um banco de dados Postgres. Quando o botão "Executar" na figura acima for pressionado, o estado da simulação (job) que estiver selecionada será alterado para "LIBERADA". Para que a simulação seja então realizada, um daemon ${ }^{7}$, a intervalos regulares, consulta o banco de dados à procura de jobs nesse estado. Então faz as seguintes atividades, para tais jobs:

- Altera o estado do job para "EXECUTANDO";

- Prepara os dados para submissão ao Ourgrid, criando um arquivo chamado Job Definition File, ou JDF;

${ }^{7}$ Daemons são aplicações que monitoram algum recurso. Na plataforma Windows, são chamadas serviços 
- Utiliza uma API desenvolvida em Java para submeter a execução da simulação ao Ourgrid;

- Aguarda a conclusão do processamento do BRAMS pelo Ourgrid;

- Quando terminar, altera o estado da simulação para "CONCLUíDA";

- Armazena os arquivos de saída no local indicado. A imagem apresentada na Figura 42 ilustra um dos arquivos produzidos pelo BRAMS como resultado da execução de uma simulação.

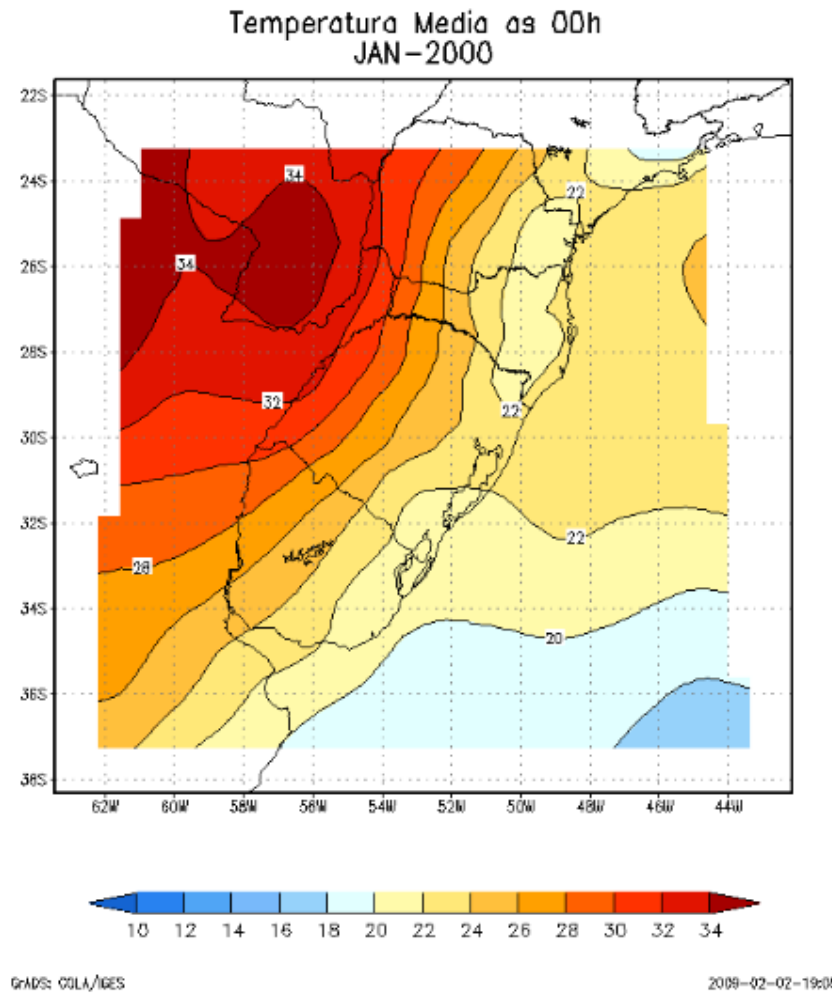

Figura 42: exemplo de saída produzida pelo BRAMS

Os arquivos JDF utilizados pelo Ourgrid, permitem a configuração de um job, que pode conter uma ou mais tarefas (tasks). O exemplo abaixo ilustra um JDF tipicamente utilizado para criação de um modelo BRAMS:

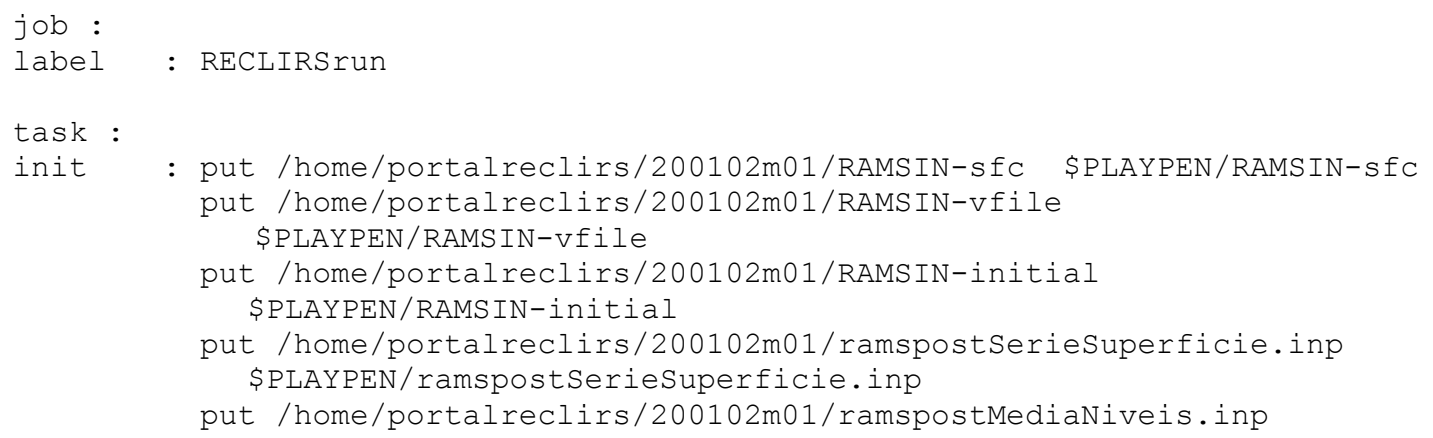




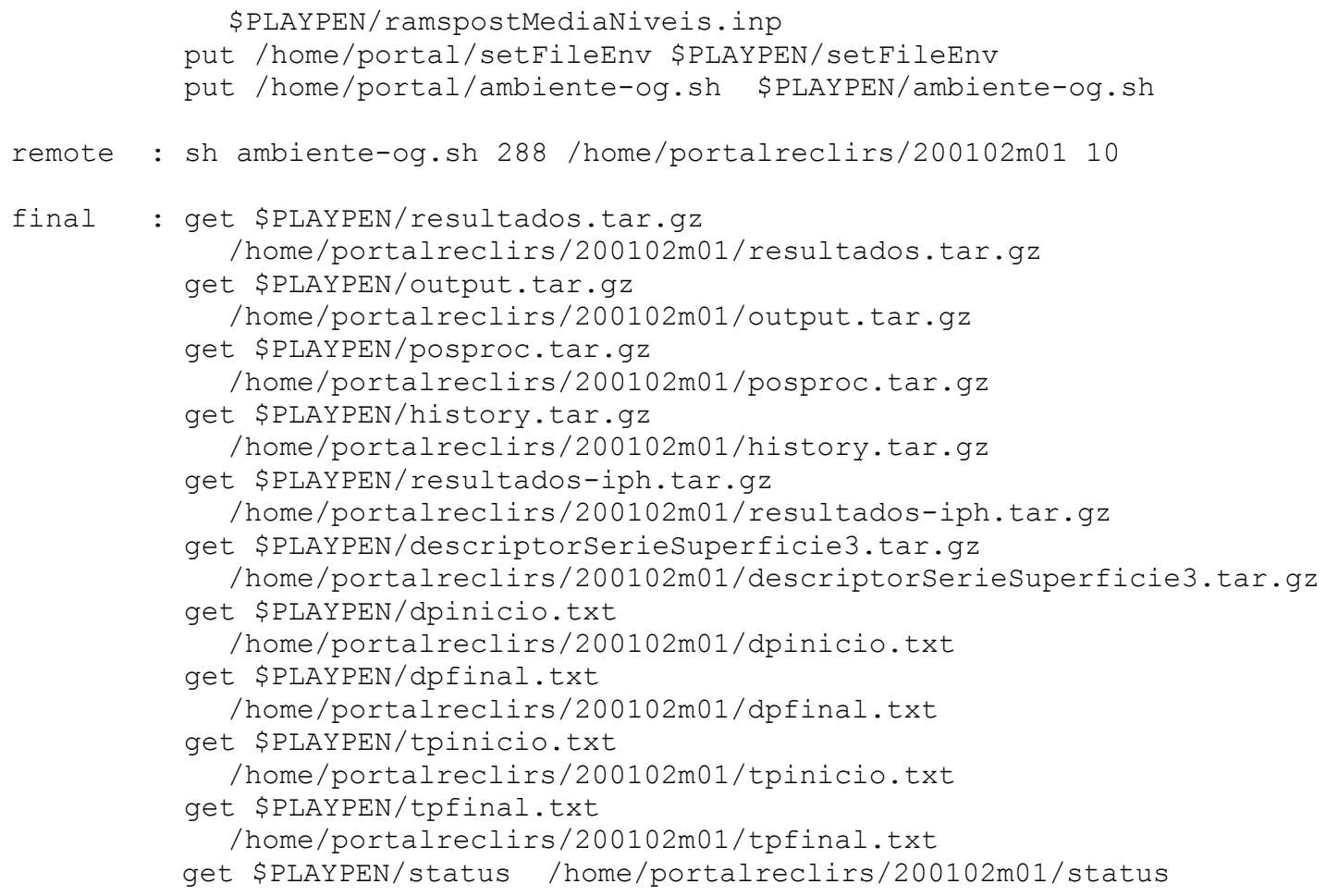

As seções init e final possuem instruções para cópia de arquivos de entrada e saída, respectivamente. A seção remote contém o comando de execução do script do BRAMS que gera o modelo climático.

Quanto ao tratamento de arquivos, quando o BRAMS é executado pelo Ourgrid, o componente Peer procura pelos arquivos de entrada e os distribui para o nó da grade onde aquela tarefa será executada. Essa transferência é feita utilizando SSH e SCP, mesmo método empregado pelo middleware, apresentado na Seção 6.4.

Vale notar que, assim como ocorre com a representação em XML do padrão no middleware, aqui um dos arquivos de entrada contém o script a ser executado - última linha com comando put no exemplo acima. No middleware, para a execução de atividade que esteja em uma biblioteca (DLL), o primeiro parâmetro de entrada do tipo file é a biblioteca em si, conforme descrito na Seção 6.3.6.2.

\subsubsection{Submissão de Atividades ao EGG para Threads}

Para a realização dos testes com atividades distintas, foi utilizada a aplicação WorkflowPJC, apresentada na Seção 6.6. Já para os testes envolvendo múltiplas instâncias de uma mesma atividade, a interface daquela aplicação é inadequada, devido ao tratamento de parâmetros para grande quantidade de instâncias. Por esse motivo, foi desenvolvida uma aplicação cliente, chamada Load Generation Tool (LGT), ilustrada na Figura 43. 


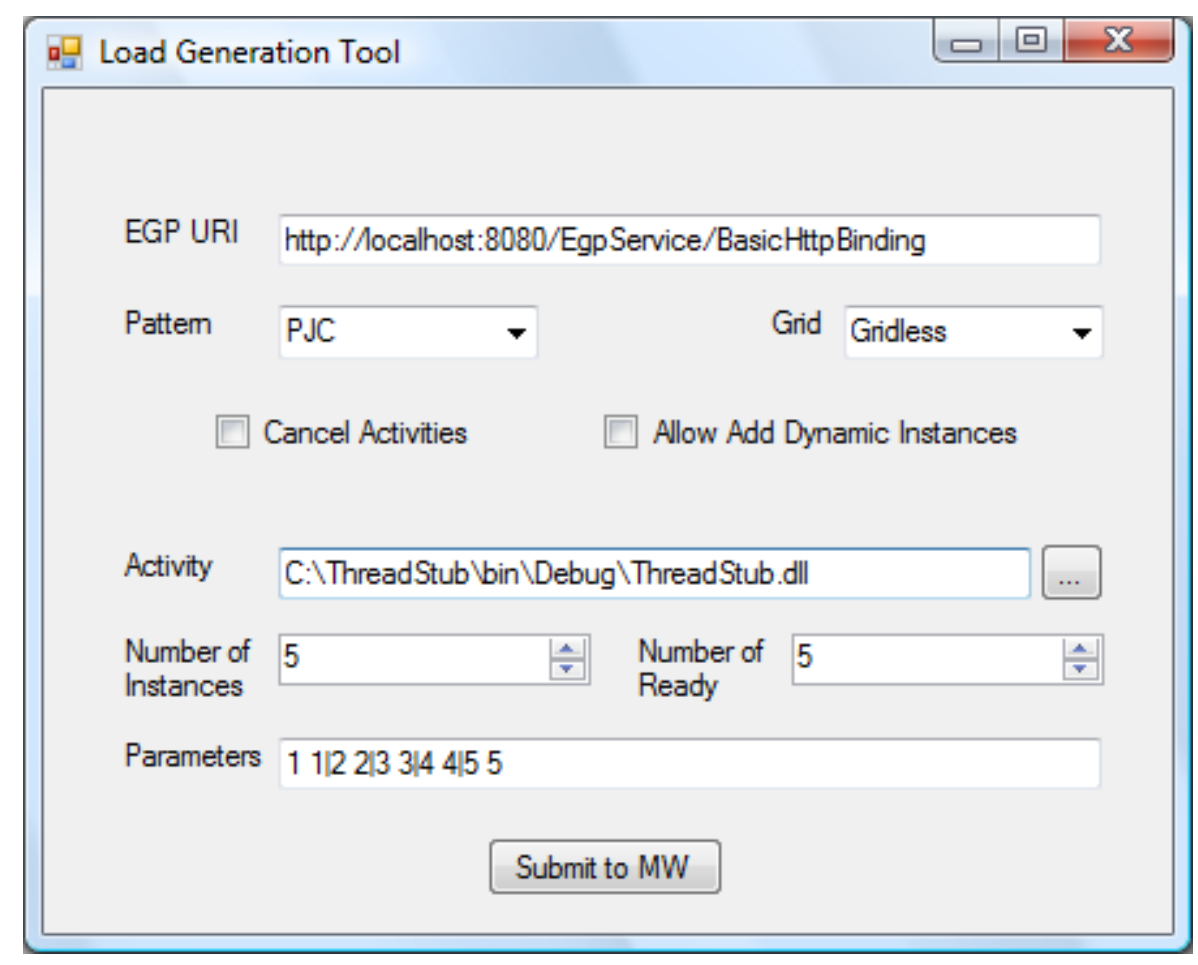

Figura 43: aplicação para submissão de atividades ao middleware

A atividade cujas instâncias serão submetidas ao middleware é definida no campo "Activity". Esse e os demais campos apresentados na figura acima são mapeados nos atributos dos elementos da representação do padrão em XML. O campo "Parameters" possui os parâmetros a serem enviados a cada instância da atividade, separados pelo caractere "|". Desse modo, a primeira instância receberá os parâmetros "1 1", a segunda "2 2", e assim por diante, análogo à aplicação WorkflowPJC descrita na Seção 6.6. Esse comportamento permanece o mesmo até cinco instâncias, o que permite a realização de testes básicos de funcionalidade. No entanto, diferentemente daquela aplicação, para um número de instâncias superior a esse limite, o primeiro parâmetro é repetido para todas as instâncias, o que facilita a interação com o usuário para testes envolvendo dezenas ou centenas de atividades a serem processadas pelo middleware. $O$ exemplo da Figura 43 refere-se à aplicação de Soma de Números Inteiros, descrita na Seção 7.1.1, e produz a seguinte entrada para o middleware:

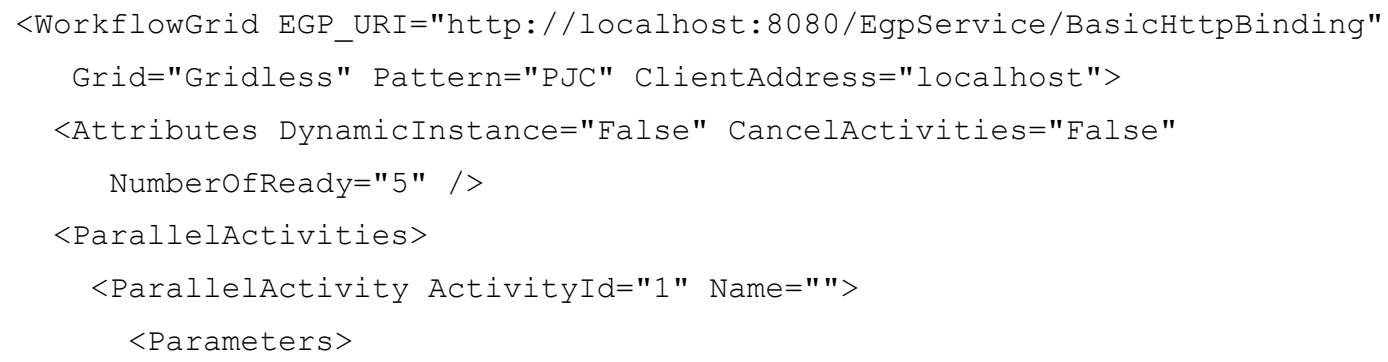




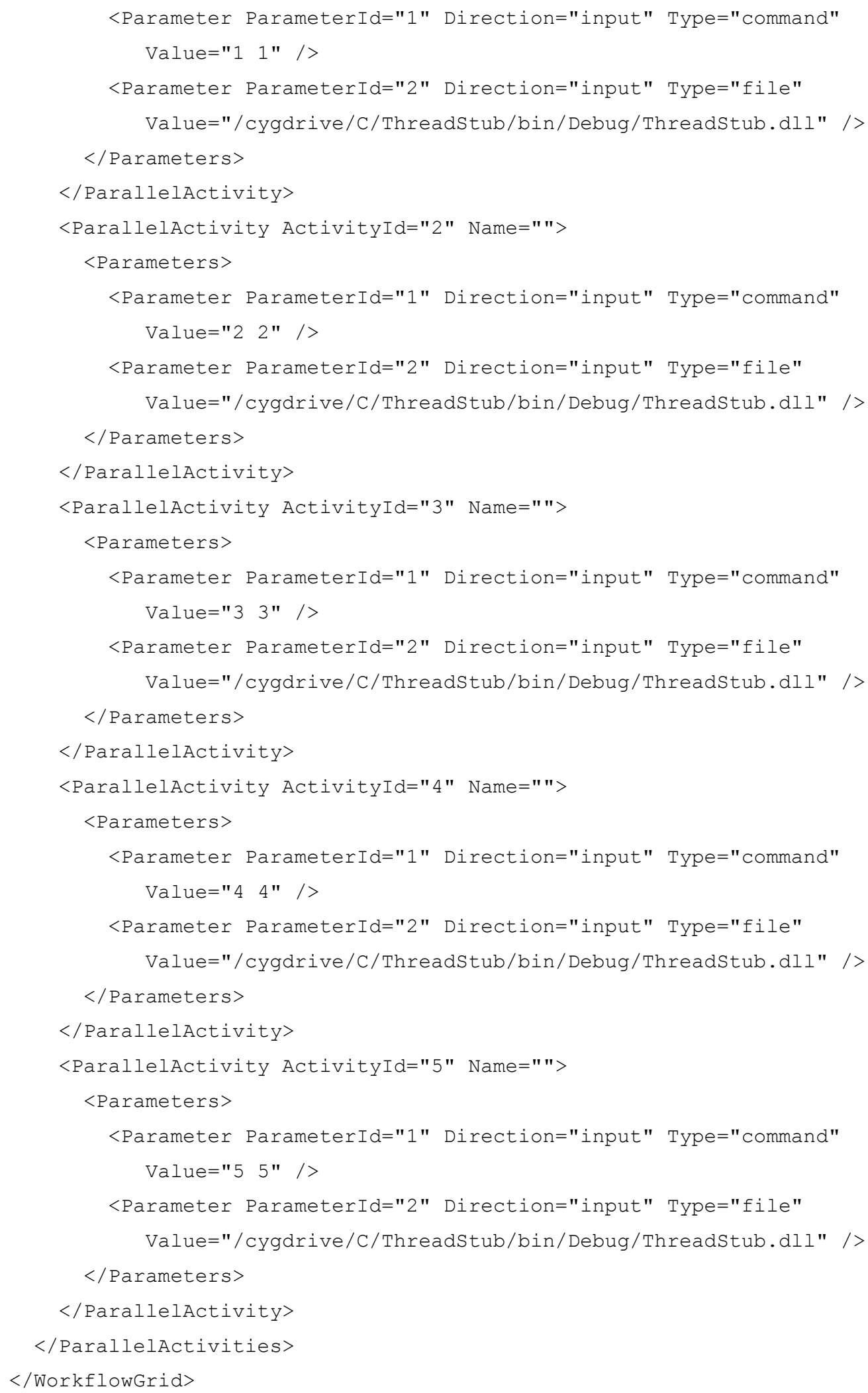


Cada instância é representada como uma atividade, de acordo com o descrito na Seção 5.1.5.1. Assim, são produzidos cinco elementos ParallelActivity que diferem apenas no atributo ActivityId e nos atributos Value dos elementos Parameter.

Observe que o atributo Value de cada elemento Parameter do tipo "command" contém os parâmetros a serem passados ao método Execute da classe Task (Seção 6.3.6.2) do primeiro arquivo de entrada - aquele com o menor valor no atributo ParameterId, com Direction="input" e Type="file".

O exemplo da figura produz o seguinte resultado:

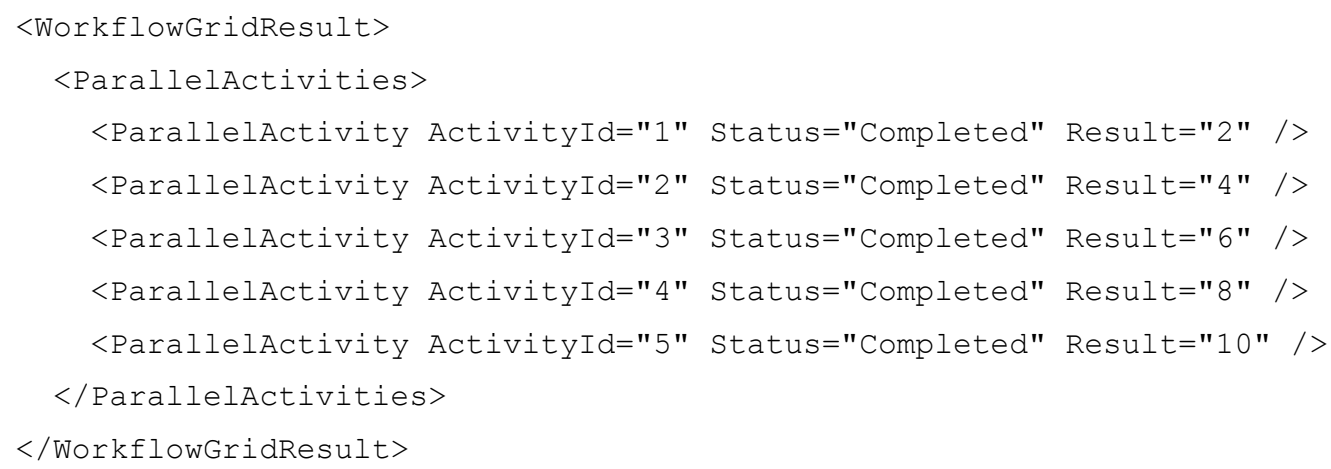

São realizados aqui dois tipos de testes: funcionalidade e carga. No primeiro, é verificado o comportamento do middleware e os resultados produzidos, gravados em arquivo texto seguindo formato XML conforme descrito na Seção 5.1.5.1. No segundo, foram submetidas quantidades crescentes de atividades, a fim de avaliar o desempenho e impacto produzidos pela presença do middleware.

\subsubsection{Submissão de Atividades ao EGG para Ourgrid}

Para os testes em cenário real, foram submetidos jobs BRAMS ao Ourgrid, utilizando o middleware. Para isso, o daemon descrito na Seção 7.1.4 foi modificado. O início do processo continua o mesmo, com a utilização do GridSphere para configuração dos jobs e armazenamento desta no Postgres. Então o daemon passa a utilizar o EGP para submissão e para consulta da situação de uma execução. Essa requisição transita pelas camadas do middleware, até chegar ao EGG para o Ourgrid. Este, por sua vez, utiliza a API do Ourgrid para submeter o job.

A Figura 44 ilustra o fluxo de execução sem o uso do middleware. Todos os aplicativos foram escritos em Java e a execução se dá sobre Linux. 


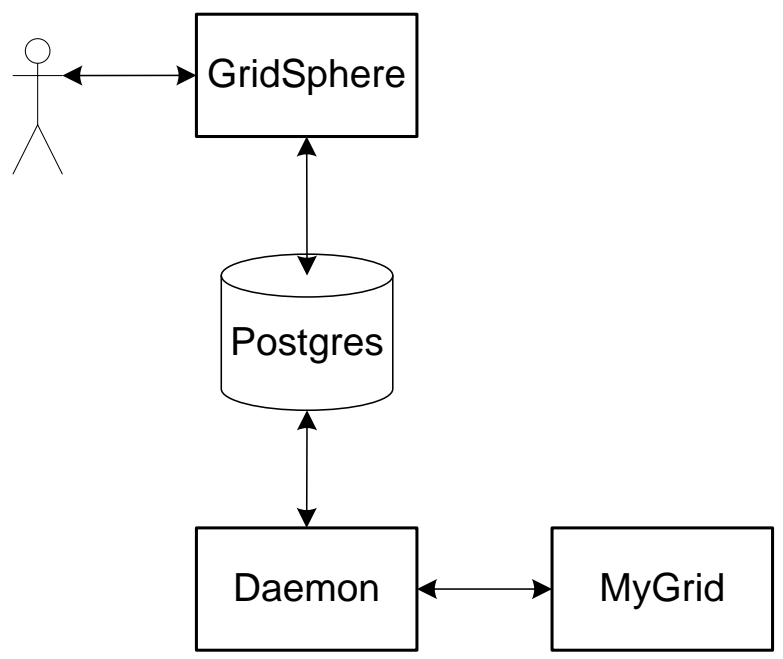

Figura 44: execução de simulações com BRAMS sem o middleware

A Figura 45 mostra em que ponto da execução o middleware é utilizado. Neste caso, os serviços do middleware foram implementados em Visual C\# e são executados sobre Windows, à exceção do EGG para Ourgrid, desenvolvido em Java e executado sobre Linux.

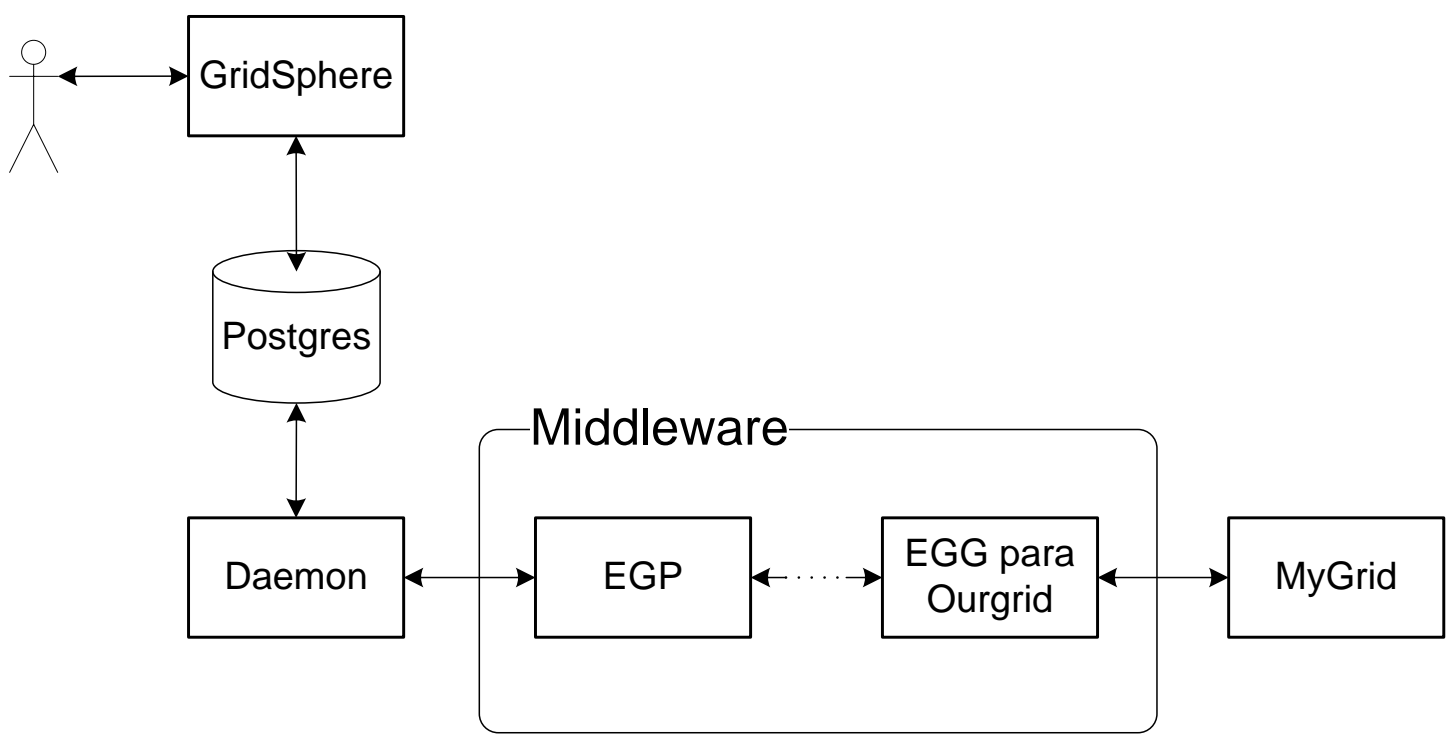

Figura 45: execução de simulações com BRAMS e com o middleware

Os testes utilizando o BRAMS com a equipe da UFRGS permitiram avaliar a percepção do usuário no tocante à independência de software gerenciador de grade que o middleware proporciona. Além disso, permitiu também validar o uso do middleware em plataformas heterogêneas, descrito mais adiante neste capítulo. 


\subsection{Testes de Funcionalidade}

Para avaliar a corretude do middleware e do PJC, foram realizados os testes constantes da Tabela 4.

Tabela 4: testes funcionais em laboratório

\begin{tabular}{|l|l|l|l|l|}
\hline$\#$ & Aplicação & Atividades & $\begin{array}{l}\mathrm{n} \\
\text { (number } \\
\text { of } \\
\text { ready) }\end{array}$ & $\begin{array}{l}\text { Cancela } \\
\text { demais } \\
\text { atividades }\end{array}$ \\
\hline 1 & WorkflowPJC & $1 \times$ Soma & 1 & false \\
\hline 2 & WorkflowPJC & $1 \times$ Soma & 1 & true \\
\hline 3 & WorkflowPJC & $5 \times$ Soma & 3 & false \\
\hline 4 & WorkflowPJC & $5 \times$ Soma & 3 & true \\
\hline 5 & WorkflowPJC & $5 \times$ Hanoi $-29|30| 31|32| 33$ & 3 & false \\
\hline 6 & WorkflowPJC & $5 \times$ Hanoi $-29|30| 31|32| 33$ & 3 & true \\
\hline 7 & WorkflowPJC & $2 \times$ Soma $-88 \mid 99$ & 6 & true \\
& & $\begin{array}{l}4 \times \text { Hanoi }-30|31| 32 \mid 29 \\
4 \times \pi-10^{8}\left|10^{9}\right| 5 \times 10^{9} \mid 2 \times 10^{9}\end{array}$ & \\
\hline 8 & LGT & $1000 \times$ Soma $-11^{\prime}$ & 1000 & false \\
\hline
\end{tabular}

Os testes 1 e 2 são triviais, e avaliam o funcionamento básico da comunicação entre as camadas do middleware. Devolvem o estado completed para a atividade executada.

Os testes 3 e 4 ilustram uma peculiaridade da implementação: como as atividades são executadas rapidamente, todas serão concluídas antes que 0 middleware tenha enviado o comando de cancelamento. Quando uma atividade for concluída, seu estado deve ser enviado do EGG para o IPG, e de lá para o EPP, no qual o padrão decide se deve ou não enviar uma requisição de cancelamento. Nesse tempo, todas as demais atividades terminam sua execução. Consequentemente, todas as atividades aparecem com o estado completed, independentemente do valor do atributo CancelActivities.

Os testes 5 e 6 utilizam o algoritmo de Torres de Hanoi com número de discos que promove maior espaço de tempo entre a conclusão das atividades. Nesse cenário é possível validar a corretude do cancelamento e do retorno do PJC. Para ambos, assim que três atividades forem concluídas, o método IsExecuting do EGP, chamado pela aplicação cliente, devolve false. Então, a chamada de GetWorkflowStatus devolverá essas três atividades com estado completed, e as demais dependerão do valor do atributo CancelActivities. 
O teste 7 ilustra a execução de dez atividades, sendo duas para Soma, quatro para Torres de Hanoi e quatro para cálculo de $\pi$. As duas somas terminam rapidamente, e então três cálculos de $\pi$ e uma execução das Torres de Hanoi também concluem. As demais atividades são então canceladas.

Finalmente, o teste 8 submete uma carga bastante grande de atividades que serão concluídas em curto intervalo de tempo, gerando carga na comunicação entre as camadas do middleware. Esse teste permitiu identificar possíveis timeouts e gargalos durante o desenvolvimento da solução, que foram devidamente eliminados.

\subsection{Testes de Desempenho}

A utilização do middleware impõe um conjunto de tarefas que impactam o desempenho final da execução, quando comparado à execução de solução sem o middleware. Essas tarefas podem ser classificadas como:

- Comunicação e processamento dos serviços web, que inclui o algoritmo do PJC e o acesso deste ao banco de dados, gerenciamento da execução das atividades pelo EGG utilizado e os tempos de instanciar e acionar os serviços das camadas do middleware;

- Tratamento de arquivos, conforme descrito na Seção 6.4, que inclui a transferência de arquivos de entrada e saída, e a criação e remoção de diretórios temporários.

Esta seção apresenta o resultado de um conjunto de testes, para os quais foram realizadas três medições de tempo (em segundos), que compõem o tempo total de uma execução ( $\left.T_{\text {total }}\right): 1$ ) tempo utilizado para tratamento de arquivos $\left.\left(T_{\text {arq }}\right) ; 2\right)$ tempo para o processamento das atividades $\left.\left(T_{\text {ativ }}\right) ; 3\right)$ tempo utilizado em comunicação e processamento de serviços web $\left(T_{\text {com }}\right)$. Desse modo, tem-se:

$$
\mathrm{T}_{\text {total }}=\mathrm{T}_{\text {arq }}+\mathrm{T}_{\text {ativ }}+\mathrm{T}_{\text {com }}
$$

Os testes foram realizados considerando os fatores que poderiam levar o middleware a impactar o desempenho da aplicação sendo submetida:

- Duração das atividades;

- Número de atividades;

- Número de arquivos de entrada;

- Número de arquivos de saída; 
- Tamanho dos arquivos de entrada;

- Tamanho dos arquivos de saída.

As próximas seções descrevem os testes realizados em função desses elementos. Esses testes foram realizados com o middleware e as aplicações de teste em um único computador, com a seguinte configuração:

- Notebook Dell D830 Latitude

- Memória: 4 GB;

- CPU: Intel Core 2 Duo - $2.60 \mathrm{GHz}$

- Disco Rígido: Hitachi HTS 7220 16K9A300

- Sistema Operacional: Windows Vista Enterprise 32-bits, com SP2

Embora a distribuição dos elementos da solução em diversos equipamentos tenham impacto no desempenho, isso se dá de modo linear em função da velocidade e utilização da rede. Por esse motivo, tal cenário foi empregado para Testes de Independência de Plataforma e de Desacoplamento, mas não para Testes de Desempenho.

\subsubsection{Desempenho em Função da Duração das Atividades}

Aqui foi utilizado o Load Generation Tool para submissão de atividades com duração linear e exponencial. Para o primeiro caso, a atividade é o cálculo de $\pi$, e, para o segundo, as Torres de Hanoi. A Tabela 5 apresenta os dados obtidos neste teste. 


Tabela 5: testes de desempenho em função da duração das atividades (tempos em segundos)
\begin{tabular}{|l|l|c|l|l|l|l|}
\hline$\#$ & Atividade & Parâmetro & $\mathrm{T}_{\text {com }}$ & $\mathrm{T}_{\text {arq }}$ & $\mathrm{T}_{\text {ativ }}$ & $\mathrm{T}_{\text {total }}$ \\
\hline 1 & Cálculo de $\pi$ & $10^{9}$ & 1.5 & 13.5 & 24.5 & 39.5 \\
\hline 2 & Cálculo de $\pi$ & $2 * 10^{9}$ & 1.9 & 19.1 & 49.1 & 70.1 \\
\hline 3 & Cálculo de $\pi$ & $3 * 10^{9}$ & 2.3 & 17.5 & 73.7 & 93.5 \\
\hline 4 & Cálculo de $\pi$ & $4 * 10^{9}$ & 1.6 & 17.6 & 98.4 & 117.6 \\
\hline 5 & Cálculo de $\pi$ & $5 * 10^{9}$ & 2.1 & 16.9 & 123.2 & 142.2 \\
\hline 6 & Torres de Hanoi & 30 & 3.2 & 13.6 & 21.7 & 38.5 \\
\hline 7 & Torres de Hanoi & 31 & 1.2 & 13.8 & 43.9 & 58.9 \\
\hline 8 & Torres de Hanoi & 32 & 2.5 & 13.5 & 86.8 & 102.8 \\
\hline 9 & Torres de Hanoi & 33 & 2.8 & 18 & 173.8 & 194.6 \\
\hline 10 & Torres de Hanoi & 34 & 2.4 & 18.3 & 348.2 & 368.9 \\
\hline
\end{tabular}

Como pode ser observado da tabela acima e na Figura 46, $T_{\text {com }}$ e $T_{\text {arq }}$ são praticamente constantes, resultando no desempenho do middleware ser diretamente proporcional ao $T_{\text {ativ }}$. Isso deve-se ao fato de $T_{\text {ativ }}$ não ser afetado pela utilização ou não do middleware, uma vez que essas atividades são executadas fora do middleware. Por isso, o impacto do middleware no tempo de execução das aplicações independe da duração das atividades. Desse modo, todos os demais testes de desempenho foram realizados em função de outros fatores, e usando atividades simples.

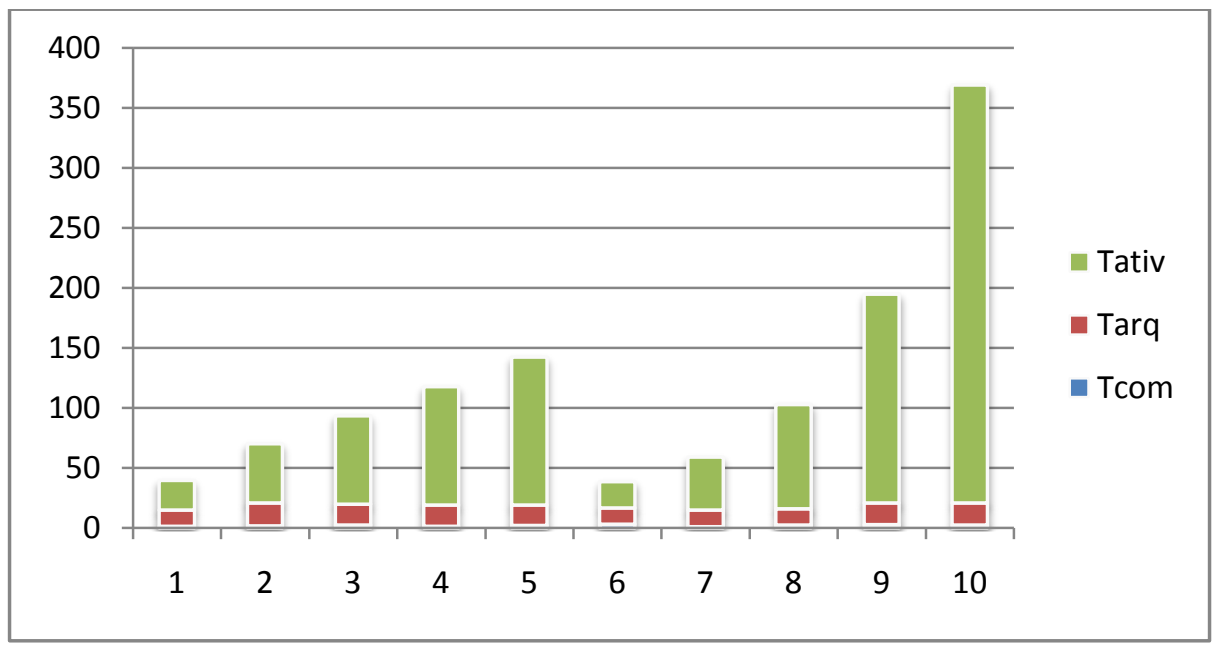

Figura 46: desempenho (em segundos) do middleware em função da duração de atividades $O(n)$ e $O\left(2^{n}\right)$ 


\subsubsection{Desempenho em Função do Número de Atividades}

Aqui foi utilizado o Load Generation Tool para submissão de número de atividades variando de 1 a 100. A atividade escolhida foi a Soma de Dois Números Inteiros. A Tabela 6 apresenta os dados obtidos neste teste.

Tabela 6: testes de desempenho em função do número de atividades (tempos em segu
\begin{tabular}{|l|l|l|l|l|l|}
\hline$\#$ & Número de Atividades & $\mathrm{T}_{\text {com }}$ & $\mathrm{T}_{\text {arq }}$ & $\mathrm{T}_{\text {ativ }}$ & $\mathrm{T}_{\text {total }}$ \\
\hline 1 & 1 & 1.4 & 13.4 & 0 & 14.8 \\
\hline 2 & 10 & 1.4 & 34.5 & 0 & 35.9 \\
\hline 3 & 20 & 1.2 & 61.9 & 0 & 63.1 \\
\hline 4 & 30 & 1.6 & 87.7 & 0 & 89.3 \\
\hline 5 & 40 & 2.4 & 117.3 & 0 & 119.7 \\
\hline 6 & 50 & 1.9 & 133.3 & 0 & 135.2 \\
\hline 7 & 60 & 2 & 163.5 & 0 & 165.5 \\
\hline 8 & 70 & 2.5 & 183.7 & 0.1 & 186.3 \\
\hline 9 & 80 & 1.8 & 216.6 & 0.1 & 218.5 \\
\hline 10 & 90 & 2.5 & 248.6 & 0 & 251.1 \\
\hline 11 & 100 & 2.8 & 269.0 & 0.2 & 271.8 \\
\hline
\end{tabular}

Como pode ser observado da tabela acima, $T_{\text {ativ }}$ é praticamente constante, valendo zero, uma vez que é o tempo de execução do número de somas igual ao número de atividades. Assim, para o teste 11, é o tempo de realização de 100 somas de números inteiros.

Conforme o gráfico da Figura 47, pode ser observado que $T_{\text {com }}$ é praticamente desprezível, e que $\mathrm{T}_{\text {arq }}$ é linear em função do número de atividades.

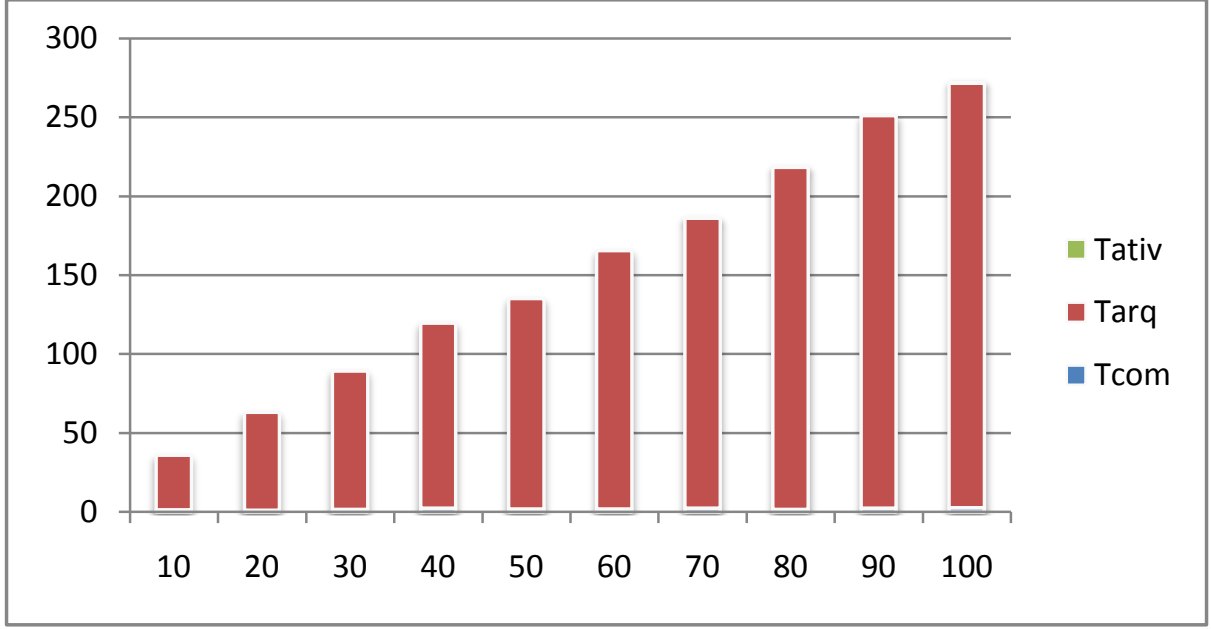

Figura 47: desempenho (em segundos) do middleware em função do número de atividades 


\subsubsection{Desempenho em Função do Número de Arquivos}

A heurística para transferência de arquivos de entrada e saída minimiza o número de conexões SSH e de comandos SCP, conforme descrito na Seção 6.4. Desse modo, o tempo de execução varia em função do número de arquivos, mas sendo adicionalmente dependente do tipo de arquivo (entrada ou saída) e do número de atividades. Os testes desta seção avaliam como é o desempenho do middleware considerando tais fatores.

Para esses testes foi utilizado o Load Generation Tool, todos utilizando a Soma de Dois Números Inteiros.

Pelo fato de $T_{\text {ativ }}$ ser praticamente zero, foi omitido das tabelas e gráficos dos próximos testes. 


\subsubsection{Variação do Número de Arquivos de Entrada com Uma Atividade}

Estes testes consideram a variação de 10 a 100 arquivos de entrada, em múltiplos de 10 arquivos. O tamanho dos arquivos é fixo em 10KB cada. Foi utilizada uma única atividade. A Tabela 7 apresenta os dados obtidos neste teste.

Tabela 7: testes de desempenho em função do número de arquivos de entrada com uma atividade (tempos em segundos)

\begin{tabular}{|l|l|r|r|r|}
\hline$\#$ & Número de Arquivos & \multicolumn{1}{|c|}{$\mathrm{T}_{\text {com }}$} & \multicolumn{1}{l|}{$\mathrm{T}_{\text {arq }}$} & \multicolumn{1}{l|}{$\mathrm{T}_{\text {total }}$} \\
\hline 1 & 10 & 2.0 & 9.3 & 11.2 \\
\hline 2 & 20 & 0.7 & 11.6 & 12.3 \\
\hline 3 & 30 & 1.1 & 18.7 & 19.8 \\
\hline 4 & 40 & 1.2 & 16.9 & 18.0 \\
\hline 5 & 50 & 0.9 & 19.5 & 20.4 \\
\hline 6 & 60 & 1.0 & 21.0 & 22.0 \\
\hline 7 & 70 & 1.2 & 24.3 & 25.5 \\
\hline 8 & 80 & 0.7 & 26.7 & 27.4 \\
\hline 9 & 90 & 0.8 & 34.2 & 35.0 \\
\hline 10 & 100 & 0.7 & 36.8 & 37.5 \\
\hline
\end{tabular}

Conforme o gráfico da Figura 48, pode ser observado que $\mathrm{T}_{\text {com }}$ é praticamente constante, e que $\mathrm{T}_{\text {arq }}$ é linear em função do número de arquivos.

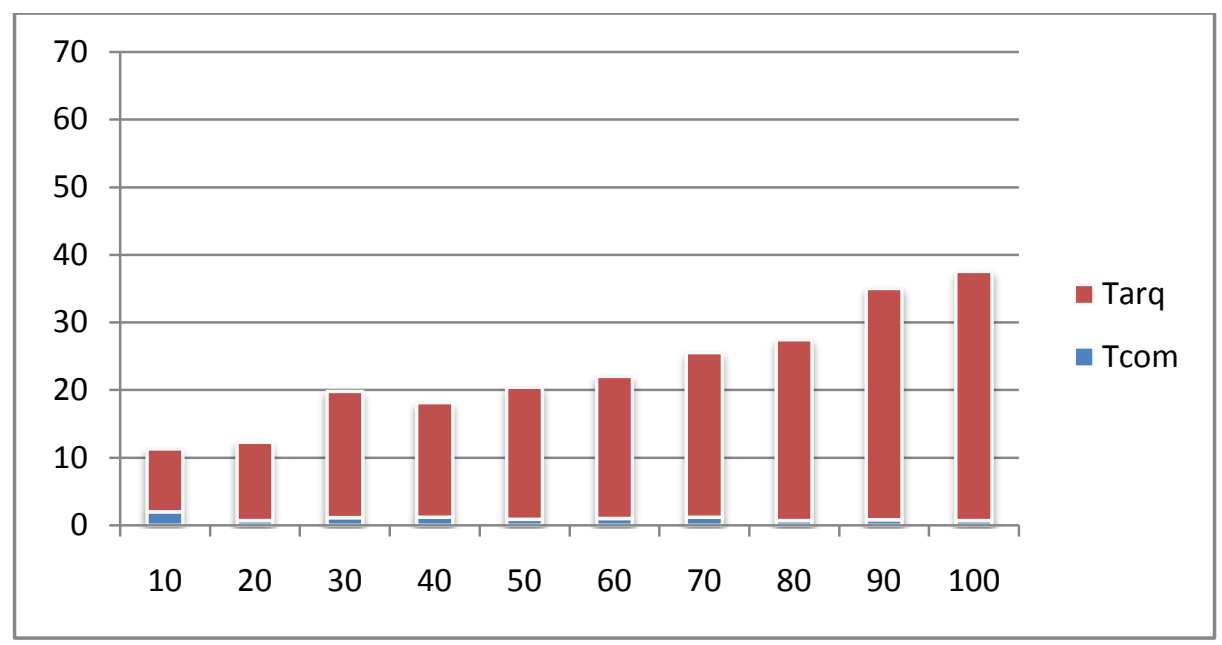

Figura 48: desempenho (em segundos) do middleware em função do número de arquivos de entrada com uma atividade 


\subsubsection{Variação do Número de Arquivos de Entrada com Diversas Atividades}

Estes testes consideram a variação de 10 a 100 arquivos de entrada, em múltiplos de 10 arquivos. O tamanho dos arquivos é fixo em 10KB cada. Os arquivos foram distribuídos igualmente em dez atividades. A Tabela 8 apresenta os dados obtidos neste teste.

Tabela 8: testes de desempenho em função do número de arquivos de entrada com dez a
\begin{tabular}{|l|l|r|r|l|}
\hline$\#$ & Número de Arquivos & $\mathrm{T}_{\text {com }}$ & $\mathrm{T}_{\text {arq }}$ & $\mathrm{T}_{\text {total }}$ \\
\hline 1 & 10 & 1.4 & 34.7 & 36.1 \\
\hline 2 & 20 & 0.4 & 34.5 & 34.8 \\
\hline 3 & 30 & 1.2 & 36.1 & 37.4 \\
\hline 4 & 40 & 1.2 & 37.7 & 38.9 \\
\hline 5 & 50 & 0.9 & 41.6 & 42.5 \\
\hline 6 & 60 & 1.0 & 43.9 & 45.0 \\
\hline 7 & 70 & 0.8 & 46.7 & 47.5 \\
\hline 8 & 80 & 0.9 & 49.0 & 50.0 \\
\hline 9 & 90 & 3.8 & 48.3 & 52.2 \\
\hline 10 & 100 & 1.2 & 56.2 & 57.4 \\
\hline
\end{tabular}

Conforme o gráfico da Figura 49, pode ser observado que $T_{\text {com }}$ é praticamente constante, e que $\mathrm{T}_{\text {arq }}$ é linear em função do número de arquivos.

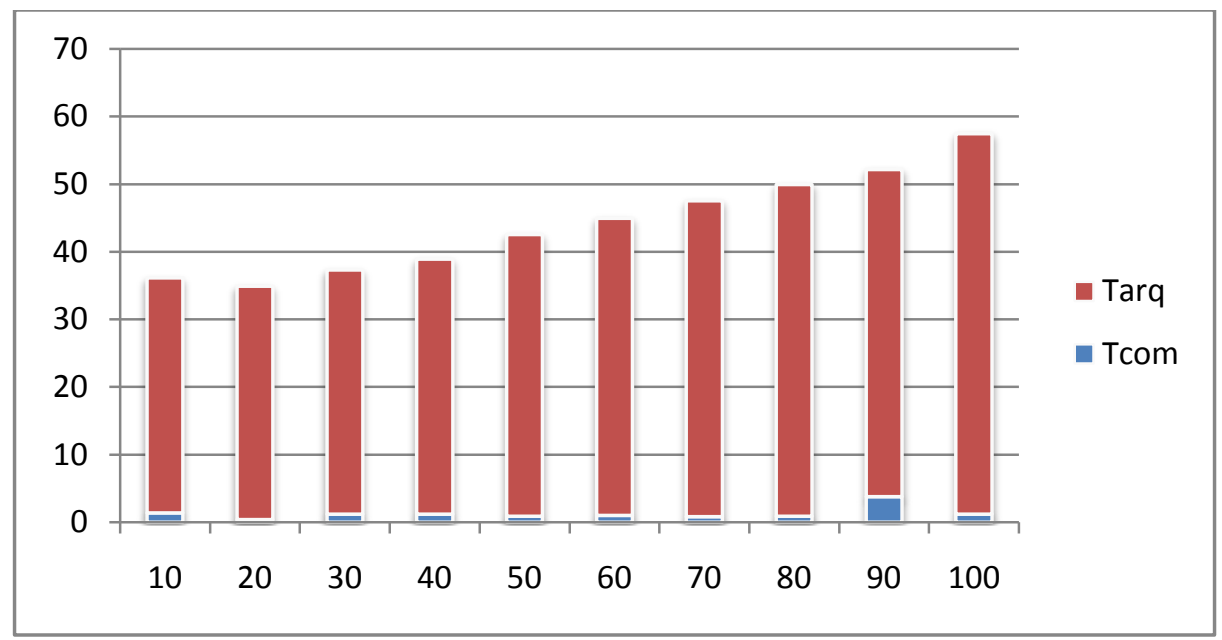

Figura 49: desempenho (em segundos) do middleware em função do número de arquivos de entrada com dez atividades 


\subsubsection{Variação do Número de Arquivos de Saída com Uma Atividade}

Estes testes consideram a variação de 10 a 100 arquivos de saída, em múltiplos de 10 arquivos. $O$ tamanho dos arquivos é fixo em $10 \mathrm{~KB}$ cada. Foi utilizada uma única atividade. A Tabela 9 apresenta os dados obtidos neste teste.

Tabela 9: testes de desempenho em função do número de arquivos de saída com uma atividade (tempos em segundos)

\begin{tabular}{|l|l|l|l|l|}
\hline$\#$ & Número de Arquivos & $\mathrm{T}_{\text {com }}$ & $\mathrm{T}_{\text {arq }}$ & $\mathrm{T}_{\text {total }}$ \\
\hline 1 & 10 & 0.7 & 8.9 & 9.6 \\
\hline 2 & 20 & 0.4 & 9.7 & 10.1 \\
\hline 3 & 30 & 0.3 & 14.0 & 14.3 \\
\hline 4 & 40 & 1.1 & 21.2 & 22.3 \\
\hline 5 & 50 & 0.9 & 23.6 & 24.5 \\
\hline 6 & 60 & 1.1 & 26.1 & 27.2 \\
\hline 7 & 70 & 0.1 & 29.0 & 29.1 \\
\hline 8 & 80 & 1.3 & 27.0 & 28.3 \\
\hline 9 & 90 & 0.8 & 34.6 & 35.4 \\
\hline 10 & 100 & 0.7 & 36.7 & 37.4 \\
\hline
\end{tabular}

Conforme o gráfico da Figura 50 , pode ser observado que $T_{\text {com }}$ é praticamente constante, e que $\mathrm{T}_{\mathrm{arq}}$ é linear em função do número de arquivos.

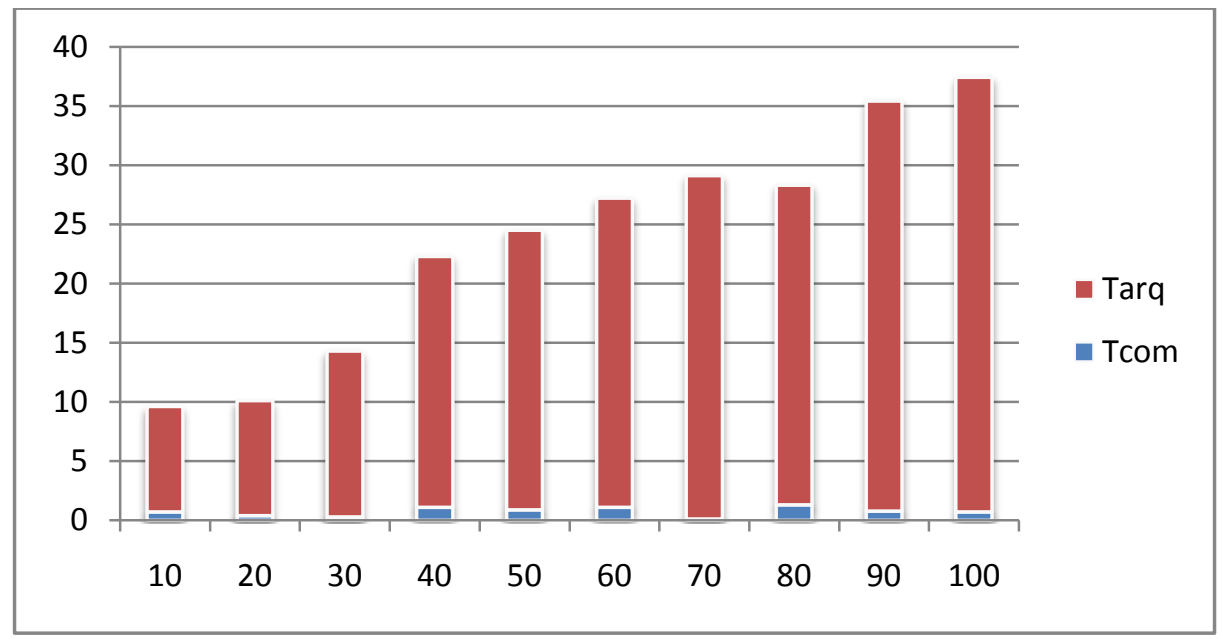

Figura 50: desempenho (em segundos) do middleware em função do número de arquivos de saída com uma atividade 


\subsubsection{Variação do Número de Arquivos de Saída com Diversas Atividades}

Estes testes consideram a variação de 10 a 100 arquivos de saída, em múltiplos de 10 arquivos. O tamanho dos arquivos é fixo em $10 \mathrm{~KB}$ cada. Os arquivos foram distribuídos igualmente em dez atividades. A Tabela 10 apresenta os dados obtidos neste teste.

Tabela 10: testes de desempenho em função do número de arquivos de saída com dez atividades (tempos em segundos)

\begin{tabular}{|l|l|l|l|l|}
\hline$\#$ & Número de Arquivos & $\mathrm{T}_{\text {com }}$ & $\mathrm{T}_{\text {arq }}$ & $\mathrm{T}_{\text {total }}$ \\
\hline 1 & 10 & 1.3 & 72.5 & 73.8 \\
\hline 2 & 20 & 1 & 71.7 & 72.7 \\
\hline 3 & 30 & 1.4 & 75.6 & 77.0 \\
\hline 4 & 40 & 1.5 & 78.9 & 80.4 \\
\hline 5 & 50 & 1.5 & 85.6 & 87.1 \\
\hline 6 & 60 & 0.8 & 79.0 & 79.8 \\
\hline 7 & 70 & 0.7 & 92.1 & 92.8 \\
\hline 8 & 80 & 1.7 & 90.1 & 91.8 \\
\hline 9 & 90 & 1.6 & 93.5 & 95.1 \\
\hline 10 & 100 & 1.3 & 101.7 & 103.0 \\
\hline
\end{tabular}

Conforme o gráfico da Figura 51, pode ser observado que $T_{\text {com }}$ é praticamente constante, e que $\mathrm{T}_{\text {arq }}$ é linear em função do número de arquivos.

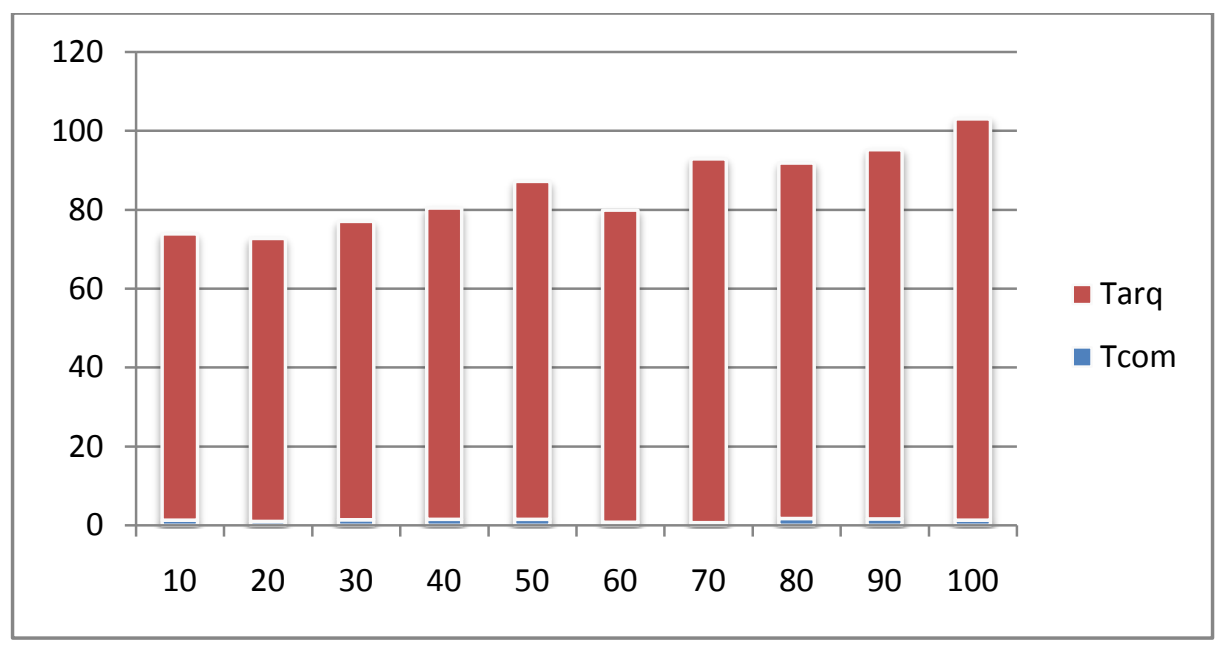

Figura 51: desempenho (em segundos) do middleware em função do número de arquivos de saída com dez atividades 


\subsubsection{Desempenho em Função do Tamanho dos Arquivos}

Assim como no caso do desempenho em função do número de arquivos, o tamanho dos arquivos influencia o tempo dos comandos SCP, portanto produzindo impacto no desempenho do middleware.

Estes testes consideram o envio de um arquivo de entrada, com tamanho variando de $10 \mathrm{MB}$ a $100 \mathrm{MB}$, em múltiplos de 10MB. A Tabela 11 apresenta os dados obtidos neste teste.

Tabela 11: testes de desempenho em função do tamanho dos arquivos (tempos em
\begin{tabular}{|l|l|l|l|l|}
\hline$\#$ & Tamanho do Arquivo (MB) & $\mathrm{T}_{\text {com }}$ & $\mathrm{T}_{\text {arq }}$ & $\mathrm{T}_{\text {total }}$ \\
\hline 1 & 10 & 1.7 & 14.0 & 15.7 \\
\hline 2 & 20 & 0.7 & 14.4 & 15.1 \\
\hline 3 & 30 & 0.3 & 15.8 & 16.1 \\
\hline 4 & 40 & 1.2 & 20.4 & 21.6 \\
\hline 5 & 50 & 1.1 & 31.0 & 32.1 \\
\hline 6 & 60 & 1.1 & 26.1 & 27.2 \\
\hline 7 & 70 & 1.4 & 36.9 & 38.3 \\
\hline 8 & 80 & 0.9 & 36.7 & 37.6 \\
\hline 9 & 90 & 1 & 34.0 & 35.0 \\
\hline 10 & 100 & 0.7 & 45.4 & 46.1 \\
\hline
\end{tabular}

Conforme o gráfico da Figura 52, pode ser observado que $T_{\text {com }}$ é praticamente constante. $T_{\text {arq }}$ é diretamente proporcional ao tamanho do arquivo.

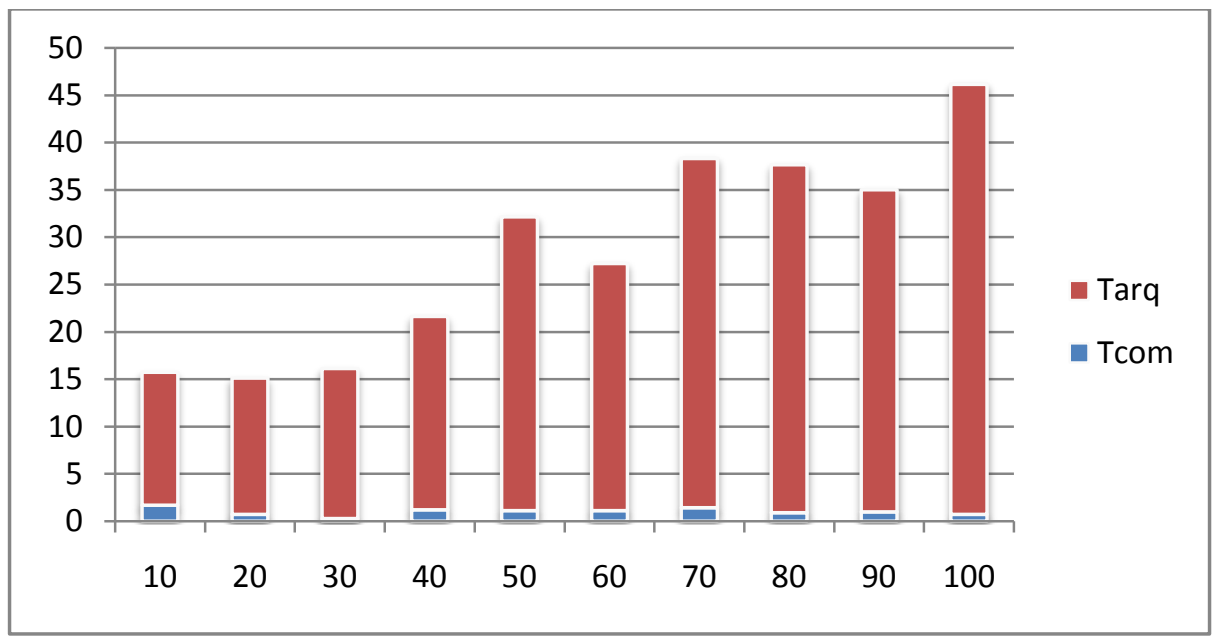

Figura 52: desempenho (em segundos) do middleware em função do tamanho dos arquivos 


\subsection{Testes de Independência de Plataforma}

A arquitetura apresentada neste trabalho foi implementada considerando seu uso e extensão em diferentes plataformas. Por esse motivo, o desenvolvimento foi realizado, conforme descrito na Seção 6.1, utilizando as seguintes ferramentas e linguagens de programação: NetBeans/Java e Visual Studio/C\#. Outras ferramentas e linguagens também podem ser utilizadas, contanto que permitam o desenvolvimento de serviços web.

A plataforma de execução, por sua vez, pode ser homogênea ou heterogênea. Assim, a aplicação cliente pode estar em plataforma distinta do middleware que, por sua vez, pode estar em plataforma distinta daquela onde se encontra o gerenciador da grade.

As combinações dessas possibilidades foram testadas, e estão listadas na Tabela 12.

Tabela 12: testes de independência de plataforma

\begin{tabular}{|l|l|l|l|l|l|l|}
\hline \multirow{2}{*}{$\#$} & \multicolumn{2}{|c|}{ Aplicação cliente } & \multicolumn{2}{c|}{ EGP, EEP, IPG } & \multicolumn{2}{c|}{ EGG } \\
\cline { 2 - 7 } & Desenv. & Execução & Desenv. & Execução & Desenv. & Execução \\
\hline 1 & C\# & Windows & C\# & Windows & C\# & Windows \\
\hline 2 & Java & Linux & C\# & Windows & Java & Linux \\
\hline 3 & C\# & Windows & C\# & Windows & Java & Linux \\
\hline
\end{tabular}

O teste 1 ilustra o desenvolvimento e execução utilizando uma linguagem de desenvolvimento e uma plataforma de execução. Trata-se do cenário homogênio, exemplificado pelos testes com as aplicações de Soma, Cálculo de $\pi$ e Torres de Hanoi, descritas na Seção 7.1.

O teste 2 é representado pela execução do BRAMS sobre o Ourgrid. Aqui é mostrado um exemplo de independência de plataforma entre: 1) a aplicação cliente (daemon desenvolvido em Java e utilizado sobre Linux) e sua comunicação com o EGP (C\# sobre Windows); 2) as camadas do middleware (IPG em C\# sobre Windows com EGG em Java sobre Linux). Este teste demonstra ser possível a substituição dos serviços do middleware por outros desenvolvidos e utilizados em outra plataforma.

O teste 3 mostra a independência entre a plataforma cliente e servidora. Para esse teste, foi desenvolvido um EGG para execução sem grade, que dispara comandos no servidor.

A utilização de SSH e SCP para transferência de arquivos teve como objetivo garantir a independência de plataforma nesse quesito. Todavia, tal escolha foi responsável pela maior parte do tempo de execução do middleware, conforme pode ser observado nos testes de desempenho descritos na Seção 7.3. 


\subsection{Testes de Extensibilidade}

A implementação possui duas camadas que podem ser estendidas: Executores Específicos de Padrões (EEPs) e Executores para Gerenciadores de Grades (EGGs). Inicialmente foram desenvolvidos um EEP (para o PJC) e um EGG (para execução sem grade, de aplicações em bibliotecas .NET).

Posteriormente foi desenvolvido um EEP para permitir a execução paralela do padrão de Sincronização, descrito na Seção 4.1.2. Embora o comportamento deste padrão possa ser obtido configurando-se o PJC com CancelActivities = False e NumberOfReady = <número de atividades a executar $>$, este novo EEP é de implementação mais simples.

Foram também criados mais dois EGGs: para Ourgrid e para execução genérica sem grade. Este último permitiu a realização do teste de desacoplamento descrito na Seção 7.6.

\subsection{Testes de Desacoplamento}

Para comprovar o baixo acoplamento da arquitetura proposta e implementada nesta pesquisa, foram realizados três experimentos:

1. Desacoplamento entre o middleware e a utilização ou não de gerenciador de workflow. O middleware foi utilizado a partir do Windows Workflow Foundation, conforme apresentado na Seção 6.6. Além disso, foi utilizado também sem a presença de gerenciador de workflow, nos testes com o Load Generation Tool ou 0 GridSphere/daemon para submissão de jobs ao Ourgrid;

2. Desacoplamento entre o middleware e a utilização ou não de gerenciador de grade. O primeiro caso pode ser observado nos testes utilizando o Ourgrid e o segundo naqueles utilizando o Load Generation Tool;

3. Desacoplamento entre a aplicação de e-Science e o gerenciador de grade. É uma decorrência do caso anterior. Esse teste foi possível a partir da implementação do EGG para execução genérica sem grade. Seu uso permitiu a criação de modelos com o BRAMS sem utilizar o Ourgrid. O EGG a ser utilizado é informado ao middleware pela aplicação cliente, no atributo Grid do XML de entrada, conforme descrito na Seção 5.1.5.1. 


\subsection{Conclusão}

A arquitetura de baixo acoplamento implementada resultou em um middleware que acrescenta custo em termos de desempenho. Entretanto, esse custo é diretamente proporcional ao número e tamanho dos arquivos transferidos pelo middleware entre a aplicação cliente e o servidor onde se encontra o EGG. Já o impacto devido ao uso de serviços web e o tempo de comunicação entre as camadas, identificados na implementação como fatores que poderiam reduzir o desempenho, mostrou-se desprezível nos testes realizados, uma vez que o número de chamadas aos serviços é reduzido. 


\section{Capítulo 8}

\section{Conclusão}

Existem vários trabalhos científicos voltados a soluções de workflows em grades e sobre a implementação ou não de padrões de controle de fluxo por produtos comerciais ou de código aberto. Todavia, a relação entre os gerenciadores de workflow e de grade não foi explorada de modo a permitir que o cientista defina seus fluxos com a utilização de padrões para paralelização que tornem transparente a existência ou não da grade.

Nesta proposta, foi apresentada uma arquitetura de baixo acoplamento que torna transparente: a utilização ou não de grade; e a implementação de padrões de execução de workflow. Foi descrito também o Padrão Junção Combinada, que oferece alternativas para a execução paralela de atividades. Isto permite ao cientista ter a eficiência desejada na solução de problemas e ao mesmo tempo se concentrar nas pesquisas de sua área de atuação sem ter preocupações de ordem operacional.

A arquitetura empregada, orientada a serviços, oferece flexibilidade e extensibilidade à solução, ao contrário dos demais trabalhos mencionados neste texto.

Os testes comprovaram a abstração do gerenciador de grade para 0 cientista e o baixo impacto causado pelo uso de serviços web.

O impacto no desempenho devido ao mecanismo de transferência de arquivos sugere otimizações nesse aspecto. Além disso, contra-indica o uso desta solução para a execução de atividades de baixa complexidade.

Esta solução se aplica aos casos de execução paralela de tarefas independentes, chamadas "bag-of-tasks". 


\subsection{Principais Contribuições}

A definição do PJC foi o primeiro resultado desta pesquisa, tendo sido apresentado na forma de artigo científico no e-Science Workshop do Simpósio Brasileiro de Bancos de Dados 2007, intitulado "Padrões para Controle de Fluxo e sua Execução em Grade" [78].

A arquitetura do middleware foi descrita no artigo científico "Um Padrão Canônico para Controle de Paralelização em Aplicações de e-Science" [79], apresentado no Application Track do Simpósio Brasileiro de Bancos de Dados 2008.

A arquitetura e os resultados obtidos estão sendo descritos em novo artigo, a ser submetido a uma conferência internacional.

Este trabalho é também base para pesquisa sobre requisitos não funcionais em ambiente distribuído, sendo iniciada na Universidade Federal de Pernambuco pelo aluno de mestrado Fabiano Arruda Ferreira das Graças, com título provisório "Instrumentação e Monitoramento de Padrões de Workflow em sua Execução em Grade sobre Uma Arquitetura de Baixo Acoplamento".

\subsection{Sugestões de Trabalhos Futuros}

Como sugestões para trabalhos futuros estão o tratamento de requisitos não funcionais, como segurança, tolerância a falhas, monitoramento e gerenciamento de workflows em grades.

A implementação de outros padrões para apoio à execução de atividades que se comuniquem também foge ao escopo deste trabalho, ficando como proposta de trabalho futuro.

Como otimização do sistema, o middleware pode avaliar o sistema operacional e o tipo de rede utilizada (LAN, Internet ou execução em um único computador), e então optar pelo método mais apropriado para execução, como grade ou cluster, por exemplo. Para trânsito de arquivos pequenos (até $500 \mathrm{~KB}$ ), foram realizados testes utilizando-se serialização dos arquivos em memória, e seu envio ao EGG como um novo atributo do objeto Job.

Este trabalho foi brevemente apresentado ao grupo de trabalho de workflow da Microsoft Research, divisão de pesquisa da Microsoft Corporation, tendo despertado interesse na realização de atividades conjuntas. O grupo pesquisa atualmente a representação gráfica dos resultados de execução de workflows. 


\section{Apêndice A}

\section{Diagramas de Classes da Implementação}

O Capítulo 6 descreve os principais elementos da implementação da solução proposta neste texto. Todavia, embora as definições das interfaces estejam lá descritas, a representação em diagramas UML é de particular interesse para o desenvolvedor que tiver a intenção de modificar ou estender os elementos do middleware. Por esse motivo, este apêndice apresenta as classes e interfaces de cada camada. Em resumo, as classes e interfaces de cada camada podem ser divididas em três grupos:

- Classes e interfaces que definem os serviços web: correspondem àquelas descritas no Capítulo 6;

- Classes e interfaces que descrevem os contratos entre o serviço da camada sendo descrito e os serviços de camadas adjacentes. Por vezes, essas classes e interfaces são ditas proxies;

- Classes e interfaces internas, para uso apenas pelo serviço sendo descrito.

Além da definição das classes que compõem o middleware, aqui também são apresentadas as classes parciais Job, Activity e Parameter, que representam o contrato de dados transferido entre camadas, e que deve ser de conhecimento principalmente do desenvolvedor de EGGs. Essas classes são acrescidas de atributos específicos em cada camada em que são utilizadas. [80].

A geração dos diagramas foi realizada utilizando a ferramenta UModel 2008 


\section{A.1 Interfaces e Classes Utilizadas e Expostas pelo EGP}

A Figura 53 apresenta a interface IEgp e a classe EgpService, descritos na Seção 6.3.2, expostas para uso pelas aplicações clientes. Esse é o ponto de entrada para o middleware. É partir da interface IEgp que se obteve o proxy para o EGP, utilizado pela aplicação cliente. Tal proxy é composto pela interface IEgp ${ }^{8}$ e pela sua implementação, EgpClient, conforme descrito na Seção 6.2.3.

\begin{tabular}{|c|}
\hline $\begin{array}{c}<<\text { interface }> \\
\text { IEgp }\end{array}$ \\
\hline $\begin{array}{c}+ \text { ExecuteWorkflow(in xml:string, in pattern:string):string } \\
+ \text { IsExecutingWorkflow(in workflowld:string, in pattern:string):bool } \\
+ \text { GetWorkflowState(in workflowld:string, in pattern:string):string } \\
\end{array}$ \\
\hline (from Services) \\
\hline$\ldots$ \\
\hline $\begin{array}{l}+ \text { EgpService() } \\
+ \text { ExecuteWorkflow(in xml:string, in pattern:string):string } \\
+ \text { IsExecutingWorkflow(in workflowld:string, in pattern:string):bool } \\
+ \text { GetWorkflowState(in workflowld:string, in pattern:string):string } \\
\quad \ldots\end{array}$ \\
\hline
\end{tabular}

Figura 53: interface IEgp exposta pelo EGP e classe EgpService, que a implementa

A Figura 54 representa as classes internas Mapping e EgpConfiguration utilizadas para representar e consultar as informações do Mapa Padrão-Implementação, descrito na Seção 5.1.5.1.

\footnotetext{
${ }^{8}$ Embora a interface no proxy tenha o mesmo nome da interface no serviço (neste caso, IEgp), isso não é obrigatório. O gerador o faz para simplificar a localização das interfaces.
} 


\begin{tabular}{|c|}
\hline \begin{tabular}{|c|} 
Mapping \\
(from Configuration)
\end{tabular} \\
\hline$\ldots$ \\
\hline $\begin{array}{ll}+ & \text { Mapping() } \\
+ & \text { Mapp():List }<\mathrm{T} 1->\text { string }> \\
+ & \text { Name(): } \text { string }\end{array}$ \\
\hline
\end{tabular}

\begin{tabular}{|l|}
\hline $\begin{array}{c}\text { EgpConfiguration } \\
\text { (from Configuration) }\end{array}$ \\
\hline$\ldots$ \\
\hline+ EgpConfiguration() \\
+ EepMapping():List $<\mathrm{T} 1$ 1->Mapping $>$ \\
$\quad \ldots$
\end{tabular}

Figura 54: classes internas para tratamento do Mapa Padrão-Implementação

$\mathrm{Na}$ Figura 55 são apresentadas as interfaces IEepEgpChannel e IEepEgp, e a classe EepEgpClient, correspondentes ao proxy gerado pelo ambiente de desenvolvimento a partir da interface IEepEgp exposta pelos EEPs.

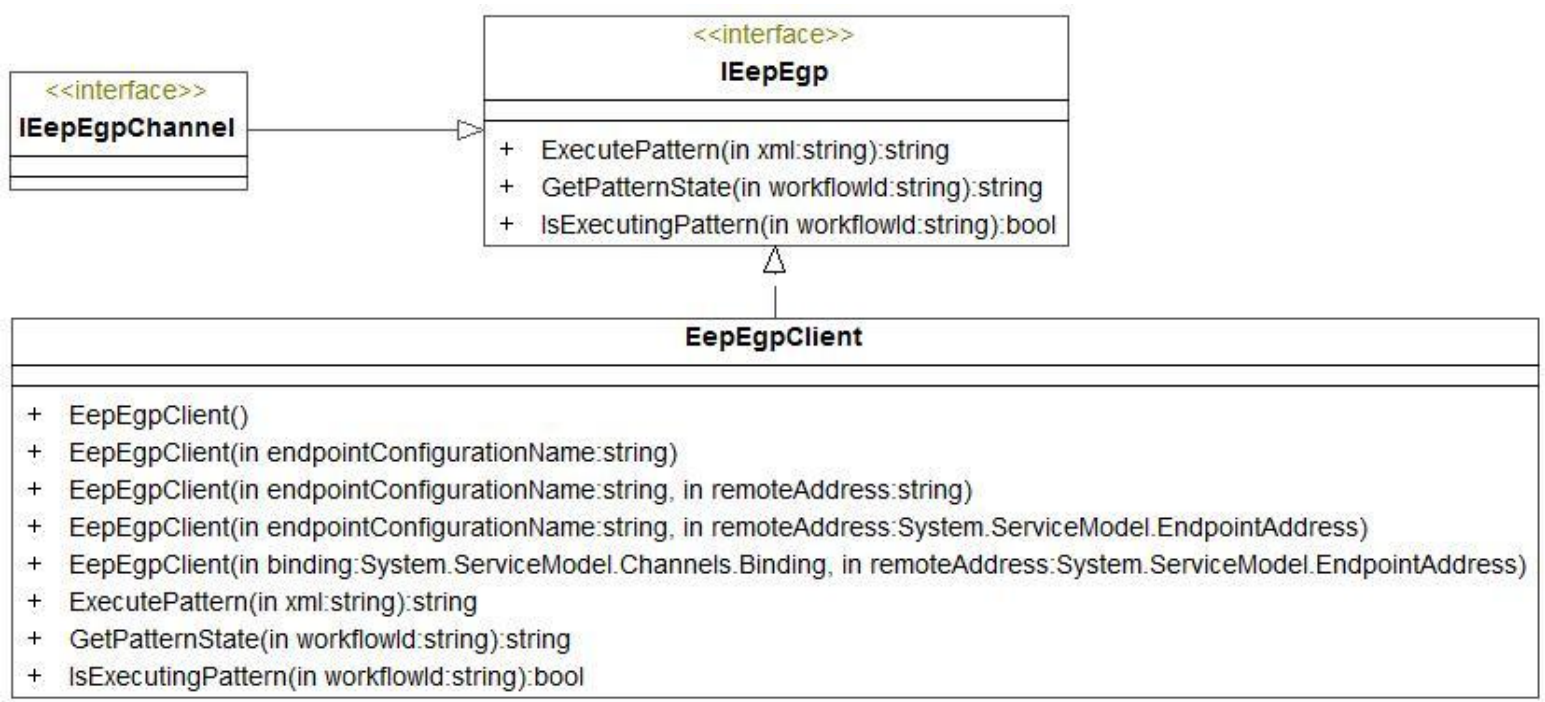

Figura 55: proxy utilizado pelo EGP para acessar os EEPs 


\section{A.2 Interfaces e Classes Utilizadas e Expostas pelos EEPs}

A Figura 56 apresenta a interface IEepEgp que contém as operações expostas ao EGP - descritas na Seção 6.3.3 - e a interface IEepIpg com a operação que expõe ao IPG - descrita na Seção 6.3.4. Além disso, a figura mostra a classe EepPjcService, que é a implementação das duas interfaces anteriores, para o PJC.

Todo EEP deve expor essas interfaces e implementá-las em uma classe, cujo nome não precisa ser fixo - para o PJC é EepPjcService. O que muda, em relação ao PJC, são os endpoints nos mapas que o EGP e o IPG utilizam.

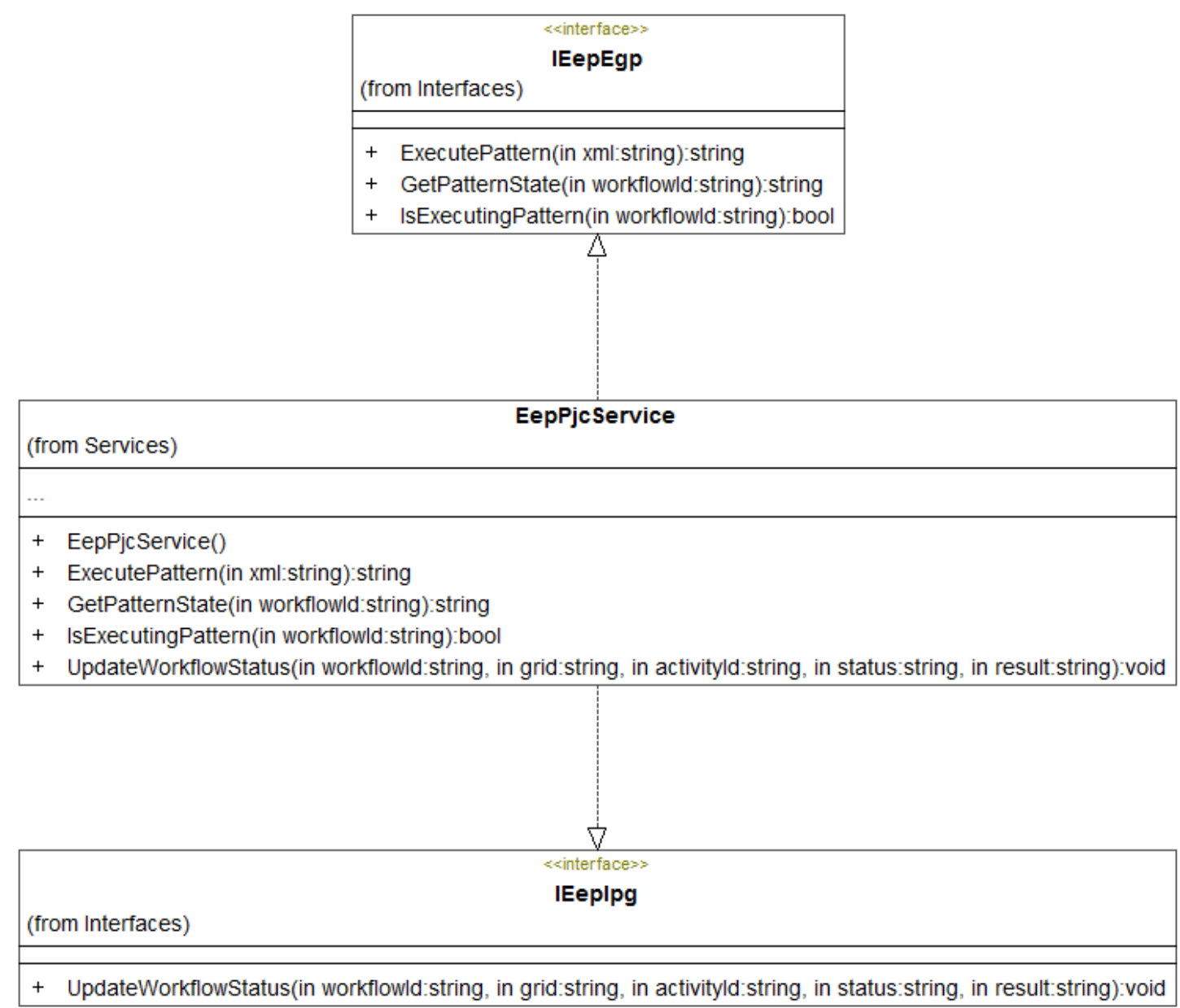

Figura 56: interfaces expostas pelo EEP e classe EepPj cService, que as implementa

A implementação do PJC persiste o estado de execução das atividades em banco de dados, conforme descrito na Seção 6.3.3. Para isso, o PJC utiliza as classes DRConnection e PjcRepository, ilustradas na Figura 57: 
- DRConnection: contém operações genéricas de acesso ao repositório de $\operatorname{dados}^{9}$. Sua implementação segue o padrão Singleton [12];

- PjcRepository: contém operações para gerenciamento de estado do PJC, que utilizam procedimentos armazenados no banco de dados de persistência, descrito no Apêndice B.

\begin{tabular}{|ll|}
\hline \multicolumn{1}{|c|}{ DRConnection } \\
(from DataAcess) \\
\hline$\ldots$ \\
\hline+ DRConnection() \\
+ DRConnection(in database:string) \\
+ ConcreteDataBase():Database \\
+ ExecuteDataSet(in dbCommand:DbCommand):DataSet \\
+ ExecuteReader(in dbCommand:DbCommand):IDataReader \\
+ ExecuteNonQuery(in cmd:DbCommand):void \\
+ ExecuteNonQueryTransaction(in dbCommand:DbCommand):void \\
+ Commit():bool \\
+ Dispose():void
\end{tabular}

\begin{tabular}{|l|}
\hline (from DataAcess) \\
\hline$\ldots$ \\
\hline+ PjcRepository() \\
+ InsertWorkflowState(in workflowld:string, in numberOfReady:int, in pattern:string, in cancelActivities:string, in grid:string):void \\
+ InsertWorkflowStateActivities(in workflowld:string, in activityld:string, in result:string):void \\
+ UpdateWorkflowStateActivities(in workflowld:string, in activityld:string, in status:string, in result:string):void \\
+ GetWorkflowResult(in workflowld:string):DataSet \\
+ SelectWorkflowState(in workflowld:string):DataSet \\
+ Commit():void
\end{tabular}

Figura 57: classes internas ao EEP para PJC, que realizam persistência de estado do padrão

O EEP utiliza operações disponibilizadas pelo IGP na interface IIpgEep, descrita na Seção 6.3.4. A partir dessa interface, é gerado um proxy, ilustrado na Figura 58 e composto pelas interfaces IIpgEepChannel e IIpgEep, e pela classe IpgEepclient.

${ }^{9}$ O prefixo DR no nome da classe DRConnection se originou do termo "Data Repository" 


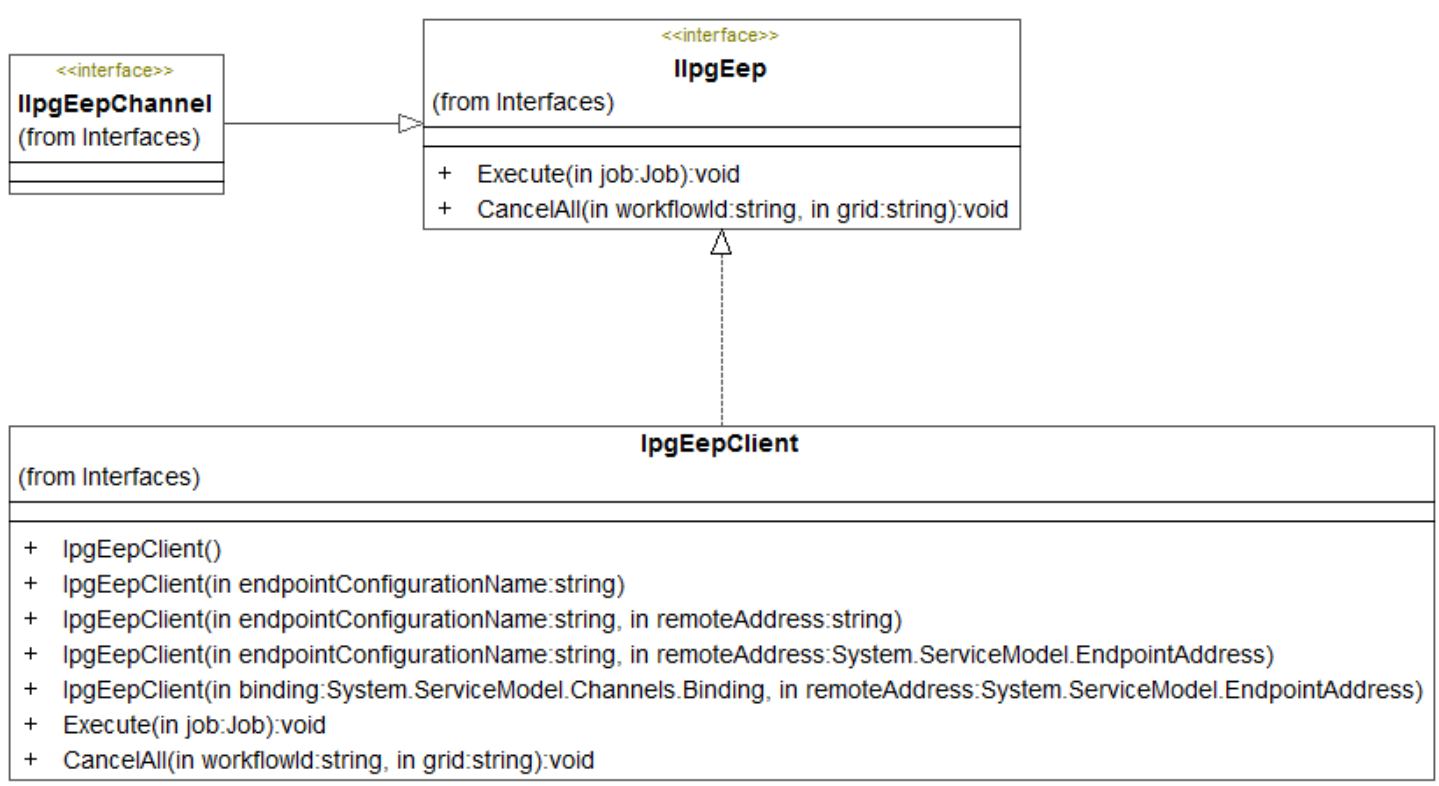

Figura 58: proxy utilizado pelos EEPs para acessar o IPG

Para que os EEPs possam utilizar a operação Execute do IPG, devem enviar a ele uma representação em objetos para os elementos que receberam no XML. Isso é obtido com as classes parciais Job, Activity e Parameter, apresentadas na Figura 59. Os atributos CancelActivities, DynamicInstance e NumberofReady são específicos para o PJC. Por isso, constam apenas do EEP para o PJC, e não são enviados ao IPG. Vale notar que outros EEPs podem demandar outros atributos.

\begin{tabular}{|ll|}
\hline \multicolumn{1}{|c|}{ Job } \\
(from Interfaces) \\
\hline$\ldots$ & \\
\hline+ & Activities():Activity[ $\left.{ }^{*}\right]$ \\
+ & CancelActivities():bool \\
+ & ClientAddress():string \\
+ & Dynamiclnstance():bool \\
+ & Grid():string \\
+ & NumberOfReady():int \\
+ & Pattern():string \\
+ & Workflowld():string \\
& $\quad$.. \\
\hline
\end{tabular}
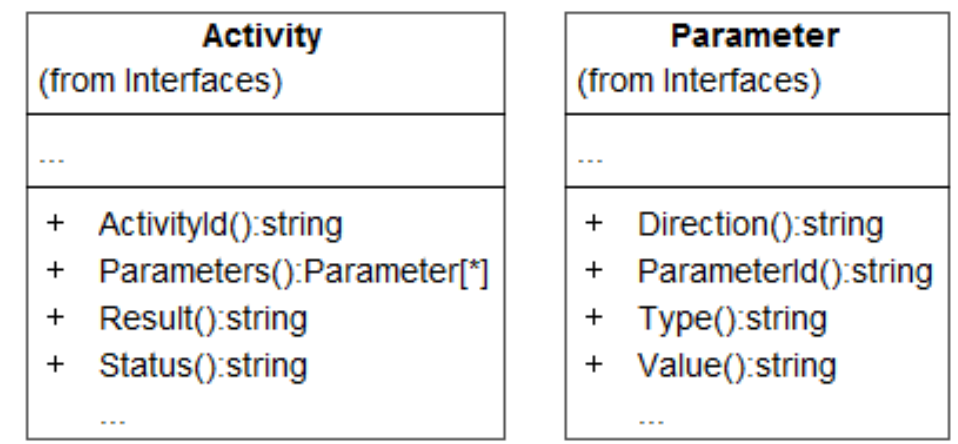

Figura 59: classes para o contrato de dados utilizado pelo EEP para o PJC 


\section{A.3 Interfaces e Classes Utilizadas e Expostas pelo IPG}

A Figura 60 apresenta a interface IIpgEep que contém as operações expostas aos EEPs - descritas na Seção 6.3.4 - e a interface IIpgEgg com a operação que expõe aos EGGs - descrita na Seção 6.3.5. Além disso, a figura mostra a classe IpgService, que é a implementação das duas interfaces anteriores.

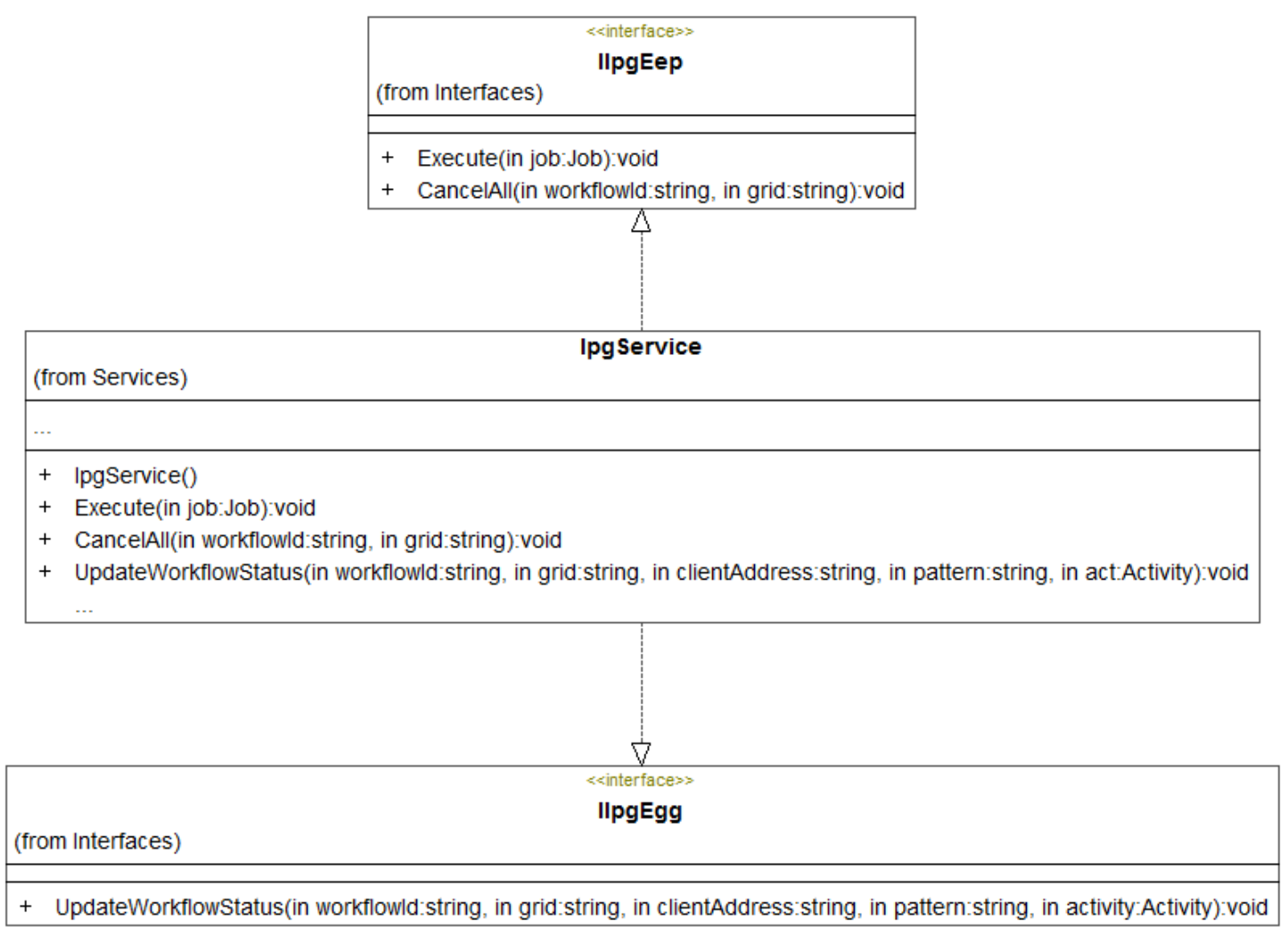

Figura 60: interfaces expostas pelo IPG e classe IpgService, que as implementa

De acordo com a Seção 6.4, o IPG é responsável pelo envio de arquivos de entrada e saída entre o servidor de arquivos onde a aplicação de e-Science se encontra e aquele onde fica o EGG e o Gerenciador da Grade. Para tanto, representa os elementos de acesso às conexões SSH na classe SshHost e utiliza as operações da classe IpgFileManager, ambas apresentadas na Figura 61. 


\begin{tabular}{|l|}
\hline \multicolumn{1}{|c|}{ SshHost } \\
\hline (from Ssh) \\
\hline$\sim$ Host():string \\
$\sim$ User():string \\
$\sim$ Pwd():string \\
$\sim$ SshConn():SshTransferProtocolBase \\
\hline
\end{tabular}

\begin{tabular}{|l|}
\hline (from Services) \\
\hline+ CopyFilesToJob(in job.Job):void \\
\hline+ CopyFilesFromActivity(in workflowld string, in grid.string, in clientAddress.string, in activity:Activity):void \\
\hline$\ldots$
\end{tabular}

Figura 61: classes utilizadas pelo IPG para transferência de arquivos usando SSH

A Figura 54 representa as classes internas EepMapping, EggMapping e EgpConfiguration utilizadas para representar e consultar as informações do Mapa Grade-Implementação, descrito na Seção 5.1.5.3.

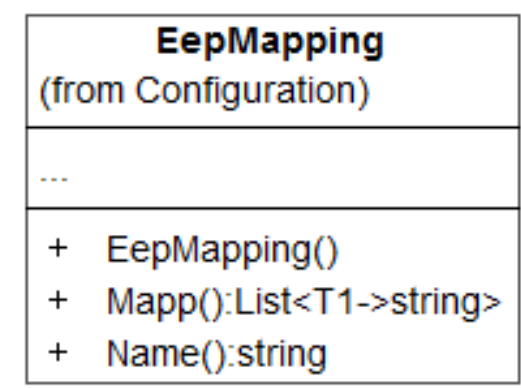

\begin{tabular}{|ll|}
\hline \multicolumn{1}{|c|}{$\begin{array}{c}\text { EggMapping } \\
\text { (from Configuration) }\end{array}$} \\
\hline$\ldots$ \\
\hline$+\quad$ EggMapping() \\
$+\quad$ Mapp():List $<$ T1->string $>$ \\
$+\quad$ Name(): string \\
\hline
\end{tabular}

Figura 62: classes internas para tratamento do Mapa Grade-Implementação

O IPG utiliza operações disponibilizadas pelos EEPs na interface IEepIpg, descrita na Seção 6.3.4. A partir dessa interface, é gerado um proxy, ilustrado na 
Figura 63 e composto pelas interfaces IEepIpgChannel e IEepIpg, e pela classe EepIpgClient.

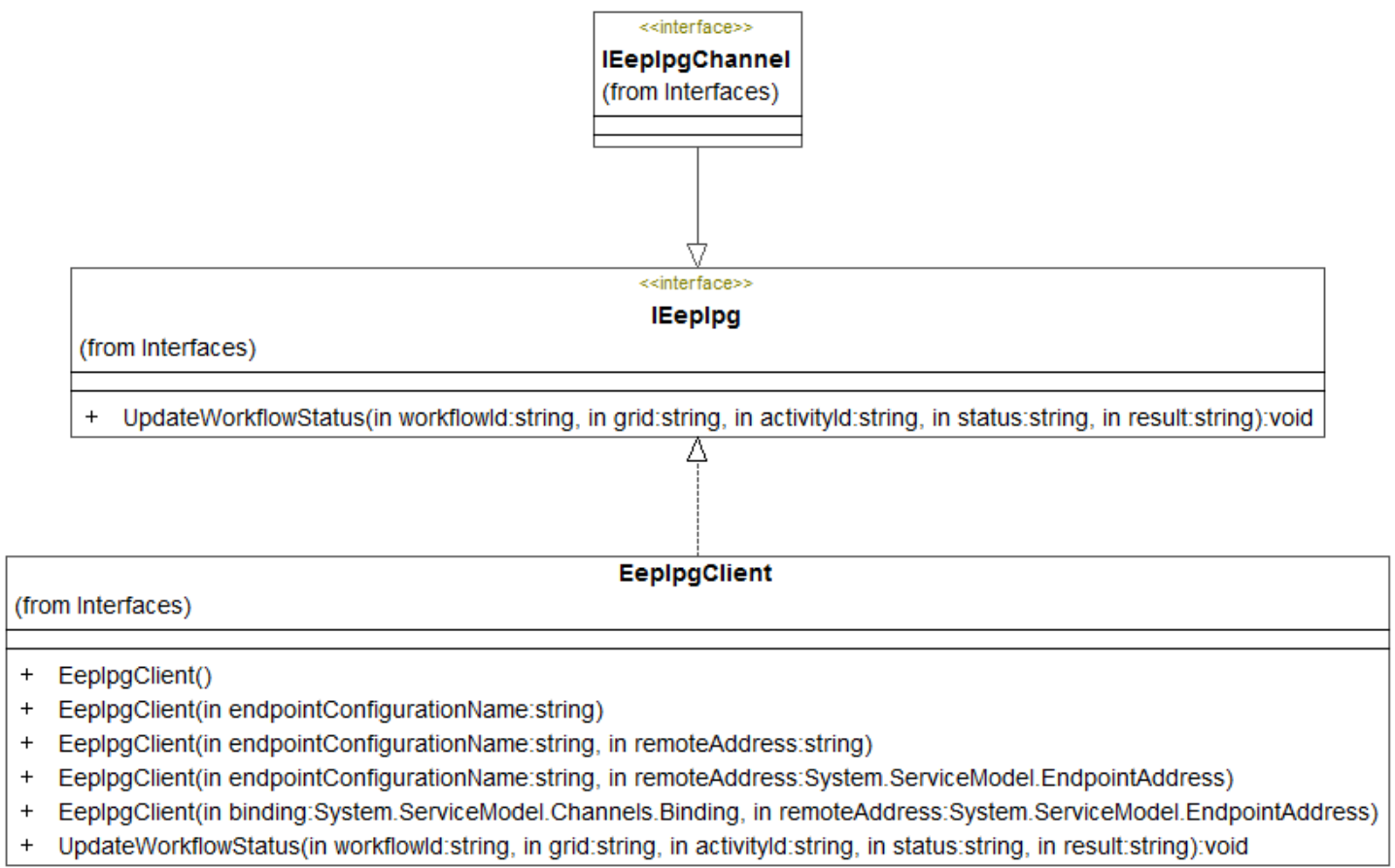

Figura 63: proxy utilizado pelo IPG para acessar os EEPs

De modo semelhante, o IPG utiliza operações disponibilizadas pelos EGGs na interface IEggIpg, descrita na Seção 6.3.5. A partir dessa interface, é gerado um proxy, ilustrado na Figura 63 e composto pelas interfaces IEepIpgChannel e IEepIpg, e pela classe EepIpgClient.

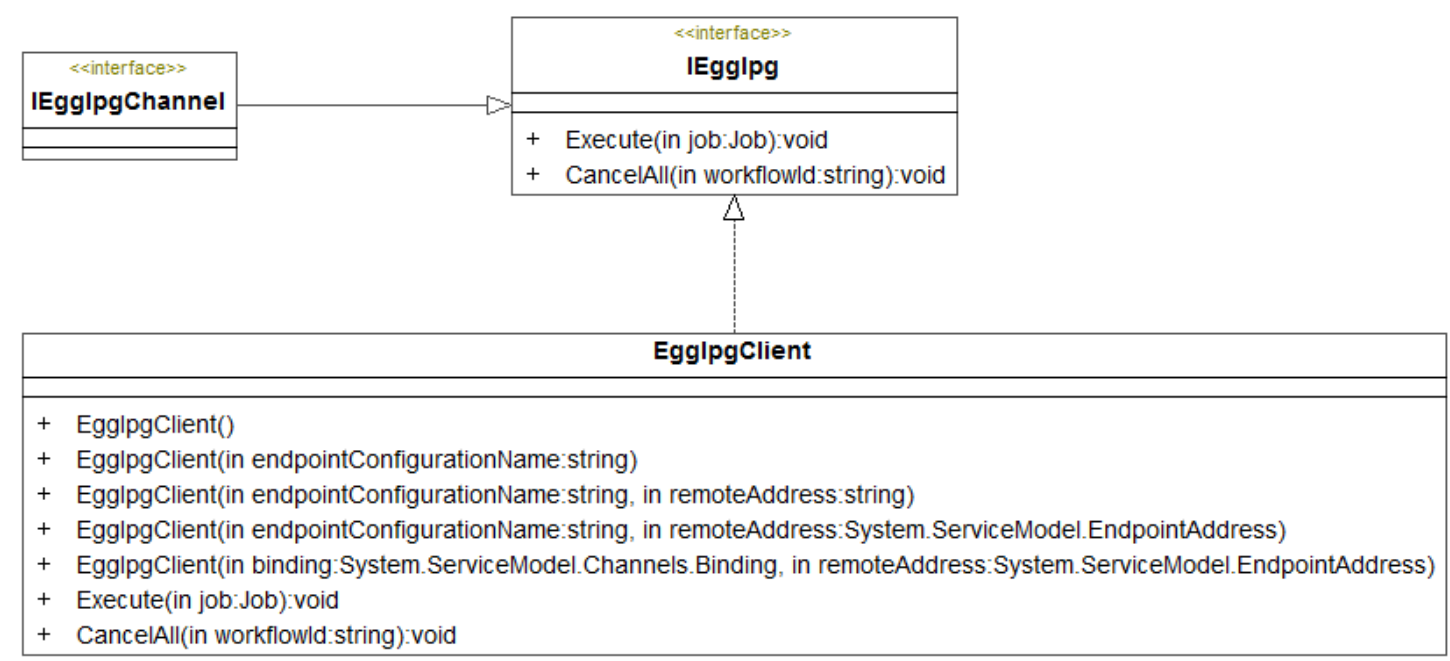

Figura 64: proxy utilizado pelo IPG para acessar os EGGs 
As classes para os contratos de dados - Job, Activity e Parameter recebidas dos EEPs, utilizadas e encaminhadas aos EGGs não possuem atributos para uso exclusivo do IPG, como pode ser observado na Figura 65.

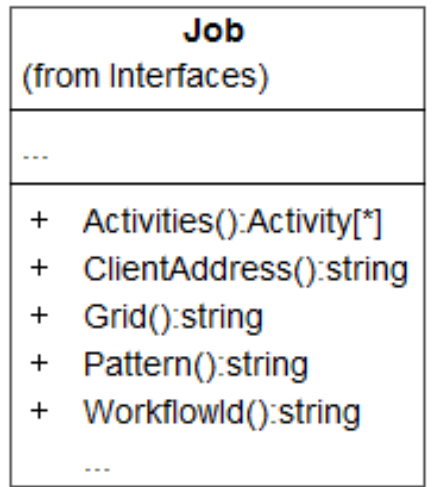
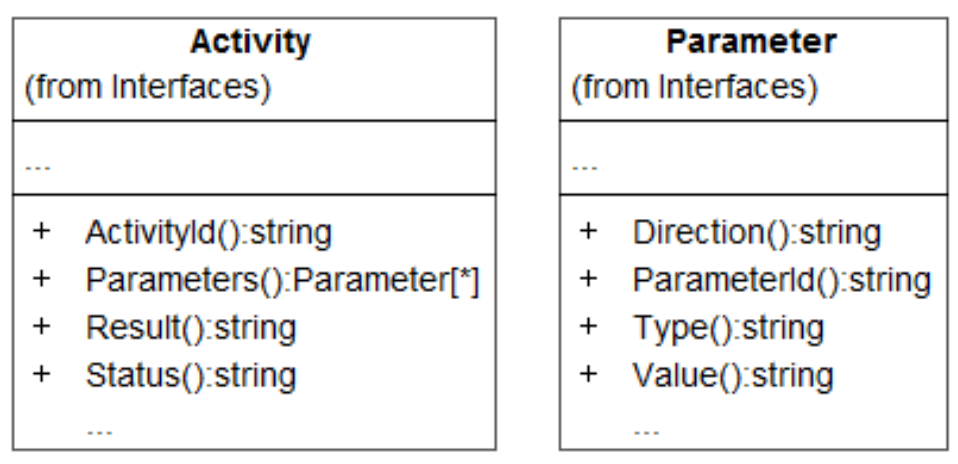

Figura 65: classes para o contrato de dados utilizado pelo IPG

\section{A.4 Interfaces e Classes Utilizadas e Expostas pelos EGGs}

A Figura 60 apresenta a interface IEggIpg que contém as operações expostas ao IPG - descritas na Seção 6.3.5. Essa interface deve ser implementada nos EGGs. Na figura está exemplificada a classe EggThreadService.

\begin{tabular}{|c|}
\hline \multicolumn{1}{|c|}{$\begin{array}{c}\text { <einterfaces } \\
\text { IEgglpg }\end{array}$} \\
\hline (from Interfaces)
\end{tabular}

Figura 66: interface IEggIpg exposta pelo EGP e classe EggThreadService, que a implementa 
O EGG acima, para uso sem grade, mantém um conjunto de threads, onde cada uma executa uma das atividades. A classe ThreadManager, ilustrada na Figura 67 faz esse gerenciamento das threads.

\begin{tabular}{|l|l|}
\hline (from Services) & ThreadManager \\
\hline$\ldots$ & \\
\hline+ & Getlnstance():ThreadManager \\
+ & Clear():void \\
+ & Count():int \\
+ & LastValue():string \\
+ & Cancel():void \\
+ & CancelAll(in workflowld:string):void \\
+ & Start(in job:Job):void \\
+ & ThreadActivityCallbackProc(in workflowld:string, in act:Activity, in appDomain:AppDomain):void \\
&
\end{tabular}

Figura 67: classe interna do EggThreadService, para gerenciamento das threads de execução

Os EGGs utilizam operações disponibilizadas pelo IPG na interface I IpgEgg, descrita na Seção 6.3.5. A partir dessa interface, é gerado um proxy, ilustrado na Figura 68 e composto pelas interfaces IIpgEggChannel e I IpgEgg, e pela classe IpgEggClient.

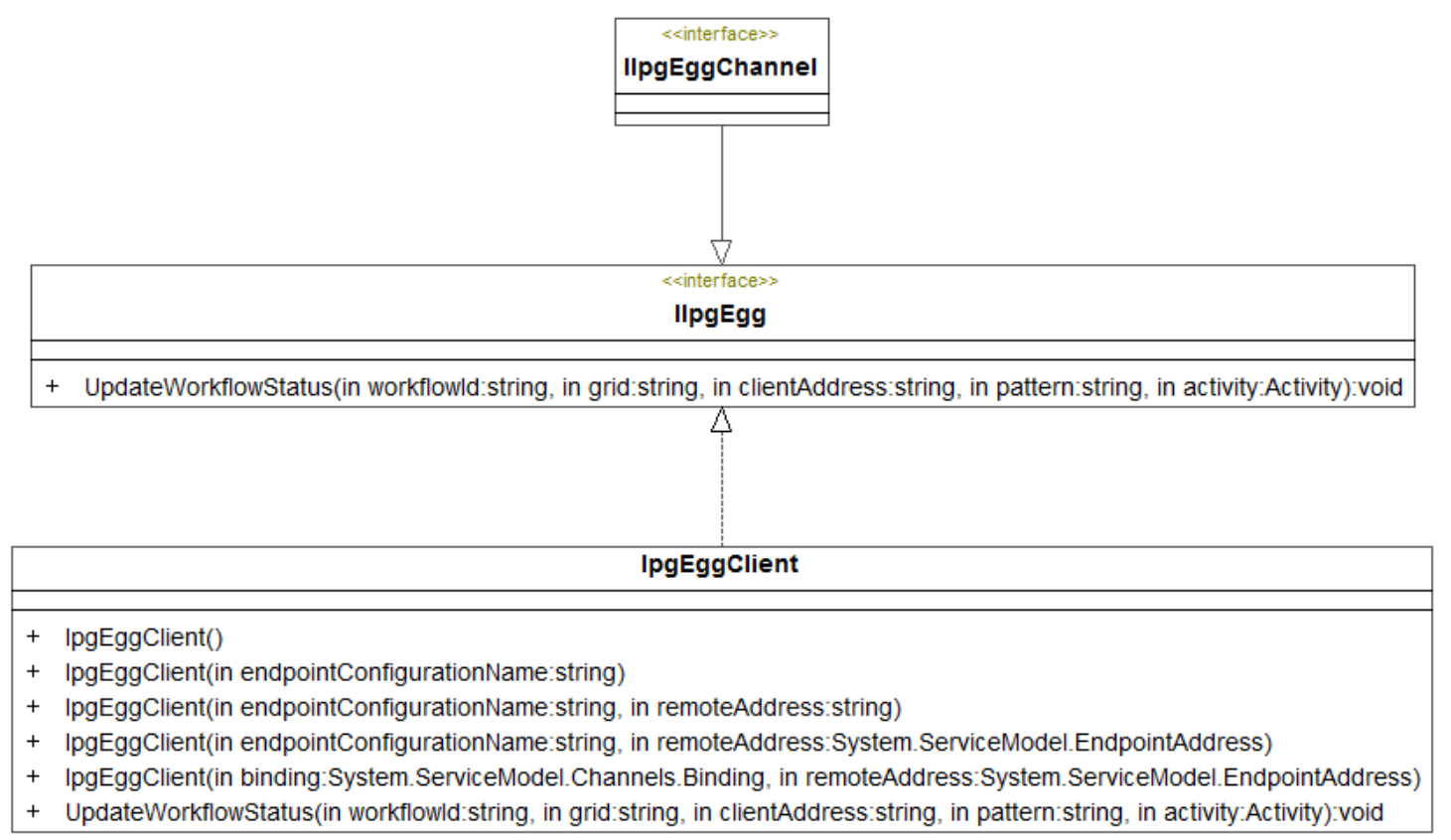

Figura 68: proxy utilizado pelos EGGs para acessar o IPG 
Com relação às classes que representam o contrato de dados utilizado no EGG de threads, o atributo ThreadId é acrescido à classe Activity, uma vez que será utilizada uma thread por atividade. Isso é representado na Figura 69. Vale notar que outros EGGs podem demandar outros atributos.
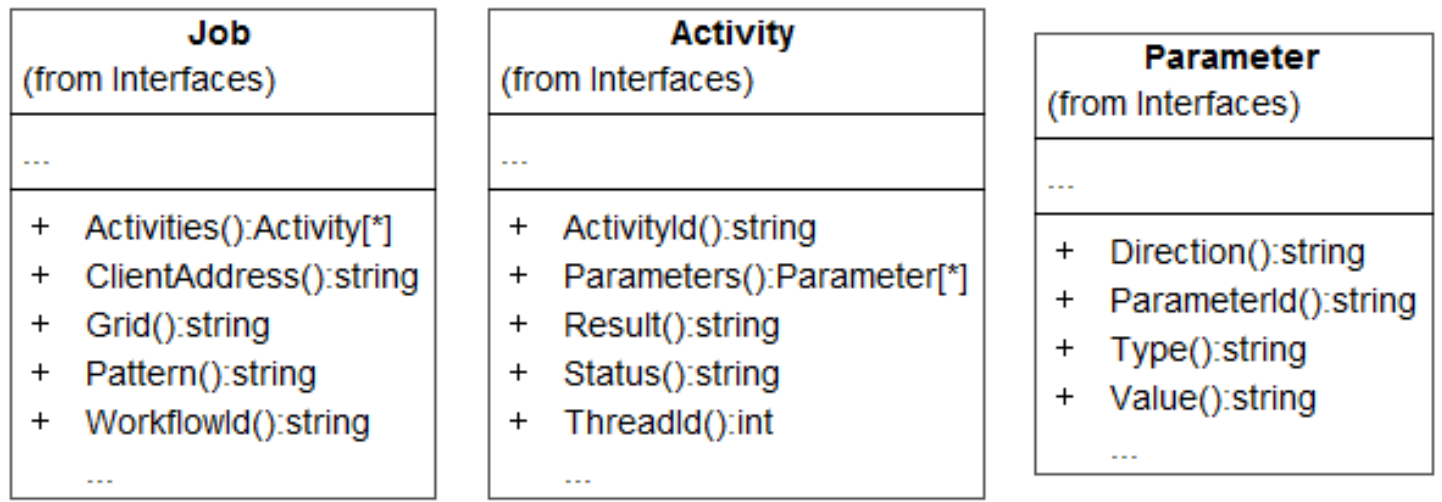

Figura 69: classes para o contrato de dados utilizado pelo EGG de threads (sem grade) 


\section{Apêndice B}

\section{Modelo de Dados para Persistência do PJC}

A fim de manter a arquitetura de baixo acoplamento e a independência entre as camadas, cada serviço web deve manter as informações a ele pertinentes. Conforme apresentado no Apêndice A, as classes para representação dos contratos de dados (Job, Activity e Parameter) são parciais, acrescidas de atributos pertinentes a cada camada, como é o caso de CancelActivities, DynamicInstance e NumberofReady, que são relevantes expecificamente para o EEP que implementa o PJC.

Esses atributos são então persistidos em um banco de dados relacional, cujo modelo é apresentado na Figura 70, seguindo o padrão IDEF1X [81]. Ao persistir tais dados, o EEP não precisa manter estado ${ }^{10}$ em memória, o que resulta em ganhos no tocante a escalabilidade e tolerância a falhas.

Workflow

\begin{tabular}{|l|l|}
\hline Workflowld (IE1) & \multicolumn{1}{|l}{ WorkflowActivities } \\
\hline Createdln & $\begin{array}{l}\text { Workflowld (FK,IE1) } \\
\text { LastUpdate }\end{array}$ \\
NumberOfReady & Activityld (IE1) \\
Pattern & Result \\
CancelActivities & Status \\
\hline
\end{tabular}

Figura 70: modelo de dados para armazenar o estado das execuções do PJC

\footnotetext{
${ }^{10}$ Esse tipo de componente, que não guarda estado, é dito stateless
} 
Para estender esses benefícios (escalabilidade e tolerância a falhas) ao middleware como um todo, sugere-se que outros EEPs e também os EGGs adotem o mesmo modelo de persistência.

Para o EEP do PJC, as classes internas DRConnection e PjcRepository, descritas na Seção A.2 fazem uso dos recursos deste banco de dados, sendo que a última utiliza os seguintes procedimentos, nele armazenados:

- spInsertWorkflow: armazena novo registro na tabela Workflow. Utilizado pelo método InsertWorkflowState;

- spInsertWorkflowActivities: armazena novo registro na tabela WorkflowActivities. Utilizado pelo método InsertWorkflowstateActivities;

- spUpdateWorkflowActivities: atualiza o estado de uma atividade na tabela WorkflowActivities e atualiza a data e hora desta operação no campo Lastupdate da tabela Workflow. Utilizado pelo método UpdateWorkflowstateActivities;

- spGetWorkflowResult: devolve o estado de cada atividade de um job. Utilizado pelo método GetWorkflowResult;

- spWorkflowReady: devolve CancelActivities, NumberOfReady e ActualNumberofReady (número de atividades do job que foram concluídas), informações necessárias para que o EEP do PJC decida se deve ou não enviar comando de cancelamento para as atividades que não tiverem sido completadas. A decisão é feita se CancelActivities = true e ActualNumberOfReady $\geq$ NumberOfReady. 


\section{Referências}

1. Aalst, Wil M. P. van der, et al. Workflow Patterns. s.l. : Springer Neitherlands, 2003. pp. 5-51. Vol. 14. ISSN 0926-8782 (Print) 1573-7578 (Online).

2. Russell, Nick, et al. Workflow Control-Flow Patterns - A Revised View. s.l. : BPM Center Report, 2006. BPM-06-22.

3. Aalst, Wil M. P. van der and Mulyar, Nataliya. Workflow Patterns Documentation. Workflow Patterns. [Online] 2005. [Cited: 06 19, 2007.] http://www.workflowpatterns.com/documentation/index.php.

4. Braghetto, Kelly Rosa, Ferreira, João Eduardo and Pu, Calton. Using ControlFlow Patterns for Specifying Business Processes in Cooperative Environments. Seoul : ACM, 2007. 1-59593-480-4.

5. Workflow Management Coallition. Process Definition Interface - XML Process Definition Language. Hingham, MA, USA : Workflow Management Coallition, 227, 2008. WFMC-TC-1025.

6. Weske, Mathias. Workflow Management Systems: Formal Foundation, Conceptual Design, Implementation Aspects. Habilitation Thesis, Universität Münster . 2000.

7. Aalst, Wil M. P. van der, Weske, Mathias and Wirtz, Guido. Advanced Topics in Workflow Management: Issues, Requirements, and Solutions. Journal of Integrated Design and Process Science. 2003, Vol. 7, 3.

8. Workflow Management Coallition. Home page. Workflow Management Coallition site. [Online] 2008. [Cited: 12 15, 2008.] http://www.wfmc.org.

9. Banco Central do Brasil. Sistema de Pagamentos Brasileiro. [Online] [Cited: 12 15, 2008.] http://www.bacen.gov.br/?SPB.

10. Barga, Roger and Gannon, Dennin. Scientific versus Business Workflows. [ed.] Ian J Taylor, et al. Workflows for e-Science - Scientific Workflows for Grids. s.1. : SpringerVerlag, 2007, Vol. 1, 2, pp. 9-18.

11. Alexander, Christopher, Ishikawa, Sara and Silverstein, Murray. A Pattern Language: Towns, Buildings, Construction. New York : Oxford University Press, 1977. 0195019199.

12. Gamma, Erich, et al. Design Patterns: Elements of Reusable Object-Oriented Software. s.1. : Addison-Wesley, 1994. ISBN 0201633612. 
13. Fowler, Martin. Patterns of Enterprise Application Architecture. s.1. : AddisonWesley, 2002. 0321127420 .

14. Aalst, Wil M. P. van der and Hofstede, Arthur H. M. ter. Workflow Patterns. Workflow Patterns. [Online] Workflow Patterns Initiative, 2007. [Cited: 10 06, 2008.] http://www.workflowpatterns.com.

15. Russel, Nick, et al. Workflow Resource Patterns. Eindhoven : Eindhoven University of Technology, 2004.

16. Russell, Nick, et al. Workflow Data Patterns. Queensland University of Technology. Brisbane : QUT Technical report, FIT-TR-2004-01, 2004.

17. - Exception Handling Patterns in Process-Aware Information Systems. s.1. : BPM CenterReport BPM 06-04, BPMcenter.org, 2006.

18. Jensen, Kurt. Coloured Petri Nets - Basic Concepts, Analysis Methods and Practical Use. Berlin : Springer, 1997. Vol. 1.

19. Microsoft Corporation. Windows Workflow Foundation. MSDN Library. [Online] 2007. http://msdn2.microsoft.com/en-us/library/ms735967.aspx.

20. Eder, Johann, Gruber, Wolfgang and Pichler, Horst. Transforming Workflow Graphs. First International Conference on Interoperability of Enterprise Software and Applications (INTEROP-ESA 2005). 2005.

\section{Aalst, Wil M. P. van der, Hofstede, Arthur H. M. ter and Russell, Nick.}

Workflow Patterns - Open Source Product Evaluation. Workflow Patterns. [Online] 2007. [Cited: 8 12, 2008.]

http://www.workflowpatterns.com/evaluations/opensource/index.php.

22. Ludäscher, Bertram, et al. Scientific workflow management and the Kepler system. Concurrency and Computation: Practice and Experience. 8 25, 2006, Vol. 18, 10, pp. 1039-1065.

23. University of Manchester. Taverna 2.0. The Taverna Project. [Online] 2008. [Cited: 01 15, 2009.] http://www.mygrid.org.uk/tools/taverna/.

24. Cardiff University. Triana. Triana Project. [Online] 2009. [Cited: 01 16, 2009.] http://www.trianacode.org/.

25. Microsoft Corporation. BizTalk Server Developer Center. MSDN. [Online] 2008. [Cited: 4 14, 2008.] http://msdn2.microsoft.com/en-us/biztalk/default.aspx.

26. - . .NET Framework Developer Center. MSDN. [Online] Microsoft Corporation, 2008. [Cited: 4 14, 2008.] http://msdn2.microsoft.com/en-us/netframework/default.aspx. 
27. University of California. SETI@Home Website. [Online] 2008. [Cited: 4 14, 2008.] http://setiathome.ssl.berkeley.edu/.

28. —. BOINC. [Online] 2008. [Cited: 4 14, 2008.] http://boinc.berkeley.edu/.

29. Foster, Ian. Globus Toolkit 4.0: Key Concepts. The Globus Alliance. [Online] 2006. [Cited: 4 14, 2008.] http://www.globus.org/toolkit/docs/4.0/key/GT4_Primer_0.6.pdf.

30. Erl, Thomas. Service-Oriented Architecture (SOA): Concepts, Technology, and Design . s.1. : Prentice Hall, 2005. ISBN 0-13-185858-0.

31. University of Chicago. The Globus Toolkit Homepage. The Globus Toolkit. [Online] 2007. [Cited: 08 06, 2007.] http://www.globus.org/toolkit/.

32. Foster, Ian. Globus Toolkit Version 4: Software for Service-Oriented Systems. IFIP International Conference on Network and Parallel Computing. 2006, pp. 2-13.

33. Federal University of Campina Grande. Ourgrid. Ourgrid. [Online] 2004. [Cited: 12 10, 2008.] http://www.ourgrid.org.

34. Andrade, Nazareno, et al. Peer-to-peer grid computing with the OurGrid Community. Salão de Ferramentas - SBRC 2005. 2005.

35. OMG. CORBA v3.0 Specification. CORBA v3.0 Specification. Needham, MA, USA : s.n., 7 2002. OMG Document 02-06-33.

36. Goldchleger, Andrei, et al. InteGrade: Object-Oriented Grid Middleware Leveraging Idle Computing Power of Desktop Machines. Concurrency and Computation: Practice \& Experience. 3 2004, Vol. 16, pp. 449-459.

37. Kon, Fabio and Song, Siang W. Documentation - Integrade: OO Grid Middleware. Integrade: OO Grid Middleware. [Online] 02 2006. [Cited: 12 10, 2008.] http://integrade.incubadora.fapesp.br/portal/files/presentations/InteGradeVisaoGeral.ppt/ download.

38. Buyya, Rajkumar and al., et. Alchemi - .NET Grid Computing Framework. Alchemi. [Online] The University of Melbourne, 2006. [Cited: 06 19, 2007.] http://www.alchemi.net/.

39. Luther, Akshay, et al. Alchemi: A .NET-based Enterprise Grid Computing System. International Conference on Internet Computing (ICOMP) 2005. 2005.

40. Fahringer, Thomas, Qin, Jun and Hainzer, Stefan. Specification of Grid Workflow Applications with AGWL: An Abstract Grid Workflow Language. Intl.Symposium on Cluster Computing and the Grid 2005 - CCGrid 2005. 2005. 
41. University of Innsbruck. Askalon Programming Environment for Grid Computing. ASKALON. [Online] [Cited: 12 12, 2008.] http://www.askalon.org.

42. - AGWL XML Schema. AGWL XML Schema. [Online] 1.2, 2008. [Cited: 12 12, 2008.] http://www.dps.uibk.ac.at/projects/agwl/agwl-1.2.xsd.

43. Prodan, Radu e Fahringer, Thomas. Dynamic Scheduling of Scientific Workflow Applications on the Grid: A Case Study. ACM Symposium on Applied Computing. 2005, p. 8.

44. - Z ZENTURIO: A Grid Middleware-based Tool for Experiment Management of Parallel and Distributed Applications. Journal of Parallel and Distributed Computing. 2004, Vol. 64, 6, pp. 693-707.

45. Pautasso, Cesare and Alonso, Gustavo. Parallel Computing Patterns for Grid Workflows. HPDC 2006. 2006.

46. Thain, Douglas, Tannenbaum, Todd and Livny, Miron. Condor and the Grid. [ed.] Fran Berman, Anthony J. G Hey and Geoffrey Fox. Grid Computing: Making The Global Infrastructure a Reality. s.1. : John Wiley, 2003.

47. The University of Wisconsin Madison. Condor Project Homepage. The University of Wisconsin Madison. [Online] 2007. [Cited: 07 04, 2007.]

http://www.cs.wisc.edu/condor/.

48. Beck, Alan. High Throughput Computing: an interview with Miron Livny. s.l. : HPCwire, 06 27, 1997.

49. Frey, James, et al. Condor-G: A Computation Management Agent for MultiInstitutional Grids. 10th IEEE Symposium on High Performance Distributed Computing (HPDC10). 2001.

50. University of Wisconsin-Madison. Condor-G. Condor-G Web Page. [Online] [Cited: 12 13, 2008.] http://www.cs.wisc.edu/condor/condorg/.

51. Deelman, Ewa, et al. Pegasus : Mapping Scientific Workflows onto the Grid. Across Grids Conference. 2004.

52. Deelman, Ewa, et al. Pegasus: a Framework for Mapping Complex Scientific Workflows onto Distributed Systems. Scientific Programming Journal. 2005, Vol. 13, 3, pp. 219-237.

53. University of Chicago. VDS - The GriPhyN Virtual Data System . GriPhyN site. [Online] 06 06, 2007. [Cited: 12 14, 2008.]

http://www.ci.uchicago.edu/wiki/bin/view/VDS/VDSWeb/WebMain. 
54. —. The Virtual Data Language. GriPhyN site. [Online] [Cited: 12 14, 2008.] http://vds.uchicago.edu/vds/doc/userguide/html/H_VDLReference.html.

55. Wang, Yong, Hu, Chunming and Huai, Jinpeng. A new grid workflow description language. Proceedings of IEEE International Conference on Service Computing 2005 (scc2005). 2005.

56. BEA, IBM, Microsoft, SAP, Siebel. Business Process Execution Language for Web Services (BPEL4WS). [Online] 2003. [Cited: 12 11, 2008.] http://www.oasisopen.org/committees/download.php/2046/BPEL\%20V11\%20May\%205\%202003\%20Final.pdf.

57. Zeng, Jin, et al. CROWN FlowEngine: A GPEL-Based Grid Workflow Engine. HPCC. 2007.

58. The Grid Workflow Forum. [Online] [Cited: 12 12, 2008.] http://www.gridworkflow.org.

59. OASIS WSRF Technical Commitee. OASIS Web Services Resource Framework Technical Commitee. Web Services Resource Framework Technical Commitee. [Online] OASIS, 04 01, 2006. [Cited: 12 11, 2008.] http://www.oasisopen.org/committees/tc_home.php?wg_abbrev=wsrf\#technical.

60. OASIS WSBPEL Technical Commitee. OASIS Web Services Business Process Execution Language Specification. Web Services Business Process Execution Language. [Online] 2.0, 04 11, 2007. [Cited: 12 11, 2008.] http://docs.oasisopen.org/wsbpel/2.0/OS/wsbpel-v2.0-OS.html.

61. Microsoft Corporation. Microsoft Open Database Connectivity (ODBC). Data Platform Developer Center. [Online] 2008. [Cited: 12 29, 2008.] http://msdn.microsoft.com/en-us/library/ms710252(VS.85).aspx.

62. - Windows Communication Foundation. MSDN Library. [Online] Microsoft Corporation, 2007. [Cited: 4 14, 2008.] http://msdn2.microsoft.com/enus/library/ms 735119.aspx.

63. —. Enterprise Library 4.1. MSDN Library. [Online] 2008. [Cited: 01 13, 2009.] http://www.microsoft.com/downloads/details.aspx?FamilyId=1643758B-2986-47F7B529-3E41584B6CE5\&displaylang=en.

64. Sun Microsystems. NetBeans 6.5. NetBeans. [Online] 2008. [Cited: 01 13, 2009.] http://www.netbeans.org/downloads/index.html.

65. - Glassfish Project. Glassfish Community. [Online] 2008. [Cited: 01 13, 2009.] https://glassfish.dev.java.net/downloads/v3-prelude.html. 
66. Web Services Interoperability Organization. WS-I Deliverables. WS-I. [Online] 2008. [Cited: 01 15, 2009.] http://www.ws-i.org/deliverables/matrix.aspx.

67. —. Basic Profile Version 1.1. WS-I. [Online] 04 10, 2006. [Cited: 01 15, 2009.] http://www.ws-i.org/Profiles/BasicProfile-1.1.html.

68. Internet Engineering Task Force (IETF). The Secure Shell (SSH) Protocol Architecture. IETF Web Site. [Online] 01 2006. [Cited: 02 01, 2009.] http://tools.ietf.org/html/rfc4251.

69. OpenBSD. OpenSSH. OpenSSH. [Online] 11 21, 2008. [Cited: 02 01, 2009.] http://www.openssh.com/.

70. Medeiros, Claudia Bauzer, et al. Workflow Management in Geoprocessing Applications. Proceedings of the 6th ACM international symposium on Advances in geographic information systems GIS '98. 1998.

71. CPTEC/INPE. BRAMS. BRAMS. [Online] [Cited: 02 12, 2009.] http://brams.cptec.inpe.br/.

72. ATMET. Atmospheric, Meteorological and Environment Technologies. [Online] [Cited: 02 12, 2009.] http://www.atmet.com.

73. IME/USP. Instituto de Matemática e Estatística/USP. [Online] [Cited: 02 12, 2009.] http://www.ime.usp.br.

74. IAG/USP. Instituto Astronômico e Geofísico/USP. [Online] [Cited: 02 12, 2009.] http://www.iag.usp.br.

75. CPTEC/INPE. Centro de Previsao de Tempo e Estudos Climáticos. CPTEC/INPE. [Online] [Cited: 02 12, 2009.] http://www.cptec.inpe.br.

76. ATMET. Operational RAMS Forecast Links. RAMS. [Online] [Cited: 02 12, 2009.] http://www.atmet.com/html/rams_operational.shtml.

77. Instituto de Informática - UFRGS. Parallel and Distributed Processing Group GPPD. Instituto de Informática - UFRGS. [Online] [Cited: 02 12, 2009.] http://gppd.inf.ufrgs.br/new/main.php.

78. Nardi, Alexandre R. and Ferreira, João E. Padrões para Controle de Fluxo e sua Execução em Grade. e-Science Workshop - SBBD-SBES 2007. 2007, Vol. 1, pp. 19-28.

79. Nardi, Alexandre R., et al. Um Padrão Canônico para Controle de Paralelização em Aplicações de e-Science. XXIII Simpósio Brasileiro de Banco de Dados. 2008, pp. 268282. 
80. Altova Company. UModel - UML tool for software modeling and application development . Altova. [Online] 2009. [Cited: 12 09, 2008.]

http://www.altova.com/products/umodel/uml_tool.html.

81. National Institute of Standards and Technology (NIST). FIPS184 IDEF1X. NIST. [Online] 05 10, 2002. [Cited: 02 06, 2009.] http://www.itl.nist.gov/fipspubs/idef1x.doc. 